\title{
Morphometric analyses to study risk factors in thoracic aortic diseases
}

Viony Maria Belvroy 



\title{
Morphometric analyses to study risk factors in thoracic aortic diseases
}

\author{
Viony Maria Belvroy
}


Colofon

Morphometric analyses to study risk factors in thoracic aortic diseases

Viony Maria Belvroy

ISBN/EAN: 978-94-6375-799-7

Copyright () 2020 Viony Maria Belvroy

All rights reserved. No part of this thesis may be reproduced, stored or transmitted in any way or by any means without the prior permission of the author, or when applicable, of the publishers of the scientific papers.

Cover design by Justine Markowski

Layout and design by Birgit Vredenburg I persoonlijkproefschrift.nl

Printing: Ridderprint | www.ridderprint.nl 
Morphometric analyses to study risk factors in thoracic aortic diseases

Morfologische analyses om risico factoren te bestuderen in thoracale aortaziektes

(met een samenvatting in het Nederlands)

\section{Proefschrift}

Ter verkrijging van de graad van doctor aan de

Universiteit Utrecht

op gezag van de

rector magnificus, prof. dr. H.R.B.M. Kummeling, ingevolge het besluit van het college voor promoties

in het openbaar te verdedigen op

donderdag 16 april 2020 des ochtends te 10.30 uur

door

\section{Viony Maria Belvroy}

Geboren op 17 april 1989

te Hengelo (ov) 
$\begin{array}{ll}\text { Promotoren: } & \text { prof. dr. F.L. Moll } \\ & \text { prof. dr. S. Trimarchi }\end{array}$

Copromotor: $\quad$ dr. J.A. van Herwaarden

Financial support by the Dutch Heart Foundation for the publication of this dissertation is gratefully acknowledged. 


\section{Contents}

Chapter 1 Introduction and dissertation outline

\section{Part 1: Introduction to endovascular repair}

Chapter 2 Identifying and addressing the limitations of EVAR technology Expert Review of Medical Devices. 2018

Chapter 3 Type 1b endoleaks after thoracic endovascular aortic repair are inadequately reported: a systematic review Annals of Vascular Surgery. 2019

\section{Part 2: Tortuosity in the descending thoracic aorta}

Chapter 4 Tortuosity of the descending thoracic aorta: normal values by age Plos One. 2019

Chapter 5 Tortuosity of the descending thoracic aorta in patients with aneurysm and type B dissection World Journal of Surgery. 2019

Chapter 6 Impact of aortic tortuosity on displacement forces in descending thoracic aortic aneurysms European Journal of Vascular and Endovascular Surgery. 2020

\section{Part 3: Dynamics in the ascending thoracic aorta}

Chapter 7 Important variances of longitudinal and circumferential movements in ZO of the aorta during the cardiac cycle Submitted

Chapter 8 Arterial strain and distensibility in type A aortic dissection before and after stent graft implantation

Submitted

\section{Part 4: Education in endovascular aortic repair}

Chapter 9 Motion metrics reliably differentiate competency: fundamentals of endovascular and vascular surgery (FEVS)

\section{Submitted}

Chapter 10 Endotherapy in Intramural Hematoma and dissection Submitted

Chapter 11 Endovascular creation of an acute in-vivo swine model and multimodality imaging for understanding the pathophysiology of type $B$ aortic dissection

Submitted

\section{Part 5: Summary and discussion}

Chapter 12 Summary, discussion and future perspectives 193

Chapter 13 Samenvatting en discussie in het Nederlands 209

Chapter 14 Review Committee 228

Acknowledgements (dankwoord) 229

List of publications $\quad 235$

$\begin{array}{ll}\text { About the author } & 237\end{array}$ 



\section{Chapter 1}

Introduction and dissertation outline 


\section{Introduction}

Aortic diseases are pathologies with high morbidity and mortality. In this dissertation two main aortic pathologies will be discussed; thoracic aortic aneurysm (TAA) and thoracic aortic dissection (TAD).

Aneurysmal diseases can occur throughout the vascular system and are characterized by dilatation of the vessel (i.e. the aorta). There are a variety of risk factor which contribute to the development of aneurysmal disease, like smoking, hypertension, male, atherosclerosis, old age, high body mass index (BMI), genetic disorders, family history, and connective tissue disorders such as Loeys-Dietz disease or Marfan syndrome'. The aneurysmal sack often grows slowly, is asymptomatic and has a chronic character. Symptoms occur when the sac causes compression on surrounding structures. In case the disease is not treated there is a risk of aortic rupture, which is associated with high mortality 2.

The aortic wall consists of three layers; adventitia (outer), media, and intima (inner). An aortic dissection is caused by a tear in the intima layer, where blood can flow through and create a false lumen within the intima and media. The main risk factors are hypertension, connective tissue disease, family history, cocaine abuse, smoking and history of cardiac surgery ${ }^{1,3-5}$. The most commonly used classification for aortic dissection is the Stanford classification. Type A aortic dissection (TAAD) involves the ascending thoracic aorta and type $B$ aortic dissection (TBAD) occurs in the descending thoracic aorta, which starts $2 \mathrm{~cm}$ distal to the left subclavian artery $(\text { LSA })^{6}$. Aortic dissection is often an acute disease occurring earlier in life (around 60 years old) than aneurysmal diseases ${ }^{7,8}$.

Treatment for both pathologies should start with medical therapy. In case this does not work the diseases can be treated with open surgical repair or thoracic aortic endovascular repair (TEVAR). Endovascular repair is currently the therapy of choice, especially in high risk patients who seem unfit for open surgical repair. Stent graft devices have evolved throughout the years and are much more conformable than the first deployed stent graft in $1950^{9}$. However, devices are still much stiffer compared to the native aorta. Complications may occur due to lacking stent grafts or difficult anatomy. This dissertation is focused on anatomical variations which may contribute to a higher complication rate and to the dynamic changes after stent graft implantation. 


\section{Dissertation outline}

The first part gives an introduction to endovascular aortic repair. Discussed are the limitations of the recently developed medical devices (Chapter 2) to improve future stent grafts and obtain durable results. Then, an overview of type $1 \mathrm{~b}$ endoleaks after thoracic endovascular aortic repair (TEVAR) is provided, focusing on risk \& predictive factors, which are inadequately reported (Chapter $\mathbf{3}$ ).

The second section is divided into three chapters outlining the effect of tortuosity in the descending thoracic aorta (DTA). Starting with describing the incidence of tortuosity in a healthy patient population, comparing young $(<65$ years) vs. old (> 65 years), where computed tomography angiography (CTA) scans are analyzed with 3Mensio (Chapter 4), followed by the same type of analyses comparing a healthy population with patients with aneurysmal diseases and type B aortic dissections (Chapter 5). As a sequel to the previous studies, the next chapter evaluates the effect of increased tortuosity on hemodynamic displacement forces. Tortuosity is divided into: low $<30^{\circ}$, moderate $30^{\circ}-60^{\circ}$ and high $>60^{\circ}$ tortuosity. The DTA is divided into four equal segments and the force is measured in all segments in all tortuosity groups (Chapter 6).

The third part is focusing on the dynamics of the ascending thoracic aorta (ATA). As the aorta continuously evolves throughout the cardiac cycle in longitudinal and circumferential directions, especially in zone 0, a more precise measurement may be necessary to improve optimal stent graft sizing. The first study compares the diameter with the perimeter and area and shows which measurement has the most narrow range calculated in electrocardiographic (ECG)-gated CT scans (Chapter 7). The effect of stent graft deployment in the ATA has not been studied well. The following study compares the strain and distensibility of the ATA before and after stent graft implantation (Chapter 8).

The fourth part involves educational studies related to the (thoracic) aorta. The Fundamentals of Endovascular and Vascular Surgery (FEVS) are developed to assess performance of endovascular trainees (Chapter 9). An endovascular model is used to differentiate between competent and non-competent performers. The second chapter is published in a book about endotherapy in patients with intramural hematoma (IMH) and dissection (Chapter 10). The endovascular approach will be discussed along with its tools and the use of imaging modalities. The final chapter in this section is about the creation of a porcine model of 


\section{Chapter 1}

type B aortic dissection (Chapter 11). This model was created to study the pathophysiology of dissection in detail with multi-modality imaging and for future studies on the treatment of aortic dissection.

The final section exists of a summary of this dissertation, a discussion section with future perspectives (Chapter 12), a summary in Dutch (Chapter 13), and the appendices (Chapter 14) which will consist of the review committee, acknowledgments, a list of publications and curriculum vitae. 


\section{References}

1. Erbel R, Aboyans V, Boileau C, et al. 2014 ESC Guidelines on the diagnosis and treatment of aortic diseases: Document covering acute and chronic aortic diseases of the thoracic and abdominal aorta of the adult. The Task Force for the Diagnosis and Treatment of Aortic Diseases of the European Society of Cardiology (ESC). Eur Heart J. 2014;35(41):2873-2926. doi:10.1093/eurheartj/ ehu281

2. Jonker FHW, Trimarchi S, Verhagen HJM, et al. Meta-analysis of open versus endovascular repair for ruptured descending thoracic aortic aneurysm. J Vasc Surg. 2010;51(4):1026-1032, 1032.e11032.e2. doi:10.1016/j.jvs.2009.10.103

3. Suzuki T, Mehta RH, Ince H, et al. Clinical profiles and outcomes of acute type B aortic dissection in the current era: Iessons from the International Registry of Aortic Dissection (IRAD). Circulation. 2003;108 Suppl 1(90101):II312-7. doi:10.1161/01.cir.0000087386.07204.09

4. Bonderman D, Gharehbaghi-Schnell E, Wollenek G, et al. Mechanisms Underlying Aortic Dilatation in Congenital Aortic Valve Malformation. Circulation. 1999;99(16):2138-2143. doi:10.1161/01. CIR.99.16.2138

5. Dean JH, Woznicki EM, O'Gara P, et al. Cocaine-related Aortic Dissection: Lessons from the International Registry of Acute Aortic Dissection. Am J Med. 2014;127(9):878-885. doi:10.1016/j. amjmed.2014.05.005

6. Daily P, Trueblood H, Stinson E, et al. Management of acute aortic dissections. Ann Thorac Surg Surg. 1970;10(3):237-247.

7. Booher AM, Isselbacher EM, Nienaber CA, et al. The IRAD classification system for characterizing survival after aortic dissection. Am J Med. 2013;126(8):730.e19-24. doi:10.1016/j. amjmed.2013.01.020

8. Hagan PG, Nienaber CA, Isselbacher EM, et al. The International Registry of Acute Aortic Dissection (IRAD): new insights into an old disease. JAMA. 2000;283(7):897-903. doi:10.1001/ jama.283.7.897

9. Volodos' NL, Shekhanin VE, Karpovich IP, et al. [A self-fixing synthetic blood vessel endoprosthesis]. Vestn Khir Im / / Grek. 1986;137(11):123-125. 



\section{Part 1: Introduction to endovascular repair}





\section{Chapter 2}

\section{Identifying and addressing limitations of EVAR technology}

Viony M. Belvroy ${ }^{1,3}$; Ignas B. Houben ${ }^{2,3}$; Santi Trimarchi'; Himanshu J. Patel2;

Frans L. Molli; ;oost A. van Herwaarden ${ }^{3}$

1 Thoracic Aortic Research Center, IRCCS Policlinico San Donato, San Donato Milanese, Italy

2 Department of Cardiovascular Surgery, Frankel Cardiovascular Center, University of Michigan Health Center, Ann Arbor, Michigan, United States

3 Department of Vascular Surgery, University Medical Center Utrecht, Utrecht, Netherlands, 


\begin{abstract}
Introduction: Endovascular aortic repair (EVAR) has improved over the last two decades. Approximately $80 \%$ of the patients presenting with an abdominal aortic aneurysm (AAA) is nowadays primarily treated with EVAR.

Areas covered: In this review the differences between endovascular and open repair, the clinical characteristics needed for EVAR, the role of clinical imaging and the developments in EVAR technology will be discussed. Early mortality is lower in EVAR as compared to open repair, whereas this benefit is lost after three years postoperatively. EVAR comes with a high reintervention rate, with endoleak being the most important predictive factor for reintervention. Expanding technical possibilities have allowed surgeons to choose from a palate of endovascular approaches in aneurysm patients with challenging anatomies.

Expert commentary: Although EVAR has taken a giant leap in development, the new developments have seemed to surpass the long term limitations with older devices. It is important to start focusing on the current limitations of EVAR, in particular the durability of devices in the human variable anatomic and dynamic environment.
\end{abstract}

Keywords: abdominal aortic aneurysm, endoprosthesis, endovascular aortic therapy, stent graft 


\section{Introduction}

The treatment for abdominal aortic aneurysm (AAA) repair has long been open repair, which was first introduced by Dubost in 1951'. Open surgical repair requires aortic cross clamping and a large surgical incision to expose the abdominal aorta. Because open surgical repair came with a morbidity and mortality of $3.0-7.5 \%$, less invasive alternatives were introduced ${ }^{2-5^{*}}$. In 1986, Volodos et al. introduced the concept of endovascular aneurysm repair $(E V A R)^{6}$. Since 1991, after Parodi reported about EVAR, it has become widely accepted as a safe technique for the treatment of $A A A^{7,8}$. Laparoscopic aortic surgery was introduced as another less invasive alternative to open surgery in 1993, but never gained popularity. This is due to the steep learning curve, the necessary experience from surgeons and the required aortic cross clamping making it inferior to EVAR. A recent propensity matched prospective trial comparing 228 consecutive AAAs and occlusive aortoiliac disease cases, non-randomly treated with laparoscopy or open surgery, suggested that even with a well-trained surgical team, the laparoscopic approach increases the risk for adverse events observed during aortic surgery9.

While EVAR was first used for treating patients who were old or unfit for open repair, it is nowadays the gold standard for patients who are anatomically suitable for endovascular aortic repair ${ }^{10 *}$. Differences in morbidity and mortality rates between endovascular and open repair are mainly found during short-term follow-up. Large randomized trials were reported since 1999 to compare EVAR versus open repair. These trials all showed an early survival benefit for EVAR, which was lost within $1-3$ years in the EVAR-1 and DREAM trials and later in the OVER trial as well2-5. The studies described above were performed over 10 years ago. Since then, stent graft material has improved and physicians have gained experience in EVAR. The clinical evidence already gives an insight, however a number of unsolved issues remain, like the high rate of reintervention ${ }^{5}$. With the giant leap in endovascular technologies, complications such as endoleaks, late device failures, and late aortic rupture must be avoided by continuously optimizing the devices and the use of the new technologies.

In this review we will discuss the differences between endovascular and open repair, the clinical characteristics needed for EVAR and the role of clinical imaging. We especially focus on the limitations of endovascular repair and stent graft material, because there is still room for improvement. 


\section{Open Surgery repair vs EVAR}

The incidence of intact AAA repair continues to increase in the western world in the $20^{\text {th }}$ century. Around 44,000 non-ruptured AAAs are treated every year in the United States and approximately $80 \%$ is treated with EVAR ${ }^{11}$. Multiple studies have been investigating the benefits of EVAR over open repair in patients with AAA, although the EVAR population might be biased, because less invasive treatment is also chosen in patients deemed unfit for open repair.

\section{Large randomized trials in elective EVAR}

Powell et al. provided a meta-analysis on the most important randomized controlled trials comparing endovascular repair with open repair. The DREAM trial randomized 351 patients (91.7\% men) in the Netherlands and Belgium². The EVAR-1 trial randomized 1252 patients (90.7\% men) in the UK ${ }^{5}$. The ACE trial randomized 306 patients (99.0\% men) in France and the OVER trial randomized 881 patients $\left(99.4 \%\right.$ men) in the USA ${ }^{3,4}$. In the overall follow up of all studies, there was no statistical difference in mortality between open surgery and EVAR ${ }^{12}$. Early mortality (0 - 6 months) was lower in the EVAR group (46 versus 73 deaths). After 5 years the estimated survival rate was $73.6 \%$ in both groups ${ }^{12}$. The overall reintervention rate was higher for the EVAR group in all studies, with a type II endoleak being the most common reason for reintervention. The meta-analysis concluded that EVAR has an advantage over open repair between 0 - 6 months, which is lost after 3 years ${ }^{12}$. A Cochrane review by Paravastu et al. also included the EVAR2 trial, and found comparative results ${ }^{8,13}$. The reported endograftrelated complications in all four trials were 34.5\%. The OVER and ACE trial only reported endoleak complications ${ }^{3,4}$. More pulmonary complications were found in the open surgery group $(p=0.08)^{8}$. EVAR1 showed slightly higher renal related deaths in the EVAR group ${ }^{5}$. There was no significant difference in creatinine levels and estimated glomerular filtration rate (eGFR) between EVAR and open repair patients ${ }^{2}$.

\section{Large randomized trials in emergency EVAR}

The IMPROVE trial investigated the difference between open surgery and EVAR in patients with ruptured abdominal aortic aneurysm ${ }^{14}$. After adjustment for sex, age and Hardman index, no difference in 30 day mortality existed (OR 0.94, $p=0.73$ ). Midterm follow up showed a lower mortality in the EVAR group (48\% 
to $56 \%$ ). Again, at 7 years follow up the overall mortality was similar with $60 \%$ in both groups ${ }^{14}$. The numbers are questionable according to Veith and Rockman ${ }^{15}$. From the 316 patients who were randomly assigned to the EVAR group, only 149 patients received EVAR. 110 patients received an open aortic repair, because they were unsuitable for EVAR ${ }^{14}$. The AJAX and EVAR trials, both with a relatively small study population (32 and 116 patients), showed similar results in mortality as the IMPROVE trial ${ }^{16,17}$.

\section{Conclusion}

In an early state the overall mortality is lower in the EVAR group, while results are equal on the long term. Many devices fail after more than 5 years, leading to significant complications discussed later in this paper. It is necessary to have an understanding of anatomical and physiological changes over the years that might cause these complications.

\section{Imaging}

Imaging in AAA treatment is used in 3 settings: preoperatively, perioperatively and postoperatively.

\section{Preoperative imaging}

The first imaging technique of choice in screening and diagnostics is ultrasonography (US). US is associated with some limitations, like the operatordependent outcome, and slight inaccuracies of aortic diameter measurement as compared to a Computed Tomography (CT) scan. Despite this difference, US outweighs CTA scanning, because of the relatively high costs, the high radiation exposure and the use of nephrotoxic contrast agents with CT scans ${ }^{18}$. Examples of US with and without doppler and CT are depicted in figure $1 \mathrm{~A}-\mathrm{E}$. 


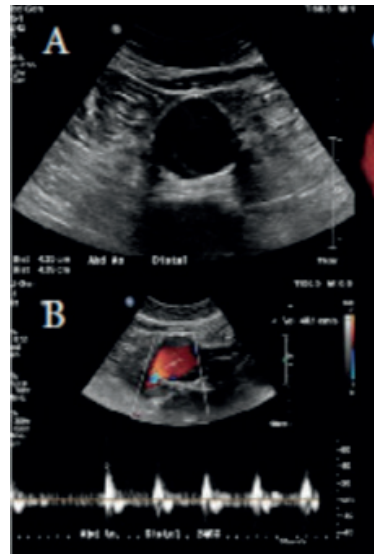

$\mathrm{E}$
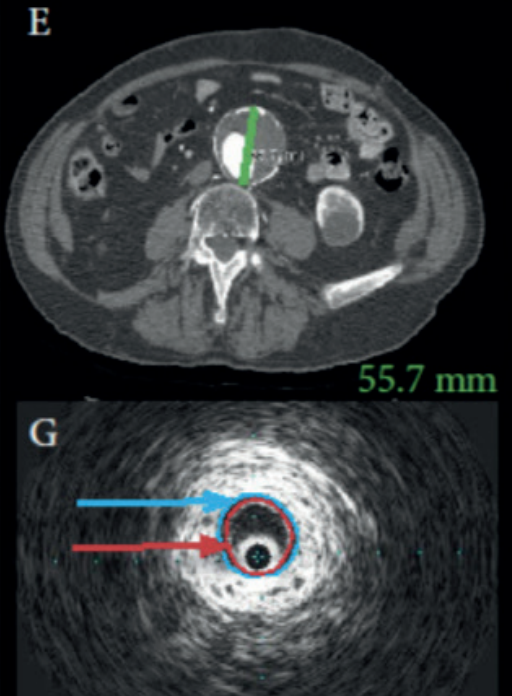

C D

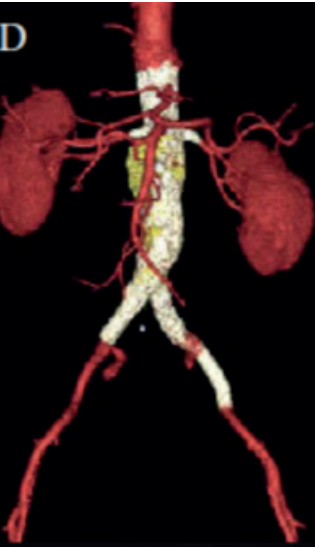

F

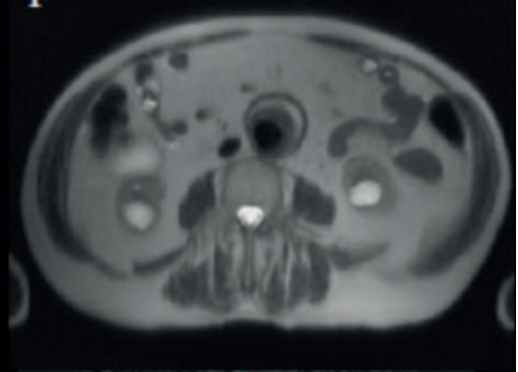

H

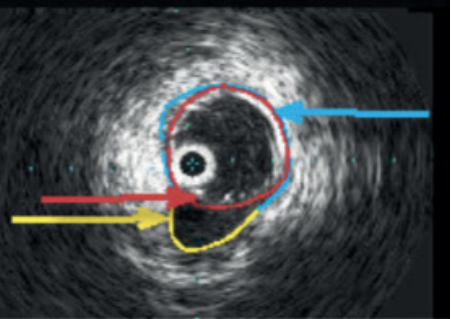

Figure 1 Imaging modalities for abdominal aortic aneurysm. A) Echo diameter measured transabdominally; maximum diameter of $4.39 \mathrm{~cm}$. B) Duplex analysis of the abdominal aneurysm. Red signifies antegrade flow, being non-pathologic. Axial preoperative images of a patient with an abdominal aortic aneurysm approximately at the 3rd lumber vertebra. C) Preoperative and D) postoperative Computational Tomography Angiography (CTA) 3-dimensional rendered images of a juxtarenal abdominal aneurysm patient with vessel in red, thrombus in yellow and stent graft in white. Echo analysis of a patient with an abdominal aneurysm. E) Computed Tomography Angiography (CTA) with a maximum aortic diameter of $55.7 \mathrm{~mm}$ and clear deposition of calcium at the aortic wall and thrombus. F) Magnetic Resonance Imaging without contrast where the outer diameter seems less accurate as compared to CTA, but layers, such as luminal blood (radiolucent, black), thrombus (less radiolucent, grey) and the outer wall can be well separated (radiopaque, light grey). Perioperative intravascular ultrasound in an aneurysm patient after deploying the stent graft. G) Stent graft in lumen clearly visible, there is an area between the endothelial cells (blue arrow) and the stent (red arrow). H) End of stent graft (red arrow) visible, before a branching artery (yellow arrow). In this figure the stent is better attached to the aortic wall (blue arrow). 


\section{Perioperative imaging}

CTA is more accurate than US in estimating the aortic diameter, the longitudinal distance, such as the neck length of the aneurysm and gives a clear view of the anatomy without possibly influencing the measurements with external pressure. This accuracy is very important for surgical planning, especially regarding the landing zones and graft sizing in EVAR ${ }^{19}$. CTA is superior as imaging modality in work-up for intervention (figure 2) ) $^{18 *}$. The cardiac cycle influence is estimated to have a profound effect on stent-graft selection and design ${ }^{20}$. This difference between systole and diastole is accounted for using high resolution electrocardiography-gated (ECG-gated) CTA. This is a dynamic CTA method, that can detect significant changes in the aortic pulsatility, by synchronizing the CT scan and the cardiac cycle ${ }^{21}$.

Magnetic Resonance Imaging (MRI, figure 1F) does not involve ionizing radiation and MR Angiography (MRA) uses less nephrotoxic contrast agents than CTA, making it the preferred imaging modality for patients with severe renal dysfunction (glomerular filtration rate $<30)^{22}$. Nevertheless, CTA remains the gold standard and MRA is exceptionally used in pregnant, very young or chronic kidney disease patients. The commonly used intraoperative techniques are fluoroscopy and angiography, providing2D plain radiographic images after intravascular admission of contrast agent. The disadvantage of angiography is the use of a nephrotoxic contrast agent and the exposal to radiation damage. A new development is CTA with fluoroscopy fusion technology. This technique uses a 3D CTA image from a cone beam CT, a preoperative CTA or a preoperative MRA and combines this with another dynamic imaging modality, usually fluoroscopy. This produces an overlay, giving a real-time 3D road-map for catheterization and guide wire movements. It limits both operation time and the nephrotoxic ionized contrast dose ${ }^{23 *}$.

A last imaging modality is intravascular ultrasound (IVUS), primarily used for research purposes (figure $1 G$ and $H$ ). It provides a cross sectional view throughout the aorta. The pulsatile movement of the aorta can be seen during imaging, so dynamic changes can be assessed and no contrast agents are needed. Despite these advantages, IVUS is operator dependent, as the probe needs to be centered in the lumen for accurate measurements. The procedure is invasive, requiring percutaneous vascular access and uses costly catheters. 
Chapter 2

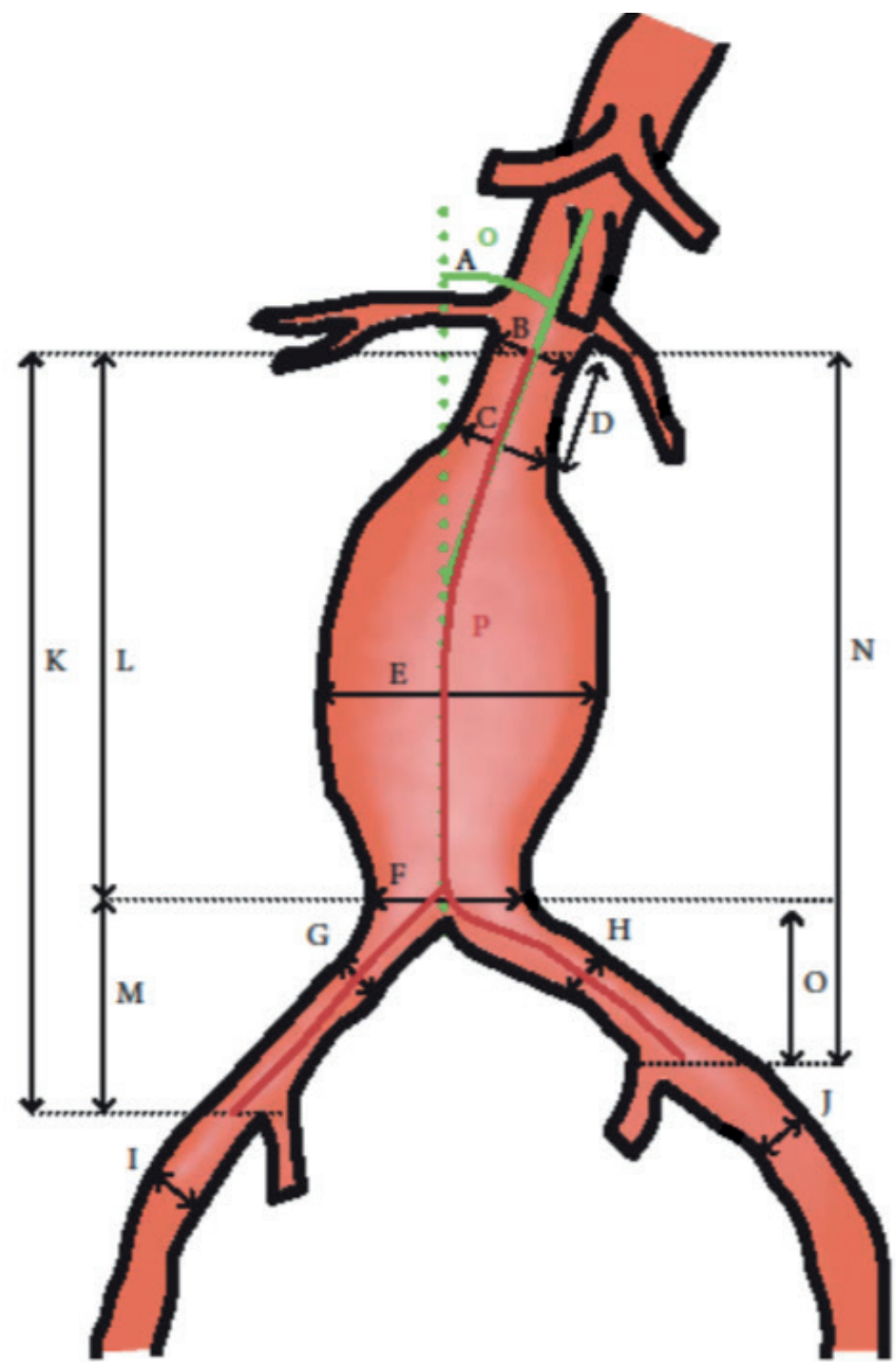

Figure 2 Schematic view of measurements of the aorta taken from a coronal plane. A) Aortic neck angle in green. B) Aortic neck diameter. C) Aortic neck diameter $15 \mathrm{~cm}$ distal to the lowest renal artery. D) Aortic neck length. E) Aneurysm diameter. F) Aortic bifurcation diameter. G) Right common iliac artery diameter. H) Left common iliac artery diameter. I) Right external iliac artery diameter. J) Left external iliac artery diameter. K) Lower renal artery to right internal iliac artery length. L) Lower renal left artery to aortic bifurcation length. M) Right iliac artery sealing lengths. N) Lower renal to left internal iliac artery length. O) Left iliac artery sealing lengths. P) Center lumen line lower renal left artery to external iliac arteries. All length measurements are taken using the center lumen line. 


\section{Postoperative imaging}

The SVS practice guidelines recommend CTA and color duplex US in the first month after EVAR, followed by annual color duplex US follow-up until the primary clinician no longer deems annual follow up necessary. Additionally, a non-contrast enhanced CT of the entire aorta 5 years after open repair or EVAR is suggested. In case of the suspicion for an endoleak within one month of follow up, CTA is required for accurate assessment of possible aneurysmal sac growth ${ }^{10}$. In a recent systematic review, 6 meta-analyses and 52 observational studies were compared to evaluate the optimal modality and frequency of surveillance after EVAR. The highest endoleak detection rates were in surveillance approaches that used combined tests of CT or MR and color duplex US ${ }^{24}$. A 2015 prospective study carried out an analysis comparing CTA scans and MRA scans of the same patient in 29 growing post EVAR aneurysms sacs. New endoleak detection methods assessing a "delayed scanning" MRA technique, using a weak albumin binding contrast agent, instead of gadolinium were shown to be far more accurate than the traditional CTA ( $83 \%$ vs $28 \%$ endoleak detection rate). With the delayed scanning technique $96 \%$ were found to have a type II endoleak ${ }^{25}$. This emphasizes that even in growing aneurysm sacs, using a very accurate imaging technique we are still not able to find all endoleaks. Consequently, if an endoleak is not spotted in a growing aneurysm sac after EVAR, it does not mean it is not there. The diagnosis is limited by the tools available. Since we may not be able to detect all type II endoleak with conventional CTA protocols, caution is suggested towards patients with a growing or permanently enlarged aneurysm sac and negative CTA findings.

There is debate about the adequate frequency of post EVAR surveillance. So far, there are no studies comparing post-EVAR surveillance interval rates, although 1, 6, 12 months and annually seems to be common in clinical practice for the first five years ${ }^{24}$. It is however important to know the clinical interpretation and implication of follow-up intensity for clinical use. First of all, some endoleaks do not require aggressive reintervention or even intensive follow-up. Immediate intraoperative aggressive pursuit for treating type 1 endoleaks is unnecessary in patient with appropriate evaluation of neck suitability, correct sizing and implantation, and might result in higher mortality risks ${ }^{26}$. Additionally, aneurysmal growth seems to be a more accessible and reliable measure than searching for endoleaks ${ }^{25}$. If the aneurysmal sac is not growing we may say that endoleaks 


\section{Chapter 2}

are unlikely or have low clinical importance. Finally, the carcinogenic radiation damage induced by CTA scans seem to have a larger impact than previously thought ${ }^{27}$. Recent analysis of mortality due to cancer in long-term-EVAR trials, suggests nearly a twofold increase in developing malignancy, induced by frequent CT-scans ${ }^{5}$. This is a 'red flag' that should push clinicians to start switching surveillance to US modalities.

Many EVAR trials have been performed, a large amount with pooled national EVAR databases. These data often lack homogeneity and are easily compared, while data on long-term follow-up may be sparse. Improved surveillance programs for post-EVAR patients are urgently required.

\section{Complications}

\section{Endoleaks}

Although EVAR is widely accepted as an effective and less invasive treatment alternative to open AAA repair, it is not free of complications. Endoleaks are the most common complications after EVAR ${ }^{28}$.

An endoleak is defined as the persistence of perfusion of the aneurysmal sac after endovascular therapy ${ }^{29}$. Endoleak can be divided into primary (first 30 days after implantation) or secondary endoleak (after 30 days of implantation). There is a specific endoleak classification, which is as follows:

Type I: This occurs when a persistent channel of blood flow is leaking into the aneurysmal sac due to an inadequate seal at the graft ends ${ }^{29}$. This type can be divided into proximal (type la) and distal (type lb) endoleak. Type Ib is more common in patients with dilated, calcified, short and tortuous iliac $\operatorname{arteries}^{30}$.

Type II: This endoleak is the retrograde filling of the aneurysm, mainly from lumbar arteries and/or inferior mesenteric artery ${ }^{29}$. This is the most common type of endoleak in endovascular abdominal aortic repair, with an overall incidence of around $10.5 \%{ }^{28}$.

Type III: This endoleak is due to inadequate sealing at graft junctions, between segments or overlapping stent grafts or it is due to rupture of the stent graft $^{28}$. These endoleaks require urgent intervention, due to their rapid repressurization of the aneurysmal sac. 
Type IV: This type of endoleak is related to porosity and the diffuse passage of blood through the fabric. These endoleaks are nowadays uncommon and resolve usually spontaneously ${ }^{28}$.

Type $V$ : Type $V$ endoleak is defined as continuous growth of the aneurysm sac without the appearance of endoleak. This is also called endotension. The cause is uncertain, it might be caused by slow flow endoleak, hygroma, pressure transmission from a thrombus from the stent graft or infection ${ }^{28}$. Other non-endoleak complications can be divided into surgical-, systemic- and ischemic complications.

\section{Surgery-related complications}

Local wound complications have an incidence of $1-10 \%{ }^{28}$. Access related artery injury like arterial thrombosis, dissection or pseudoaneurysm could occur up to $3 \%{ }^{31}$. According to Wald et al. contrast-induced nephropathy occurs in $6.7 \%$ of the cases, which may result in acute renal failure ${ }^{32}$. A study by Arnaoutoglou et al. shows that one-third of the patients after EVAR develop post-implantationsyndrome ${ }^{33}$. Predictive factors are pre-operative white-blood-cell count, endograft material and heart failure. Likewise, more frequently major adverse cardiovascular events happen in patients with post-implantation-syndrome.

\section{Systemic complications}

Infection of the stent graft can occur in $0.5-1 \%$ and untreated it can result in generalized sepsis and death ${ }^{34}$. Cases of stent graft infections have been reported after having a kidney stone or after an appendectomy with a peri-appendicular abscess ${ }^{35,36}$. Also aorto-enteric fistulas have been described as a cause of creating stent graft infections ${ }^{37}$.

\section{Ischemic complications}

Ischemic complications can occur due to a clot formation or clot embolization, but also due to incorrect placement of the stent graft while covering side branches of the aortic or iliac arteries. Systematic overstenting of the inferior mesenteric artery can cause bowel ischemia. The incidence of bowel ischemia in open repair is similar to EVAR and lies between $1-3 \%$ of the cases ${ }^{38}$. It is a serious complication, with a $50 \%$ mortality rate within one month. Spinal cord ischemia is rare in infrarenal EVAR and has an incidence of $0.21 \%{ }^{39}$. Unrecognized renal artery occlusion after EVAR is very rare, since total occlusion will always show on 


\section{Chapter 2}

a check-up angiogram. If unrecognized and untreated, it often leads to permanent failure, mandating dialysis or renal replacement therapy ${ }^{40}$. Limb thrombosis after EVAR is a known complication and can occur in $2 \%$ of the cases in the early phase $^{10}$. Most of these events are caused by stent graft kinking and extension of the small diameter stent graft into the external iliac artery ${ }^{10}$. See table 1 for an overview of the comparison of complications between EVAR and open surgery ${ }^{41-52}$.

Table 1. Incidence of morbidities associated with open surgical repair and endovascular therapy ${ }^{44-55}$.

\begin{tabular}{lll}
\hline & $\begin{array}{l}\text { Open surgical repair } \\
\text { (average percentage) }\end{array}$ & $\begin{array}{l}\text { Endovascular therapy } \\
\text { (average percentage) }\end{array}$ \\
\hline All cardiac & $2.5-21.4 \%$ & $0.8-8.4 \%$ \\
Pulmonary (excludes atelectasis) & $0.6-14.3 \%$ & $3.2-7.0 \%$ \\
Renal failure & $1.9-7.1 \%$ & $2.5-7.3 \%$ \\
Cerebrovascular accident & $0.1-3.5 \%$ & $1.1-3.2 \%$ \\
Paraplegia/paraparesis & $0.6-3.5 \%$ & $<0.1 \%$ \\
Access/deployment failure & - & $2.1-8.3 \%$ \\
Endoleak & $1.1 \%$ & $8.9-20.7 \%$ \\
Vascular & $1.8 \%$ & $1.5-6.3 \%$ \\
Thrombotic/embolic & $1.9-2.5 \%$ & $0.9-12.5 \%$ \\
Gastrointestinal & $2.1-10.7 \%$ & $1.3-5.1 \%$ \\
Impotence & $0.2 \%$ & $0 \%$ \\
Hematoma/bleeding & $1.2-3.6 \%$ & $0.8-7.5 \%$ \\
Wound healing/infection & $0.6-7.1 \%$ & $1.6-14.3 \%$ \\
\hline
\end{tabular}

\section{Reinterventions}

EVAR comes with a high rate of reintervention of around $20 \%$, which is associated with an increase in postoperative mortality ${ }^{2}$. Significant causes leading to secondary interventions were migration, rupture, infections and type I and II endoleaks, according to a systematic review by de la Motte et al ${ }^{53}$.

A recent systematic review by Patel et al. studied preoperative risk factors for reintervention after EVAR ${ }^{54}$. The most common risk factor for reintervention was the AAA diameter ${ }^{55,56}$. Iliac artery morphology was associated with endograft related aortic complications ${ }^{56-58}$. Age was associated with endograft complications in the EVAR 1 and EVAR 2 trial ${ }^{56,57}$. Different studies on risk scores based on preoperative variables have been done ${ }^{55,58}$. The most important one was the St George's Vascular Institute (SGVI) score, which was derived from aortic 
morphology data over 400 patients from the UK ${ }^{58}$. It combined the two most commonly reported risk factors; the AAA diameter and the common iliac artery (CIA) morphology, with a sensitivity and specificity of $81.5 \%$ and $84.1 \%^{58}$. Patel et al. described the intraoperative predictive factors, saying that there was little evidence to examine the potential role of varied oversizing of the stent graft to seal zones or for comparing the reintervention rate associated with different endograft models ${ }^{54}$. The most common postoperative predictive factor for reintervention is endoleak ${ }^{54}$. A type II endoleak resolves spontaneously in $50 \%$ of the cases, so according to the SVS guidelines there is no need for immediate treatment. The risk of sac expansion with a type II endoleak is rare. At 6 months follow-up the incidence lays between $10-15 \%$. Treatment is necessary when sac expansion occurs with $>5 \mathrm{~mm}^{10}$.

A recent meta-analysis of Kent et al. looked at the device related failure for EVAR stent grafts ${ }^{59}$. They state that only one study had enough patients to look at non-inferiority at two years of follow-up, calling for urgent requirement of more data on device failure. Moreover, it was highlighted that the EVAR-1 trial shows a reversed survival benefit in the EVAR group at 8 years ${ }^{60 *}$. Given this information, it is important to have a closer look at EVAR devices, the reason for their failures and possible solutions.

\section{Devices}

\section{Takeoff in EVAR research}

In 1986 Volodos et al. introduced the first abdominal aortic stent graft, followed by Parodi et al ${ }^{6,7}$. The first patient treated by Parodi et al. needed a secondary intervention, because of a type $1 \mathrm{~b}$ endoleak. An additional aorto-uni-iliac endograft was placed, with occlusion of the contralateral CIA and femoro-femoral bypass. Similar to Parodi's aorto-aortic endograft, Lazarus designed an endograft for Endovascular Technologies Inc. (EVT) in 1992, called the Endovascular Grafting System (EGS) I. This became the first successfully deployed company manufactured endograft in $1993^{61}$. During phase I and the early phase II trial, the device had several failures, such as attachment hook and frame breaks, type Ib endoleaks and distal migration of the endograft. The original trial was eventually discontinued with retraction of the FDA approval in 1995. 


\section{Bifurcated stent grafts}

Many device failures occurred, due to unsuitable morphology in the distal landing zone. As a consequence unibody bifurcated grafts were developed for literally bypassing this problem ${ }^{52}$. EVT introduced a new bifurcated design called the EGS II and continued the phase II trial with improved results ${ }^{61}$. Less type Ib endoleaks were reported with the new device and less migration. However, the new method came with new issues, like limb obstructions due to iliac stenosis, infolding of the graft or calcifications. After the phase II trial, 38\% of patients needed additional intervention for limb abnormalities. Closer intraoperative attention was paid to limb luminal compromise, which resulted in only $3 \%$ needing additional limb interventions in the phase III trial. All the EGS II trials were concluded with success and in 1999, it became one of two FDA approved aortic endografts to reach the market, with the name Ancure ${ }^{\mathrm{TM}}$ (Guidant, EndoVascular Technologies Inc., USA). The other stent graft was the AneuRx ${ }^{\mathrm{TM}}$ (Medtronic Inc. USA).

\section{Modular stent grafts}

A first noticeable difference between the Ancure and the following devices was that most of the new designs no longer had unsupported fabric between a proximal and a distal stent. Instead, the endografts now consisted of a full length stent and a graft. In most cases the struts were located on the outside, called an exoskeleton (AneuRx, Excluder, Talent, Zenith) and in some stent grafts the struts were located on the inside, called an endoskeleton (Cordis, Vanguard). The shape of the stent was mainly Z-shaped as rings (Talent, Zenith) or as a helical continuum (Excluder). These new stent grafts had several advantages. They were more rigid with a better radial force and less likely to infold or migrate. The main advantage however was that each stent graft segment could now be customized on its own, introducing the ability of forming a modular stent graft as opposed to the unibody stent graft. The modular concept entailed that the stent graft comprised of two or three components. The first was a body placed in the aorta to exclude the aneurysm sac. The body had one short limb and one other limb, either short (three component system) or long (two component system). Separate limb extensions would make up the second or third component of the stent graft. This was a major breakthrough in EVAR and allowed to treat patients with variable distal aortic and/or iliac anatomy. Also it made the intraoperative deployment of the contralateral iliac limb easier and more reliable. These were the first large 
scale developed stent grafts, to be manufactured by several companies. They would later be known as the first generation stent grafts. Introducing the modular stent graft allowed for an increased risk of type III endoleak, among others seen in the no longer manufactured Vanguard stent graft ${ }^{62}$. Reoccuring type IV endoleaks partially led to a temporary manufacturing halt and change of graft material of the AneuRx stent graft $^{63}$. Other issues such as flexibility and a high profile delivery system were two impediments to the old designs, that have been overcome by progressive engineering over the last 15 years.

\section{Current generation infrarenal stent grafts}

Based on the indications of many companies producing aortic stent grafts, the native aortic proximal neck should have at least $10-15 \mathrm{~mm}$ in length, a neck diameter of $\leq 32 \mathrm{~mm}$ and a neck angulation of $\leq 60$ degrees. When circumferential mural thrombus is present, there is a higher risk of type la endoleak or migration during follow-up. A narrow distal aorta $(<15 \mathrm{~mm})$ just above the iliac bifurcation, high iliac artery tortuosity or calcification can increase the risk of complications ${ }^{10}$. The landing zone is usually in the CIA and the length is supposed to be at least $15 \mathrm{~mm}$. Asian people often have a shorter CIA. A significant difference in length of the CIA compared to the western population is published by Cheng et al. To pursue an adequate landing zone, it is necessary to overstent the internal iliac artery. This can result in buttock claudication ${ }^{64}$. Several stent grafts have been developed that stretch the limits of the standard anatomical limitations for EVAR, discussed in the aforementioned chapter. Some infrarenal stent grafts are especially designed for patients with a challenging anatomy. The Endurant II by Medtronic has been licensed to deploy the main body in a patient with a short non-pathologic proximal neck of only $10 \mathrm{~mm}$. A more recent device is the Ovation by Trivascular (now Endologix), also allowing a deployment in a short neck with 2 polymer filled rings between the stent and the native aortic wall, providing durable sealing. The Aorfix (Lombard Medical) and the Anaconda (Terumo, Vascutek) are flexible for a high proximal neck angulation of up to 90 degrees. In 2016 an infrarenal graft without a main body has been introduced, called the Altura (Lombard Medical). This device consists of two extended limbs that form kissing stents in the proximal neck and can be interchangeably repositioned. The limbs consecutively both lead into one iliac artery. Other devices are optimal for an easyuse delivery device, low profile sheaths (Ovation, Incraft, Altura), a wide variety 


\section{Chapter 2}

of length or diameters in stent graft possibilities or the ability to recapture and reposition the body. See table 2 for an overview of the current common infrarenal stent grafts and their main properties ${ }^{65-69}$.

The stent must be strong and conformable to keep the endoprosthesis in place in challenging anatomy and to prevent expansion beyond the physiological diameter. Additionally it should be compressible for device deliverability. The stent graft relies primarily on outward tension in the proximal graft to maintain the positioning of the graft, acquired by physiological intraluminal pressure and through characteristics of the self-expanding stent graft materials, most commonly nitinol, a "shape-memory" alloy of nickel and titanium.

Material properties of the graft are important for a variety of reasons. A graft must be able to endure radial and axial forces of pulsatile movement of the blood pressure and the native aorta while at the same time it should be flexible for expansion and compliant in order to regulate pressure and flow. The surface must be smooth in order to avoid stasis and thrombus formation. The inflammatory response to this corpus alienum cannot be excessive and the permeability of the material should be low. All currently available grafts are manufactured with polyethylene terephthalate (PET; e.g. Dacron) or polytetrafluoroethylene (PTFE; e.g. Teflon). These are strong, resilient and lightweight materials.

Despite all engineering developments and increased interventional experience of physicians the long term-outcomes of EVAR graft leave room for improvement,as mortality remains equal to open repair and many grafts show issues after 5 years in terms of type I-III endoleak, graft migration or proximal or distal aneurysm neck dilation, 2,4,60. To date, no randomized controlled trial comparing two different stent graft types has been conducted.

\section{Juxtarenal EVAR}

Approximately $15 \%$ of the patients with abdominal aneurysms have a more proximal pathology, extending to the renal arteries ${ }^{70}$. Open surgery for these aneurysms uses suprarenal aortic clamping with periods of renal ischemia, and visceral ischemia if clamped more proximally. The mean operative mortality and need for new onset dialysis after elective open juxtarenal surgery is described to be $2.9 \%$ and $3.3 \%^{71}$. In 1996 the first 2 cases of fenestrated endovascular aortic therapy (FEVAR) were described, making a hole in the stent graft at the sites where the visceral abdominal arteries branched ${ }^{72}$. Anderson J. subsequently 
performed 13 FEVARs between 1998 and 2000 without any 30-day mortality ${ }^{73}$. The fenestrated Zenith was, in 2012, the first FDA approved stent graft to incorporate the preservation of renal artery flow in their juxtarenal aneurysm treatment (figure 3). It is now followed in manufacturing by Vascutek, Terumo with the fenestrated Anaconda. The FEVAR can be deployed throughout the entire abdominal aorta and allows preserved flow to the renal arteries, the superior mesenteric artery (SMA) and the celiac trunk through fenestrations or scallops, thus covering the entire abdominal aorta. Additional stents are deployed in the target vessels for extra sealing and patency. FEVAR has proven to have a lower 30-day mortality, a comparable mid-term mortality and lower renal morbidity rate to open juxtarenal aneurysm repair ${ }^{74,75 *}$. Limitations of the fenestrated stent graft are severe aortic angulation at the level of the target vessels, excessive thrombus or stenosis of the target vessels and it can only be used in elective setting. Due to the custom-made requirement it is more costly than open surgery ${ }^{75}$. Some of the limitations have been overcome through innovative technologies, such as the preloaded fenestrated stent graft, first introduced in $2010^{76}$. This device allows easy positioning of the fenestration by a guiding through-and-through wire, mounted to the fenestration sites of the graft. The two main advantages are a decrease in catherization time and secondly, it allows deployment of a fenestrated stent graft using just one femoral entry point. With more introduced wires however, the risk of entanglement or twisting components becomes higher. The method is therefore best suited for experienced operators.

With the introduction of longer native aortic graft coverage however, a higher risk of spinal cord ischemia has to be taken into account. Long-term results of clinical trials comparing FEVAR to open surgery management are required to provide insight on the future of FEVAR. 


\begin{tabular}{|c|c|c|c|c|c|c|}
\hline $\begin{array}{l}\text { Endovascular } \\
\text { aortic therapy } \\
\text { devices }\end{array}$ & Latest model & $\begin{array}{l}\text { Market } \\
\text { introduction } \\
\text { first design }\end{array}$ & $\begin{array}{l}\text { FDA } \\
\text { approved }\end{array}$ & $\begin{array}{l}\text { Neck } \\
\text { diameter } \\
(\mathrm{mm})\end{array}$ & $\begin{array}{l}\text { Neck } \\
\text { length } \\
(\mathbf{m m})\end{array}$ & $\begin{array}{l}\text { Maximum } \\
\text { neck } \\
\text { angulation } \\
\left({ }^{\circ}\right) \\
\end{array}$ \\
\hline $\begin{array}{l}\text { Excluder }^{\circledR} \\
\text { (W.L. Gore \& } \\
\text { Associates, } \\
\text { USA) }\end{array}$ & C3 Excluder ${ }^{\circledR}$ & 2002 & Yes & $19-32$ & 15 & 60 \\
\hline $\begin{array}{l}\text { Zenith }^{\circledR} \text { (Cook } \\
\text { Medical } \\
\text { Technologies, } \\
\text { USA) }\end{array}$ & Zenith Flex ${ }^{\circledast}$ & 2003 & Yes & $18-32$ & 15 & 60 \\
\hline $\begin{array}{l}\text { Anaconda }{ }^{\circledR} \\
\text { (Terumo, } \\
\text { Vascutek, UK) }\end{array}$ & $\begin{array}{l}\text { Anaconda } \\
\text { ONE LOK }\end{array}$ & 2005 & $\mathrm{No}^{*}$ & $17.5-31$ & 15 & 90 \\
\hline $\begin{array}{l}\text { Endurant }^{\circledR} \\
\text { (Medtronic } \\
\text { Vascular, USA) }\end{array}$ & Endurant $\|{ }^{\circledast}$ & 2010 & Yes & $19-32$ & 10 & 60 \\
\hline $\begin{array}{l}\text { AFX }{ }^{\circledR} \\
\text { (Endologix, } \\
\text { USA) }\end{array}$ & $\operatorname{AFX} 2^{\circledR}$ & 2011 & Yes & $18-32$ & 15 & 60 \\
\hline $\begin{array}{l}\text { Ovation }{ }^{\circledR} \\
\text { (Trivascular, } \\
\text { USA) }\end{array}$ & Ovation i $X^{\oplus}$ & 2011 & Yes & $16-30$ & 10 & 60 \\
\hline $\begin{array}{l}\text { Aorfix }{ }^{\circledR} \\
(\text { Lombard } \\
\text { Medical, UK) }\end{array}$ & Aorfix ${ }^{\circledast}$ & 2013 & Yes & $19-33$ & 15 & 90 \\
\hline $\begin{array}{l}\text { Treovance }^{\circledR} \\
\text { (Bolton } \\
\text { Medical, USA) }\end{array}$ & TREO ${ }^{\circledR}$ & 2013 & $\mathrm{No}^{*}$ & $17-32$ & 10 & 60 \\
\hline $\begin{array}{l}\text { Incraft }{ }^{\circledR} \text { (Cordis } \\
\text { Corporation, } \\
\text { USA) }\end{array}$ & Incraft ${ }^{\circledR}$ & 2014 & $\mathrm{No}^{*}$ & $17-31$ & 10 & 60 \\
\hline $\begin{array}{l}\text { Altura }^{\circledR} \\
(\text { Lombard } \\
\text { Medical, UK) }\end{array}$ & Altura $^{\circledast}$ & 2015 & $\mathrm{No}^{*}$ & $18-28$ & 15 & 60 \\
\hline
\end{tabular}

Table 2. Main properties for current common used infrarenal stent grafts

* CE mark approved, phase II trials concluded, running phase III trials for FDA approval Abreviations: FDA, Food and Drug Administration; PTFE, polytetrafluoroethylene; FEP, fluorinated ethylene propylene; PET, polyethylene terephthalate; CCA, cobalt chromium alloy, CE, Conformité Européenne 


\begin{tabular}{|c|c|c|c|c|c|c|c|}
\hline $\begin{array}{l}\text { Iliac artery } \\
\text { diameter } \\
(\mathbf{m m})\end{array}$ & $\begin{array}{l}\text { Iliac artery } \\
\text { length } \\
(\mathrm{mm})\end{array}$ & $\begin{array}{l}\text { Sheath } \\
\text { diameter } \\
\text { (French) }\end{array}$ & $\begin{array}{l}\text { Stent } \\
\text { material }\end{array}$ & $\begin{array}{l}\text { Graft } \\
\text { material }\end{array}$ & Components & $\begin{array}{l}\text { Suprarenal } \\
\text { fixation }\end{array}$ & $\begin{array}{l}\text { Active } \\
\text { proximal } \\
\text { fixation }\end{array}$ \\
\hline $8-25$ & 10 & $18-20$ & Nitinol & $\begin{array}{l}\text { PTFE/ } \\
\text { FEP }\end{array}$ & 2 & No & Yes \\
\hline $7.5-20$ & 10 & $18-20$ & $\begin{array}{l}\text { Stainless } \\
\text { steel }\end{array}$ & PET & 3 & Yes & Yes \\
\hline $8.5-21$ & 20 & $\begin{array}{l}20.4- \\
22.5\end{array}$ & Nitinol & PET & 3 & No & Yes \\
\hline $8-25$ & 15 & $18-20$ & Nitinol & PET & 2 & Yes & Yes \\
\hline $10-23$ & 15 & 21 & CCA & PTFE & 1 & Yes & No \\
\hline $8-25$ & 10 & $14-16$ & Nitinol & PTFE & 3 & Yes & Yes \\
\hline $9-19$ & 15 & 18 & Nitinol & PET & 2 & No & Yes \\
\hline $8-13$ & 10 & $18-19$ & Nitinol & PET & 3 & Yes & Yes \\
\hline $7-22$ & 10 & $14-16$ & Nitinol & PET & 3 & Yes & Yes \\
\hline $8-18$ & 15 & 14 & Nitinol & PET & 4 & Yes & Yes \\
\hline
\end{tabular}


Chapter 2

\section{Biomechanical features of the stent graft}

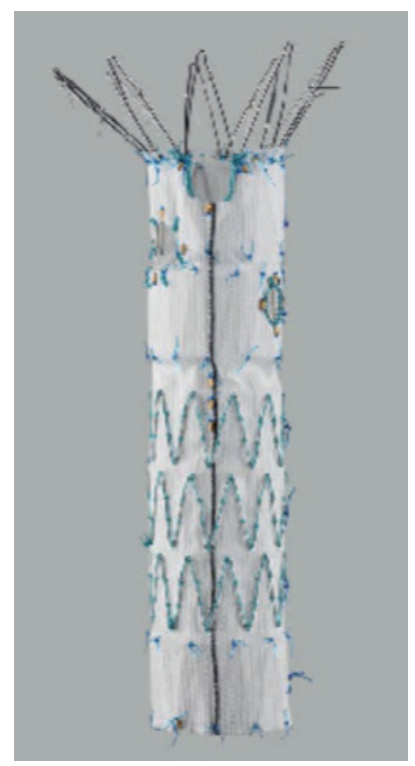

Figure 3 The Fenestrated Zenith stent graft with side branch ostia to the renal arteries and a scallop at the superior mesenteric artery (courtesy of Cook Medical, Bloomington, IN, USA).

\section{Emergency EVAR}

Ruptured aneurysms do not allow extensive planning of EVAR. In juxtarenal aortic aneurysm adjusted EVAR devices have been developed to encompass emergency use. These off-the-shelf fenestrated/ branched stent grafts (OSFGs) are precustomized and can be quickly assessed in renal and visceral aortic branching. Even though OSFGs have been around for a long time, no FDA approved model exists yet. Currently, a multicenter pivotal trial is being conducted in the United States in order to obtain FDA approval for a Cook off-the-shelf branched stent graft. The two variants are the $\mathrm{p}$-branch, for juxtarenal aneurysms and the t-branch, designed for thoracoabdominal aortic aneurysms. The p-branch is a fenestrated stent graft, with fenestration of the renal arteries and the SMA and a scallop for the celiac trunk. The renal fenestrations are dome shaped to accommodate variability in renal artery diameter and position (figure 4). The t-branch consists of a larger suprarenal stent graft and has small side-arm stent grafts sutured to the main body for the renal arteries, the SMA and the celiac trunk 
(figure 4). The first off-the-shelf models were not actual OSFGs, but physician modulated regular stent grafts (PMSG). A systematic review by Georgiadis GS at el., published in 2016, analyzed 23 clinical studies containing a total of 308 patients, where outcomes of either OSFGs and PMSGs were investigated. Major adverse events within 30 days occurred in $12.8 \%$ of PMSG patients and in $7.4 \%$ of OSFG patients, suggesting that expanding EVAR to branched segments of the aorta is safe and effective, with OSFG even more so than with PMSG [77]. No clinical studies have yet been performed on the long term follow-up after treating with an OSFG, although the use of emergent EVAR seems to be feasible in up to $80 \%$ of cases $^{78}$.

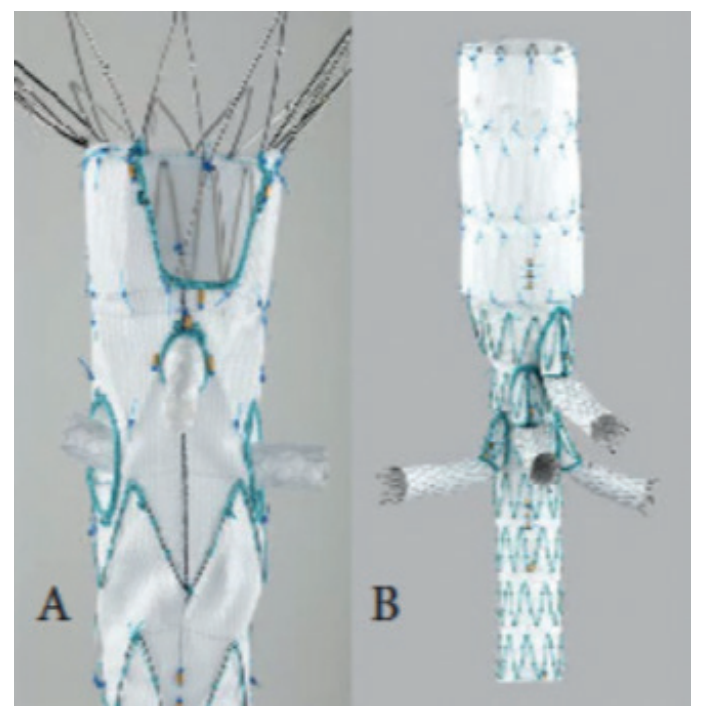

Figure 4 A) Cook Medical Zenith p-branch graft, an off the shelf stent graft for juxtarenal aneurysm repair. It shows two renal artery side-branches out of dome shaped lateral sides, a superior mesenteric artery side branch and a scallop at the celiac trunk. B) Cook Medical Zenith t-branch graft, an off the shelf stent graft for thoracoabdominal aneurysm repair. It shows a tapering device with branches for the four main abdominal branching visceral arteries (courtesy of Cook Medical Inc., Bloomington, IN, USA).

\section{Expert commentary}

As we look back on almost 20 years of approved clinical use of EVAR, there has been a giant leap in engineering. The initial anatomical limitations have been overcome and the ability to adjust for tortuosity and aneurysm neck angulation are improved. As our population becomes older, durability cannot be provided and the long term shortcomings of EVAR are painfully highlighted ${ }^{2-5}$. 


\section{Chapter 2}

Significant factors that lead to reinterventions are migration, rupture, type I and type III endoleaks ${ }^{53}$. We would like to discuss two other important features of postoperative long-term anatomical changes, which need attention. These are widening of the aortic neck and increased tortuosity.

\section{Aortic neck widening}

The aneurysm process may continue at the borders of the endograft area. A stent graft without anchorage is of no use in a pulsatile environment with blood flow. The landing zones provide this anchorage. Stent graft oversizing of more than $10 \%$ provides a necessary contact pressure and friction coefficient on the walls ${ }^{79,80}$. This is lost with the gradual loss of the oversizing gradient due to aortic neck widening. Too much oversizing on the other hand is not the solution, since it increases the chance of stent graft infolding. Type I endoleak and migration are obvious consequences of neck widening. Additionally, with the increased instability at the landing zone the stent graft will become more susceptible to bending and twisting forces. These can lead to erosion of the stent graft, especially in Z-shaped stents with relatively sharp angles ${ }^{81}$.

\section{Increased tortuosity}

The length of the aorta increases as patients get older. This process differs per patient and may cause serious angulation. A stent graft in an angulated aorta tends to twist or bend, losing its frictional field in the landing zone ${ }^{80}$. The twisted stent grafts may cause shortening or lengthening of the stent graft ${ }^{82}$. The bended stent graft is susceptible to fabric tears or stent breakage $\mathrm{e}^{79}$. As the stented region may grow longer in an angulated aorta, modular stent grafts can get disconnected, causing type III endoleak. This happens especially when intersegmental slipping coefficients are high and the stent grafts do not have a lot of overlap ${ }^{83}$.

A solution to both of the aforementioned challenges is strived to be found with new technologies. Stents are altered to prevent fabric tears through fatigue breaks or too sharp Z-element angles. Graft material is made strong and durable. Systemic treatment may be combined with EVAR, used to target further aneurysm formation ${ }^{84}$. Other examples of new technologies are discussed below.

\section{EVAR assist device}

A manufacturer can attach small devices to a stent graft to prevent it from migrating and to optimize sealing. However, in some cases additional devices 
are deemed necessary by the clinician to establish these goals, like endoanchors. The spiral shaped, stainless steel endoanchor penetrates the graft and the aortic wall. The Medtronic, HeliFx EndoAnchor system received FDA approval in 2011 as a primary fixation device (figure 5A). The low rates of aortic neck dilatation and endoleak type 1 with the use of endostaple systems in primary implantation of endografts are promising, according to a systematic review published in 2013. However, no randomized controlled trial for its use has yet been performed ${ }^{85}$.

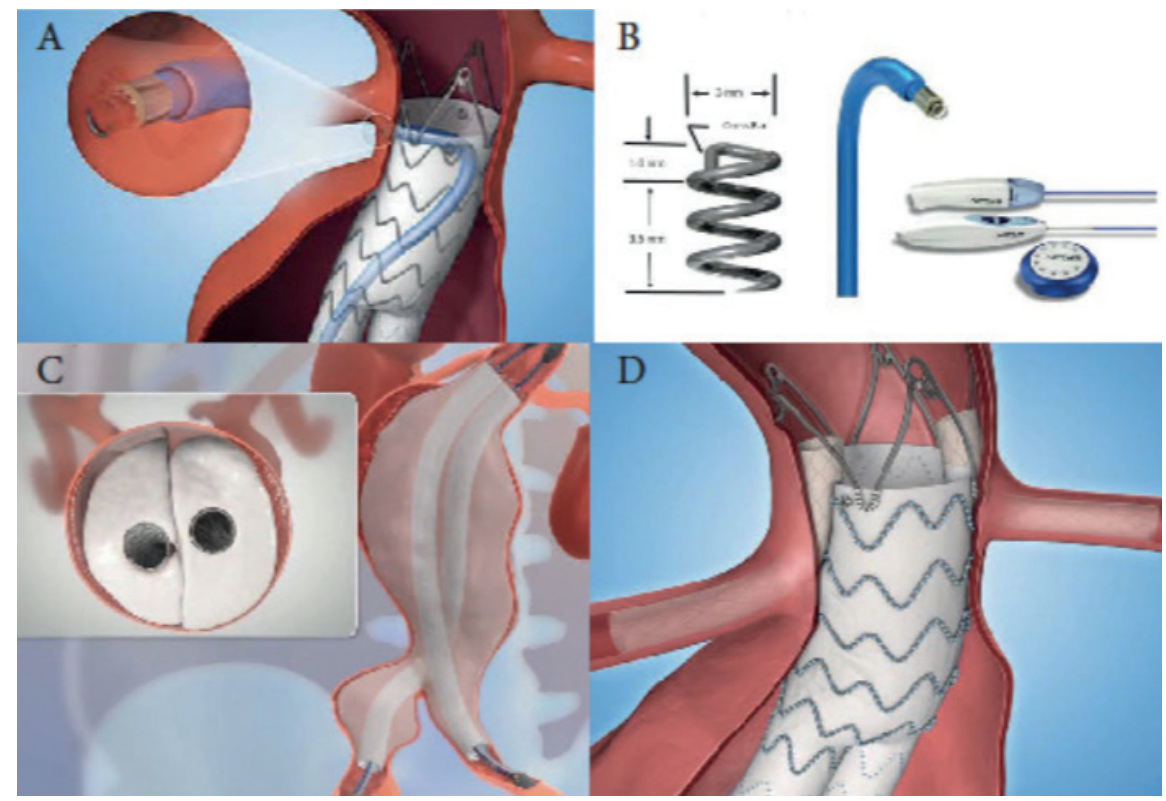

Figure 5 New applications on the market for endovascular therapy. A) An overview of application of the Heli-Fx endoanchor assist device. B) The Heli-Fx endoanchor size, the tip of the system applier and the handles of the system applier. C) An overview of the deployed Nellix endovascular aneurysm sealing device, with a separate window showing a proximal axial view of deployment of the polymer filled sac around the stent grafts. D) An overview of the deployed Endurant II stent graft with two chimney stent grafts providing flow to the renal arteries, originating more proximally to the Endurant II graft. (courtesy of Medtronic Inc., Minneapolis, MN, USA and courtesy of Endologix Inc., Irving, CA, USA).

\section{Non FDA approved devices}

Endovascular aneurysm sealing (EVAS) is an alternative therapy for conventional infrarenal EVAR. An example of EVAS is the Nellix system (figure 5B). This is a dual lumen balloon expandable PTFE alloy with stainless steel stent graft, surrounded by a compartment, which fills with polyethene glycol and aims to obliterate the aneurysm sac and maintain endograft position. EVAS using Nellix 


\section{Chapter 2}

was first described in 2011 and was claimed to be excellent in the setting of AAA with adverse anatomic features, although the indications for use reveal to be not much different from previous infrarenal devices ${ }^{86}$. Another described advantage of EVAS is the lower risk of post implantation syndrome (PIS) by having a more blunted systemic inflammatory response with the aortic wall than the polyester stent-grafts used in most EVAR cases ${ }^{87}$. When Nellix was first introduced, the procedure was considered technically simple and quick, with wide patient applicability. This has changed considerably over time. The current best practice involves careful positioning of the device, with the endobags placed immediately below the renal arteries. Since its introduction the inclusion criteria in the instructions for use had to be altered multiple times ${ }^{88}$. Nellix is awaiting FDA approval, but has received a Conformité Européene (CE) mark in 2016. Although results look promising, longer term results of this group are being awaited ${ }^{89}$.

Another more recent variant of EVAS is Arsenal, which uses a polymer thick fluid introduced directly into the aneurysm sac around the conventional placed EVAR tube. It is claimed to be user friendlier than Nellix and would form a reliable and easy way to prevent type I and specifically type II endoleaks. However, no convincing results have yet been published.

For the complex abdominal aneurysms (juxtarenal or suprarenal) without an adequate landing zone, an alternative to the fenestrated and branched EVAR has been first described by Greenberg and colleagues in $2003^{90}$. The chimney (i.e. snorkel or periscope) technique uses the delivery of smaller stent grafts into the visceral branches running parallel to the main endograft. The main endograft does not require any branches or fenestrations and therefore requires less customization. Compared to fenestrated or branched endografts this technique may be a more cost-effective and time efficient technique, which is less technically challenging ${ }^{91,92}$. Following the good results of the PROTAGORAS study, the Endurant II was the first stent graft in 2016 to receive a CE mark on regulated use of chimney extensions ${ }^{92 *}$. The chimney technique is known to have a higher incidence of type I endoleaks, likely due to 'gutter' formation between the chimney and the main body graft (figure $5 \mathrm{C}$ ) ${ }^{93}$. However, a recent publication studying 33 patients treated with a chimney graft, reported a significant decrease of gutter size over time. According to the investigators EVAR using chimney grafts for branch vessel preservation was an acceptable option for high-risk patients with large, complex aneurysms who were unfit for open repair and who had been 
excluded from fenestrated EVAR ${ }^{94}$. The combined use of endoanchors or EVAS and chimneys in complex aneurysms may be promising to prevent the type I endoleaks ${ }^{95}$.

Cardiatis has proposed a new way of treating aortic aneurysms by using a multilayer flow modulator (MFM), which received a CE-mark. The device consists of multiple bare cobalt alloy stents in an overlapping fashion, causing micro openings between the actual lumen and the aneurysm sac. The theory is that the main blood flow is diverted through the newly formed lumen, although blood is also allowed to flow into the aneurysm sac. The new diverted flow through the lumen would create a laminar flow and reduces turbulent flow in the aneurysmal sac, thereby said to promote thrombus formation and sac shrinkage. The advantage of the MFM is that it can be used in patients unfit for both conventional endovascular therapy and open surgery, since the self-expanding stent is easy in sizing and is claimed to be deployable over branches, since sufficient flow would be preserved ${ }^{96}$. Beside the fascinating physic concept, results of MFM aortic aneurysm treatment need to be cautiously evaluated according to a systematic review by Hynes et al. Of all studies included (3 multicenter studies, 3 observational cohort studies and 9 case reports), counting 171 patients a low technical success rate of $77 \%$ was reported $^{97}$. No official benefit for the use in EVAR could yet be deducted from current available studies and no evident sac shrinkage could yet be observed. Randomized controlled trials are needed to confirm if this new technology is really safe and efficient for use in aortic aneurysms.

\section{Five-year view}

The field of endovascular interventions is changing rapidly. Considering the first step in EVAR repair took approximately 20 years to become a gold standard, we are yet to be surprised by long term outcomes that the new developments of the last turbulent technological decade will bring. We believe that 5 years from now the majority of emergency cases will be managed with endovascular therapy. As for the elective cases, $80 \%$ of cases might become $90 \%$ treated with EVAR. Especially more proximal cases of EVAR including visceral branches will see a global increase in the next 5 years. If the burden of iodinated contrast fluid and radiation exposure can be decreased, the numbers of patients treated endovascularly may become even higher. New randomized trials investigating the latest stent technology versus open repair are needed soon in order to get a grasp on the durability. 


\section{Key issues}

EVAR has a low early post procedural mortality, although from three years onwards no difference in overall mortality has been proven compared to open surgery.

EVAR comes with a high complication and reintervention rate, with endoleak being the most important predictive factor for reintervention.

Close imaging follow-up is of high essence and the primary outcome is aneurysm sac growth. Endoleak is a secondary outcome.

EVAR patients may be more susceptible to malignancy due to follow-up radiation exposure.

Postoperative follow-up can be done with contrast enhanced ultrasound.

Device failures are estimated to be due to widening of the aortic neck and increased tortuosity over time.

New designs aim to prevent type I, II and III endoleaks on the long term.

EVAR is done in approximately $80 \%$ of cases and is likely to continue to increase in the next 5 years. 


\section{References}

* = of importance

1. Dubost C, Allary M, Oeconomos N. [Treatment of aortic aneurysms; removal of the aneurysm; reestablishment of continuity by grafts of preserved human aorta]. Mem Acad Chir. 1951;77:381-383.

2. ${ }^{*}$ De Bruin JL, Baas AF, Buth J, et al. Long-term outcome of open or endovascular repair of abdominal aortic aneurysm. N. Engl. J. Med. 2010;362:1881-1889.

3. *Becquemin J-P, Pillet J-C, Lescalie F, et al. A randomized controlled trial of endovascular aneurysm repair versus open surgery for abdominal aortic aneurysms in low- to moderate-risk patients. J. Vasc. Surg. 2011;53:1167-1173.e1.

4. *Lederle FA, Freischlag JA, Kyriakides TC, et al. Long-term comparison of endovascular and open repair of abdominal aortic aneurysm. N. Engl. J. Med. 2012;367:1988-1997.

5. *Patel R, Sweeting MJ, Powell JT, et al. Endovascular versus open repair of abdominal aortic aneurysm in 15-years' follow-up of the UK endovascular aneurysm repair trial 1 (EVAR trial 1): a randomised controlled trial. Lancet. 2016;388:2366-2374.

6. Volodos' NL, Shekhanin VE, Karpovich IP, et al. [A self-fixing synthetic blood vessel endoprosthesis]. Vestn. Khir. Im. I. I. Grek. 1986;137:123-125.

7. Parodi JC, Palmaz JC, Barone HD. Transfemoral intraluminal graft implantation for abdominal aortic aneurysms. Ann. Vasc. Surg. 1991;5:491-499.

8. Paravastu S, Jayarajasingam R, Cottam R, et al. Endovascular repair of abdominal aortic aneurysm. Cochrane Database Syst Rev. 2014;CD004178.

9. Ricco JB, Cau J, Biancari F, et al. Outcome after open and laparoscopic aortic surgery in matched cohorts using propensity score matching. Eur. J. Vasc. Endovasc. Surg. 2016;52:179-188.

10. Chaikof EL, Dalman RL, Eskandar MK, et al. The Society for Vascular Surgery practice guidelines on the care of patients with an abdominal aortic aneurysm. J. Vasc. Surg. 2018;67:2-77.

11. Schermerhorn ML, Bensley RP, Giles KA, et al. Changes in abdominal aortic aneurysm rupture and short-term mortality, 1995-2008: A retrospective observational study. Ann. Surg. 2012;256:651658.

12. Powell JT, Sweeting MJ, Ulug P, et al. Meta-analysis of individual-patient data from EVAR-1, DREAM, OVER and ACE trials comparing outcomes of endovascular or open repair for abdominal aortic aneurysm over 5 years. Br. J. Surg. 2017;104:166-178.

13. EVAR trial participants. Endovascular aneurysm repair and outcome in patients unfit for open repair of abdominal aortic aneurysm (EVAR trial 2): randomised controlled trial. Lancet. 2005;365:2187-2192.

14. Powell J, IMPROVE trial investigators. Comparative clinical effectiveness and cost effectiveness of endovascular strategy vs open repair for ruptured abdominal aortic aneurysm: three year results of the IMPROVE randomised trial. BMJ. 2017;359:j4859.

15. Veith FJ, Rockman CB. The recent randomized trials of EVAR versus open repair for ruptured abdominal aortic aneurysms are misleading. Vascular. 2015;23:217-219.

16. Reimerink JJ, Hoornweg LL, Vahl AC, et al. Endovascular repair versus open repair of ruptured abdominal aortic aneurysms: A multicenter randomized controlled trial. Ann. Surg. 2013;258:248256.

17. Desgranges P, Kobeiter H, Katsahian S, et al. ECAR (endovasculaire ou chirurgie dans les anévrysmes aorto-iliaques rompus): a French randomized controlled trial of endovascular versus open surgical repair of ruptured aorto-iliac aneurysms. Eur. J. Vasc. Endovasc. Surg. 2015;50:303310 .

18. *Moll FL, Powell JT, Fraedrich G, et al. Management of abdominal aortic aneurysms clinical practice guidelines of the European society for vascular surgery. Eur. J. Vasc. Endovasc. Surg. 2011;41:S1-S58.

19. Green RM. Patient selection for endovascular abdominal aortic aneurysm repair. J. Am. Coll. Surg. 2002;194:S67-73.

20. van Keulen JW, van Prehn J, Prokop M, et al. Dynamics of the aorta before and after endovascular aneurysm repair: a systematic review. Eur. J. Vasc. Endovasc. Surg. 2009;38:586-596. 


\section{Chapter 2}

21. Muhs BE, Vincken KL, van Prehn J, et al. Dynamic cine-CT angiography for the evaluation of the thoracic aorta; insight in dynamic changes with implications for thoracic endograft treatment. Eur. J. Vasc. Endovasc. Surg. 2006;32:532-536.

22. Prince MR, Arnoldus C, Frisoli JK. Nephrotoxicity of high-dose gadolinium compard with iodinated contrast. J. Magn. Reson. Imaging. 1996;5:162-166.

23. *Sailer AM, De Haan MW, Peppelenbosch AG, et al. CTA with fluoroscopy image fusion guidance in endovascular complex aortic aneurysm repair. Eur. J. Vasc. Endovasc. Surg. 2014;47:349-356.

24. Zaiem F, Almasri J, Tello M, et al. Surveillance after endovascular aortic repair. J. Vasc. Surg. 2017;67(1):320-331.e37.

25. Habets J, Zandvoort HJA, Moll FL, et al. Magnetic resonance imaging with a weak albumin binding contrast agent can reveal additional endoleaks in patients with an enlarging aneurysm after EVAR. Eur. J. Vasc. Endovasc. Surg. 2015;50:331-340.

26. O'Donnell TFX, Corey MR, Deery SE, et al. Select early type IA endoleaks after endovascular aneurysm repair will resolve without secondary intervention. J. Vasc. Surg. 2018;67:119-125.

27. Motaganahalli R, Martin A, Feliciano B, et al. Estimating the risk of solid organ malignancy in patients undergoing routine computed tomography scans after endovascular aneurysm repair. J. Vasc. Surg. 2012;56:929-937.

28. Liaw JVP, Clark M, Gibbs R, et al. Update: complications and management of infrarenal EVAR. Eur. J. Radiol. 2009;71:541-551.

29. Golzarian J, Struyven J. Imaging of complications after endoluminal treatment of abdominal aortic aneurysms. Eur. Radiol. 2001;11:2244-2251.

30. Zarins CK, Bloch DA, Crabtree T, et al. Stent graft migration after endovascular aneurysm repair: Importance of proximal fixation. J. Vasc. Surg. 2003;38:1264-1272.

31. Maleux G, Koolen M, Heye S. Complications after endovascular aneurysm repair. Semin. Intervent. Radiol. 2009;26:3-9.

32. Wald R, Waikar SS, Liangos O, et al. Acute renal failure after endovascular vs open repair of abdominal aortic aneurysm. J. Vasc. Surg. 2006;43(3):460-466.

33. Arnaoutoglou E, Kouvelos G, Papa N, et al. Prospective evaluation of post-implantation inflammatory response after EVAR for AAA: Influence on patients' 30 day outcome. Eur. J. Vasc. Endovasc. Surg. 2015;49:175-183.

34. Sharif MA, Lee $B, L a u L L$, et al. Prosthetic stent graft infection after endovascular abdominal aortic aneurysm repair. J. Vasc. Surg. 2007;46:442-448.

35. Perera KG, Wong E, Devine T. Stent graft infection secondary to appendicitis: an unusual complication of endovascular abdominal aortic aneurysm repair. J. Surg. Case Reports. 2014;2014:rju108-rju108.

36. Van Den Berg HR, Leijdekkers VJ, Vahl A. Aortic stent-graft infection following septic complications of a kidney stone. Cardiovasc. Intervent. Radiol. 2006;29:443-445.

37. Saratzis N, Saratzis A, Melas N, et al. Aortoduodenal fistulas after endovascular stent-graft repair of abdominal aortic aneurysms: single-center experience and review of the literature. J. Endovasc. Ther. 2008;15:441-448.

38. Perry RJT, Martin MJ, Eckert MJ, et al. Colonic ischemia complicating open vs endovascular abdominal aortic aneurysm repair. J. Vasc. Surg. 2008;48:272-277.

39. Berg P, Kaufmann D, Van Marrewijk CJ, et al. Spinal cord ischaemia after stent-graft treatment for infra-renal abdominal aortic aneurysms. Analysis of the Eurostar database. Eur. J. Vasc. Endovasc. Surg. 2001;22:342-347.

40. Adu J, Cheshire NJ, Riga C V., et al. Strategies to tackle unrecognized bilateral renal artery occlusion after endovascular aneurysm repair. Ann. Vasc. Surg. 2012;26(8):1127.e1-7.

41. Mialhe C, Amicabile C, Becquemin JP. Endovascular treatment of infrarenal abdominal aneurysms by the Stentor system: preliminary results of 79 cases. J. Vasc. Surg. 1997;26:199-209.

42. Brewster DC, Geller SC, Kaufman JA, et al. Initial experience with endovascular aneurysm repair: comparison of early results with outcome of conventional open repair. J. Vasc. Surg. 1998;27:992995.

43. Zarins CK, White RA, Schwarten D, et al. Aneurx stent graft versus open surgical repair of abdominal aortic aneurysms: multicenter prospective clinical trial. J. Vasc. Surg. 1999;29:292308. 
44. May J, White GH, Waugh R, et al. Adverse events after endoluminal repair of abdominal aortic aneurysms: A comparison during two successive periods of time. J. Vasc. Surg. 1999;29:32-39.

45. Buth J, Laheij RJF. Early complications and endoleaks after endovascular abdominal aortic aneurysm repair: report of a multicenter study. J. Vasc. Surg. 2000;31:134-146.

46. May J, White GH, Yu W, et al. Concurrent comparison of endoluminal versus open repair in the treatment of abdominal aortic aneurysms: analysis of 303 patients by life table method. J. Vasc. Surg. 1998;27:213-221.

47. Stelter W, Umscheid T, Ziegler P. Three-year experience with modular stent-graft devices for endovascular AAA treatment. J. Endovasc. Surg. 1997;4:362-369.

48. Richardson JD, Main KA. Repair of abdominal aortic aneurysms. Arch. Surg. 1991;126:614.

49. Perry MO, Calcagno D. Abdominal aortic aneurysm surgery: the basic evaluation of cardiac risk. Ann. Surg. 1988;208:738-742.

50. Bernstein EF, Dilley RB, Randolph III HF. The improving long-term outlook for patients over 70 years of age with abdominal aortic aneurysms. Ann. Surg. 1988;207:318-322.

51. Diehl JT, Cali RF, Hertzer NR, et al. Complications of abdominal aortic reconstruction. An analysis of perioperative risk factors in 557 patients. Ann. Surg. 1983;197:49-56.

52. Chuter TAM, Risberg B, Hopkinson BR, et al. Clinical experience with a bifurcated endovascular graft for abdominal aortic aneurysm repair. J. Vasc. Surg. 1996;24:655-666.

53. de la Motte L, Falkenberg M, Koelemay MJ, et al. Is EVAR a durable solution: indications for reinterventions. J. Cardiovasc. Surg. (Torino). 2018;59(2):201-212.

54. Patel SR, Allen C, Grima MJ, et al. A systematic review of predictors of reintervention after EVAR: guidance for risk-stratified surveillance. Vasc. Endovascular Surg. 2017;51:417-428.

55. Barnes M, Boult M, Maddern G, et al. A model to predict outcomes for endovascular aneurysm repair using preoperative variables. Eur. J. Vasc. Endovasc. Surg. 2008;35:571-579.

56. Brown LC, Greenhalgh RM, Powell JT, et al. Use of baseline factors to predict complications and reinterventions after endovascular repair of abdominal aortic aneurysm. Br. J. Surg. 2010;97:12071217.

57. Wyss TR, Dick F, Brown LC, et al. The influence of thrombus, calcification, angulation, and tortuosity of attachment sites on the time to the first graft-related complication after endovascular aneurysm repair. J. Vasc. Surg. 2011;54:965-971.

58. Karthikesalingam A, Holt PJ, Vidal-Diez A, et al. Predicting aortic complications after endovascular aneurysm repair. Br. J. Surg. 2013;100:1302-1311.

59. Kent F, Ambler G, Bosanquet D, et al. The safety of device registries for endovascular abdominal aortic aneurysm repair: systematic review and meta-regression. Eur. J. Vasc. Endovasc. Surg. 2017;55(2):177-183.

60. ${ }^{*}$ Greenhalgh R, Brown L, Powel J, et al. Endovascular versus Open Repair of Abdominal Aortic Aneurysm. N. Engl. J. Med. 2010;362:2239-2246.

61. EVT Investigators. Transfemoral endovascular repair of abdominal aortic aneurysm: results of the North American EVT phase 1 trial. J. Vasc. Surg. 1996;23:543-553.

62. Holtham SJ, Rose JDG, Jackson RW, et al. The vanguard endovascular stent-graft: Mid-term results from a single centre. Eur. J. Vasc. Endovasc. Surg. 2004;27:311-318.

63. Howell MH, Strickman N, Mortazavi A, et al. Preliminary results of endovascular abdominal aortic aneurysm exclusion with the AneuRx stent-graft. J. Am. Coll. Cardiol. 2001;38:1040-1046.

64. Cheng SWK, Ting ACW, Ho P, et al. Aortic aneurysm aorphology in Asians: features affecting stent-graft application and design. J. Endovasc. Ther. 2004;11:605-612.

65. US Food and Drug Administration. Medical devices: device approvals and clearances. Center for Devices and Radiological Health. 2017; Available from: https://www.fda.gov/MedicalDevices/ ProductsandMedicalProcedures/DeviceApprovalsandClearances/Recently-ApprovedDevices/ default.htm.

66. Bolton Medical. Treo AAA stent graft - instructions for use. 2017; Available from: https://www. boltonmedical.com/wp-content/uploads/2017/01/TREO-IFU.pdf.

67. Vascutek. Anaconda ONE-LOK AAA stent graft system, Anaconda iliac stent graft system, Anaconda AAA stent graft system, aortic cuff instructions for use. 2018; Available from: http:// www.vascutek.com/site/301-179.pdf. 


\section{Chapter 2}

68. Lombard Medical Inc. Lombard Medical Inc. 2016; Available from: http://www.altituderegistry. com/assets/altura-sizing-guide.pdf.

69. Bertoglio L, Logaldo D, Marone EM, et al. Technical features of the INCRAFT AAA stent graft system. J. Cardiovasc. Surg. (Torino). 2014;55:705-715.

70. Taylor SM, Mills JL, Fujitani RM. The juxtarenal abdominal aortic aneurysm: a more common problem than previously realized? Arch. Surg. 1994;129:734-737.

71. Jongkind V, Yeung KK, Akkersdijk GJM, et al. Juxtarenal aortic aneurysm repair. J. Vasc. Surg. 2010;52:760-767.

72. Park JH, Chung JW, Choo IW, et al. Fenestrated stent-grafts for preserving visceral arterial branches in the treatment of abdominal aortic aneurysms: preliminary experience. J. Vasc. Interv. Radiol. 1996;7:819-823.

73. Anderson $J$ L, Berce M, Hartley DE. Endoluminal aortic grafting with renal and superior mesenteric artery incorporation by graft fenestration. J. Endovasc. Ther. 2001;8:3-15.

74. *Ultee KHJ, Zettervall SL, Soden PA, et al. Perioperative outcome of endovascular repair for complex abdominal aortic aneurysms. J. Vasc. Surg. 2017;65:1567-1575.

75. Michel M, Becquemin J-P, Marzelle J, et al. A study of the cost-effectiveness of fenestrated/ branched EVAR compared with open surgery for patients with complex aortic aneurysms at 2 years. Eur. J. Vasc. Endovasc. Surg. 2018;1-7.

76. Manning BJ, Harris PL, Hartley DE, et al. Preloaded Fenestrated Stent-Grafts for the Treatment of Juxtarenal Aortic Aneurysms. J. Endovasc. Ther. 2010;17:449-455.

77. Georgiadis GS, Van Herwaarden JA, Antoniou GA, et al. Systematic review of off-the-shelf or physician-modified fenestrated and branched endografts. J. Endovasc. Ther. 2016;23:98-109.

78. Carpenter JP, Baum RA, Barker CF, et al. Impact of exclusion criteria on patient selection for endovascular abdominal aortic aneurysm repair. J. Vasc. Surg. 2001;34:1050-1054.

79. van Prehn J, Schlösser FJ V, Muhs BE, et al. Oversizing of aortic stent grafts for abdominal aneurysm repair: a systematic review of the benefits and risks. Eur. J. Vasc. Endovasc. Surg. 2009;38:42-53.

80. Prasad A, Xiao N, Gong X-Y, et al. A computational framework for investigating the positional stability of aortic endografts. Biomech Model Mechanobiol. 2013;12:869-887.

81. Lin J, Guidoin R, Du J, et al. An in vitro twist fatigue test of fabric stent-grafts supported by Z-stents vs. ringed stents. Materials (Basel). 2016;9:1-19.

82. Lee K, Hossain S, Sabalbal M, et al. Explaining endograft shortening during endovascular repair of abdominal aortic aneurysms in severe aortoiliac tortuosity. J. Vasc. Surg. 2017;65:1297-1304.

83. Prasad A, To LK, Gorrepati ML, et al. Computational Analysis of Stresses Acting on Intermodular Junctions in Thoracic Aortic Endografts. J Endovasc Ther 2011;18:559-568.

84. Fujimura N, Xiong J, Kettler EB, et al. Metformin treatment status and abdominal aortic aneurysm disease progression. J. Vasc. Surg. 2016;64:46-54.e8.

85. Bail DHL, Walker T, Giehl J. Vascular endostapling systems for vascular endografts (T)EVAR systematic review - current state. Vasc. Endovascular Surg. 2013;47:261-266.

86. Endologix Inc. https://endologix.com/safety-information-nellix/. 2018; Available from: https:// endologix.com/safety-information-nellix/.

87. White GH, Yu W, May J, et al. A new nonstented balloon-expandable graft for straight or bifurcated endoluminal bypass. J. Endovasc. Surg. 1994;1:16-24.

88. Reijnen MMPJ, Holden A. Status of endovascular aneurysm sealing after 5 years of commercial use. J. Endovasc. Ther. 2018;25(2):201-206.

89. Carpenter JP, Cuff R, Buckley C, et al. Results of the Nellix system investigational device exemption pivotal trial for endovascular aneurysm sealing. J. Vasc. Surg. 2016;63:23-31e1.

90. Greenberg RK, Clair D, Srivastava S, et al. Should patients with challenging anatomy be offered endovascular aneurysm repair? J. Vasc. Surg. 2003;38:990-996.

91. Tolenaar JL, Van Keulen JW, Trimarchi S, et al. The chimney graft, a systematic review. Ann. Vasc. Surg. 2012;26:1030-1038.

92. *Donas KP, Torsello GB, Piccoli G, et al. The PROTAGORAS study to evaluate the performance of the Endurant stent graft for patients with pararenal pathologic processes treated by the chimney/ snorkel endovascular technique. J. Vasc. Surg. 2016;63:1-7. 
93. Tolenaar JL, Zandvoort HJA, Moll FL, et al. Technical considerations and results of chimney grafts for the treatment of juxtarenal aneursyms. J. Vasc. Surg. 2013;58:607-615.

94. de Beaufort HWL, Cellitti E, de Ruiter QMB, et al. Midterm outcomes and evolution of gutter area after endovascular aneurysm repair with the chimney graft procedure. J. Vasc. Surg. 2018;67:104112.e3.

95. Thompson M, Youssef M, Jacob R, et al. Early experience with endovascular aneurysm sealing in combination with parallel grafts for the treatment of complex abdominal aneurysms: the ASCEND registry. J. Endovasc. Ther. 2017;24:764-772.

96. Sultan S, Hynes N, Kavanagh EP, et al. How does the multilayer flow modulator work? The science behind the technical innovation. J. Endovasc. Ther. 2014;21:814-821.

97. Hynes N, Sultan S, Elhelali A, et al. Systematic review and patient-level meta-analysis of the streamliner multilayer flow modulator in the management of complex thoracoabdominal aortic pathology. J. Endovasc. Ther. 2016;23:501-512. 



\section{Chapter 3}

Type 1B Endoleaks after Thoracic

Endovascular Aortic Repair are

Inadequately Reported: A Systematic

Review

Viony M. Belvroy 1,2,3; Hector W.L. de Beaufort ${ }^{2,3}$; Joost A. van Herwaarden ${ }^{3}$; Santi Trimarchi' ${ }^{4,5}$; Frans L. Moll'; Jean Bismuth ${ }^{1}$

Presented in the Rising Stars \& Global Stars session at

Charing Cross Conference 2019, April 15 - 18

London, United Kingdom

1 Houston Methodist DeBakey Heart \& Vascular Center, Houston, Texas, United States

2 Thoracic Aortic Research Center, IRCCS Policlinico San Donato, San Donato Milanese, Italy

3 Department of Vascular Surgery, University Medical Center Utrecht, Utrecht, Netherlands,

4 Department of Health and Community Science, University of Milan, Milan, Italy

5 Fondazione IRCCS Ca' Granda Ospedale Maggiore Policlinico Milan, Milan, Italy 


\section{Abstract}

Objective: Complications after thoracic endovascular aortic repair (TEVAR) are common. Even after a successful TEVAR, a late endoleak (>30 days) can occur. The objective of this study is to summarize the current evidence and, if lacking, the need of evidence regarding the incidence and predictive factors for type $1 \mathrm{~b}$ endoleak in patients with aortic aneurysm treated with TEVAR.

Method: A systematic review of the literature was performed on endoleak type 1b, in patients with aortic aneurysm, after TEVAR. The PubMed and EMBASE databases were systematically searched for articles regarding endoleak type $1 \mathrm{~b}$ up to January 2019. The main subjects discussed are the incidence, risk factors, treatment and prognosis.

Results: Seven hundred and twenty-two articles were screened and sixteen articles were included in this review. The reported incidence of endoleak is between 1.0 - 15.0\%, with a mean follow-up duration of at least 1 year. Type $1 \mathrm{~b}$ endoleak is associated with an increased aortic tortuosity index $\left(>0.15 \mathrm{~cm}^{-1}\right)$. No significant difference is found in relation to age and gender. Treatment is required in most cases (22/27) and is usually performed with distal extension of the stent graft (21/27). There is no data regarding stent graft oversizing, length of distal landing zone and differences between devices or the prognosis for patients with type $1 \mathrm{~b}$ endoleak.

Conclusion: Limited literature is available on the occurrence of type $1 \mathrm{~b}$ endoleak following TEVAR. A tortuous aorta can be associated as a predictive factor for the occurrence of type $1 b$ endoleak. Data clearly delineating the anatomical variables predicting type $1 \mathrm{~b}$ endoleak should be examined and listed. Likewise, the impact of more recent, conformable devices, to prevent complications like type $1 \mathrm{~b}$ endoleaks from occurring, should be elucidated.

Key words: aneurysm, type $1 \mathrm{~b}$ endoleak, complication, thoracic endovascular aortic repair, TEVAR 


\section{Introduction}

After our Electrocardiographic (ECG)-gated computed tomography (CT) and magnetic resonance (MR) studies pre- and post-TEVAR (Thoracic Endovascular Aortic Repair) in combination with Computational Fluid Dynamic (CFD) simulation, a late type Ib endoleak occurred'. The simulation showed that the stent graft migrated $17.1 \mathrm{~mm}$ in dorsocranial direction, which correlated with the displacement force, see figure 1. The suspicion arose whether this phenomenon was seen more often by other institutions and what the anatomical and morphological risks factors are for this feature.
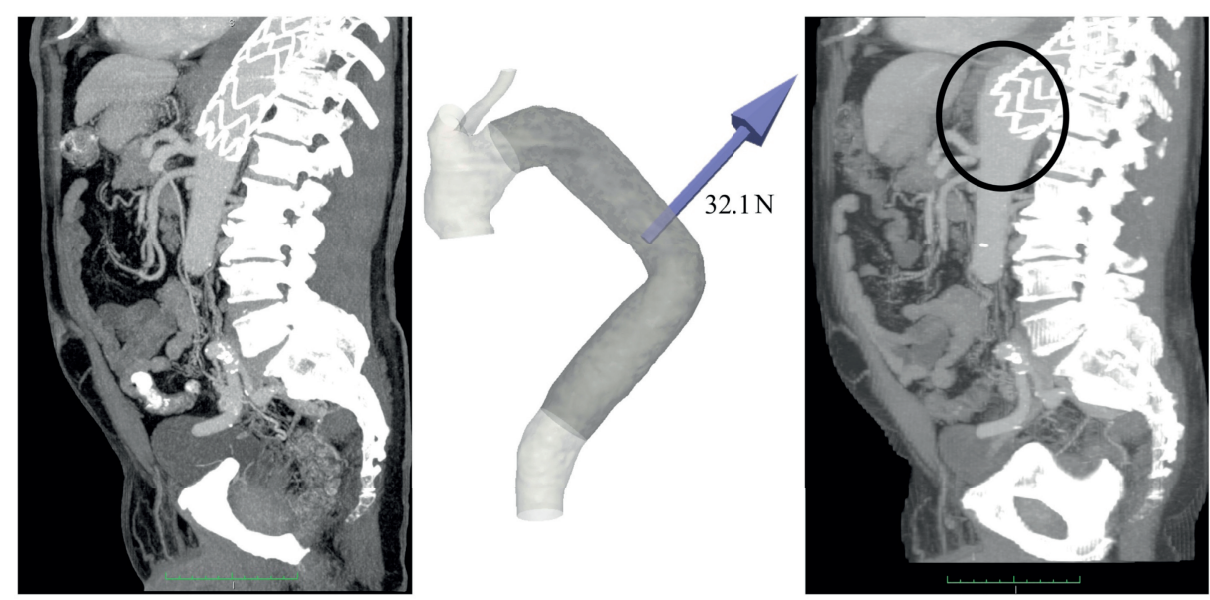

Figure 1. Displacement force and type $1 \mathrm{~b}$ endoleak at 1 year follow-up.

Left: 1-month postoperative CTA scan; Middle: Postoperative CFD model with calculated displacement force vector; Right: 1-year postoperative scan showing type 1b endoleak and proximal stent graft migration.

Reprinted from Van Bakel et al. with permission of AORTA, Thieme Publishers1.

Traditionally, the standard treatment for thoracic aortic diseases (TAD) was open surgery, which is associated with high rates of morbidity and mortality². In 1994 Dake et. al. introduced the endovascular stent graft in the repair of descending thoracic aortic aneurysms, which rapidly gained popularity ${ }^{3,4}$.

After a successful and state-of-the-art TEVAR, significant upward dragforces were observed in the curvature of the aortic arch. When the forces going into the descending aorta, pushing the aorta laterally-oblique in the thorax-cavity, provoke a proximal migration force to the distal end of the thoracic stent graft, 


\section{Chapter 3}

resulting in endoleaks. The definition of a type 1 endoleak is flow entering into the aneurysm sac from either the proximal or distal end of the stent graft with higher risk of aneurysm sac expansion and rupture ${ }^{5-7}$. As a type 1 endoleak develops, the renewed pressure on the weakened aortic wall has an increased rupture risk in comparison to an unrepaired aneurysm with the same diameter ${ }^{8}$. Therefore, proximal and distal type 1 endoleaks both need re-intervention?.

There is lack of evidence on type $1 \mathrm{~b}$ endoleak, as many articles only focus on the proximal type 1 endoleak $^{9-11}$. This is mostly attributable to the angulation of the aortic arch, which is a risk factor for bird-beak configuration and suboptimal stent graft deployment ${ }^{12}$. The ever-evolving technology has brought on the development of more conformable stent grafts, to minimize this complication. Type $1 \mathrm{~b}$ endoleaks in endovascular aortic repair (EVAR) are much more substantiated by published evidence. Among other elements, tortuosity of the iliac arteries and the influence of drag forces for abdominal aortic aneurysms have been investigated. Likewise, an increase in neck angulation, resulting in higher drag forces, could cause endoleaks ${ }^{13,14}$.

In our studies we documented an increase of the aortic diameter over time at the transition zone from the stent graft into the non-stented aorta ${ }^{15}$. When the spiraling blood stream enters the stent graft and has to change its original vortex due to a significant change in shear stresses inside a long-segmental stent graft compared to the elastic properties of a native non-stented aorta. This might be responsible for an energy burst at the outlet of the stent graft inducing dilatation of the native aorta at this transition zone.

To investigate whether more institutions have observed a type $1 \mathrm{~b}$ endoleak with or without proximal migration of the distal part of the thoracic stent graft at long term follow-up, we started a systematic review, with emphasis on late type Ib endoleaks, after initially successful implantation in patients with thoracic aortic aneurysm.

\section{Methods}

The PubMed and Embase databases were systematically searched. The search was last updated in January 2019. The following keywords were used to search the electronic databases: "endoleak", "endovascular repair", "endovascular procedures", "endovascular aortic repair" and "thoracic aorta". For the PubMed database the following search was used: (Endoleak[Mesh] OR Endoleak) AND 
(Endovascular Procedures[Mesh] OR Endovascular repair OR Endovascular Procedures) AND (Aorta, Thoracic[Mesh] OR thoracic aorta). A similar search was applied for the Embase database.

The articles were screened for eligibility based on title and abstract by two independent reviewers (V.M.B. and H.W.L.d.B.). The quality measurement was done using the Newcastle Ottawa Scale (NOS) ${ }^{16}$. Inclusion criteria were: incidence and description of data specifically on predictors of type $1 \mathrm{~b}$ endoleak after TEVAR, with a mean follow-up period of at least one year. Exclusion criteria were: variables of interest for type $1 \mathrm{~b}$ endoleak not specified, type $1 \mathrm{~b}$ endoleak after TEVAR in dissections, variables of interest for type $1 \mathrm{~b}$ after EVAR, emergency and extended surgery (e.g. chimney technique) and study population of $<20$. Reference lists of the included articles were searched for potentially relevant additional articles.

The articles were reviewed using the MOOSE guidelines ${ }^{17}$. Due to heterogeneity between the articles it was not possible to perform a metaanalysis, so only a pooled analysis was performed for the incidence, follow-up and treatment.

\section{Results}

A total of eight hundred and twenty-eight articles were found and after removing duplicates six hundred and eighty-three articles were left. After reading of all titles and abstracts, eighty full-text articles were read and a total of sixteen articles were included in this systematic review, all retrospective small cohort studies. For full search strategy, see figure 2 and articles list in table I.

\section{Incidence}

Sixteen articles reported the incidence of endoleak type $1 \mathrm{~b}$ after TEVAR $\mathrm{R}^{9,11,26-31,18-}$ 25. The mean follow-up duration was between 12 and 76 months. In the selected articles the incidence for the overall endoleak type $1 \mathrm{~b}$ was between $1.0-15.0 \%$. Type $1 \mathrm{~b}$ endoleak can occur as an early (<30 days) or late ( $>30$ days) endoleak. Early type $1 \mathrm{~b}$ endoleak occurred in $1.3-8.1 \%$ and late type $1 \mathrm{~b}$ endoleak occurred in $3.1-5.0 \%$. There were three articles describing the incidence of type $1 \mathrm{~b}$ endoleak beyond 5 years of follow-up, which was $1.1-3.1 \%$, although it was not reported at what point during the follow-up period the endoleaks occured ${ }^{20,23}$.

When dividing the incidence in two periods ( $1-2$ years and $3-5$ years) the incidence remains the same. Ten articles with a 1-2 year follow up duration had an 


\section{Chapter 3}

incidence between 1.0 - 15.0\% $9,11,18,21,24-29$ and six articles with a follow up duration of 3 - 5 year had an incidence between $0.4-16 \%{ }^{19,20,22,23,30,31}$.

A pooled analysis was performed for the sixteen articles, which gives a mean incidence of $4.3 \%$. See table I.

\section{Risk factors}

\section{Morphological/anatomical Tortuosity}

One of the sixteen selected articles addresses the influence of tortuosity of the aorta on endoleak formation ${ }^{25}$. Nakatamari et al. looked at the association between native thoracic aortic curvature and the development of endoleaks in 40 patients ${ }^{25}$. A higher curvature index $\left(>0.15 \mathrm{~cm}^{-1}\right)$ was associated with a higher incidence of type $1 \mathrm{~b}$ endoleak. The curvature ratio was measured as the inverse radius of curvature $(\mathrm{cm}(-1))$ at $10-\mathrm{mm}$ intervals along the median luminal centerline (MLC) on 3D reconstructions of computed tomography (CT) angiograms ${ }^{25}$.

Related to extreme tortuosity in the descending thoracic aorta Kratimenos et al. reported a technical failure; the deployment of the endograft was unsuccessful due to tortuosity ${ }^{30}$, see also table II.

\section{Clinical characteristics}

No articles report on the clinical characteristics of type $1 \mathrm{~b}$ endoleak. It is important to know whether the diameter of the aneurysm is of influence, length of the landing zone, or other stent graft or aneurysmal related characteristics. 

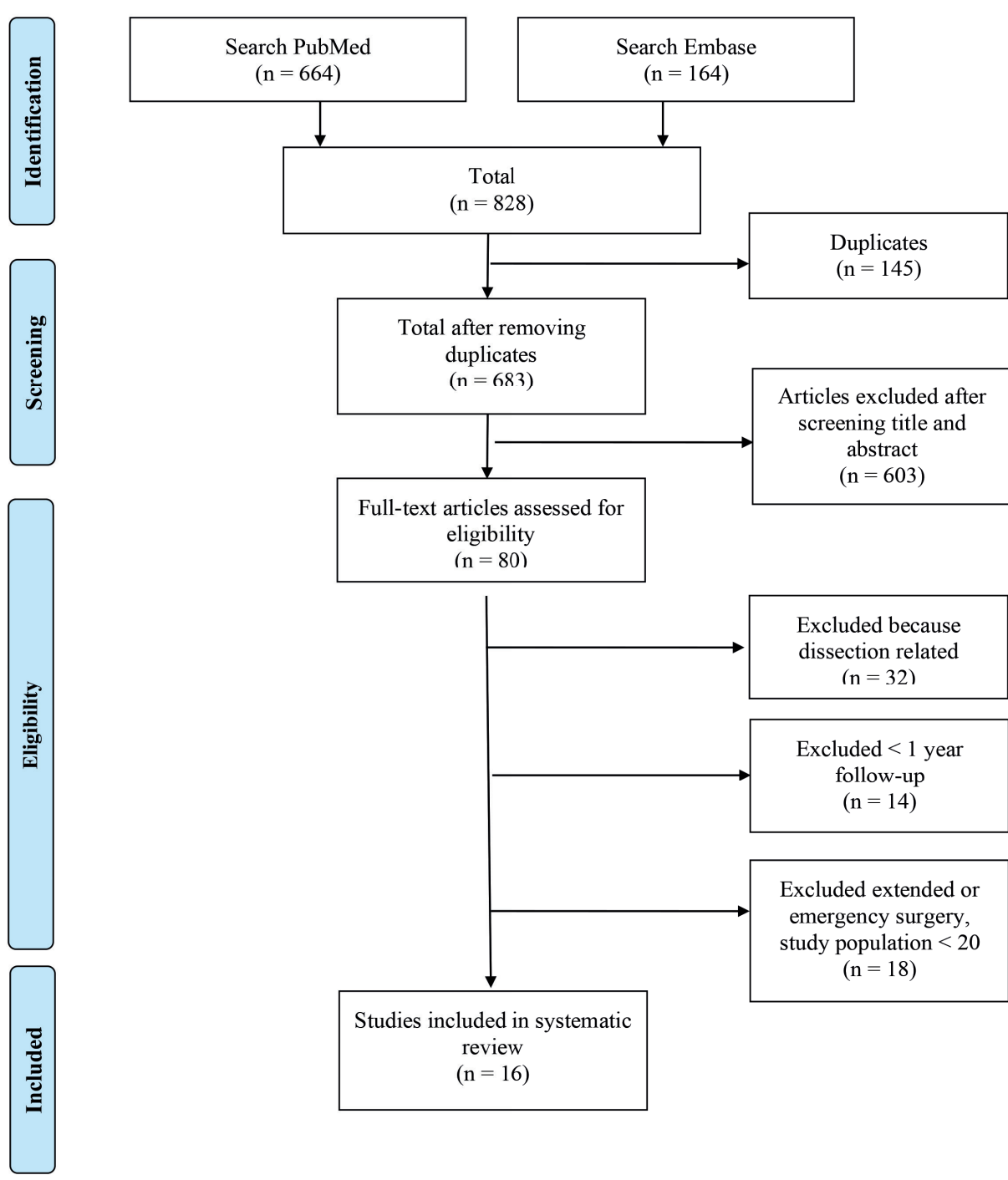
eligibility

$(\mathrm{n}=80)$

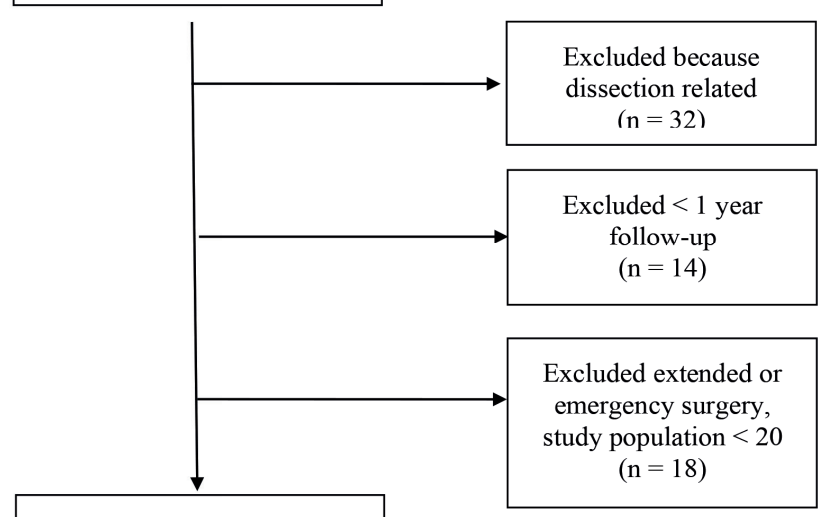

Studies included in systematic review

$(\mathrm{n}=16)$

Figure 2. Flow diagram search 
Chapter 3

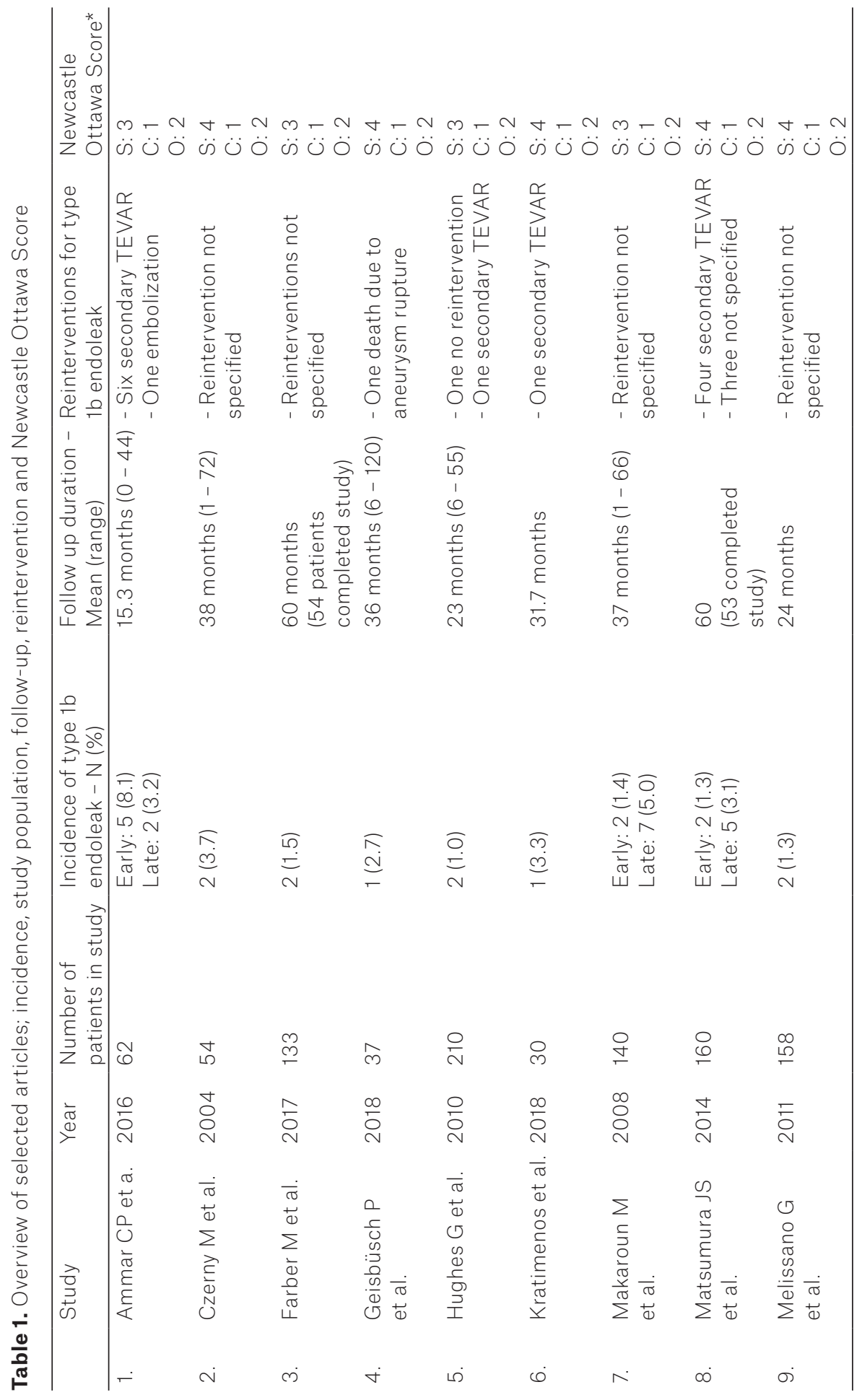


Review type $1 \mathrm{~b}$ endoleaks

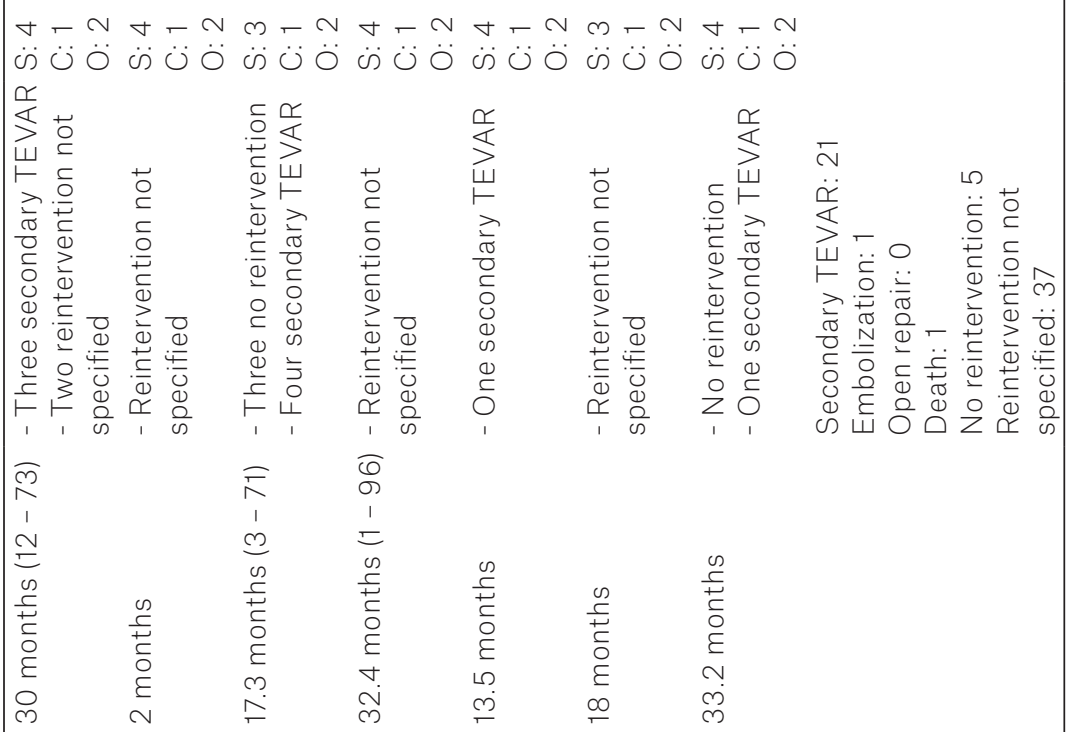

$\dot{m}$
1
0
0
0
$\frac{1}{0}$
0
0
$\stackrel{ \pm}{J}$
0
0
0
$\frac{0}{0}$
$\frac{1}{0}$

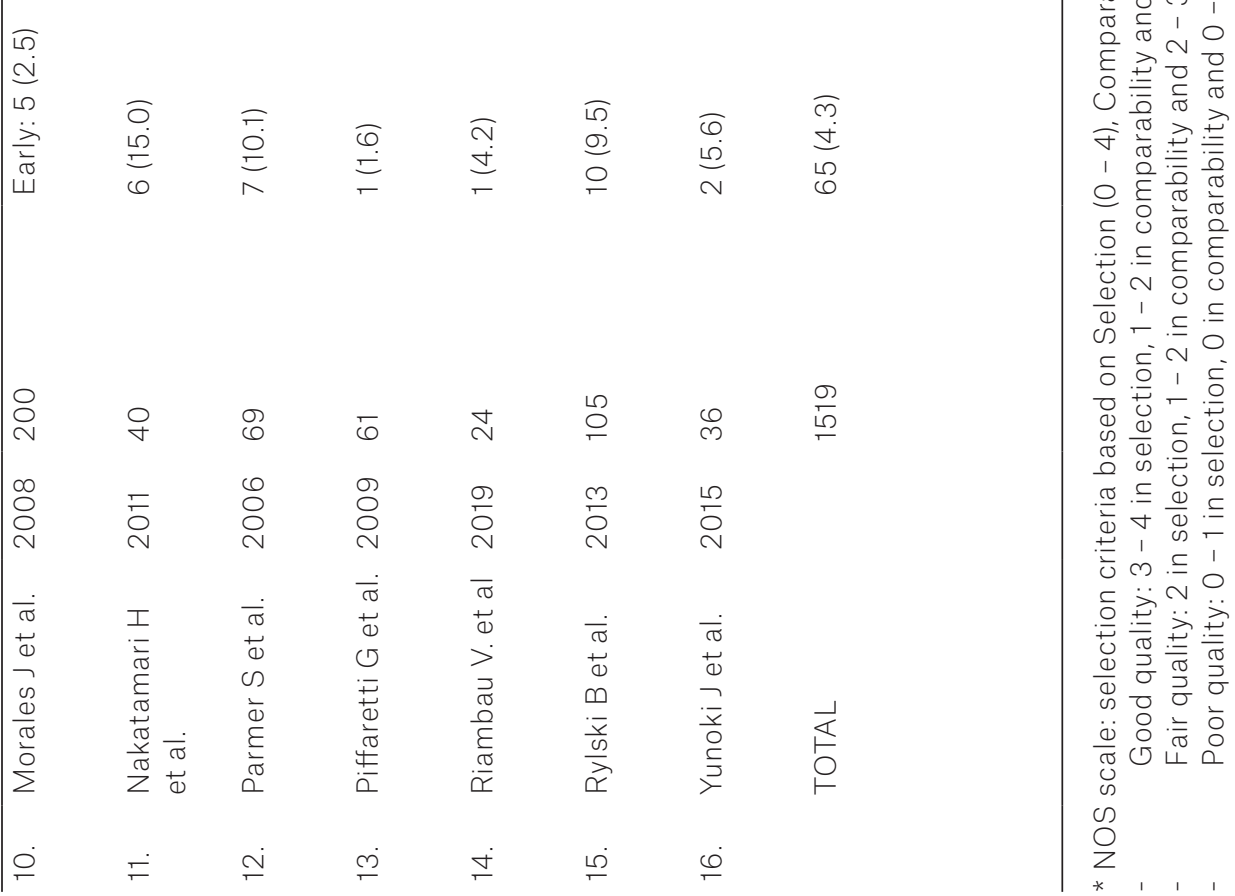




\section{Chapter 3}

Table 2. Risk factors type $1 \mathrm{~b}$ endoleak

\begin{tabular}{llll}
\hline Study & Aim & Study design & Risk factors related to type 1b endoleak \\
\hline Nakatamari & Impact of & Retrospective & Large curvature index at the \\
Het al. & $\begin{array}{l}\text { thoracic aortic } \\
\text { morphology on } \\
\text { development of } \\
\text { endoleaks }\end{array}$ & $\begin{array}{l}\text { observational } \\
\text { study }\end{array}$ & $\begin{array}{l}\text { thoracoabdominal junction (related to } \\
\text { endoleak type 1b) }\end{array}$ \\
& & \\
\hline
\end{tabular}

\section{Treatment}

In most cases treatment is required to prevent expansion of the aneurysm sac $^{6,32}$, although in some cases early type 1 endoleaks may resolve without interventions ${ }^{33,34}$. The majority of the articles report that reinterventions were performed to treat type $1 \mathrm{~b}$ endoleak. Of the 63 reported type $1 \mathrm{~b}$ endoleaks, the management is described for 27 cases. This included: 21 secondary TEVARs/ distal stent graft extensions (76.9\%), 1 embolization (3.8\%), 0 open repairs (0\%) and 5 had no reintervention (19.2\%). One type $1 \mathrm{~b}$ endoleak resulted in death due to aneurysm rupture ${ }^{31}$. See also table I for further specifications.

\section{Prognosis}

One article in this systematic review reported that a type $1 \mathrm{~b}$ endoleak was spontaneously resolved ${ }^{9}$. Of the 5 patients who had a type $1 \mathrm{~b}$ endoleak but did not undergo reintervention, 3 endoleaks (60\%) resolved spontaneously and 2 patients (40\%) refused reintervention. No reasons were given on how it was possible that the endoleaks resolved spontaneously. The study did not specify whether the endoleaks presented early or late in the patient's postoperative course. There were no articles comparing the prognosis of patients with a type $1 \mathrm{~b}$ endoleak to patients versus those who did not have type $1 \mathrm{~b}$ endoleak.

\section{Discussion}

This manuscript shows there is lack of data surrounding type $1 \mathrm{~b}$ endoleaks in TEVAR. Unfortunately due to the paucity of data, no firm conclusions can be made regarding morbidity, mortality, risk factors, aortic interventions and prognosis. Most commonly a type 1 endoleak is described without differentiating between the proximal or distal type 1 endoleak. Typically, the focus has been on the proximal type 1a endoleaks. This may stem from a heightened awareness due to an advanced understanding and greater interest in the more challenging treatment 
of the aortic arch due to curvature and the supra-aortic trunks ${ }^{35}$. However, both proximal and distal type 1 endoleaks need treatment because of the high risk of aneurysm rupture ${ }^{32}$.

As the overall quality of the articles included in this review is mediocre and consist of only retrospective reviews of small case series, there are some limitations to this review. There are no randomized controlled trials included and due to heterogeneity a meta-analysis could not be conducted. In all studies it has not been described whether the Instructions for Use (IFU) for the devices was followed. A study by Schanzer et al. report that complications in EVAR is not always caused by device failure ${ }^{36}$. A great part is also dedicated to the physicians who are not following the IFU for the devices and use them in poorly suited anatomy. Furthermore, nothing is reported on the postoperative imaging protocol to give a better insight in the follow-up period and when the type $1 \mathrm{~b}$ endoleaks were discovered. The variable length of follow-up, with only three articles reporting on endoleaks with a mean follow-up of 5 years, shows the need of better postoperative protocol. This to understand the natural habitat of endoleaks and to obtain durable results. Likewise, no articles report on the differences between older and newer generations of stent grafts. Technologies are evolving, so the complication rate might be lower in the more conformable stent grafts. No articles report characteristics related to type $1 \mathrm{~b}$ endoleak such as, the influence of distal neck length (i.e. the distal sealing zone), which preferably should be $20 \mathrm{~mm}$, the amount of oversizing and different brands of stent grafts. Some stent grafts have designed components for active fixation after $\operatorname{EVAR}^{37}$. The effect of active fixation on the prevention of endoleaks should be investigated for endoleaks after TEVAR. A recent study shows that the use of EndoAnchors prevent complications after TEVAR ${ }^{38}$, but still no long data is available. Future studies need to address the more clinical and anatomical risk factors for type $1 \mathrm{~b}$ endoleak.

The incidence of type $1 \mathrm{~b}$ endoleak seems to be between $1.0-15.0 \%$, which is relatively high compared to major endograft trials where the incidence lies between 1.3 - 5.6\% 20,22-24,28. An explanation might be selection bias or lower incidence in the major trials due to strict adherence to anatomical inclusion criteria. The type 1a endoleak incidence lies between 0 - 11.4\% ${ }^{20,22-24,28}$, which is similar to the incidence of a type $1 b$. As the incidence is similar, it is likely that both endoleaks have the same pathophysiology and are equally important. 


\section{Chapter 3}

Nowadays, more conformable stent grafts minimize bird beaking from happening related to type 1a endoleak ${ }^{39}$. Comparing a type 1 endoleak in TEVAR to EVAR, the incidence for type 1 endoleak in TEVAR is relatively higher ${ }^{14}$. According to the literature this could be due to the size of the thoracic aorta and the angulations of the $\operatorname{arch}^{14}$ or due to the change of diameter of the thoracic aorta in the cardiac cycle ${ }^{40}$. The occurrence of a type $1 \mathrm{~b}$ endoleak in TEVAR is difficult to predict and often results in re-interventions or even treatment failure ${ }^{41,42}$. In EVAR type 1b endoleaks are more common in patients with dilated, calcified, short and tortuous iliac arteries ${ }^{14}$. This has not been investigated in such a granular fashion for type $1 \mathrm{~b}$ endoleaks after TEVAR.

One of the articles included reports a relationship between a highly tortuous aorta and the incidence of endoleak type $1 \mathrm{~b}^{25}$. Two other studies, that were not selected for this systematic review because of short follow-up duration, reported similar outcomes ${ }^{43,44}$. Both investigated the influence of aortic tortuosity on the occurrence of type $1 \mathrm{~b}$ endoleak. Kotelis et al. researched aortic conicity and stent graft oversizing on the occurrence of endoleaks in a patient sample of $57^{43}$. The study of Ueda et al. assessed the native thoracic aortic tortuosity and the development of endoleaks in 40 patients ${ }^{44}$, which is similar to Nakatamari et al ${ }^{25}$. Measurements done with computed tomography angiography showed a larger tortuosity index at the distal fixation zone in patients with type 1b endoleak, compared to those with no endoleak ${ }^{44}$.

Piffaretti et al. looked at different clinical characteristics related to endoleaks, however, not specified for type $1 \mathrm{~b}$ endoleak ${ }^{26}$. In endoleak vs. no endoleak the TAA diameter reached statistical significance ( $p=0.03 ; 7.7 \mathrm{~mm}$ vs. $5.4 \mathrm{~mm}$ ). Likewise, a number of stent graft variables were measured; stent diameter $(39 \mathrm{~mm}$ vs. $34.8 \mathrm{~mm})$ and aortic length coverage $(20.7 \mathrm{~mm}$ vs. $18.3 \mathrm{~mm})$ and number of stents (1.9 vs. 1.2), with each of these reaching statistical significance ${ }^{26}(p=0.003$; $p=0.022 ; p=0.002)$. No articles reported other factors, which influenced type $1 \mathrm{~b}$ endoleak, see also table II. The correlation with an increasing incidence of endoleaks could not be shown for parameters such as, type of aneurysm, age, gender or atherosclerotic burden, but again it was not specified whether type $1 \mathrm{~b}$ endoleaks were expressly being addressed 9,26,45. Consequently, the data is limited and more research is needed to be able to draw any conclusions, particularly as it relates to clinical outcomes. 
One of the purported theories for the development of type $1 \mathrm{~b}$ endoleaks is supported by flow studies, which demonstrates that in long thoracic aortic stent grafts high shear stress creates an explosion of energy at the end of the stent graft $^{15}$. This phenomenon has been observed to create a dilation of the native aorta at the transition between the stent and the aorta. High displacement forces have been shown to push the stent graft retrograde with potentially causing a type $1 \mathrm{~b}$ endoleak at long term follow up. These observations should be investigated prospectively to get a better awareness of the occurrence of type $1 \mathrm{~b}$ endoleak.

Whether this is ultimately one of the main causes of Type $1 \mathrm{~b}$ endoleaks, it is clear from our review with only one case describing spontaneous resolution of a Type $1 \mathrm{~b}$ endoleak ${ }^{9}$, we can likely draw a safe conclusion that most will probably require an intervention. The paucity of data does not allow us to draw any conclusions as to the number of endoleaks that will require reintervention, nor the ideal approach to managing this event.

In this review dissections have not been included, because it is widely acknowledged that the criteria for the definition of endoleaks for aneurysm are not fully applicable to dissections ${ }^{46}$. A variety of definitions have been used for type $1 \mathrm{~b}$ endoleak after TEVAR in dissections. Some authors reported endoleak as flow into the false lumen (FL) due to an ineffective seal at one extremity of the stent-graft 47 , others as any failure of entry tear closure resulting in continued antegrade or retrograde $\mathrm{FL}$ perfusion ${ }^{48}$, or as any radiologic evidence of blood flow outside the stent graft, except persistent retrograde $\mathrm{FL}$ perfusion ${ }^{49}$. Consensus reporting criteria are required to account for situations unique to dissection ${ }^{46}$.

In conclusion, long term follow-up should not only be recommended, but also be documented. Sustainable safety and efficacy is of the utmost importance in endovascular treatment for aorta pathology. Possible late complications, such as type lb endoleaks in initially successful TEVAR can only be determined when long term follow-up is taken seriously with a minimum of lost to followup. Our systematic review has demonstrated that there is a serious need for better registration and publication of possible complications which might not be expected after an initial successful TEVAR. Data clearly delineating the anatomical variables predicting type $1 \mathrm{~b}$ endoleak should be examined and listed. Likewise, the impact of more recent, conformable devices, to prevent complications like type $1 \mathrm{~b}$ endoleaks from occurring, should be elucidated. 


\section{References}

1. van Bakel T, Romarowski R, Morganti S, et al. Blood Flow after Endovascular Repair in the Aortic Arch: A Computational Analysis. AORTA. 2018;06(03):081-087. doi:10.1055/s-0039-1683771

2. Arnaoutakis DJ, Arnaoutakis GJ, Abularrage CJ, et al. Cohort comparison of thoracic endovascular aortic repair with open thoracic aortic repair using modern end-organ preservation strategies. Ann Vasc Surg. 2015;29(5):882-890. doi:10.1016/j.avsg.2015.01.007

3. Dake MD, Miller DC, Semba CP, et al. Transluminal Placement of Endovascular Stent-Grafts for the Treatment of Descending Thoracic Aortic Aneurysms. N Engl J Med. 1994;331(26):1729-1734. doi:10.1056/NEJM199412293312601

4. Bavaria JE, Appoo JJ, Makaroun MS, et al. Endovascular stent grafting versus open surgical repair of descending thoracic aortic aneurysms in low-risk patients: A multicenter comparative trial. J Thorac Cardiovasc Surg. 2007;133(2):369-377.e4. doi:10.1016/j.jtcvs.2006.07.040

5. White GH, Yu W, May J, et al. Endoleak as a Complication of Endoluminal Grafting of Abdominal Aortic Aneurysms: Classification, Incidence, Diagnosis, and Management. J Endovasc Surg. 1997;4(2):152-168. doi:10.1583/1074-6218(1997)004<0152:EAACOE>2.0.CO;2

6. Wain RA, Marin ML, Ohki T, et al. Endoleaks after endovascular graft treatment of aortic aneurysms: Classification, risk factors, and outcome. J Vasc Surg. 1998;27(1):69-80. doi:10.1016/ S0741-5214(98)70293-9

7. Chuter TAM, Faruqi RM, Sawhney R, et al. Endoleak after endovascular repair of abdominal aortic aneurysm. J Vasc Surg. 2001;34(1):98-105. doi:10.1067/mva.2001.111487

8. Antoniou GA, Georgiadis GS, Antoniou SA, et al. Late Rupture of Abdominal Aortic Aneurysm After Previous Endovascular Repair. J Endovasc Ther. 2015;22(5):734-744. doi:10.1177/1526602815601405

9. Parmer SS, Carpenter JP, Stavropoulos SW, et al. Endoleaks after endovascular repair of thoracic aortic aneurysms. J Vasc Surg. 2006;44(3):447-452. doi:10.1016/j.jvs.2006.05.041

10. Jackson BM, Woo EY, Bavaria JE, et al. Gender analysis of the pivotal results of the Medtronic Talent Thoracic Stent Graft System (VALOR) trial. YMVA. 2011;54:358-363.e1. doi:10.1016/j. jvs.2010.12.064

11. Morales JP, Greenberg RK, Lu Q, et al. Endoleaks Following Endovascular Repair of Thoracic Aortic Aneurysm: Etiology and Outcomes. J Endovasc Ther. 2008;15:631-638.

12. Ueda T, Fleischmann D, Dake MD, et al. Incomplete endograft apposition to the aortic arch: birdbeak configuration increases risk of endoleak formation after thoracic endovascular aortic repair. Radiology. 2010;255(2):645-652. doi:10.1148/radiol.10091468

13. Molony DS, Kavanagh EG, Madhavan P, et al. A Computational Study of the Magnitude and Direction of Migration Forces in Patient-specific Abdominal Aortic Aneurysm Stent-Grafts. Eur J Vasc Endovasc Surg. 2010;40(3):332-339. doi:10.1016/j.ejvs.2010.06.001

14. Cao P, De Rango P, Verzini F, et al. Endoleak after endovascular aortic repair: classification, diagnosis and management following endovascular thoracic and abdominal aortic repair. J Cardiovasc Surg (Torino). 2010;51(1):53-69.

15. Karmonik C, Bismuth J, Davies MG, et al. A Computational Fluid Dynamics Study Pre-and PostStent Graft Placement in an Acute Type B Aortic Dissection. doi:10.1177/1538574410389342

16. Wells G, Shea B, O'Connell D, et al. The Newcastle-Ottawa Scale (NOS) for assessing the quality of nonrandomised studies in meta-analyses [webpage on the Internet]. Ottawa Hosp Res Inst. 2011; Available.

17. Stroup DF, Berlin JA, Morton SC, et al. Meta-analysis of observational studies in epidemiology: a proposal for reporting. Meta-analysis Of Observational Studies in Epidemiology (MOOSE) group. JAMA. 2000;283(15):2008-2012.

18. Ammar CP, Larion S, Ahanchi SS, et al. Anatomic severity grading score for primary descending thoracic aneurysms predicts procedural difficulty and aortic-related reinterventions after thoracic endovascular aortic repair. J Vasc Surg. 2016;64(4):912-920.e1. doi:10.1016/j.jvs.2016.03.451

19. Czerny $M$, Cejna M, Hutschala D, et al. Stent-graft placement in atherosclerotic descending thoracic aortic aneurysms: midterm results. J Endovasc Ther. 2004;11(1):26-32. doi:10.1177/152660280401100103 
20. Farber MA, Lee WA, Szeto WY, et al. Initial and midterm results of the Bolton Relay Thoracic Aortic Endovascular Pivotal Trial. 2017;65(6):1556-1566.e1. doi:10.1016/j.jvs.2016.11.061

21. Hughes GC, Lee SM, Daneshmand MA, et al. Endovascular repair of descending thoracic aneurysms: results with \&quot;on-label\&quot; application in the post Food and Drug Administration approval era. Ann Thorac Surg. 2010;90(1):83-89. doi:10.1016/j.athoracsur.2010.03.052

22. Makaroun MS, Dillavou ED, Wheatley GH, et al. Five-year results of endovascular treatment with the Gore TAG device compared with open repair of thoracic aortic aneurysms. J Vasc Surg. 2008;47(5):912-918. doi:10.1016/j.jvs.2007.12.006

23. Matsumura JS, Melissano G, Cambria RP, et al. Five-year results of thoracic endovascular aortic repair with the Zenith TX2. J Vasc Surg. 2014;60:1-10. doi:10.1016/j.jvs.2014.01.043

24. Melissano G, Kahlberg A, Bertoglio L, et al. Endovascular exclusion of thoracic aortic aneurysms with the 1- and 2-component Zenith TX2 TAA endovascular grafts: analysis of 2-year data from the TX2 pivotal trial. J Endovasc Ther. 2011;18(3):338-349. doi:10.1583/10-3340.1

25. Nakatamari $H$, Ueda $T$, Ishioka F, et al. Discriminant analysis of native thoracic aortic curvature: Risk prediction for endoleak formation after thoracic endovascular aortic repair. J Vasc Interv Radiol. 2011;22(7):974-979. doi:10.1016/j.jvir.2011.02.031

26. Piffaretti G, Mariscalco G, Lomazzi C, et al. Predictive factors for endoleaks after thoracic aortic aneurysm endograft repair. J Thorac Cardiovasc Surg. 2009;138(4):880-885. doi:10.1016/j. jtcvs.2009.02.024

27. Rylski B, Blanke P, Siepe M, et al. Results of high-risk endovascular procedures in patients with non-dissected thoracic aortic pathology: intermediate outcomes. Eur J Cardiothorac Surg. 2013;44(1):156-162. doi:10.1093/ejcts/ezs694

28. Yunoki J, Kuratani T, Shirakawa Y, et al. Mid-term results of endovascular treatment with the Gore TAG device for degenerative descending thoracic aortic aneurysms. Gen Thorac Cardiovasc Surg. 2015;63(1):38-42. doi:10.1007/s11748-014-0436-4

29. Riambau V, Giudice R, Trabattoni P, et al. Prospective multicenter study of the low-profile Relay stent-graft in patients with thoracic aortic disease: the RE-GENERATION study. Ann Vasc Surg. January 2019. doi:10.1016/j.avsg.2018.10.017

30. Kratimenos T, Antonopoulos CN, Tomais D, et al. Repair of descending thoracic aortic aneurysms with Ankura Thoracic Stent Graft. J Vasc Surg. October 2018. doi:10.1016/j.jvs.2018.07.065

31. Geisbüsch P, Skrypnik D, Ante M, et al. Endograft migration after thoracic endovascular aortic repair. J Vasc Surg. December 2018. doi:10.1016/j.jvs.2018.07.073

32. Alsac J-M, Khantalin I, Julia P, et al. The Significance of Endoleaks in Thoracic Endovascular Aneurysm Repair. Ann Vasc Surg. 2011;25(3):345-351. doi:10.1016/j.avsg.2010.08.002

33. Väärämäki S, Suominen V, Pimenoff G, et al. Long-Term Experience of Endovascular Repair for Thoracic Aortic Aneurysms and Dissections. doi:10.1177/1538574416652244

34. Boufi M, Aouini F, Guivier-Curien C, et al. Examination of factors in type i endoleak development after thoracic endovascular repair. J Vasc Surg. 2015;61(2):317-323. doi:10.1016/j.jvs.2014.08.002

35. Törnqvist P, Resch T. Endoleaks after EVAR and TEVAR: indications for treatment and techniques. J Cardiovasc Surg (Torino). 2014;55(2 Suppl 1):105-114

36. Schanzer A, Greenberg RK, Hevelone N, et al. Predictors of abdominal aortic aneurysm sac enlargement after endovascular repair. Circulation. 2011;123(24):2848-2855. doi:10.1161/ CIRCULATIONAHA.110.014902

37. Tadros RO, Sher A, Kang M, et al. Outcomes of using endovascular aneurysm repair with active fixation in complex aneurysm morphology. J Vasc Surg. 2018;68(3):683-692. doi:10.1016/j. jvs.2017.12.039

38. Ongstad SB, Miller DF, Panneton JM. The use of EndoAnchors to rescue complicated TEVAR procedures. J Cardiovasc Surg (Torino). 2016;57(5):716-729.

39. Banno H, Akita N, Fujii T, et al. Proximal bare stent may reduce bird-beak configuration, which is associated with distal migration of stent graft in the aortic arch. Ann Vasc Surg. October 2018. doi:10.1016/j.avsg.2018.08.081

40. Muhs BE, Vincken KL, van Prehn J, et al. Dynamic Cine-CT Angiography for the Evaluation of the Thoracic Aorta; Insight in Dynamic Changes with Implications for Thoracic Endograft Treatment. Eur J Vasc Endovasc Surg. 2006;32(5):532-536. doi:10.1016/j.ejvs.2006.05.009 


\section{Chapter 3}

41. Geisbüsch P, Hoffmann S, Kotelis D, et al. Reinterventions during midterm follow-up after endovascular treatment of thoracic aortic disease. J Vasc Surg. 2011;53(6):1528-1533. doi:10.1016/j. jvs.2011.01.066

42. Sze DY, Van Den Bosch MAAJ, Dake MD, et al. Factors portending endoleak formation after thoracic aortic stent-graft repair of complicated aortic dissection. Circ Cardiovasc Interv. 2009;2(2):105-112. doi:10.1161/CIRCINTERVENTIONS.108.819722

43. Kotelis D, Brenke C, Wörz S, et al. Aortic morphometry at endograft position as assessed by 3D image analysis affects risk of type I endoleak formation after TEVAR. Langenbeck's Arch Surg. 2015;400(4):523-529. doi:10.1007/s00423-015-1291-1

44. Ueda T, Takaoka H, Raman B, et al. Impact of quantitatively determined native thoracic aortic tortuosity on endoleak development after thoracic endovascular aortic repair. Am J Roentgenol. 2011;197(6):1140-1146. doi:10.2214/AJR.11.6819

45. Petersen J, Glodny B. The burden of hard atherosclerotic plaques does not promote endoleak development after endovascular aortic aneurysm repair: A risk stratification. Cardiovasc Intervent Radiol. 2011;34(5):918-925. doi:10.1007/s00270-010-0095-5

46. Haulon S. Comments regarding \&quot; Endovascular repair of Stanford type B aortic dissection: early and mid-term outcomes of 121 cases\&quot; by Chang Guangqi, Li Xiaoxi, Chen Wei, Li Songqi, Yao Chen, Li Zilun, Wang Shenming. Eur J Vasc Endovasc Surg. 2009;38(4):427-428. doi:10.1016/j.ejvs.2009.06.014

47. Guangqi C, Xiaoxi L, Wei C, et al. Endovascular Repair of Stanford Type B Aortic Dissection: Early and Mid-term Outcomes of 121 Cases. Eur J Vasc Endovasc Surg. 2009;38(4):422-426. doi:10.1016/j.ejvs.2009.04.015

48. Czerny M, Roedler S, Fakhimi S, et al. Midterm results of thoracic endovascular aortic repair in patients with aneurysms involving the descending aorta originating from chronic type B dissections. Ann Thorac Surg. 2010;90(1):90-94. doi:10.1016/j.athoracsur.2010.04.001

49. Böckler D, Schumacher H, Ganten M, et al. Complications after endovascular repair of acute symptomatic and chronic expanding Stanford type B aortic dissections. J Thorac Cardiovasc Surg. 2006;132(2):361-368. doi:10.1016/j.jtcvs.2006.02.056 
Review type $1 \mathrm{~b}$ endoleaks 

Tortuosity in the descending thoracic aorta

\section{Part 2:}





\section{Chapter 4}

\section{Tortuosity of the Descending Thoracic Aorta: normal values by Age}

Viony M. Belvroy ${ }^{1,2,3}$, Hector W.L. de Beaufort ${ }^{1,2}$, Joost A. van Herwaarden², Jean Bismuth ${ }^{3}$, Frans L. Moll2 ${ }^{2}$, Santi Trimarchi ${ }^{4,5}$

1 Thoracic Aortic Research Center, IRCCS Policlinico San Donato, San Donato Milanese, Italy

2 Department of Vascular Surgery, University Medical Center Utrecht, Utrecht, Netherlands

3 Houston Methodist DeBakey Heart \& Vascular Center, Houston, Texas, United States

4 Department of Scienze Cliniche e di Comunità, University of Milan, Milan, Italy

5 Fondazione IRCCS Ca' Granda Ospedale Maggiore Policlinico Milan, Milan, Italy 


\section{Chapter 4}

\section{Abstract}

Background: Aging changes the aorta in length, tortuosity and diameter. This is relevant in thoracic endovascular aortic repair (TEVAR) and in the long term follow up.

Methods and results: Two groups of hundred patients $<65$ years and hundred patients $\geq 65$ years, with no vascular diseases were made. Thin cut CT scans were analyzed with 3Mensio Vascular software and the following measurements were collected; tortuosity index, curvature ratio, maximum tortuosity in degrees and the level of vertebrae of the maximum tortuosity. The descending thoracic aorta (DTA) was analyzed and was divided into four zones of equal length. Subjects were divided into three groups based on their maximum tortuosity value: low $<$ $\left.30^{\circ}\right)$, moderate $\left(30^{\circ}-60^{\circ}\right)$ and high $\left(>60^{\circ}\right)$. A linear regression model was built to test the effect of age and gender on tortuosity. Tortuosity was more pronounced in the $\geq 65$ compared to the $<65$ group (tortuosity index: 1.05 vs. 1.14, respectively; $p<0.001$ ), curvature ratio (1.00 vs. 1.01; $p<0.001)$, maximum tortuosity (22.24 vs. 27.26; $p<0.001$ ), and group of angulation (low vs. low; $p<0.001$ ). Additionally, the location of maximum tortuosity was further distal for the $\geq 65$ group (level of vertebrae; 5.00 vs. 5.00; $p<0.001$ ), and zone of maximum tortuosity (4A vs. 4A; $p$ $<0.001)$. There was no significant difference between male and female subjects.

Conclusion: Normal DTA tortuosity increases with age. This is important to understand natural aging and for TEVAR planning and follow-up.

Key words: tortuosity, aging, thoracic endovascular aortic repair, TEVAR 


\section{Introduction}

As every stent graft has a fixed length and diameter, which allows only some oversizing, it is important to understand how the aorta changes in length, tortuosity and diameter during follow-up after thoracic endovascular aortic repair (TEVAR). This inevitable process of ageing may sabotage the initial excellent endovascular results. Hence, more knowledge about this physiological phenomenon might help to improve stent grafts designs in order to create durable results of endovascular repairs.

Aging of the healthy and diseased aorta is an irreversible process, of which a number of aspects have been clarified. First of all, the aorta may lengthen by itself $^{1-4}$., or become longer as the vertebral column may decrease over time due to spinal shrinkage ${ }^{5}$, inducing increased tortuosity of the descending thoracic aorta (DTA). Second, aging has been shown to be a substantial risk factor for the decrease of elastin and increase of collagen in the aortic wall ${ }^{6}$. Loss or malfunctioning of elastin structures is pernicious for the cardiovascular system ${ }^{7.8}$. As elastic tissue breaks down in the aortic wall, the amount of sclerotic tissue increases. Consequently, arteriosclerosis increases and the aorta becomes less compliant, which needs to be compensated with an increase of the systolic blood pressure, also called a decrease of the Windkessel effect ${ }^{9}$. In addition, a German study from 1977 shows that the aortic diameter increases with age ${ }^{3,9}$. According to Laplace's law, wall tension is directly dependent on aortic diameter, so at an older age aortic wall tension is increased due to this phenomenon as well.

The Ishimaru classification gives a good view of the aortic arch and recently an additional classification has been published ${ }^{10,11}$. Zone 4 , the descending thoracic aorta, is the longest zone, which can get angulated with aging. An update on this classification is therefore needed. Likewise, this stems out of the importance of TEVAR for the treatment of thoracic aortic diseases. The proximal and distal landing zones should be healthy and have ideally a diameter of $<40$ $\mathrm{mm}$ and length of $>20 \mathrm{~mm}$. It is recognized that higher angulation can result in an inadequate seal or migration of the stent graft, which can lead to endograft failure ${ }^{12,13}$, and tortuosity has been identified as a risk factor for type $1 \mathrm{~b}$ endoleak ${ }^{14}$.

In order to define acceptable landing zones, the normal tortuosity of the descending aorta needs to be defined, which is the principal aim of this study. 


\section{Chapter 4}

Therefore, we started to study the descending thoracic aorta of 200 non-vascular patients of different age, as age is likely to be an important confounding factor.

\section{Methods}

\section{Patients}

The local Ethical Committee of I.R.C.C.S. Policlinico San Donato approved of this retrospective study and waived the requisite to obtain informed consent from patients. Two hundred CT scans of adult patients who underwent diagnostic evaluation for various indications, like pulmonary diseases, at our institution in 2017 were selected at random. Patients with aortic aneurysm or dissection were excluded from this study, so only aortas without vascular diseases were selected. The patients were divided in two groups; $100<65 y$ patients and $100 \geq 65 y$ patients. Patient demographics are summarized in table 1.

Table 1. Baseline Demographic Characteristics of Patients

\begin{tabular}{llll}
\hline & $<65 y(N=100)$ & $\geq 65 y(N=100)$ & $p$-value \\
\hline Age (y) & $50.94+/-6.68$ & $78.40+/-7.80$ & $<0.001^{*}$ \\
Range & $32-59$ & $65-91$ & \\
Gender & & & \\
Male & 50 & 50 & \\
Female & 50 & 50 & $<0.001^{*}$ \\
Type of arch & & $38(38 \%)$ & \\
Type I & $66(66 \%)$ & $43(43 \%)$ & \\
Type II & $30(30 \%)$ & $19(19 \%)$ & $<0.001^{*}$ \\
Type III & $4(4 \%)$ & $212.8+/-22.2$ & \\
Mean centreline & $190.7+/-16.5$ & & \\
length (cm) & &
\end{tabular}

${ }^{*} \mathrm{P}$-value is significant when $p<0.05$

\section{Image analysis \& outcomes}

Selection criteria for the image analyses were thin cut CT scan slices of 1.0 or $1.5 \mathrm{~mm}$. Most scans did not have contrast, and were only selected when quality was good to perform the measurements. The type of arch was measured using the aortic arch classification ${ }^{15}$.

The CT scans were analyzed with 3Mensio Vascular software (3Mensio Medical Imaging B.V., Bilthoven, The Netherlands). The measurements were performed in the DTA, where a center lumen line was created semi-automated 
from two centimeters after the left subclavian artery (LSA), where zone 4 starts in Ishimaru's aortic map ${ }^{10}$, up to the celiac trunk. The length of the center lumen line was automatically calculated. Two markers were placed at the beginning and at the end of the centerline. The functional true length was measured in a 3D model, which is the distance between the beginning and the end of zone 4 in a straight beeline. The tortuosity index was calculated by dividing the length of the center lumen line by the true length ${ }^{16,17}$. See fig 1.

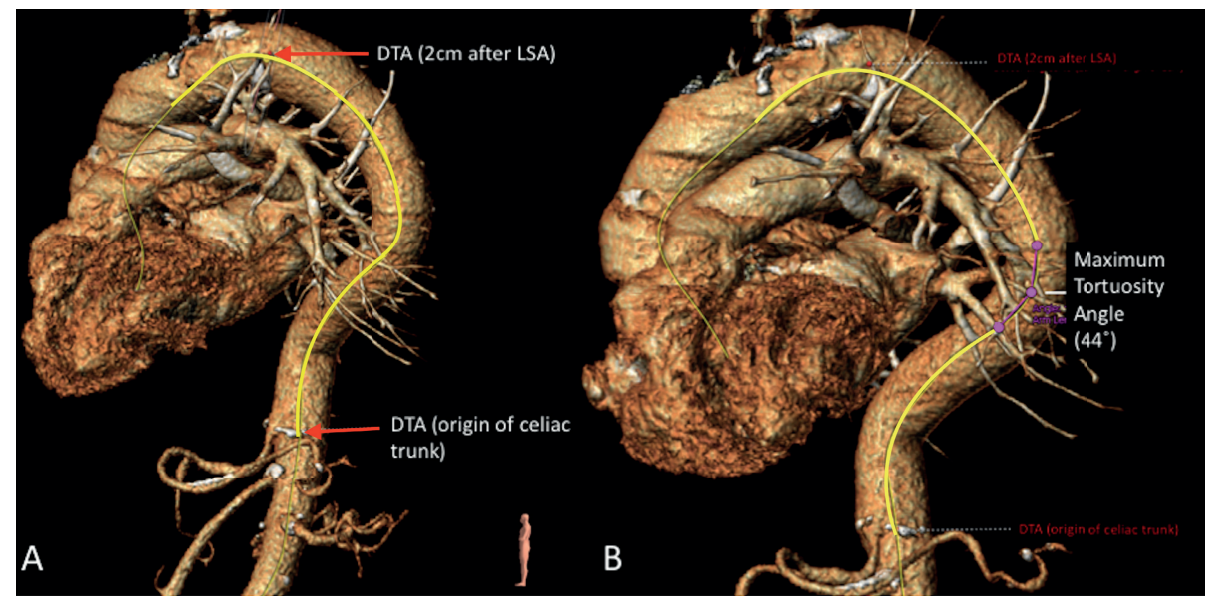

Figure 1. CT scan Measurements performed in 3Mensio Software Two images of measurements in 3Mensio in the DTA; A: Center lumen line created for zone 4 (yellow line), with the start of the DTA $2 \mathrm{~cm}$ after the LSA up to the celiac trunk; B: Maximum tortuosity angle with two line elements that are defined by three control points over the centerline to measure the tortuosity in degrees.

The tortuosity angle function of 3 Mensio was used to measure the tortuosity in degrees over the centerline ${ }^{18}$. This angle is measured between two line elements that are defined by three control points over the centerline, see fig 1, the maximum tortuosity angle. The first point is the start of the first line element, the second point is the end of the first and the start of the second line element. The third point is the end of the second line element. The distance between the first and the third was set at $15 \mathrm{~mm}$, a standard setting in 3Mensio. The maximum degrees of tortuosity was collected, together with the height of occurrence of this tortuosity. This was measured with the level of vertebras.

The curvature ratio was calculated by the outer curvature length of the descending thoracic aorta divided by the length of the center lumen line. 
Chapter 4

The DTA was divided into four zones (see fig 2). The centerline was divided in four equal parts and numbered from proximal to distal in $4 A$ to $4 D$. The maximum tortuosity in degrees was put in a scatter plot to see how the tortuosity can be divided in groups (see fig 3 ). The groups were divided as followed: low tortuosity $<30^{\circ}$, moderate tortuosity $30^{\circ}-60^{\circ}$ and high tortuosity $>60^{\circ}$. See fig 4 .

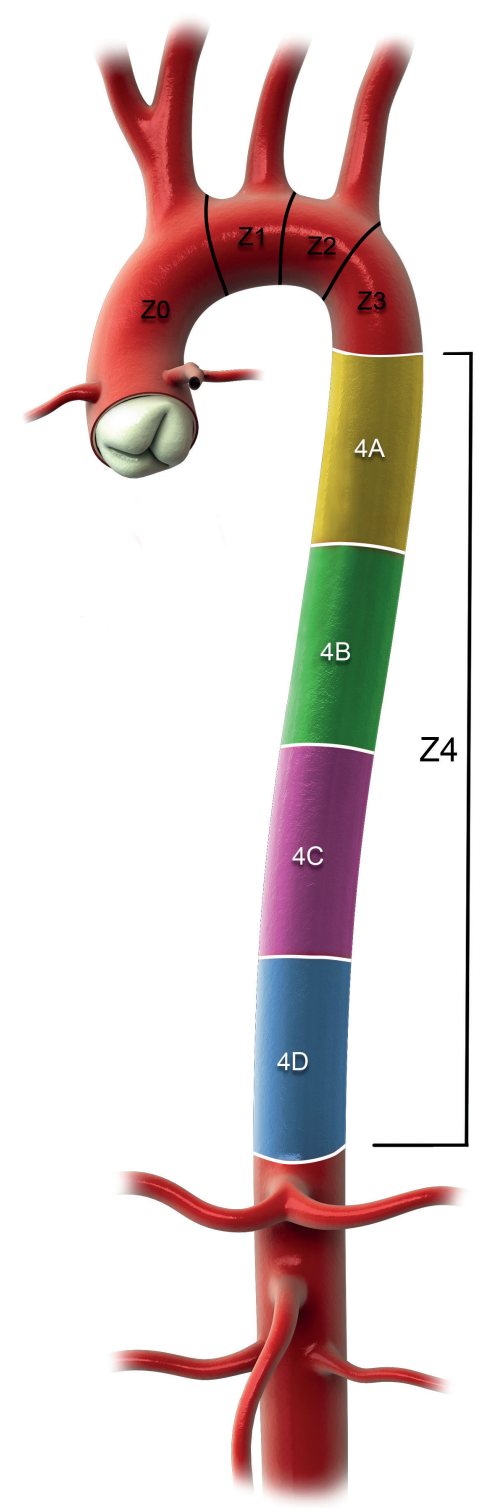

Figure 2. The Four Equal Zones of the Descending Thoracic Aorta - 4A to 4D 


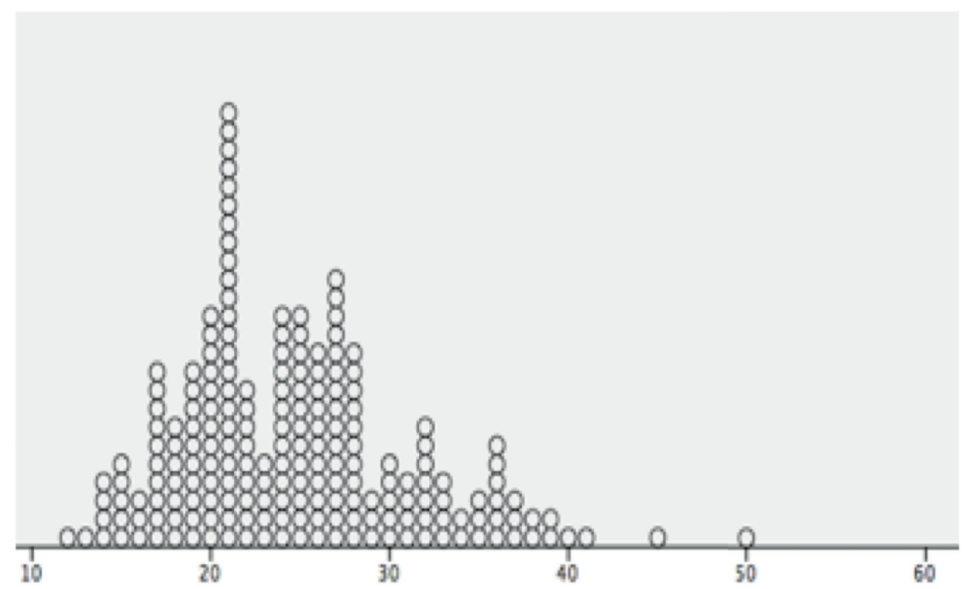

Figure 3. Scatterplot by SPSS Software of the Maximum Tortuosity in degrees. This scatterplot shows how to divide the normal tortuosity in degrees. Most patients have a maximum tortuosity $<30^{\circ}$, so the cut-off point between low and moderate tortuosity is $30^{\circ}$.

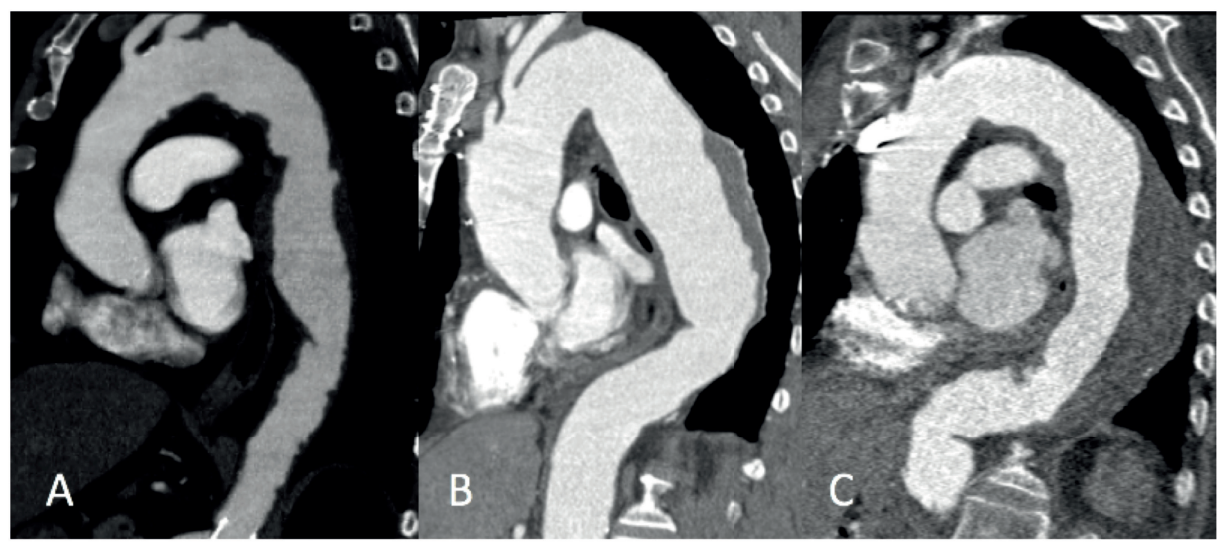

Figure 4. Three Groups of amount of Tortuosity. A: Iow tortuosity $<30^{\circ}$; B: moderate tortuosity $30^{\circ}-60^{\circ}$; C: high tortuosity $>60^{\circ}$

Measurements were repeated for 40 scans (20\%) randomly selected from the study group to assess intra-observer and inter-observer creditability (by V.M.B. \& H.W.L.d.B.). 


\section{Chapter 4}

Statistical analysis

The data was analyzed using SPSS Statistics 23 software (IBM Corp, Armonk, NY). Normality was tested with the Shapiro Wilk test. Comparison between the two groups was done with the independent sample T-test for normally distributed data or the Mann-Whitney $U$ test for non-normally distributed data. The effect of age and gender on tortuosity was analyzed calculating a linear regression model. Intra- and inter observer variability was tested with the Intraclass Correlation Coefficient (ICC).

\section{Results}

The patients were split into two groups of 100 patients. The < 65y patients had a mean age of 50.9 years old and the $\geq 65 y$ patients had a mean age of 77.9 years old. The type of arch was measured in all patients, type $1(<65 y=66 ; \geq 65 y=38)$, type $2(<65 y=30 ; \geq 65 y=43)$ and type $3(<65 y=4 ; \geq 65 y=19)$, see fig 5 . The mean length of the centerline differs between the groups $(<65 \mathrm{y}=190.7 \mathrm{~cm}$ vs. $\geq$ $65 y=212.5 \mathrm{~cm} ; 0.000)$, see table 1 . The differences were measured between the $<65 y$ and $\geq 65 y$ patients in tortuosity index (1.05 vs. 1.14; $p=0.000$ ), curvature ratio (1.00 vs. 1.01; $p=0.000$ ), maximum tortuosity in degrees (22.24 vs. 27.26; $p=0.000$ ), the level of vertebrae of the maximum tortuosity (5.00 vs. 5.00; $p=0.001)$, the zone of maximum tortuosity (4A vs. $4 A ; p=0,000)$, and the groups of angulation (low vs. low; $p=0,000$ ). For an overview see table 2 and fig 6. 
Table 2. Outcome Measurements comparing patients young vs. old

\begin{tabular}{|c|c|c|c|}
\hline & $\begin{array}{l}<65 y(N=100) \\
\text { Mean (std.) }\end{array}$ & $\begin{array}{l}\geq 65 y(N=100) \\
\text { Mean (std.) }\end{array}$ & p-value \\
\hline $\begin{array}{l}\text { Tortuosity index } \\
\mathrm{Cl}^{\mathrm{a}}\end{array}$ & $\begin{array}{l}1.05(0.024) \\
1.05-1.06\end{array}$ & $\begin{array}{l}1.14(0.078) \\
1.13-1.16\end{array}$ & $<0.001^{*}$ \\
\hline $\begin{array}{l}\text { Curvature ratio } \\
\mathrm{Cl}^{\mathrm{a}}\end{array}$ & $\begin{array}{l}1.00(0.105) \\
0.99-1.00\end{array}$ & $\begin{array}{l}1.01(0.012) \\
1.01-1.01\end{array}$ & $<0.001^{*}$ \\
\hline $\begin{array}{l}\text { Maximum Tortuosity } \\
\mathrm{Cl}^{\mathrm{a}} \\
\text { Range }\end{array}$ & $\begin{array}{l}22.24(4.710) \\
21.31-23.17\end{array}$ & $\begin{array}{l}27.26(7.233) \\
25.82-28.70\end{array}$ & $<0.001^{*}$ \\
\hline $\begin{array}{l}\text { Level of Vertebrae } \\
\text { Range }\end{array}$ & $\begin{array}{l}5 \\
5-10\end{array}$ & $\begin{array}{l}5 \\
5-12\end{array}$ & $0.001^{*}$ \\
\hline $\begin{array}{l}\text { Minimum Tortuosity } \\
\mathrm{Cl}^{\mathrm{a}}\end{array}$ & $\begin{array}{l}0.83(0.753) \\
0.68-0.98\end{array}$ & $\begin{array}{l}1.67(1.386) \\
1.40-1.94\end{array}$ & $<0.001^{*}$ \\
\hline $\begin{array}{l}\text { Level of Vertebrae } \\
\text { Range }\end{array}$ & $\begin{array}{l}11 \\
8-12\end{array}$ & $\begin{array}{l}11 \\
7-12\end{array}$ & $0.032^{*}$ \\
\hline $\begin{array}{l}\text { Zone of maximum } \\
\text { Tortuosity } \\
\text { Range }\end{array}$ & $\begin{array}{l}4 A \\
4 A-D\end{array}$ & $\begin{array}{l}4 A \\
4 A-4 D\end{array}$ & $<0.001^{*}$ \\
\hline $\begin{array}{l}\text { Group of angulation } \\
\text { Range }\end{array}$ & $\begin{array}{l}\text { Low } \\
\text { Low - Moderate - High }\end{array}$ & $\begin{array}{l}\text { Low } \\
\text { Low - Moderate - High }\end{array}$ & $<0.001^{*}$ \\
\hline $\begin{array}{l}\text { Percentage of patients } \\
\text { with high tortuosity }\end{array}$ & 0 (0\%) & $0(0 \%)$ & \\
\hline
\end{tabular}

${ }^{*}$ P-value is significant when $p<0.05$

aCl: Confidence Interval 
Chapter 4

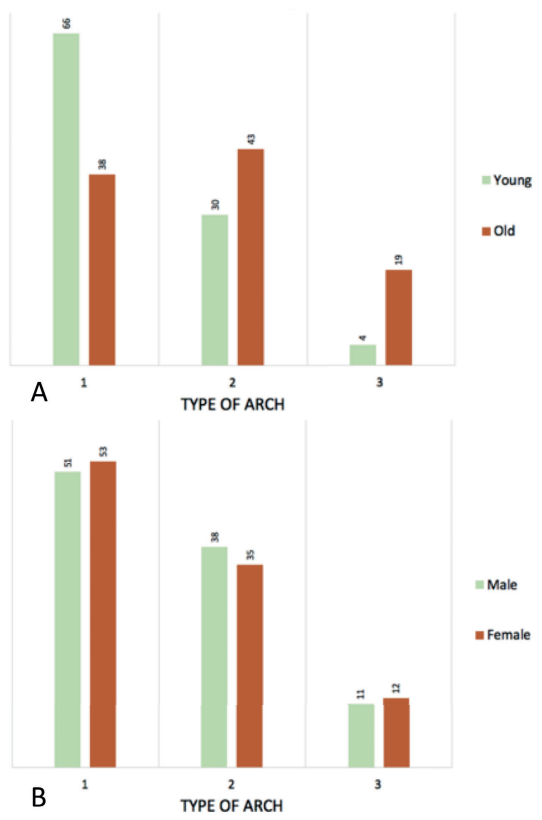

Figure 5. Histogram of the Type of Arch. A: young vs. old; B: male vs. female

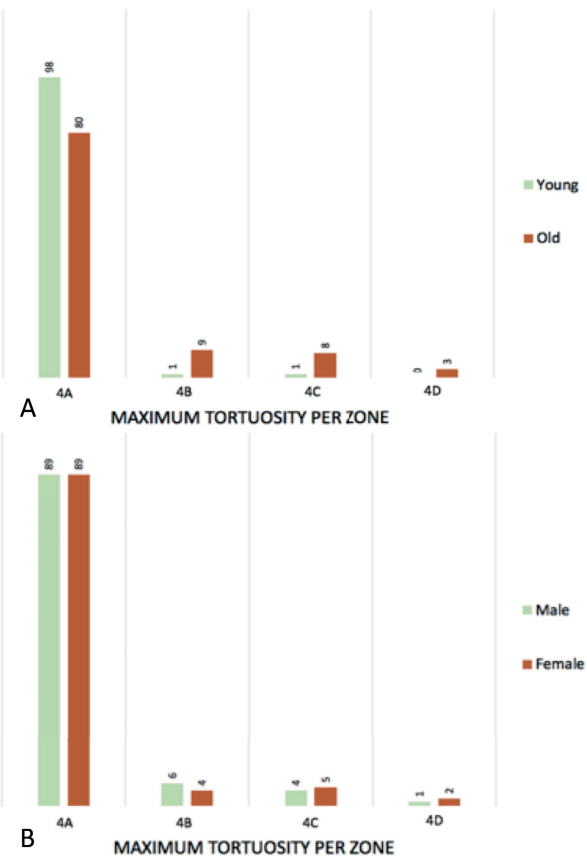

Figure 6. Histogram of the Maximum Tortuosity per Zone. A: young vs. old; B: male vs. female 
After a stepwise linear regression analysis only one independent variable has a significant correlation with the tortuosity and the maximum angulation, which is age. With aging the tortuosity becomes higher, see also table 3.

Table 3. Linear Regression Model of Tortuosity Index and Maximum Tortuosity in Relation to Age and Gender

\begin{tabular}{llll}
\hline \multicolumn{3}{l}{ All patients $(\mathrm{N}=200)$} & \\
\hline $\begin{array}{l}\text { Geometrical variable } \\
\text { Tortuosity Index }\end{array}$ & $\beta$ & P value & Model r \\
Age & 0.03 & $<0.001^{*}$ & 0.652 \\
Gender & 0.06 & 0.424 & 0.654 \\
Maximum Tortuosity & & & \\
Age & 0.175 & $<0.001^{*}$ & 0.405 \\
Gender & -0.393 & 0.647 & 0.406 \\
\hline
\end{tabular}

${ }^{*}$ P-value is significant when $p<0.05$

The same measurements were done comparing males with females. The type of arch in all patients was as followed; type 1 (Male $=51$; female $=53$ ), type $2($ male $=38 ;$ female $=35)$ and type $3($ male $=11$; female $=12)$, see fig 5 . The measurements between males and females in tortuosity index (1.09 vs. 1.10; $p=0.626)$, curvature ratio (1.00 vs. 1.01; $p=0.411$ ), maximum tortuosity in degrees ( 24.58 vs. $24.65 ; p=0.960$ ), the level of vertebrae of the maximum tortuosity (5.00 vs. 5.00; $p=1.000$ ), the zone of maximum tortuosity (low vs. low; $p=0.821$ ), and the groups of angulation (4A vs. $4 \mathrm{~A} ; \mathrm{p}=0.862$ ). For an overview see table 4 and fig 6.

Table 4. Outcome Measurements comparing patients male vs. female

\begin{tabular}{|c|c|c|c|}
\hline & $\begin{array}{l}\text { Male }(N=100) \\
\text { Mean (std.) }\end{array}$ & $\begin{array}{l}\text { Female }(\mathrm{N}=100) \\
\text { Mean (std.) }\end{array}$ & $p$-value \\
\hline $\begin{array}{l}\text { Age (y) } \\
\text { Range }\end{array}$ & $\begin{array}{l}63.88(14.381) \\
(31-90)\end{array}$ & $\begin{array}{l}64.98(16.076) \\
(32-92)\end{array}$ & 0.626 \\
\hline $\begin{array}{l}\text { Type of arch } \\
\text { Type I } \\
\text { Type II } \\
\text { Type III }\end{array}$ & $\begin{array}{l}51(51 \%) \\
38(38 \%) \\
11(11 \%)\end{array}$ & $\begin{array}{l}53(53 \%) \\
35(35 \%) \\
12(12 \%)\end{array}$ & 0.861 \\
\hline $\begin{array}{l}\text { Tortuosity index } \\
\mathrm{Cl}^{\mathrm{a}}\end{array}$ & $\begin{array}{l}1.09(0.623) \\
1.08-1.11\end{array}$ & $\begin{array}{l}1.10(0.081) \\
1.09-1.12\end{array}$ & 0.807 \\
\hline $\begin{array}{l}\text { Curvature ratio } \\
\mathrm{Cl}^{\mathrm{a}}\end{array}$ & $\begin{array}{l}1.00(0.120) \\
1.00-1.00\end{array}$ & $\begin{array}{l}1.00(0.012) \\
1.00-1.00\end{array}$ & 0.411 \\
\hline
\end{tabular}


Chapter 4

Table 4. Continued

\begin{tabular}{|c|c|c|c|}
\hline & $\begin{array}{l}\text { Male }(N=100) \\
\text { Mean (std.) }\end{array}$ & $\begin{array}{l}\text { Female }(\mathrm{N}=100) \\
\text { Mean (std.) }\end{array}$ & $p$-value \\
\hline $\begin{array}{l}\text { Maximum Tortuosity } \\
\mathrm{Cl}^{a} \\
\text { Range }\end{array}$ & $\begin{array}{l}24.58(6.854) \\
23.49-26.21\end{array}$ & $\begin{array}{l}24.65(6.343) \\
23.39-25.91\end{array}$ & 0.960 \\
\hline $\begin{array}{l}\text { Level of Vertebrae } \\
\text { Range }\end{array}$ & $\begin{array}{l}5 \\
5-12\end{array}$ & $\begin{array}{l}5 \\
5-12\end{array}$ & 1.000 \\
\hline $\begin{array}{l}\text { Minimum Angulation } \\
\mathrm{Cl}^{\mathrm{a}}\end{array}$ & $\begin{array}{l}1.21(1.20) \\
0.97-1.45\end{array}$ & $\begin{array}{l}1.29(1.183) \\
1.06-1.52\end{array}$ & 0.449 \\
\hline $\begin{array}{l}\text { Level of Vertebrae } \\
\text { Range }\end{array}$ & $\begin{array}{l}11 \\
7-12\end{array}$ & $\begin{array}{l}11 \\
8-12\end{array}$ & 1.000 \\
\hline $\begin{array}{l}\text { Zone of max angulation } \\
\text { Range }\end{array}$ & $\begin{array}{l}4 A \\
4 A-4 D\end{array}$ & $\begin{array}{l}4 A \\
4 A-4 D\end{array}$ & 0.821 \\
\hline $\begin{array}{l}\text { Group of angulation } \\
\text { Range }\end{array}$ & $\begin{array}{l}\text { Low } \\
\text { Low - Moderate - High }\end{array}$ & $\begin{array}{l}\text { Low } \\
\text { Low - Moderate - High }\end{array}$ & 0.862 \\
\hline $\begin{array}{l}\text { Percentage of patients } \\
\text { with high tortuosity }\end{array}$ & $0(0 \%)$ & $0(0 \%)$ & \\
\hline
\end{tabular}

${ }^{*} \mathrm{P}$-value is significant when $\mathrm{p}<0.05$

$\mathrm{aCl}$ : Confidence Intervals

For the intra- and interobserver variability we used the ICC. The ICC is normally between 0 and 1; an ICC close to 1 indicates high similarity between values. The ICC was above 0.80 for the tortuosity index, curvature ratio, maximum angulation, the level of vertebrae of the maximum angulation and the zone of the maximum angulation.

\section{Discussion}

The physiological effect of aging on the DTA is inevitable. Knowing that the aorta becomes more tortuous and longer with age can help to improve future generations of stent grafts to obtain less complications and better outcomes.

When Ishimaru introduced the classification of the thoracic aorta in 1996, zone 4 (the DTA) was divided into different zones correlated to the thoracic vertebras ${ }^{10}$. This article shows that zone 4 does not always start with thoracic vertebra 4. As a new classification for the aortic arch was proposed by MarroccoTrischitta et al. there is no clear classification on zone 4. In the literature tortuosity is an important risk factor for the occurrence of endoleaks in the DTA, including the distal type $e^{13,14,16}$. As the human body is becoming smaller, the aorta length 
can become even longer ${ }^{1}$, and therefore with a high tortuosity (> 60 degrees) can occur with age. As tortuosity in the DTA has not been investigated yet, this study contributes to future planning of TEVAR to obtain positive results during follow-up.

In this study we looked at the type of arch in $<65 y$ and $\geq 65 y$ old people. Most people in the < 65y group had a type 1 arch, where people in the $\geq 65 y$ group had a balance between the different types, see figure 5. The reason for this phenomenon can be multifactorial. One of the factors might be the decrease of elastin and increase of collagen in the aortic wall, which comes with aging and the anatomy of the aorta changes ${ }^{6}$. Secondly, aortic elongation in combination with the fixation of the supra-aortic trunks may account for entry tear formation ${ }^{19}$. The tortuosity index, curvature ratio and the maximum tortuosity are higher in the $\geq 65 y$ group. An explanation as previously mentioned; with aging the human body shrinks, but the aorta is getting longer ${ }^{1}$. A study by Craiem et al. shows that the volume, the diameter and the length of the thoracic aorta increases with age ${ }^{2}$. The curvature radius increased too, but the tortuosity was decreasing, which is in contrast with our findings. This difference might be because of the their different way of measuring tortuosity. Likewise, the maximum degrees of tortuosity is higher in $\geq 65 y$ old people, which can be explained the same way ${ }^{1}$. The level of highest tortuosity is in the $\geq 65 y$ group more distal in the DTA.

Similar to Rylski et al. this study shows that there is no difference in tortuosity and angulation between males and females ${ }^{20}$. A recent study by Tawfik et al. was conducted to define the relation between age and gender on tortuosity ${ }^{21}$. The methodology was similar and the outcome was the same.

We showed that the aorta is more tortuous in older patients, who usually benefit from endovascular repair. However, they do have a higher risk of complications after TEVAR ${ }^{22,23}$. Previously it has been confirmed that a type $1 \mathrm{~b}$ endoleak is associated with aortic tortuosity ${ }^{13,14,16}$. The findings of this study can declare the higher risk of complications and help with future planning for TEVAR.

Limitations of this study are that only the physiological geometry has been analyzed. The influence of cardiovascular diseases has not been taken into account, whilst this can be of importance. Also the influence of other risk factors for atherosclerosis (i.e. Diabetes Mellitus) were not examined and tested in a regression model. Furthermore, the cross-sectional study design is a limitation. Future studies with a longitudinal design could be informative. Nevertheless, our 


\section{Chapter 4}

findings support previous work and so adds to the existing literature in providing some support for the natural evolution of aortic geometry.

Conclusion, the tortuosity and curvature of the DTA increase significantly with age. This acknowledgment is useful for further research on the descending thoracic aorta and to understand the natural development with age, when tortuosity is becoming more important in the planning and follow-up strategy of TEVAR. 


\section{References}

1. Redheuil A, Yu W-C, Mousseaux E, Harouni AA, Kachenoura N, Wu CO, et al. Age-Related Changes in Aortic Arch Geometry Relationship With Proximal Aortic Function and Left Ventricular Mass and Remodeling. JAC. 2011;58:1262-1270. doi:10.1016/j.jacc.2011.06.012

2. Craiem D, Casciaro ME, Graf S, Chironi G, Simon A, Armentano RL. Effects of aging on thoracic aorta size and shape: A non-contrast CT study. In: 2012 Annual International Conference of the IEEE Engineering in Medicine and Biology Society. Vol 2012. IEEE; 2012:4986-4989. doi:10.1109/ EMBC.2012.6347112

3. Craiem D, Chironi G, Redheuil A, Casciaro M, Mousseaux E, Simon A, et al. Aging impact on thoracic aorta 3D morphometry in intermediate-risk subjects: looking beyond coronary arteries with non-contrast cardiac CT. Ann Biomed Eng. 2012;40(5):1028-1038. doi:10.1007/s10439-0110487-y

4. Stulp G, Barrett L. Evolutionary perspectives on human height variation. Biol Rev. 2016;91(1):206234. doi:10.1111/brv.12165

5. Osakabe T, Hayashi M, Hasegawa K, Okuaki T, Ritty TM, Mecham RP, et al. Age- and gender-related changes in ligament components. Ann Clin Biochem. 2001;38(Pt 5):527-532. doi:10.1177/000456320103800510

6. Tsamis A, Krawiec JT, Vorp DA. Elastin and collagen fibre microstructure of the human aorta in ageing and disease: a review. J R Soc Interface. 2013;10(83):20121004. doi:10.1098/rsif.2012.1004

7. O'Rourke MF. Arterial aging: pathophysiological principles. Vasc Med. 2007;12(4):329-341. doi:10.1177/1358863X07083392

8. Lakatta EG, Levy D. Arterial and cardiac aging: major shareholders in cardiovascular disease enterprises: Part I: aging arteries: a \&quot; set up\&quot; for vascular disease. Circulation. 2003;107(1):139-146. http://www.ncbi.nlm.nih.gov/pubmed/12515756. Accessed April 13, 2018.

9. Liebhart, prof. dr.,Spann P dr. med. Aorteninnemunfang in Abhängigkeit zum Alter. 1977; (Institut für Rechtsmedizin der Universität München).

10. Ishimaru S. Endografting of the Aortic Arch. J Endovasc Ther. 2004;11(SupplementII):II-62-II-71. doi:10.1583/04-1407.1

11. Marrocco-Trischitta MM, de Beaufort HW, Secchi F, van Bakel TM, Ranucci M, van Herwaarden JA, et al. A geometric reappraisal of proximal landing zones for thoracic endovascular aortic repair according to aortic arch types. J Vasc Surg. 2017;65(6):1584-1590. doi:10.1016/j.jvs.2016.10.113

12. Grabenwoger M, Fleck T, Ehrlich M, Czerny M, Hutschala D, Schoder M, et al. Secondary surgical interventions after endovascular stent-grafting of the thoracic aorta. Eur J Cardiothorac Surg. 2004;26(3):608-613. doi:10.1016/j.ejcts.2004.05.003

13. Kotelis D, Brenke C, Wörz S, Rengier F, Rohr K, Kauczor H-UU, et al. Aortic morphometry at endograft position as assessed by 3D image analysis affects risk of type I endoleak formation after TEVAR. Langenbeck's Arch Surg. 2015;400(4):523-529. doi:10.1007/s00423-015-1291-1

14. Nakatamari H, Ueda T, Ishioka F, Raman B, Kurihara K, Rubin GD, et al. Discriminant analysis of native thoracic aortic curvature: Risk prediction for endoleak formation after thoracic endovascular aortic repair. J Vasc Interv Radiol. 2011;22(7):974-979. doi:10.1016/j.jvir.2011.02.031

15. Madhwal S, Rajagopal V, Bhatt DL, Bajzer CT, Whitlow P, Kapadia SR. Predictors of difficult carotid stenting as determined by aortic arch angiography. J Invasive Cardiol. 2008;20(5):200204. http://www.ncbi.nlm.nih.gov/pubmed/18460700. Accessed November 10, 2017.

16. Ueda T, Takaoka H, Raman B, Rosenberg J, Rubin GD. Impact of quantitatively determined native thoracic aortic tortuosity on endoleak development after thoracic endovascular aortic repair. Am J Roentgenol. 2011;197(6):1140-1146. doi:10.2214/AJR.11.6819

17. Chen CK, Liang IP, Chang HT, Chen WY, Chen IM, Wu MH, et al. Impact on outcomes by measuring tortuosity with reporting standards for thoracic endovascular aortic repair. $J$ Vasc Surg. 2014;60(4):937-944. doi:10.1016/j.jvs.2014.04.008

18. van Keulen JW, Moll FL, Tolenaar JL, Verhagen HJM, van Herwaarden JA. Validation of a new standardized method to measure proximal aneurysm neck angulation. J Vasc Surg. 2010;51(4):821828. doi:10.1016/j.jvs.2009.10.114 


\section{Chapter 4}

19. Chi Q, He Y, Luan Y, Qin K, Mu L. Numerical analysis of wall shear stress in ascending aorta before tearing in type A aortic dissection. Comput Biol Med. 2017;89:236-247. doi:10.1016/j. compbiomed.2017.07.029

20. Rylski B, Desjardins B, Moser W, Bavaria JE, Milewski RK. Gender-related changes in aortic geometry throughout life. Eur J Cardio-Thoracic Surg. 2014;45(5):805-811. doi:10.1093/ejcts/ ezt597

21. Tawfik AM, Sobh DM, Gadelhak B, Sobh HM, Batouty NM. The effect of age and gender on tortuosity of the descending thoracic Aorta. Eur J Radiol. 2019;110:54-59. doi:10.1016/j. ejrad.2018.11.017

22. Czerny M, Funovics M, Ehrlich M, Hoebartner M, Sodeck G, Dumfarth J, et al. Risk Factors of Mortality in Different Age Groups After Thoracic Endovascular Aortic Repair. Ann Thorac Surg. 2010;90(2):534-538. doi:10.1016/j.athoracsur.2010.03.096

23. De Rango P, Isernia G, Simonte G, Cieri E, Marucchini A, Farchioni L, et al. Impact of age and urgency on survival after thoracic endovascular aortic repair. J Vasc Surg. 2016;64(1):25-32. doi:10.1016/j.jvs.2015.11.054 
Tortuosity aging population 



\section{Chapter 5}

\section{Tortuosity of the Descending Thoracic Aorta in patients with Aneurysm and Type B Dissection}

Viony M. Belvroy ${ }^{1,2,3}$; Hector W.L. de Beaufort ${ }^{1,2}$; Joost A. van Herwaarden²; Jean Bismuth ${ }^{3}$; Gabriele Piffaretti4; Frans L. Moll2; Santi Trimarchi ${ }^{5,6}$

Awarded $2^{\text {nd }}$ prize for best poster presentation at the

ESVS 32 ${ }^{\text {nd }}$ Annual Meeting 2018, September 25 - 28

Valencia, Spain

1 Thoracic Aortic Research Center, IRCCS Policlinico San Donato, San Donato Milanese, Italy

2 Department of Vascular Surgery, University Medical Center, Utrecht, Netherlands

3 Houston Methodist DeBakey Heart \& Vascular Center, Houston, Texas, United States

4 Vascular Surgery, Department of Medicine and Surgery, ASST Settelaghi University Teaching Hospital, University of Insubria School of Medicine, Varese, Italy

5 Fondazione IRCCS Ca' Granda Ospedale Maggiore Policlinico Milan, Milan, Italy

6 Department of Clinical and Community Science, University of Milan, Milan, Italy 


\section{Chapter 5}

\section{Abstract}

Objective Tortuosity in the descending thoracic aorta (DTA) comes with aging and increases the risk of endoleaks after TEVAR. With this report we would like to define and classify tortuosity in the DTA of patients with thoracic aortic disease.

Methods Retrospective case-control study of two hundred seven patients, comparing sixty-nine controls without aortic disease (CG), to sixty-nine patients with descending thoracic aortic aneurysm (AG) and sixty-nine patients with type $B$ aortic dissection (DG). 3Mensio Vascular software was used to analyze CTA scans and collect the following measurements; tortuosity index, curvature ratio and the maximum tortuosity of the DTA. The DTA was divided into four equal zones. The maximum tortuosity was divided into three groups: Iow $\left(<30^{\circ}\right)$, moderate $\left(30^{\circ}-60^{\circ}\right)$ and high tortuosity $\left(>60^{\circ}\right)$.

Results Compared to the CG, tortuosity was more pronounced in the DG, and even more in the AG, evidenced by the tortuosity index (1.11 vs. 1.20 vs. 1.31; $p$ $<0.001$ ), curvature ratio (1.00 vs. 1.01 vs. 1.03; $p<0.001$ ), maximum tortuosity in degrees (28.17 vs. 33.29 vs. 43.83; $p<0.001)$, and group of tortuosity $(p<0.001)$. The maximum tortuosity was further distal for the $D G$ and $A G$, evidenced by the zone of maximum tortuosity (4A vs. 4B vs. 4B; $p<0.001$ ).

Conclusion This study shows that tortuosity in the DTA is more prominent in diseased aortas, especially in aneurysmal disease. This phenomenon needs to be taken into account during planning of TEVAR to prevent stent-graft related complications and to obtain positive long-term outcome.

Key words: aneurysm, dissection, tortuosity, thoracic endovascular aortic repair, TEVAR 


\section{Introduction}

Thoracic endovascular aortic repair (TEVAR) is the gold standard for treating most descending thoracic aortic disease 1 , if the patient is anatomically suitable. Meaning that a landing zone length of $>20 \mathrm{~mm}$ and neck diameter of $<40 \mathrm{~mm}$ is required, not only proximally but also distally, to ensure adequate stent graft sealing ${ }^{2}$. Besides landing zone length and diameter, tortuosity also influence sealing, and the literature reports that high tortuosity increases the occurrence of endoleaks, mal-positioning and deployment failure ${ }^{3-5}$. However, the literature does not report on the incidence of tortuosity in diseased aortas. Therefore, we want to define and classify the tortuosity in diseased descending thoracic aorta (DTA).

The healthy and diseased aging aorta is an irremediable process and some has been clarified. To start with, the aorta can gain length on itself $f^{6-9}$, or lengthen when spinal shrinkage occurs and the vertebral column decreases ${ }^{10}$, causing tortuosity in the descending thoracic aorta (DTA $)^{11}$. A decrease in elastin and increase in collagen is a substantial risk factor in the aortic wall due to aging ${ }^{12}$. Loss or malfunctioning of elastin structures is pernicious for the cardiovascular system ${ }^{13,14}$.

Previously, a method was published to easily get an impression of the tortuosity of the proximal TEVAR landing zones ${ }^{15}$ by elaborating on the Ishimaru classification ${ }^{16}$. However, the geometrical characteristics of zone 4 of the Ishimaru classification and further distally were not included. The literature reports that with aging the distal aorta becomes more tortuous ${ }^{6,7}$. A previous study reports a new classification on the DTA ${ }^{11}$, based on zone 4 of the Ishimaru classification. While older patients benefit from endovascular repair, the tortuosity of the descending thoracic aorta becomes most relevant in TEVAR candidates. Surgeons speculate on tortuosity being an important factor for stent graft failure, but nothing is written on the amount of tortuosity and its clinical implications. We studied the morphologic feature tortuosity as a first step in the diseased DTA, to give an insight in the differences in tortuosity among vascular diseases in the aorta. 


\section{Methods}

\section{Patients}

A single center retrospective study was conducted at I.R.C.C.S. Policlinico San Donato where the local Ethical Committee approved of this study and waived the need to obtain informed consent from patients. From April 2017 until March 2018 data was collected for a retrospective case-control study of two hundred seven patients with CT images, comparing sixty-nine controls without aortic disease, to sixty-nine patients with descending thoracic aortic aneurysm (DTAA) and sixty-nine patients with type $B$ aortic dissection (TBD). A total number of 69 cases were found at our institution with DTAA. Consecutively a number of 69 patients with TBD and 69 healthy patients were found, searched from most recent until the total number was reached. At the end of patient collection, gender differences were slightly matched to have equal numbers throughout the three groups. Overall exclusion criteria were patients with no thin cut CT scan slices (> $1.5 \mathrm{~mm}$ ). There were no other exclusion criteria for the Healthy group. For the Aneurysm group patients with saccular aneurysm, aneurysm of the ascending aorta or aortic arch were excluded. For the Dissection group patients with a Stanford type A dissections were excluded from this study. No difference was made in chronic and acute dissection. Patient demographics are summarized in table 1.

Table 1. Baseline Demographic \& Morphological Characteristics of Patients

\begin{tabular}{|c|c|c|c|c|}
\hline & $\begin{array}{l}\text { Control } \\
(\mathrm{N}=69) \\
\text { Mean (std.) }\end{array}$ & $\begin{array}{l}\text { Dissection } \\
(\mathrm{N}=69) \\
\text { Mean (std.) }\end{array}$ & $\begin{array}{l}\text { Aneurysmal } \\
(\mathrm{N}=69) \\
\text { Mean (std.) }\end{array}$ & P-value \\
\hline Age & $\begin{array}{l}68.32(15.42) \\
32-91\end{array}$ & $\begin{array}{l}64.13(13.43) \\
35-90\end{array}$ & $\begin{array}{l}72.19(7.14) \\
55-85\end{array}$ & 0.001 \\
\hline $\begin{array}{l}\text { Gender } \\
\text { Male } \\
\text { Female }\end{array}$ & $\begin{array}{l}44 \\
25\end{array}$ & $\begin{array}{l}44 \\
25\end{array}$ & $\begin{array}{l}44 \\
25\end{array}$ & \\
\hline $\begin{array}{l}\text { Type of arch } \\
\text { Type I } \\
\text { Type II } \\
\text { Type III }\end{array}$ & $\begin{array}{l}28(40.6 \%) \\
28(40.6 \% \\
13(18.8 \%)\end{array}$ & $\begin{array}{l}15(21.7 \%) \\
24(34.8 \%) \\
30(43.5 \%)\end{array}$ & $\begin{array}{l}8(11.6 \%) \\
36(52.2 \%) \\
25(36.2 \%)\end{array}$ & $<0.001$ \\
\hline $\begin{array}{l}\text { Age } \\
<70 y \\
>70 y\end{array}$ & $\begin{array}{l}33 \\
36\end{array}$ & $\begin{array}{l}39 \\
30\end{array}$ & $\begin{array}{l}48 \\
21\end{array}$ & \\
\hline
\end{tabular}




\section{Image analysis \& outcome measurements}

Methods for image analysis were previously reported by Belvroy et al. ${ }^{11}$ Thin cut CT scan slices (1.0 and/or $1.5 \mathrm{~mm}$ ) were included in this study and analyzed. According to the aortic arch classification the type of arch was measured ${ }^{17}$.

The CT scans were analyzed with 3Mensio Vascular software (3Mensio Medical Imaging B.V., Bilthoven, The Netherlands). According to Ishimaru's aortic map $^{16}$ the DTA starts two centimeters after the left subclavian artery (LSA) up to the celiac trunk where a center lumen line was semi-automated created. Placing two markers at the start and the end of the centerline, the total length was automatically created. The true length (i.e. the shortest distance between both markers in 3D space) was measured. Different outcome measures were collected. The second outcome measurement was calculated by dividing the length of the center lumen line by its true length ${ }^{3,18}$, called the tortuosity index. See figure 1.

The maximum tortuosity angle was calculated in degrees with the special tortuosity angle function in $3 \mathrm{Mensio}^{19}$. Over the centerline there are three control points. Between the first and second point is the first line element and between the second and third is the second line element. The angle is measured between two line elements at the middle control point, see figure 1. The length of the two element lines is $15 \mathrm{~mm}$, which is a standard setting in 3Mensio. The maximum amount of tortuosity in degrees was collected, combined with the level of occurrence of the tortuosity angle, named the level of vertebras.

In relation to aortic tortuosity we measured the curvature ratio by dividing the outer curvature length by the length of the center lumen line. 


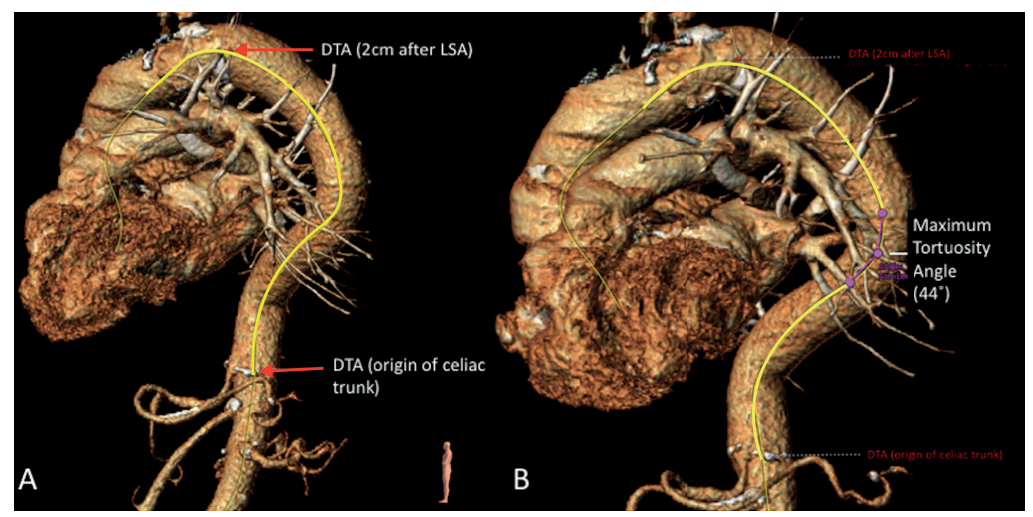

Figure 1. An example of the measurements conducted in 3Mensio Software using CT scans. Two images of measurements in 3 Mensio in the DTA. A: The DTA; zone 4, starting $2 \mathrm{~cm}$ after the LSA up to the celiac trunk, with center lumen line (yellow line). B: The amount of tortuosity in degrees measured with the two line element function over the centerline; the maximum tortuosity angle.

Reprinted from Belvroy et al. published by PLOSONE, open access journals ${ }^{11}$.

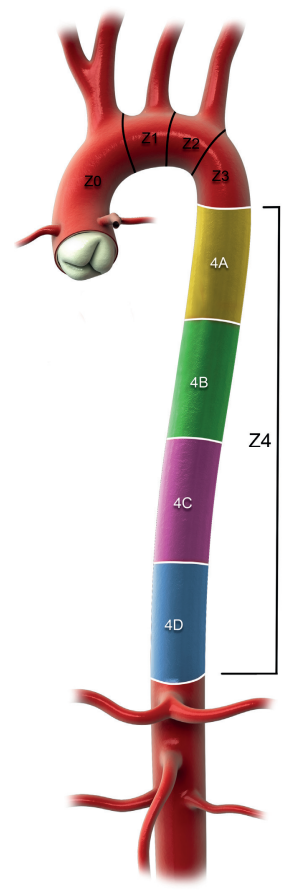

Figure 2. The Descending Thoracic Aorta divided into Four Equal Zones - 4A to 4D Reprinted from Belvroy et al. published by PLOSONE, open access journals ${ }^{11}$ 


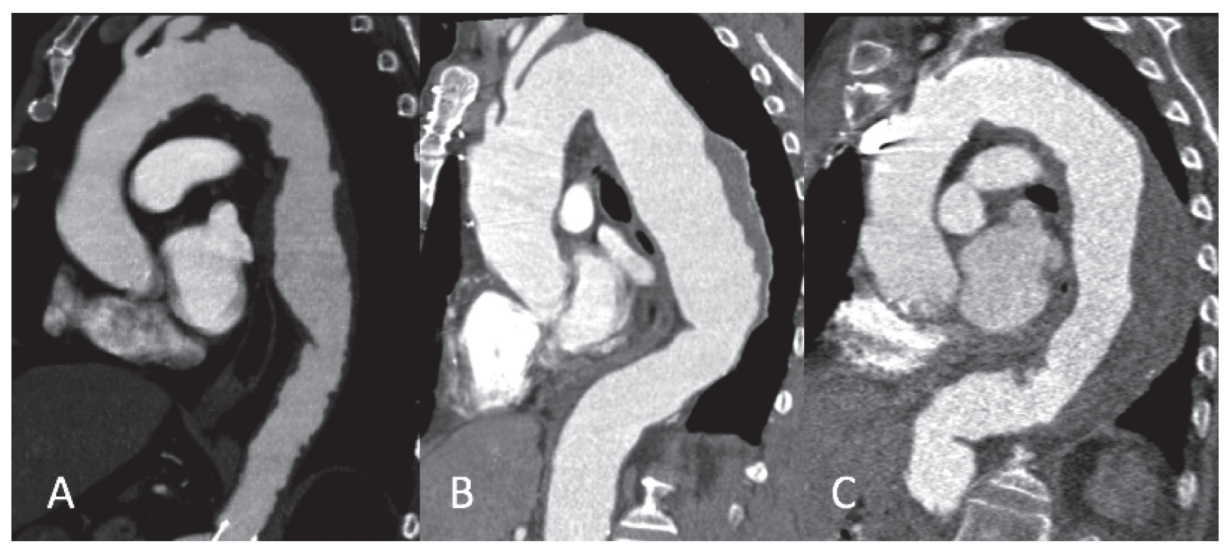

Figure 3. The amount of tortuosity in degrees divided into Three Groups. A: Iow tortuosity $<30^{\circ}, \mathrm{B}$ : moderate tortuosity $30^{\circ}-60^{\circ}$, C: high tortuosity $>60^{\circ}$ Reprinted from Belvroy et al. published by PLOSONE, open access journals'11.

Figure 2 shows the centerline of the DTA divided into four equal zones, which are numbered from proximal to distal in $4 A$ to $4 D$. The amount of tortuosity was divided into three groups: low tortuosity $<30^{\circ}$, moderate tortuosity $30^{\circ}-60^{\circ}$ and high tortuosity $>60^{\circ}$, see figure 3 .

Measurements were repeated for 40 scans (20\%) randomly selected from the study group to assess intra-observer and inter-observer creditability by two independent authors (V.M.B. \& H.W.L.d.B.).

\section{Statistical analysis}

The data were analyzed using SPSS Statistics 23 software (IBM Corp, Armonk, NY). Normality was tested with the Shapiro Wilk test. Comparison between the three groups was done with the One-way ANOVA for normally distributed data or the Kruskal-Wallis test for non-normally distributed data. When there were significant differences, post-hoc test were performed to find the statistical difference between de groups. The Intraclass Correlation Coefficient, which lays between 0 and 1, tested the intra- and inter observer variability. An ICC close to 1 indicates high similarity between values.

\section{Results}

The mean age of the Control group (CG) was 68.3 years, in the Dissection group (DG) 64.1 years and in the Aneurysm group (AG) 72.2 years. In all patients the 


\section{Chapter 5}

type of arch was measured, type $1(C G=28, D G=15, A G=8$,), type $2(C G=28$, $D G=24, A G=36)$, and type $3(C G=13, D G=30, A G=25)$, see also table 1 .

The mean length of the center luminal line (in $\mathrm{mm}$ ) increases in the diseased aorta $(C G=212 ; D G=240 ; A G=272)$. Compared to the $C G$, tortuosity was more pronounced in the $D G$, and even more in the $A G$, as evidenced by the tortuosity index (1.11 vs. 1.20 vs. 1.31, respectively; $p$ < 0.001), curvature ratio (1.00 vs. 1.01 vs. 1.03; $p<0.001)$, maximum tortuosity in degrees (28.17 vs. 33.29 vs. 43.83; $p<0.001$ ), and group of tortuosity (low vs. moderate vs. moderate; $p<0.001$ ), see table 2. The percentage of severe tortuosity is the highest in the aneurysm group $(C G=0 \% ; D G=10.1 \% ; A G=14 \%)$, ranging from $61-95$ degrees $(D G)$ and 61 - 114 degrees (AG), see table 2 and figure 4.

Table 2. Outcomes Measurements Comparing Control patients with Dissection and Aneurysmal

\begin{tabular}{|c|c|c|c|c|}
\hline & $\begin{array}{l}\text { Control } \\
(\mathrm{N}=69) \\
\text { Mean (std.) }\end{array}$ & $\begin{array}{l}\text { Dissection } \\
(\mathrm{N}=69) \\
\text { Mean (std.) }\end{array}$ & $\begin{array}{l}\text { Aneurysmal } \\
(\mathrm{N}=69) \\
\text { Mean (std.) }\end{array}$ & P-value \\
\hline $\begin{array}{l}\text { Length Center luminal line } \\
\text { Range }\end{array}$ & $\begin{array}{l}212.10(20.251) \\
167.50-280.40\end{array}$ & $\begin{array}{l}239.83(33.164) \\
157.30-338.10\end{array}$ & $\begin{array}{l}272.46(30.810) \\
214.10-335.30\end{array}$ & $<0.001$ \\
\hline $\begin{array}{l}\text { Tortuosity index } \\
\text { Confidence Interval* }\end{array}$ & $\begin{array}{l}1.11(0.081) \\
1.09-1.13\end{array}$ & $\begin{array}{l}1.20(0.119) \\
1.17-1.23\end{array}$ & $\begin{array}{l}1.31(0.148) \\
1.28-1.35\end{array}$ & $<0.001$ \\
\hline $\begin{array}{l}\text { Curvature ratio } \\
\text { Confidence Interval* }\end{array}$ & $\begin{array}{l}1.01(0.011) \\
1.002-1.008\end{array}$ & $\begin{array}{l}1.01(0.023) \\
1.002-1.013\end{array}$ & $\begin{array}{l}1.03(0.020) \\
1.020-1.034\end{array}$ & $<0.001$ \\
\hline $\begin{array}{l}\text { Maximum tortuosity } \\
\text { Confidence Interval* } \\
\text { Range }\end{array}$ & $\begin{array}{l}28.17^{\circ}(7.34) \\
26.41-29.94 \\
15^{\circ}-50^{\circ}\end{array}$ & $\begin{array}{l}33.29^{\circ}(17.86) \\
29.00-37.59 \\
13^{\circ}-95^{\circ}\end{array}$ & $\begin{array}{l}43.83^{\circ}(20.33) \\
38.94-48.71 \\
15^{\circ}-114^{\circ}\end{array}$ & $<0.001$ \\
\hline $\begin{array}{l}\text { Level of Vertebrae** } \\
\text { Range }\end{array}$ & $\begin{array}{l}5 \\
5-10\end{array}$ & $\begin{array}{l}8 \\
5-12\end{array}$ & $\begin{array}{l}9 \\
5-12\end{array}$ & $<0.001$ \\
\hline $\begin{array}{l}\text { Zone of maximum } \\
\text { Tortuosity } \\
\text { Range }\end{array}$ & $\begin{array}{l}4 A \\
4 A-4 D\end{array}$ & $\begin{array}{l}4 B \\
4 A-4 D\end{array}$ & $\begin{array}{l}4 B \\
4 A-4 D\end{array}$ & $<0.001$ \\
\hline $\begin{array}{l}\text { Group of Tortuosity } \\
\text { Range }\end{array}$ & $\begin{array}{l}\text { Low } \\
\text { Low - moderate } \\
\text { - high }\end{array}$ & $\begin{array}{l}\text { Moderate } \\
\text { Low - moderate } \\
\text { - high }\end{array}$ & $\begin{array}{l}\text { Moderate } \\
\text { Low - moderate } \\
\text { - high }\end{array}$ & $<0.001$ \\
\hline $\begin{array}{l}\text { Percentage of patients } \\
\text { with high tortuosity }\end{array}$ & $0(0 \%)$ & 7 (10.1\%) & 14 (20.3\%) & \\
\hline
\end{tabular}

* Confidence Interval of $95 \%$

** The thoracic vertebrae were used as reference point for the level of vertebrae. 

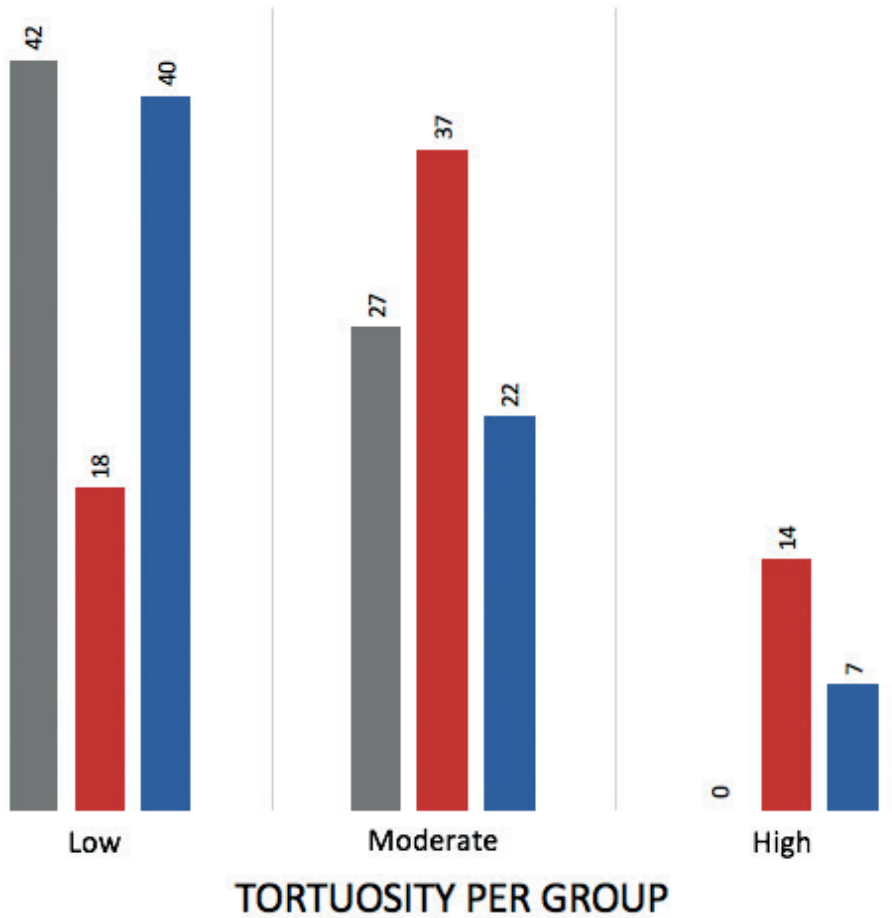

- Control

aneurysm

Dissection

Figure 4. The Number of Patients per Tortuosity Group

Additionally, compared to CG, the location of maximum tortuosity was further distal for the DG and even further in the $A G$, as evidenced by the vertebral level of maximum angulation ( 5 vs. 8 vs. $9 ;$ p < 0.001), and zone of maximum tortuosity (4A vs. $4 \mathrm{~B}$ vs. $4 \mathrm{~B} ; \mathrm{p}<0.001$ ), see table 2 . In figure 5 the maximum tortuosity is mainly in zone $4 \mathrm{~A}$ for the $C \mathrm{G}$, where zone $4 \mathrm{C}$ is becoming more prominent in the AG. The DG looks similar to the CG with the maximum tortuosity in zone 4A, but zone $4 \mathrm{C}$ comes in second place.

The post-hoc tests for the tortuosity index was statistical significant between all groups $(p<0.001)$. For the curvature ratio and the maximum tortuosity the test was only significant between the CG vs. AG and the DG vs. AG (both $P<$ 0.001). This shows similarities between the CG and the DG. The location of the maximum tortuosity is further distal for the DG and $A G$ compared to the CG, reaching both a statistical significance $(p<0.001)$, however, not between the DG and the AG ( $p=0.84)$. 


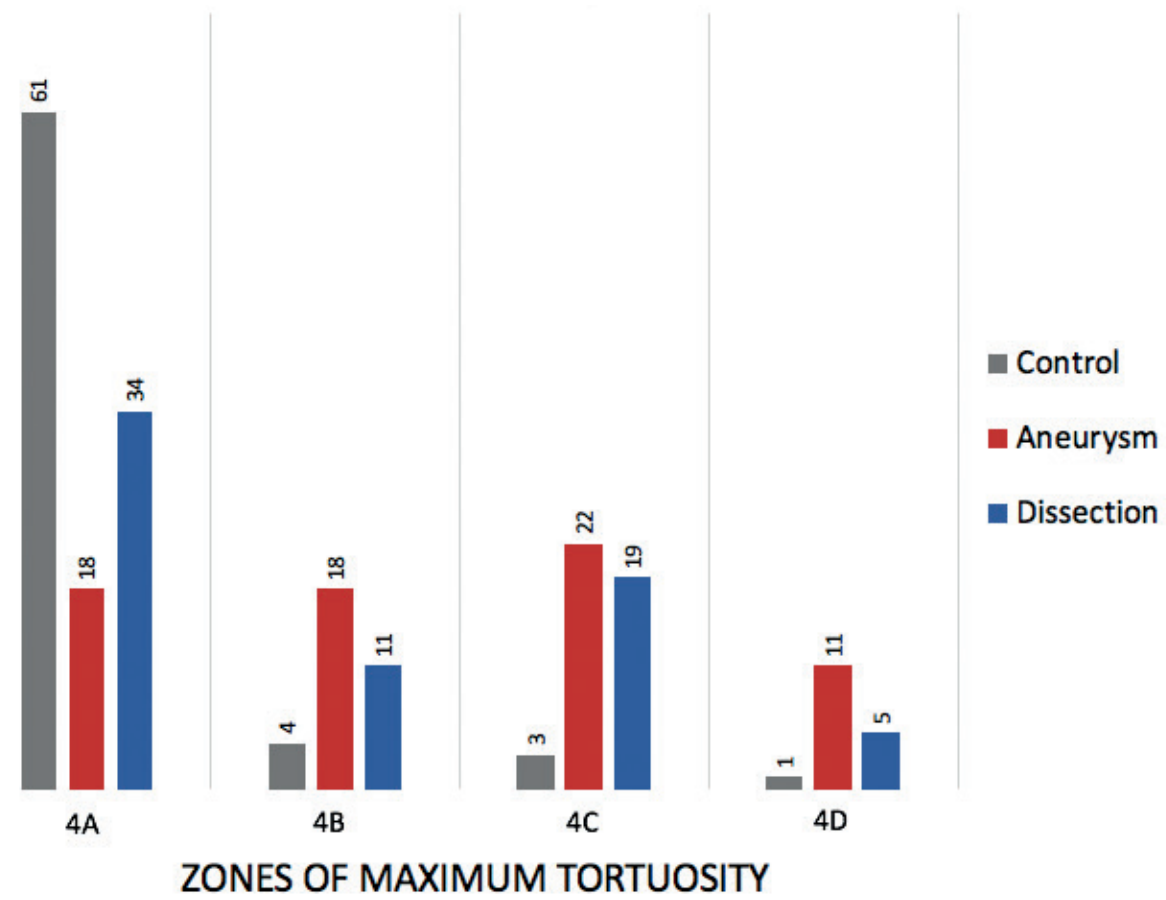

Figure 5. Histogram of the Maximum Tortuosity per Zone

Stratifying aortic tortuosity by age ( $<70$ y old and $>70$ y old $)$ resulted in significant difference between young and old for the tortuosity index in the $C G$ (1.07 vs. $1.15 ; p<0.001)$, the $D G(1.15$ vs. $1.27 ; p<0.001)$ and the $A G(1.23$ vs. 1.35; $p=0.001)$, see table 3 . The curvature ratio reached a statistical significance only in the CG (1.00 vs. 1.01; $p=0.002)$. The tendency is the same in the DG (1.00 vs. $1.01 ; p=0.177)$, however, in the $A G$ younger patients have a higher curvature ratio (1.03 vs. $1.02 ; p=0.216$ ). The maximum tortuosity angle is higher in the $C G$ (24.27 vs. $31.75 ; p<0.001)$ and $D G(28.90$ vs. $39.00 ; p=0.019)$. In the $A G$ the maximum tortuosity angle is the same $(p=0.902)$, see table 3 .

The ICC was measured for the tortuosity index (0.92), curvature ratio (0.85), maximum tortuosity (0.89), the level of vertebrae of the maximum tortuosity (0.82) and the zone of the maximum tortuosity (0.80). They are all above 0.80, indicating good reliability of the measurements. 
Table 3. Aortic Tortuosity per group comparing young ( $<70$ y) with old patients ( $>70$ y)

\begin{tabular}{|c|c|c|c|c|c|c|}
\hline & $\begin{array}{l}\text { Control } \\
\text { Mean (std.) }\end{array}$ & P-value & $\begin{array}{l}\text { Dissection } \\
\text { Mean (std.) }\end{array}$ & P-value & $\begin{array}{l}\text { Aneurysmal } \\
\text { Mean (std.) }\end{array}$ & P-value \\
\hline \multicolumn{7}{|l|}{ Tortuosity Index } \\
\hline$<70 y$ & 1.07 (0.038) & $<0.001$ & 1.15 (0.093) & $<0.001$ & $1.23(0.104)$ & 0.001 \\
\hline$>70 y$ & 1.15 (0.089) & & $1.27(0.113)$ & & $1.35(0.150)$ & \\
\hline \multicolumn{7}{|l|}{ Curvature Ratio } \\
\hline$<70 y$ & $1.00(0.010)$ & 0.002 & $1.00(0.023)$ & 0.177 & $1.03(0.035)$ & 0.216 \\
\hline$>70 y$ & $1.01(0.011)$ & & $1.01(0.022)$ & & $1.02(0.027)$ & \\
\hline \multicolumn{7}{|l|}{$\begin{array}{l}\text { Maximum } \\
\text { Tortuosity }\end{array}$} \\
\hline$<70 y$ & $24.27(5.724)$ & $<0.001$ & $28.90(16.451)$ & 0.019 & $44.29(22.904)$ & 0.902 \\
\hline$>70 y$ & $31.75(6.880)$ & & $39.00(18.270)$ & & 43.63 (19.349) & \\
\hline
\end{tabular}

\section{Discussion}

As tortuosity in the descending thoracic aorta is becoming associated with endoleaks, it has to be taken into account during the planning of TEVAR. Hence, we wanted to define the tortuosity of the DTA in patients with thoracic aortic diseases. We found that tortuosity of the DTA is more pronounced in patients with thoracic aortic diseases, especially patients with aneurysmal disease.

When planning for TEVAR it is important to understand what the impact is of tortuosity to obtain durable results. In endovascular aortic repair (EVAR), it has been reported that tortuosity comes with higher displacement forces, which is related to endoleaks ${ }^{20,21}$. Likewise, tortuosity is associated with type $1 \mathrm{~b}$ endoleak after TEVAR ${ }^{3,22}$. To obtain durable results, the landing zone needs to be $<60$ degrees angulation, according to the IFU (Instructions For Use) for multiple stent grafts. In some cases distal extension is the solution to overcome this tortuosity ${ }^{23,24}$. With stent graft extension there is a higher risk of spinal cord ischemia ${ }^{25,26}$, but the question remains if this is the only solution to overcome tortuosity. The literature does not report on this.

With tortuosity being an important risk factor for endoleaks it is necessary to know the cause of an tortuous aorta. Literature shows that aging is of influence in the healthy aorta ${ }^{8}$. However, nothing has been reported about the diseased aorta. A first step for future research is defining the amount of tortuosity that occurs in diseased aortas.

This study shows that the tortuosity index, curvature ratio and the maximum tortuosity is significantly higher in patients with aneurysmal disease, see table 2. 


\section{Chapter 5}

Mainly, as aneurysmal diseases are chronic and occur at a later age compared to dissection, see table 1. It is already known that aging is a risk factor for tortuosity, as the aorta elongates with age. In addition, in aneurysmal diseases the aortic wall is weakened, which can cause an even higher amount of tortuosity ${ }^{12,27}$. These explanations might be the reason why the descending thoracic aorta is more tortuous in DTAA.

A previous study by Belvroy et al. reports that tortuosity is more prominent in the older population ${ }^{11}$. Our study shows the same results for the CG and the DG, see table 3. However in the AG the curvature ratio and the maximum tortuosity angle is slightly higher in the young patient group, both non-significant. The number of patient in each group $(<70: N=48 ;>70: N=21)$ is unequal, which may be the cause for not showing the same tendency as in the CG and DG.

The control group with healthy aortas have a higher incidence of type 1 or 2 arch, see table $1 \&$ figure 3 . Secondly, in our study we see a higher incidence of type 3 arch in patients with dissection. Early structural changes in the aorta are associated with cardiovascular diseases ${ }^{14}$ and again elongation of the aorta with age can cause higher tortuosity in the DTA. In addition, the steep angulation of a type 3 arch, which causes high sheer stress and an increase of hemodynamic forces on the aortic wall ${ }^{28,29}$ can predispose for aortic dissection. However, it can also be a vice versa effect; because of the aneurysmal or dissected changes the geometry proximally and distally can get distorted.

DTAA generally occur at a later age than aortic dissection, see table 1. Older patients have more comorbidity and they have an higher risk of complications after TEVAR ${ }^{30,31}$. However, they benefit from an endovascular repair, as the surgery is less invasive. To optimize and understand the occurrence of complications, like a type $1 \mathrm{~b}$ endoleak which is associated with aortic tortuosity ${ }^{18,22,32}$, it is needed to understand the development of tortuosity in the DTA. These findings help with future planning for TEVAR.

Future studies should focus on the clinical implications of tortuosity after TEVAR as the incidence of high tortuosity in a diseased aorta is relatively high (TBD $=10 \%$; DTAA 14\%). There are two major risks of complications related to tortuosity. First of all, the literature reports on tortuosity being a risk factor for type $1 \mathrm{~b}$ endoleak and this study defines tortuosity in three categories among the diseased aortas, with the highest incidence of a high tortuosity angle in DTAA. A close follow-up period is necessary to catch complications at an early stage. 
Secondly, a high tortuosity angle comes with higher forces, and is related to stent graft migration which can result in a type $1 \mathrm{~b}$ endoleak $20,21,33$. More research is necessary regarding the descending thoracic aorta as a landing zone for TEVAR and the clinical implications of tortuous landing zone.

There are a few limitations to this study. This is a cross-sectional study, while a longitudinal design could be more informative. The follow-up in patients over the years and study the tortuosity occurrence over the years. In addition, cardiovascular comorbidities have not been taken into account. This could have been important as this could have an influence on the aortic wall and thus the tortuosity. Nevertheless, to our knowledge this has been the first study that reports on the geometry in diseased aortas.

Conclusion, this study shows that tortuosity in the descending thoracic aorta is more prominent in diseased aortas, especially for patients with aneurysmal disease. While patients are getting older and benefit from endovascular repair, it is necessary to understand the natural anatomical variation of tortuosity. The clinical implications need to be further explored in future studies, based on the three categories of tortuosity, in order to prevent stent graft related complications in the distal thoracic aorta and to obtain positive long-term outcome after TEVAR. 


\section{References}

1. Riambau V, Böckler D, Brunkwall J, et al. Editor's Choice - Management of Descending Thoracic Aorta Diseases: Clinical Practice Guidelines of the European Society for Vascular Surgery (ESVS). Eur J Vasc Endovasc Surg. 2017;53(1):4-52. doi:10.1016/j.ejvs.2016.06.005

2. Erbel R, Aboyans V, Boileau C, et al. 2014 ESC Guidelines on the diagnosis and treatment of aortic diseases. Jeroen J Bax. doi:10.1093/eurheartj/ehu281

3. Chen CK, Liang IP, Chang HT, et al. Impact on outcomes by measuring tortuosity with reporting standards for thoracic endovascular aortic repair. J Vasc Surg. 2014;60(4):937-944. doi:10.1016/j. jvs.2014.04.008

4. Bowman JN, Silverberg D, Ellozy S, et al. The Role of Anatomic Factors in Predicting Success of Endovascular Repair of Thoracic Aortic Aneurysms. Vasc Endovascular Surg. 2010;44(2):101-104. doi:10.1177/1538574409347392

5. Boufi M, Guivier-Curien C, Dona B, et al. Risk Factor Analysis for the Mal-Positioning of Thoracic Aortic Stent Grafts. Eur J Vasc Endovasc Surg. 2016;52(1):56-63. doi:10.1016/j.ejvs.2016.03.025

6. Redheuil A, Yu W-C, Mousseaux E, et al. Age-Related Changes in Aortic Arch Geometry Relationship With Proximal Aortic Function and Left Ventricular Mass and Remodeling. JAC. 2011;58:1262-1270. doi:10.1016/j.jacc.2011.06.012

7. Craiem D, Casciaro ME, Graf S, et al. Effects of aging on thoracic aorta size and shape: A noncontrast CT study. In: 2012 Annual International Conference of the IEEE Engineering in Medicine and Biology Society. Vol 2012. IEEE; 2012:4986-4989. doi:10.1109/EMBC.2012.6347112

8. Craiem D, Chironi G, Redheuil A, et al. Aging impact on thoracic aorta 3D morphometry in intermediate-risk subjects: looking beyond coronary arteries with non-contrast cardiac CT. Ann Biomed Eng. 2012;40(5):1028-1038. doi:10.1007/s10439-011-0487-y

9. Stulp G, Barrett L. Evolutionary perspectives on human height variation. Biol Rev. 2016;91(1):206234. doi:10.1111/brv.12165

10. Osakabe T, Hayashi M, Hasegawa K, et al. Age- and gender-related changes in ligament components. Ann Clin Biochem. 2001;38(Pt 5):527-532. doi:10.1177/000456320103800510

11. Belvroy VMVM, de Beaufort HWLHWL, Van Herwaarden JAJA, et al. Tortuosity of the descending thoracic aorta: Normal values by age. Kirchmair R, ed. 2019;14(4):e0215549. doi:10.1371/journal. pone.0215549

12. Tsamis A, Krawiec JT, Vorp DA. Elastin and collagen fibre microstructure of the human aorta in ageing and disease: a review. J R Soc Interface. 2013;10(83):20121004. doi:10.1098/rsif.2012.1004

13. O'Rourke MF. Arterial aging: pathophysiological principles. Vasc Med. 2007;12(4):329-341. doi:10.1177/1358863X07083392

14. Lakatta EG, Levy D. Arterial and cardiac aging: major shareholders in cardiovascular disease enterprises: Part I: aging arteries: a set up for vascular disease. Circulation. 2003;107(1):139-146.

15. Marrocco-Trischitta MM, de Beaufort HW, Secchi F, et al. A geometric reappraisal of proximal landing zones for thoracic endovascular aortic repair according to aortic arch types. J Vasc Surg. 2017;65(6):1584-1590. doi:10.1016/j.jvs.2016.10.113

16. Ishimaru S. Endografting of the Aortic Arch. J Endovasc Ther. 2004;11(SupplementII):II-62-II-71. doi:10.1583/04-1407.1

17. Madhwal S, Rajagopal V, Bhatt DL, et al. Predictors of difficult carotid stenting as determined by aortic arch angiography. J Invasive Cardiol. 2008;20(5):200-204.

18. Ueda T, Takaoka H, Raman B, et al. Impact of quantitatively determined native thoracic aortic tortuosity on endoleak development after thoracic endovascular aortic repair. Am J Roentgenol. 2011;197(6):1140-1146. doi:10.2214/AJR.11.6819

19. van Keulen JW, Moll FL, Tolenaar JL, et al. Validation of a new standardized method to measure proximal aneurysm neck angulation. J Vasc Surg. 2010;51(4):821-828. doi:10.1016/j.jvs.2009.10.114

20. Cao P, De Rango P, Verzini F, et al. Endoleak after endovascular aortic repair: classification, diagnosis and management following endovascular thoracic and abdominal aortic repair. J Cardiovasc Surg (Torino). 2010;51(1):53-69. 
21. Molony DS, Kavanagh EG, Madhavan P, et al. A Computational Study of the Magnitude and Direction of Migration Forces in Patient-specific Abdominal Aortic Aneurysm Stent-Grafts. Eur J Vasc Endovasc Surg. 2010;40(3):332-339. doi:10.1016/j.ejvs.2010.06.001

22. Nakatamari $H$, Ueda T, Ishioka F, et al. Discriminant analysis of native thoracic aortic curvature: Risk prediction for endoleak formation after thoracic endovascular aortic repair. J Vasc Interv Radiol. 2011;22(7):974-979. doi:10.1016/j.jvir.2011.02.031

23. Morales JP, Greenberg RK, Lu Q, et al. Endoleaks Following Endovascular Repair of Thoracic Aortic Aneurysm: Etiology and Outcomes. J Endovasc Ther. 2008;15:631-638.

24. Matsumura JS, Melissano G, Cambria RP, et al. Five-year results of thoracic endovascular aortic repair with the Zenith TX2. J Vasc Surg. 2014;60:1-10. doi:10.1016/j.jvs.2014.01.043

25. Scali ST, Wang SK, Feezor RJ, et al. Preoperative prediction of spinal cord ischemia after thoracic endovascular aortic repair. J Vasc Surg. 2014;60(6):1481-1490.e1. doi:10.1016/j.jvs.2014.08.103

26. Hiraoka T, Komiya T, Tsuneyoshi H, et al. Risk factors for spinal cord ischaemia after thoracic endovascular aortic repair. Interact Cardiovasc Thorac Surg. 2018;27(1):54-59. doi:10.1093/icvts/ ivy 037

27. Barrett HE, Cunnane EM, Hidayat $\mathrm{H}$, et al. On the influence of wall calcification and intraluminal thrombus on prediction of abdominal aortic aneurysm rupture. J Vasc Surg. 2018;67(4):1234-1246. e2. doi:10.1016/j.jvs.2017.05.086

28. Nathan DP, Xu C, Gorman JH, et al. Pathogenesis of acute aortic dissection: a finite element stress analysis. Ann Thorac Surg. 2011;91(2):458-463. doi:10.1016/j.athoracsur.2010.10.042

29. Poullis MP, Warwick R, Oo A, et al. Ascending aortic curvature as an independent risk factor for type A dissection, and ascending aortic aneurysm formation: a mathematical model. Eur J Cardiothorac Surg. 2008;33(6):995-1001. doi:10.1016/j.ejcts.2008.02.029

30. Czerny M, Funovics M, Ehrlich M, et al. Risk Factors of Mortality in Different Age Groups After Thoracic Endovascular Aortic Repair. Ann Thorac Surg. 2010;90(2):534-538. doi:10.1016/j. athoracsur.2010.03.096

31. De Rango P, Isernia G, Simonte $G$, et al. Impact of age and urgency on survival after thoracic endovascular aortic repair. J Vasc Surg. 2016;64(1):25-32. doi:10.1016/j.jvs.2015.11.054

32. Kotelis D, Brenke C, Wörz S, et al. Aortic morphometry at endograft position as assessed by 3D image analysis affects risk of type I endoleak formation after TEVAR. Langenbeck's Arch Surg. 2015;400(4):523-529. doi:10.1007/s00423-015-1291-1

33. van Bakel T, Romarowski R, Morganti S, et al. Blood Flow after Endovascular Repair in the Aortic Arch: A Computational Analysis. AORTA. 2018;06(03):081-087. doi:10.1055/s-0039-1683771 



\section{Chapter 6}

\section{Impact of Aortic Tortuosity on Displacement Forces in Descending Thoracic Aortic Aneurysms}

Viony M. Belvroy ${ }^{1,2,3}$, Rodrigo M. Romarowski ${ }^{4}$, Theodorus M.J. van Bakel ${ }^{3,4}$, Joost A. van Herwaarden ${ }^{3}$, Jean Bismuth ${ }^{2}$, Ferdinando Auricchio ${ }^{6}$, Frans L. Mollc, Santi Trimarchig,h

Abstract presented at the

SCVS 47 th Annual Symposium 2019, March $16-20$

Boca Raton, Fl, United States

1 a Thoracic Aortic Research Center, IRCCS Policlinico San Donato, San Donato Milanese, Italy,

b Houston Methodist DeBakey Heart \& Vascular Center, Houston, Texas, United States,

c Department of Vascular Surgery, University Medical Center Utrecht, Utrecht, Netherlands,

d 3D and Computer Simulation Laboratory, IRCCS Policlinico San Donato, San Donato Milanese, Italy

e Department of Cardiothoracic Surgery, Erasmus Medical Center, Rotterdam, Netherlands

f Department of Civil Engineering and Architecture, University of Pavia, Pavia, Italy

g Fondazione IRCCS Ca' Grande Ospedale Maggiore Policlinico Milano, Milan, ItalyDepartment of Health and Community Sciences, University of Milan, Milan, Italy 


\title{
Chapter 6
}

\begin{abstract}
Objective As elastin fibers in the aorta deteriorate with age, the descending thoracic aorta (DTA) becomes longer and more tortuous. In patients with DTA aneurysms, this increased tortuosity may result in a hostile hemodynamic environment for thoracic endovascular aortic repair (TEVAR). The objective of this study was to analyze how increased tortuosity affects hemodynamic displacement forces (DFs) in different segments of the DTA in patients with DTA aneurysms (DTAAs).
\end{abstract}

Methods 30 patients with DTAAs were selected to form three equal groups based on the maximum tortuosity of their DTA: low $<30^{\circ}$, moderate $30^{\circ}-60^{\circ}$ and high $>60^{\circ}$. Computational Fluid Dynamics simulations were performed to calculate DFs in all patients. Image-based segmentations were carried out to create patient-specific models of the aortic geometry. When physiologic simulation results were obtained, the hemodynamic DFs on the aortic wall were calculated in four segments of the DTA (zones 4A-D). To enable comparison of DFs in different segments, the DF was normalized by the aortic wall surface area, the equivalent surface traction (EST).

Results Mean age was 73 years old, 67\% male. In zone 4C, where most tortuosity occurs, the EST in patients with high tortuosity was more than three times higher, than those with low tortuosity (low: $743 \mathrm{~N} / \mathrm{m}^{2}$, moderate: $956 \mathrm{~N}$ / $\mathrm{m}^{2}$, high: $\left.2294 \mathrm{~N} / \mathrm{m}^{2} ; \mathrm{p}=0.004\right)$. These differences could be attributed to the higher sideways components of the DF vectors, which were more than two times greater in patients with high tortuosity compared to patients with low or moderate tortuosity (low: $5.01 \mathrm{~N}$, moderate: $5.50 \mathrm{~N}$, high $13.21 \mathrm{~N} ; \mathrm{p}=0.009$ ).

Conclusion High tortuosity results in increased displacement forces in the distal segments of the DTA. These forces should be taken into account when planning for TEVAR, as they potentially increase the risk of stent-graft related complications, such as migration and endoleak.

Key words: Tortuosity, aneurysm, thoracic aorta, displacement forces, computational fluid dynamics 


\section{Introduction}

Thoracic endovascular aortic repair (TEVAR) is increasingly being used because of its favorable outcomes compared to open surgery. ${ }^{1,2}$ However, stent-graft related complications such as endograft migration and endoleak occur over time and their pathophysiology is not well understood.

To gain insight in the impact of aortic morphology on local hemodynamics, Computational Fluid Dynamic (CFD) modelling techniques can be used. Using patient-specific 3D models of the aorta, CFD can calculate the magnitude and direction of hemodynamic displacement forces (DFs) that work on the surface of the aortic wall and stent-graft. Previous studies have shown that the DF is predominantly directed sideways in the abdominal aorta $^{3}$, while the direction of the DF is upwards in the proximal thoracic aorta ${ }^{4}$. Furthermore, it was found that geometrical characteristics of the aorta, such as tortuosity, affect the magnitude and direction of the DFs ${ }^{3,5}$. This knowledge aids planning for TEVAR, as longer landing zone lengths can be selected to counteract these larger forces and prevent stent graft migration. As elastin fibers in the aorta deteriorate with age, the descending thoracic aorta (DTA) becomes longer and more tortuous. This is associated with formation of endoleaks in the elderly population ${ }^{6}$. The objective of this study was to analyze how increased tortuosity affects hemodynamic displacement forces (DFs) in different segments of the DTA in patients with DTA aneurysms (DTAAs).

\section{Methods}

\section{Patient population}

Thirty patients with a descending thoracic aortic aneurysm (DTAA) were retrospectively selected from our database at the I.R.C.C.S. Policlinico San Donato for this study based on their aortic geometry. The patients were selected by the fusiform appearance of the aneurysm and were all endovascularly treated. The diameter and the extent of the aneurysm was not taken into account. This study was approved by the local ethics committee and the need for informed consent was waived due to the retrospective nature of the study and use of anonymized data. The standard CTA protocol for aortic imaging at our institution includes a 64-multislice computed tomography (CT) scan (SOMATOM Definition AS, 


\section{Chapter 6}

Siemens, Germany) after administration of a contrast agent (lomeron 370, Bracco, Italy). Only CT angiography (CTA) image data with thin cut slices (1.0 mm or 1.5 $\mathrm{mm}$ ) were used. Patients with a history of aortic dissection or aneurysmal disease of the aortic arch were excluded.

\section{Image analysis}

Aortic morphology was analyzed from CTA image data using 3Mensio Vascular software (3Mensio Medical Imaging 8.1 B.V., Bilthoven, The Netherlands). A center lumen line was semi-automatically generated from Ishimaru zone $4^{7}$ (two centimeters distal to the origin of the left subclavian artery (LSA) to the celiac trunk).

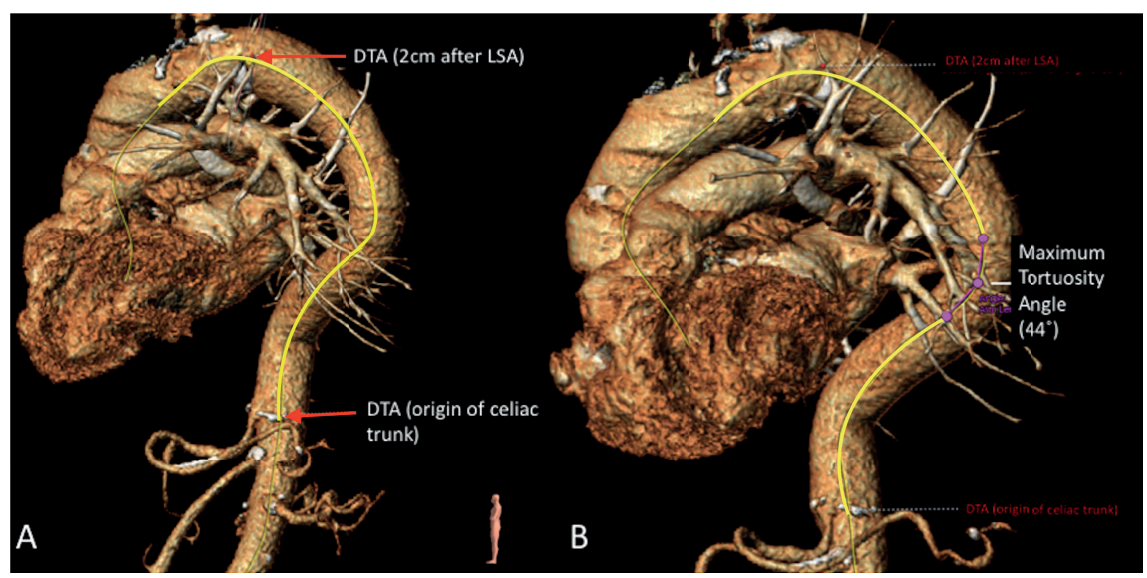

Figure 1. This figure presents an example of the maximum tortuosity angle measurement in 3 Mensio. On the left, the centerline is shown in yellow, our measurements begin $2 \mathrm{~cm}$ distal to the origin of the LSA and end at the origin of the celiac trunk. On the right, the maximum tortuosity angle is presented in pink. LSA = left subclavian artery. Reprinted from Belvroy et al. published by PLOSONE, open access journal ${ }^{14}$.

The tortuosity angle function of 3 Mensio was used to measure the tortuosity in degrees over the centerline in different segments of the DTA ${ }^{8}$. This angle is measured between two line elements that are defined by three control points on the centerline (see Figure 1). The first point is the start of the first line element, the second point is the end of the first and the start of the second line element. The third point is the end of the second line element. The distance between the first and third points was set at $15 \mathrm{~mm}$, the default setting in 3 Mensio. The angle is calculated at point 2 , in between the two line elements. In order to analyze the 
effects of local tortuosity, the center lumen line of the DTA was divided into four segments of equal length: zones 4A-D (Figure 2).

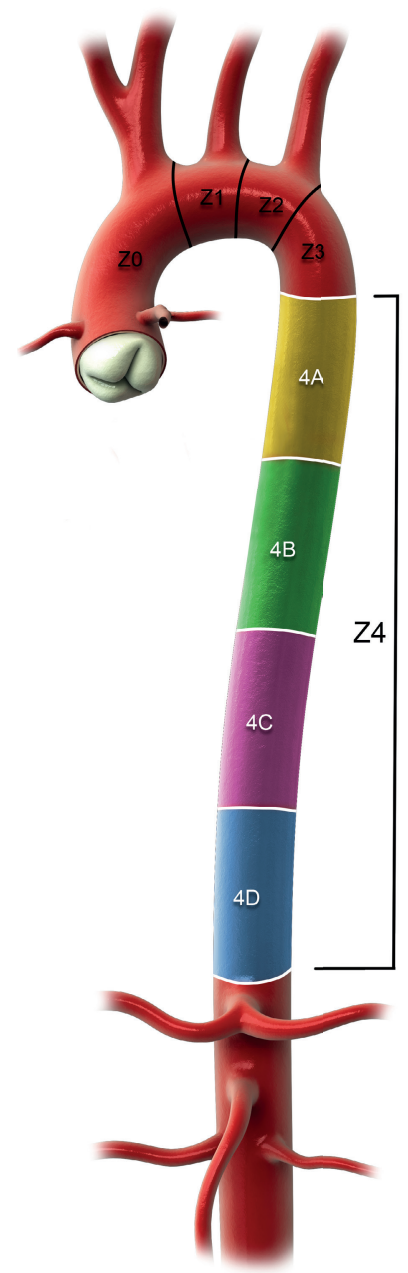

Figure 2. The center lumen line of the DTA was divided in four equal sections that define the segments of Ishimaru's zone 4: 4A (yellow); 4B (green); 4C (purple); 4D (blue). DTA = descending thoracic aorta.

Reprinted from Belvroy et al. published by PLOSONE, open access journal14.

The maximum tortuosity angle was measured in each patient in the DTA and used to categorize their aortic geometry in three groups: group A low tortuosity angle $\left(<30^{\circ}\right)$; group $\mathrm{B}$ moderate tortuosity angle $\left(30^{\circ}-60^{\circ}\right)$; and group $\mathrm{C}$ high tortuosity angle $\left(>60^{\circ}\right)$, see Figure 3 for representative cases. 


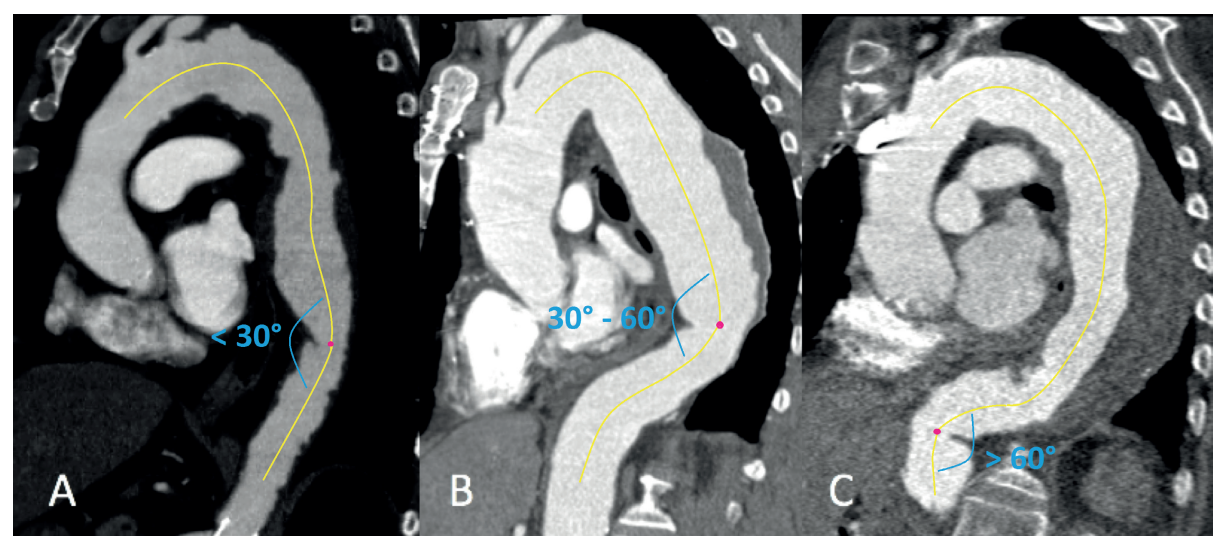

Figure 3. Patients were categorized in three groups based on the maximum tortuosity angle of their DTA. Yellow line represents the centerline and in pink the point of maximum tortuosity: group A: low tortuosity $\left(<30^{\circ}\right)$; group B: moderate tortuosity $\left(30^{\circ}-60^{\circ}\right)$; and group C: high tortuosity $\left(>60^{\circ}\right)$. DTA = descending thoracic aorta.

Reprinted from Belvroy et al. published by PLOSONE, open access journal14.

\section{Computational modelling}

Computational Fluid Dynamics simulations of local hemodynamics in the DTA were performed using similar methods as in our previously published paper on DFs in the proximal landing zones of the aortic arch ${ }^{9}$. In brief, displacement forces are the sum of the pressure and the wall shear stress acting on the aortic wall in a specified segment (i.e. the descending aortic landing zones). Figure IV presents a depiction of the pressure and WSS acting on the aortic wall. It illustrates the pressure and WSS distribution in zone 4A of a patient in the high tortuosity group.

For each patient, a computational model of the aorta was created to study the fluid flows by solving the Navier-Stokes equations, characterizing the motion of an incompressible fluid (i.e. blood). Each model requires the following elements: (1) a three-dimensional (3D) geometric model of the vascular anatomy of interest; and (2) a set of inflow and outflow boundary conditions that represent the physiologic flow and pressure conditions of the subject.

\section{Geometric model construction}

The anatomy of the thoracic aorta was extracted from the CTA image data using the commercially available software Mimics v18.0 (Materialise NV, Leuven, Belgium). The model started at the ascending aorta and ended at the level of the celiac trunk. The proximal segments of the supra-aortic branches were included in the geometric models. 
Subsequently, the 3D aortic models were discretized into a millions of elements using the Vascular Modelling ToolKit (VMTK) v1.3 $3^{10,11}$ to generate computational volume meshes suitable for CFD analysis. An average cutoff of 4 million tetrahedral elements was considered for the simulations. This cutoff was based on a mesh convergence analysis that showed that further mesh refining would have produced a difference of less than $1 \%$ in the computed displacement forces.

\section{Boundary conditions}

As there was no patient specific hemodynamic data available, the same inflow and outflow boundary conditions were applied in all cases. A typical ascending aortic flow waveform representing a cardiac output of $5 \mathrm{~L} / \mathrm{min}$ was assigned at the inlet (ascending aorta). The inlet waveform is previously described by MarroccoTrischitta et al. ${ }^{9}$ At the outlets, 3-element Windkessel circuits were attached to simulate the compliance and resistance of the distal vasculature. We used the parameter values of the Windkessel circuits that were previously reported by Romarowski et $\mathrm{al}^{12}$. Doing so, physiological blood pressure values were measured in all patients (averaging 124/78 $\mathrm{mmHg}$ ). A null velocity on the luminal surface was prescribed, resulting in the assumption of a rigid aortic wall.

\section{Computational analysis}

All the CFD simulations were performed using the open source parallel finite element solver based on C++ library LifeV (www.lifev.org), tailored to blood flow applications ${ }^{13}$. The duration of the cardiac cycle was 1 and each time-step was 0.001 s. The computational analysis was run for six cardiac cycles to ensure the convergence of the velocity and pressure fields ${ }^{12}$.

\section{Post processing}

The CFD simulation results of the last cardiac cycle were post-processed using an in-house developed Python script and Paraview software v5.52 (Kitware Ing., France) to calculate the DF vectors. The DTA was cut along the center lumen line into four equal zones (see Figure II), using a previous reported classification ${ }^{14}$. For each zone, the DF was then calculated by integrating the pressure and wall shear stress acting on the surface of the aortic wall in peak systole.

The magnitude and direction of the displacement force was calculated in all four zones in each patient. Subsequently, the displacement force was normalized 


\section{Chapter 6}

by the aortic wall surface area to calculate the so-called Equivalent Surface Traction (EST). The EST enables comparison of DFs between zones of different size. Finally, the upwards and sideways components of the displacement force vectors were compared for each zone. Equations used for calculating displacement forces are previously reported in the appendix by Marrocco-Trischitta et al. ${ }^{9}$

Statistical analysis

The data were analyzed using SPSS Statistics 23 software (IBM Corp, Armonk, NY). Normality was tested with the Shapiro-Wilk test. Comparison between the three groups was done with the One-way ANOVA for normally distributed data or the Kruskal-Wallis test for non-normally distributed data. Statistical significance was reached when the $p$-value was $<0.05$. The effect of age and gender on tortuosity and the angulation was analyzed calculating a linear regression model. Intra- and inter observer variability was tested with the Intraclass Correlation Coefficient.

\section{Results}

Thirty patients were selected (67\% male) with a mean age of 73 years to create three equal groups $(A-C)$ with a different tortuosity angle (maximum tortuosity angle $<30^{\circ}$; maximum tortuosity angle $30^{\circ}-60^{\circ}$; and maximum tortuosity angle $>60^{\circ}$ ). The DTA was divided in four zones (4A - 4D) to enable analysis of regional tortuosity. In the low and moderate tortuosity group, the maximum tortuosity angle was located in zone $4 \mathrm{~A}$ and in the high tortuosity group this was in zone 4C. Representative examples of the DF per DTA zone in the three groups are presented in Figure 4.
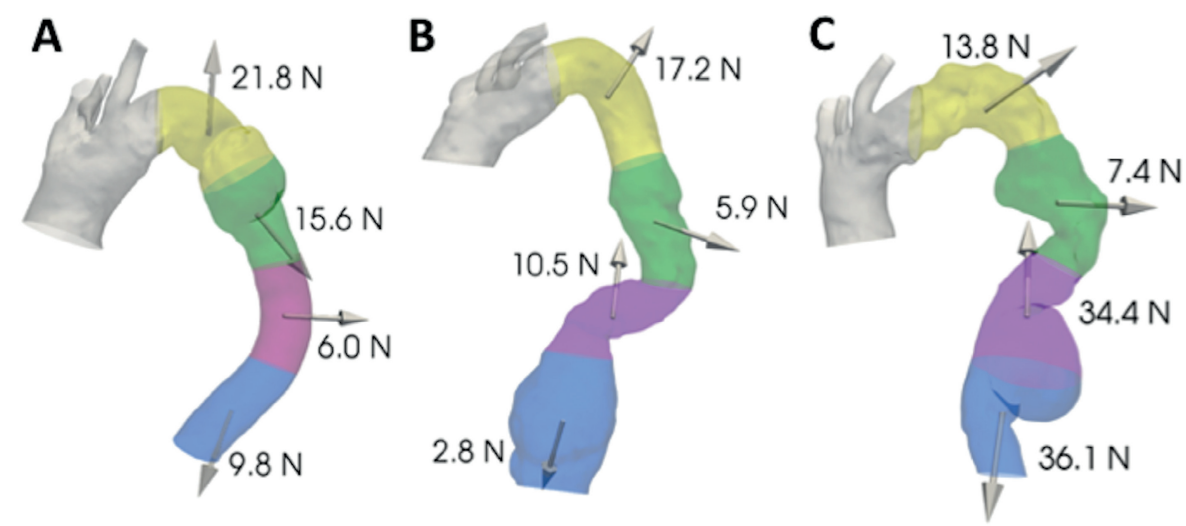
Figure 4. The magnitude and direction of the displacement force vectors in zones 4A-D are shown in representative cases for groups low - moderate - high tortuosity. Interestingly, we note that the magnitude of the displacement force vector increases significantly with increased tortuosity (highest in zone 4C/D of group C), while the trend remains relatively similar between groups.

Table 1 reports the DFs in all DTA zones. The DF was 2-3 times higher in zones $4 \mathrm{~B}, 4 \mathrm{C}$ and $4 \mathrm{D}$ in the high tortuosity group compared to the low and moderate tortuosity groups ( $p=0.021 ; p<0.001 ; p=0.012$ respectively). In the low and moderate tortuosity groups, the DFs in zone $4 \mathrm{~A}$ are twice as high compared to the more distal landing zones ( $p<0.001$ and $p=0.003$ respectively).

Table 1. Displacement Force (DF) in Newton (N) in the different Zones 4A - 4D

\begin{tabular}{|c|c|c|c|c|}
\hline Zones & Low & Moderate & High & $P$ - value \\
\hline \multicolumn{5}{|l|}{ Zone 4A } \\
\hline $\begin{array}{l}\text { Force - N } \\
\text { Range }\end{array}$ & $\begin{array}{l}21.23 \pm 5.55 \\
(17.27-25.20)\end{array}$ & $\begin{array}{l}23.45 \pm 10.46 \\
(15.96-30.93)\end{array}$ & $\begin{array}{l}22.19 \pm 12.76 \\
(13.06-31.32)\end{array}$ & 0.736 \\
\hline \multicolumn{5}{|l|}{ Zone 4B } \\
\hline $\begin{array}{l}\text { Force - N } \\
\text { Range }\end{array}$ & $\begin{array}{l}9.75 \pm 7.60 \\
(4.32-15.19)\end{array}$ & $\begin{array}{l}9.90 \pm 4.86 \\
(6.43-13.38)\end{array}$ & $\begin{array}{l}23.06 \pm 17.55 \\
(10.51-35.61)\end{array}$ & 0.021 \\
\hline \multicolumn{5}{|l|}{ Zone 4C } \\
\hline $\begin{array}{l}\text { Force - N } \\
\text { Range }\end{array}$ & $\begin{array}{l}5.41 \pm 3.11 \\
(3.18-7.63)\end{array}$ & $\begin{array}{l}7.96 \pm 8.56 \\
(1.84-14.08)\end{array}$ & $\begin{array}{l}31.59 \pm 20.88 \\
(16.66-46.53)\end{array}$ & $<0.001$ \\
\hline \multicolumn{5}{|l|}{ Zone 4D } \\
\hline $\begin{array}{l}\text { Force - N } \\
\text { Range }\end{array}$ & $\begin{array}{l}6.51 \pm 5.24 \\
(2.76-10.25)\end{array}$ & $\begin{array}{l}10.41 \pm 6.82 \\
(5.53-15.29)\end{array}$ & $\begin{array}{l}18.98 \pm 11.67 \\
(10.64-27.33)\end{array}$ & 0.012 \\
\hline P - value & $<0.001$ & 0.003 & 0.374 & \\
\hline
\end{tabular}

Data are presented as mean \pm stand deviation (SD) unless otherwise stated.

Table 2 reports the normalized EST. The EST was significantly higher in zone 4C of the high tortuosity group compared to the low and moderate tortuosity groups (low: $743 \mathrm{~N} / \mathrm{m}^{2}$, moderate: $956 \mathrm{~N} / \mathrm{m}^{2}$, high: $2294 \mathrm{~N} / \mathrm{m}^{2} ; \mathrm{p}=0.001$ ). 
Table 2. Equivalent Surface Traction (EST) in Newton per square meter (N/m2) zone 4A $-4 \mathrm{D}$

\begin{tabular}{lllll}
\hline Zones & Low & Moderate & High & P - value \\
\hline Zone 4A & & & & \\
Force $-N$ & $2720 \pm 396$ & $2690 \pm 918$ & $2548 \pm 801$ & 0.859 \\
Range & $(2437-3003)$ & $(2033-3346)$ & $(1975-3121)$ & \\
Zone 4B & & & & \\
Force $-N$ & $1316 \pm 837$ & $1358 \pm 729$ & $2122 \pm 1341$ & 0.150 \\
Range & $(717-1915)$ & $(837-1880)$ & $(1163-3081)$ & \\
Zone 4C & & & & \\
Force $-\mathrm{N}$ & $743 \pm 269$ & $956 \pm 762$ & $2294 \pm 1366$ & 0.001 \\
Range & $(550-935)$ & $(412-1501)$ & $(1317-3271)$ & \\
Zone 4D & & & & \\
Force $-\mathrm{N}$ & $888 \pm 526$ & $1248 \pm 854$ & $2022 \pm 1253$ & 0.037 \\
Range & $(511-1264)$ & $(637-1859)$ & $(1125-2918)$ & \\
P-value & $<0.001$ & $<0.001$ & 0.398 & \\
\hline
\end{tabular}

Data are presented as mean \pm stand deviation (SD) unless otherwise stated.

EST in zones 4A and 4D were significantly different in the low and moderate tortuosity groups (both $p<0.001$ ). In the latter two groups, the maximum tortuosity angle was highest in zone 4A (located close to the aortic arch), and resulted in a significantly higher EST compared to the more distal zone 4D (see Table II). Interestingly, patients in the high tortuosity had an equally high EST in zone $4 \mathrm{~A}$ and $4 \mathrm{~B}$ compared to the low and moderate tortuosity groups. However, there was no decline in the more distal landing zone, resulting in no significant difference in the DTA ( $p=0.398)$.

The DF vector can be divided in an upwards and sideways component that determine the orientation of the force. Comparisons of the sideways and upward components of the DF vector are reported in Tables 3 and IV, respectively. The sideways forces were significantly higher in zone 4C and even two times greater in the high tortuosity group compared to the low and moderate tortuosity groups (low: $5.01 \mathrm{~N}$, moderate: $5.50 \mathrm{~N}$, high $13.21 \mathrm{~N} ; \mathrm{p}=0.009$ ). The upward forces in the high tortuosity group were positive in zone $4 \mathrm{~A}$ and negative in zone $4 \mathrm{C}$, indicating a shift in the orientation of the DF vector from upward to downward in the DTA. The same phenomenon was found in the low and moderate tortuosity groups ( $p$ $<0.001$ in both). 
Figure 5 illustrates the pressure and WSS distribution in zone 4A of a patient in the high tortuosity group.

Table 3. Sideways forces in Newton (N) in Zone 4A - 4D

\begin{tabular}{lllll}
\hline Zones & Low & Moderate & High & P - value \\
\hline Zone 4A & & & & \\
Force $-N$ & $13.95 \pm 6.45$ & $14.35 \pm 8.86$ & $14.03 \pm 5.49$ & 0.817 \\
Range & $(9.34-18.56)$ & $(8.02-10.69)$ & $(10.11-17.96)$ & \\
Zone 4B & & & & \\
$\quad$ Force $-N$ & $7.83 \pm 6.77$ & $8.78 \pm 4.77$ & $15.15 \pm 10.04$ & 0.090 \\
Range & $(2.99-12.68)$ & $(5.37-12.19)$ & $(7.97-22.34)$ & \\
Zone 4C & & & & \\
Force $-\mathrm{N}$ & $5.01 \pm 2.81$ & $5.50 \pm 6.62$ & $14.72 \pm 8.21$ & 0.004 \\
Range & $(3.00-7.03)$ & $(0.77-10.23)$ & $(8.85-20.59)$ & \\
Zone 4D & & & & \\
Force $-\mathrm{N}$ & $4.42 \pm 3.83$ & $7.40 \pm 5.95$ & $10.56 \pm 8.32$ & 0.222 \\
Range & $(1.68-7.16)$ & $(3.14-11.65)$ & $(4.61-16.51)$ & \\
P- value & 0.005 & 0.019 & 0.586 & \\
\hline
\end{tabular}

Data are presented as mean \pm stand deviation (SD) unless otherwise stated.

Table 4. Upwards direction forces in Newton (N) in Zone 4A - 4D

\begin{tabular}{lllll}
\hline Zones & Low & Moderate & High & p-value \\
\hline Zone 4A & & & & \\
Force $-N$ & $14.50 \pm 6.35$ & $16.83 \pm 9.92$ & $13.31 \pm 16.26$ & 0.517 \\
Range & $(9.96-19.04)$ & $(9.73-23.93)$ & $(1.67-24.94)$ & \\
Zone 4B & & & & \\
Force $-N$ & $-0.93 \pm 6.95$ & $-2.77 \pm 3.96$ & $1.09 \pm 23.27$ & 0.834 \\
Range & $(-5.91-4.04)$ & $(-5.60-0.07)$ & $(-15.57-17.72)$ & \\
Zone 4C & & & & \\
Force $-N$ & $-0.67 \pm 2.42$ & $-0.33 \pm 8.13$ & $-5.02 \pm 24.88$ & 0.746 \\
Range & $(-2.40-1.06)$ & $(-6.15-5.49)$ & $(-22.82-12.78)$ & \\
Zone 4D & & & & \\
Force $-\mathrm{N}$ & $-4.53 \pm 3.89$ & $-3.55 \pm 7.54$ & $-3.87 \pm 18.08$ & 0.981 \\
Range & $(-7.32--1.75)$ & $(-8.94-1.85)$ & $(-16.80-9.07)$ & \\
P-value & $<0.001$ & $<0.001$ & 0.105 & \\
\hline
\end{tabular}

Data are presented as mean \pm stand deviation (SD) unless otherwise stated. 


\section{Chapter 6}
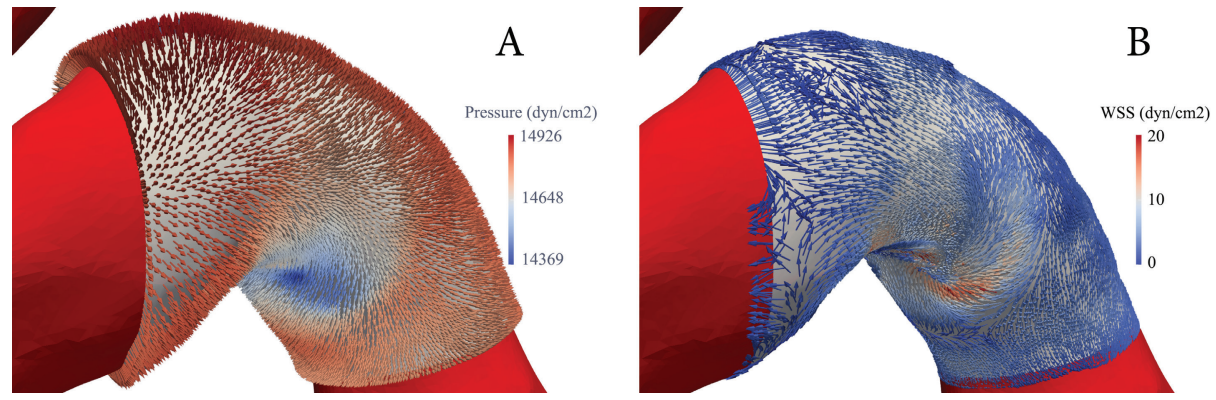

Figure 5. Pressure (A) and WSS (B) distributions in zone 4a of a patient with high tortuosity of the DTA. The displacement force is calculated for each zone by integrating both stresses, calculating the total force exerted on the aortic wall by the pulsatile flow. Please note that the magnitude of the stresses caused by WSS are negligible compared to the stresses induced by blood pressure. DTA = descending thoracic aorta; WSS = wall shear stress

\section{Discussion}

This study shows that higher displacement forces in the DTA are associated with a higher tortuosity angle. Previous study showed that increased angulation of the aortic arch resulted in higher displacement forces in the proximal landing zones of the aortic $\mathrm{arch}^{4}$. In the present study, we investigated how tortuosity in the DTA affects local displacement forces. Again, we found that increased aortic tortuosity is associated with increased hemodynamic DFs. Interestingly, we found that in patients with a high tortuosity angle, highest hemodynamic DFs were located in zone 4C. In contrast, highest DFs in patients with low or moderate tortuosity angles were found in zone 4A. Zone 4A starts after the aortic arch, but can still be slightly angulated, The maximum tortuosity angle was found in zone 4A in the low and moderate tortuosity groups. In the DTA, a high tortuosity angle $\left(>60^{\circ}\right)$ is associated with increased risk of stent-graft related complications, as the DF magnitudes lie within the range of pullout forces described by Rahmani et al. ${ }^{15}$. There are, however, no guidelines that describe how to plan TEVAR in patients with a more tortuous aorta.

Another important observation in this study is related to the direction of the DF vectors and their impact on the stent-graft over time. Patients with a DTAA and high aortic tortuosity, have a high upward force in zone $4 \mathrm{~A}(13.31 \mathrm{~N})$, with simultaneous forces working downward in the distal zones (zones 4C and 4D; $-5.07 \mathrm{~N}$ and $-3.87 \mathrm{~N}$, respectively). In these patients, overlapping segments of a multimodular stent-graft may dislocate over time, resulting in type III endoleak, as the proximal segment of the stent-graft migrates proximally and the distal 
segment migrates distally. To overcome these issues, longer proximal, distal and intermodular sealing zone lengths should be chosen to counteract the increased DFs in patients with high tortuosity.

Previously, it has been reported that angulation can cause higher DFs in the aortic $\operatorname{arch}^{9}$ and the iliac arteries ${ }^{3}$. Furthermore, clinical studies reported stent-graft migration in a longitudinal or caudal direction ${ }^{16}$. The present study shows that the DFs in the DTA have a predominantly sideways orientation. These results are in agreement with the observations of Figueroa at al. ${ }^{3}$, and it has been described that lateral movement (resulting from the DFs) can cause stent-graft instability ${ }^{17}$.

Current stent-graft designs mainly use the radial force resulting from oversizing to secure endograft stability in the proximal and distal landing zones. We argue that when planning TEVAR for a DTAA in the presence of high tortuosity, the use of a stent-graft with active fixation modalities in the sealing zones, such as hooks or additional rings, should be considered ${ }^{18}$. Additionally, the increased hemodynamic forces that act on the surface of the stent-graft need to be taken into account when designing new stent-grafts, as these forces are endured by the stent-graft with every heartbeat and may damage the stent-graft due to material fatigue. This is especially important in younger patient populations with a tortuous morphology of the DTA.

We acknowledge multiple limitations in this study. First, the high computational costs of CFD simulations limited our study population to 30 patients. Performing the same study in a larger patient population could potentially influence the results. Secondly, no patient-specific hemodynamic data was available to validate our simulation results. Acquiring patient-specific flow and pressure data, using e.g. Magnetic Resonance Imaging and invasive pressure measurements, would have enabled clinical validation of our computational results, but this was not feasible. Third, this study is a first step in understanding the flow dynamics in a tortuous aorta. To learn more about the clinical importance it is necessary to investigate the impact of tortuosity and its forces on the stent graft after implantation. This preliminary study creates a base for future studies addressing this topic. Lastly, the CFD simulations performed for this study used a rigid wall assumption. It is possible to model a deformable aortic wall using fluid structure interaction techniques, yet the computational costs of these simulations are significantly higher ${ }^{19}$. Nevertheless, we think our data is valid as it gives an 


\section{Chapter 6}

insight in the displacement forces throughout the DTA and the effect of these limitations may not have a significant influence on the data as it currently shows.

In conclusion, our results showed that higher tortuosity is associated with higher hemodynamic DFs in the DTA. Furthermore, the direction of the DF vector changed from proximal to distal. These findings should be taken into account when planning for TEVAR, as precautions should be taken to prevent stent-graft migration and related complications. In addition, our results can be used in the development of new stent-grafts that account for high tortuosity and hemodynamic DFs in patients with a DTAA. 


\section{References}

1. Goodney PP, Travis L, Lucas FL, Fillinger MF, Goodman DC, Cronenwett JL, et al. Survival after open versus endovascular thoracic aortic aneurysm repair in an observational study of the Medicare population. Circulation. 2011;124(24):2661-9.

2. Gopaldas RR, Huh J, Dao TK, LeMaire SA, Chu D, Bakaeen FG, et al. Superior nationwide outcomes of endovascular versus open repair for isolated descending thoracic aortic aneurysm in 11,669 patients. J Thorac Cardiovasc Surg. 2010;140(5):1001-10.

3. Figueroa CA, Taylor CA, Yeh V, Chiou AJ, Zarins CK. Effect of curvature on displacement forces acting on aortic endografts: a 3-dimensional computational analysis. J Endovasc Ther [Internet]. 2009 Jun [cited 2019 Feb 16];16(3):284-94. Available from: http://jet.sagepub.com/lookup/ doi/10.1583/08-2667.1

4. Figueroa CA, Taylor CA, Chiou AJ, Yeh V, Zarins CK. Magnitude and Direction of Pulsatile Displacement Forces Acting on Thoracic Aortic Endografts. J Endovasc Ther [Internet]. 2009 Jun [cited 2019 Feb 16];16(3):350-8. Available from: http://www.ncbi.nlm.nih.gov/pubmed/19642798

5. Chen J, Gutmark E, Mylavarapu G, Backeljauw PF, Gutmark-Little I. Numerical investigation of mass transport through patient-specific deformed aortae. J Biomech [Internet]. 2014 Jan 22 [cited 2019 Feb 16];47(2):544-52. Available from: http://www.ncbi.nlm.nih.gov/pubmed/24210472

6. Nakatamari H, Ueda T, Ishioka F, Raman B, Kurihara K, Rubin GD, et al. Discriminant analysis of native thoracic aortic curvature: Risk prediction for endoleak formation after thoracic endovascular aortic repair. J Vasc Interv Radiol [Internet]. 2011;22(7):974-9. Available from: http://dx.doi. org/10.1016/j.jvir.2011.02.031

7. Ishimaru S. Endografting of the Aortic Arch. J Endovasc Ther [Internet]. 2004 Dec [cited 2018 Mar 29];11(SupplementII):II-62-II-71. Available from: http://www.ncbi.nlm.nih.gov/pubmed/15760265

8. van Keulen JW, Moll FL, Tolenaar JL, Verhagen HJM, van Herwaarden JA. Validation of a new standardized method to measure proximal aneurysm neck angulation. J Vasc Surg [Internet]. 2010 Apr [cited 2018 Oct 10];51(4):821-8. Available from: http://www.ncbi.nlm.nih.gov/ pubmed/20347677

9. Marrocco-Trischitta MM, van Bakel TM, Romarowski RM, de Beaufort HW, Conti M, van Herwaarden JA, et al. The Modified Arch Landing Areas Nomenclature (MALAN) Improves Prediction of Stent Graft Displacement Forces: Proof of Concept by Computational Fluid Dynamics Modelling. Eur J Vasc Endovasc Surg [Internet]. 2018 Apr [cited 2019 Mar 7];55(4):58492. Available from: https://linkinghub.elsevier.com/retrieve/pii/S1078588417307712

10. Morbiducci U, Ponzini R, Rizzo G, Cadioli M, Esposito A, De Cobelli F, et al. In vivo quantification of helical blood flow in human aorta by time-resolved three-dimensional cine phase contrast magnetic resonance imaging. Ann Biomed Eng [Internet]. 2009 Mar 6 [cited 2018 Nov 27];37(3):516-31. Available from: http://link.springer.com/10.1007/s10439-008-9609-6

11. Antiga L, Piccinelli M, Botti L, Ene-lordache B, Remuzzi A, Steinman DA. An image-based modeling framework for patient-specific computational hemodynamics. Med Biol Eng Comput [Internet]. 2008 Nov 11 [cited 2018 Nov 27];46(11):1097-112. Available from: http://www.ncbi.nlm. nih.gov/pubmed/19002516

12. Romarowski RM, Lefieux A, Morganti S, Veneziani A, Auricchio F. Patient-specific CFD modelling in the thoracic aorta with PC-MRI-based boundary conditions: A least-square three-element Windkessel approach. Int j numer method biomed eng [Internet]. 2018 Nov [cited 2019 Mar 21];34(11):e3134. Available from: http://doi.wiley.com/10.1002/cnm.3134

13. Passerini T, Quaini A, Villa U, Veneziani A, Canic S. Validation of an open source framework for the simulation of blood flow in rigid and deformable vessels. Int j numer method biomed eng [Internet]. 2013 Nov [cited 2019 Mar 21];29(11):1192-213. Available from: http://doi.wiley. com/10.1002/cnm.2568

14. Belvroy VMVM, de Beaufort HWLHWL, Van Herwaarden JAJA, Bismuth J, Moll FLFL, Trimarchi S. Tortuosity of the descending thoracic aorta: Normal values by age. Kirchmair R, editor. 2019 Apr 23 [cited 2019 Apr 24];14(4):e0215549. Available from: http://dx.plos.org/10.1371/journal. pone.0215549 


\section{Chapter 6}

15. Rahmani S, Grewal IS, Nabovati A, Doyle MG, Roche-Nagle G, Tse LW. Increasing angulation decreases measured aortic stent graft pullout forces. J Vasc Surg. 2016;63(2):493-9.

16. Cao P, Verzini F, Zannetti S, De Rango P, Parlani G, Lupattelli L, et al. Device migration after endoluminal abdominal aortic aneurysm repair: analysis of 113 cases with a minimum follow-up period of 2 years. J Vasc Surg [Internet]. 2002 Feb [cited 2019 Mar 7];35(2):229-35. Available from: http://www.ncbi.nlm.nih.gov/pubmed/11854719

17. Rafii BY, Abilez OJ, Benharash P, Zarins CK. Lateral movement of endografts within the aneurysm sac is an indicator of stent-graft instability. J Endovasc Ther [Internet]. 2008 Jun [cited 2019 Mar 7];15(3):335-43. Available from: http://jet.sagepub.com/lookup/doi/10.1583/08-2422.1

18. Ongstad SB, Miller DF, Panneton JM. The use of EndoAnchors to rescue complicated TEVAR procedures. J Cardiovasc Surg (Torino) [Internet]. 2016 Oct [cited 2017 Nov 20];57(5):716-29. Available from: http://www.ncbi.nlm.nih.gov/pubmed/27465392

19. Brown AG, Shi Y, Marzo A, Staicu C, Valverde I, Beerbaum P, et al. Accuracy vs. computational time: translating aortic simulations to the clinic. J Biomech. 2012;45(3):516-23. 
CFD in tortuous DTAA 



\section{Part 3: \\ Dynamics in the ascending thoracic aorta}





\section{Chapter 7}

\section{Important Longitudinal and Circumferential Pulsatile Changes in zone 0 of the Aorta during the Cardiac Cycle}

Viony M. Belvroy ${ }^{1,2}$; M. Mujeeb Zubairi; Joost A. van Herwaarden²; Santi Trimarchi3,4; Frans L. Moll2; Jean Bismuth ${ }^{1}$

Abstract accepted for presentation at

SCVS (Society for Clinical Vascular Surgery) 48 ${ }^{\text {th }}$ Symposium 2020,

March 14-18

Huntington Beach, $\mathrm{Ca}$, United States

1 Houston Methodist DeBakey Heart \& Vascular Center, Houston, Texas, United States

2 Department of Vascular Surgery, University Medical Center, Utrecht, Utrecht, Netherlands

3 Fondazione IRCCS Ca' Grande Ospedale Maggiore Policlinico Milano, Milan, Italy

4 Department of Clinical and Community Sciences, University of Milan, Milan, Italy 


\section{Abstract}

Objective During the cardiac cycle the aorta moves in longitudinal and circumferential directions. Correct stent graft sizing is important when planning for thoracic endovascular repair in Zone 0. As the movements of the aorta are constantly evolving during the cardiac cycle, diameter may not be the only important measurement. The aim of this study is to investigate the need for additional measurements when planning for thoracic endovascular repair in Zone 0.

Methods Ninety-two patients, who were evaluated for trans-catheter aortic valve replacement, were selected for this retrospective study. Their electrocardiogram-gated cardiac computed tomography was analyzed. We identified diameters, area, perimeter and lengths of the thoracic aorta in zone 0 (ZO). The measurements were made in multi-planar views perpendicular to the semi-automatically created centerline in both systolic and diastolic phases.

Results The mean age of our study cohort was $77 \pm 11$ years. The mean area change $\left(\mathrm{mm}^{2}\right)$, perimeter change $(\mathrm{mm})$ and maximum diameter change $(\mathrm{mm})$ were compared during the cardiac cycle at three different locations in the ascending aorta. At the sinotubular junction (0.78 vs. 0.89 vs. $1.41 ; p<0.001), 4 \mathrm{~cm}$ proximal to the BCA (0.72 vs. 0.68 vs. $0.81 ; p<0.001)$ and at the proximal edge of the BCA (0.76 vs. 0.73 vs. $0.73 ; p<0.001)$. The change in percentage is the smallest in the area for zone OA compared to the perimeter and diameter (2.6\% vs. 3.1\% vs. $4.7 \%$ ).

Conclusion This study shows the difference in measurements in the ascending aorta. The variance in the diameter is greater than in the area and it is important to understand the potential clinical implications of this finding. Especially in zone OA where the changes are more pronounced. It may be necessary to measure the area and perimeter when planning for thoracic endovascular repair to maximize results. A prospective study comparing these different measurements regarding the outcomes is advised by the authors to understand the clinical implications.

Key words: ascending aorta, cardiac motion, thoracic endovascular aortic repair, TEVAR, 


\section{Introduction}

Aortic diseases in the ascending thoracic aorta (ATA) is becoming more commonly treated with endovascular repair ${ }^{1}$. For correct endograft sizing the diameter of the ATA is of importance. Incorrect sizing may result in complications like endoleaks or stent graft migration ${ }^{2}$. The aortic diameter is commonly measured in magnetic resonance imaging (MRI) and computed tomography (CT) and more recently electrocardiography (ECG)-gated CT has been added as a new imaging modality to obtain the aortic diameter when planning for thoracic aortic endovascular repair (TEVAR) ${ }^{3}$. The difference in diameter during the cardiac cycle is important for stent graft sizing. However, only a few studies have been conducted to investigate these differences and their importance. During the cardiac cycle the ATA moves in multiple directions, which results in not only diameter changes, but also longitudinal and circumferential directions. With these movements the aorta can even change into an oval shape, instead of keeping its round form throughout the cardiac cycle. This makes aortic planning even more challenging, especially when the landing zone is in Zone 0 . A recently published article on a new classification in Zone 0 shows an important difference ${ }^{4}$. Treatment close to the aortic root predicts worse outcomes. They suggest devices should be tailored to the aortic pathology and location and its characteristics.

As the movements of the aorta are constantly evolving during the cardiac cycle, diameter may not be the only important measurement. The aim of this study is to investigate whether other measurements, like area and/or perimeter, are more precise when planning for thoracic endovascular repair in Zone 0.

\section{Methods}

This study was approved by the local institutional review board and the need to obtain informed consent was waived, due to the retrospective character of this study and the use of anonymized data.

\section{Patient selection}

Ninety-two patients were included for morphometric analysis in this study. The patient underwent ECG gated CTA for the evaluation of Transcatheter Aortic Valve Replacement (TAVR) and the scans were retrospectively gated. Measurements of the maximum and minimum diameters and lengths of the thoracic aorta were collected. A protocol was established to do the measurement during different 


\section{Chapter 7}

phases of the cardiac cycle, respectively systole, diastole and a $R-R$ interval between $30-40 \%$ and $70-80 \%$ of the systolic and diastolic phases for all patients.

Exclusion criteria were patients with aortic dissection, TEVAR and left ventricular ejection fraction $<40 \%$. CTA scans without systolic or diastolic phases were also excluded.

\section{Morphometric measurements}

Different measurements were taken from the ascending aorta at three different locations. Zone OA (sinotubular junction (STJ)), zone OB (4 cm proximal to brachiocephalic artery (BCA), and zone OC (proximal edge of the BCA)(figure 1). The measurement location points were based on Roselli's et al. classification ${ }^{4}$.

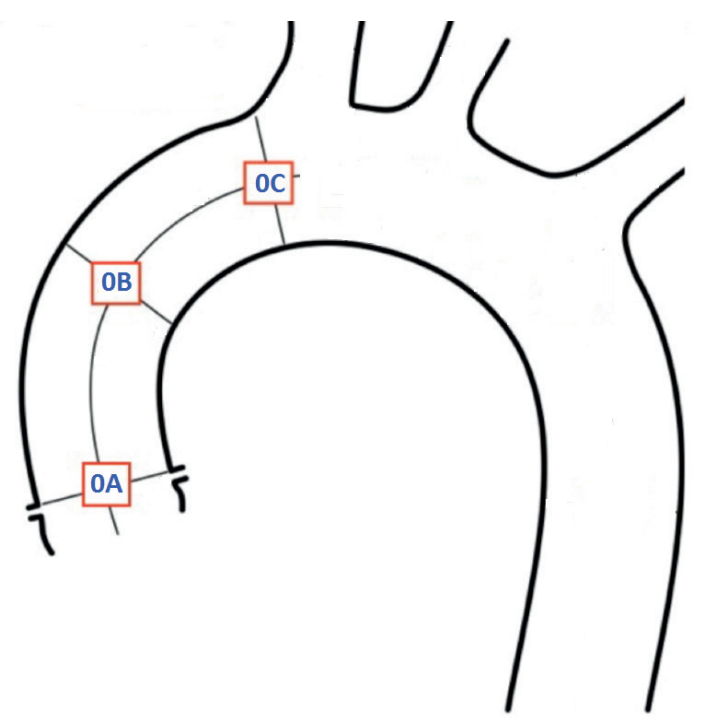

Figure 1. Locations of the measurements in the ascending aorta; Group OA: Sinotubular Junction (STJ), Group OB: Mid Ascending, Group OC: proximal brachiocephalic artery (BCA)

Measurements were made using a commercially available software (Syngo.Via, Siemens Healthcare GmbH, Germany). These were made in multi-planar views perpendicular to the semi-automatically created centerline in both systolic and diastolic phases (figure 2). An initial validation study was performed for ten patients to ensure inter and intra user consistency using the intra-correlation coefficient (ICC). These measurements were made independently by two physicians. Final measurements for 92 patients were made by one physician. 
Agatston score was used to calculate ascending, arch and descending thoracic aortic calcium similar to the way it is used to calculate coronary calcium. Total thoracic calcium was the sum of ascending, arch and descending calcium content in Hounsfield units (HU). These calculations are a built-in function on Syngo.via software.

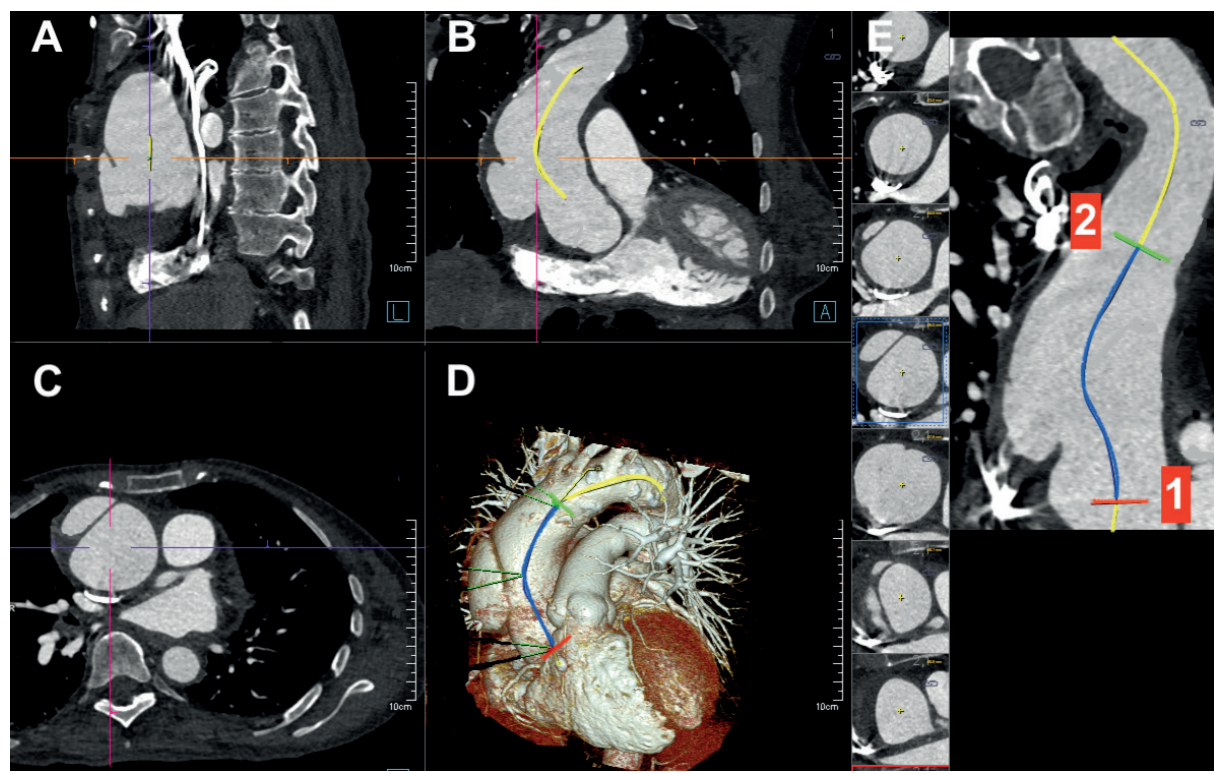

Figure 2. Multiplanar views of aortic measurements in sagittal view (A), frontal (B), axial $(C)$, three-dimensional (D) and the centerline of the ascending aorta (E) with; 1) location of the sinotubular junction and 2) the proximal brachiocephalic artery.

\section{Statistical analysis}

The data was analyzed using SPSS Statistics 23 software (IBM Corp, Armonk, NY). Normality was tested with the Shapiro Wilk test. Comparison between the two groups was done with the paired sample T-test for normally distributed data or the Wilcoxon signed-rank test for non-normally distributed data.

\section{Results}

The mean age of our study cohort was $77 \pm 11$ years and $53.3 \%$ were male. The population was mainly Caucasian (76.1\%) and other baseline characteristics are found in table 1. The most common comorbidities of the study population are hypertension (91.3\%), smoking (46.7\%), diabetes (40.2\%), CAD (46.7\%) and aspirin use (50.2\%), see table 2 . 
Chapter 7

Table 1. Baseline characteristics

\begin{tabular}{|c|c|c|c|}
\hline & & $\begin{array}{l}\text { Mean (std.) } \\
(\mathrm{N}=92)\end{array}$ & $\begin{array}{l}\text { Total }(\%) \\
(\mathrm{N}=92)\end{array}$ \\
\hline \multicolumn{2}{|c|}{ Age } & $77.0(10.8)$ & \\
\hline \multicolumn{2}{|c|}{ Male } & & 49 (53.3) \\
\hline \multicolumn{4}{|c|}{ Blood pressure $(\mathrm{mmHg})$} \\
\hline- & Systole & $137(22)$ & \\
\hline- & Diastole & $69(12)$ & \\
\hline \multicolumn{3}{|c|}{ Race } & - \\
\hline- & Caucasian & & $70(76.1)$ \\
\hline- & Afro American & & $9(9.8)$ \\
\hline- & Hispanic & & $11(12.0)$ \\
\hline- & Other & & $2(2.2)$ \\
\hline \multicolumn{2}{|c|}{ Height (ins.) } & $67.9(13.2)$ & \\
\hline \multicolumn{2}{|c|}{ Weight (Ibs.) } & $178.2(44.8)$ & \\
\hline \multicolumn{2}{|c|}{$\mathrm{BMI}^{*}\left(\mathrm{~kg} / \mathrm{m}^{2}\right)$} & $28.4(6.4)$ & \\
\hline \multicolumn{2}{|c|}{ LVEF* (\%) } & $62.2(11.9)$ & \\
\hline \multicolumn{2}{|c|}{ Aortic Valve Gradient (mmHg) } & $41.8(14.2)$ & \\
\hline
\end{tabular}

* $\mathrm{BMI}=$ body mass index; LVEF = left ventricular ejection fraction

Table 2. The comorbidity of patients in percentages

\begin{tabular}{ll}
\hline & Total (\%) \\
& $(\mathrm{N}=92)$ \\
\hline Diabetes & $37(40.2)$ \\
ESRD* & $5(5.4)$ \\
Smoking & $43(46.7)$ \\
Chronic Kidney Disease & $32(34.8)$ \\
Hypertension & $84(91.3)$ \\
CAD* & $43(46.7)$ \\
Prior PCl* & $18(19.6)$ \\
Prior CABG* & $13(14.1)$ \\
Atrial Fibrillation & $27(29.3)$ \\
Cerebral Vascular Accident & $12(13.0)$ \\
Peripheral Arterial Disease & $11(12.0)$ \\
Dyslipidemia & $71(77.2)$ \\
COPD* & $7(7.6)$ \\
Hypercoagulation disorder & $4(4.3)$ \\
Aspirin use & $46(50.0)$ \\
Antiplatelet use & $28(30.4)$ \\
Anticoagulation use & $22(23.9)$ \\
Steroid use & $5(5.4)$ \\
ACE-inhibitor use* & $30(32.6)$ \\
\hline
\end{tabular}

* $\mathrm{ACE}$ = angiotensin converting enzyme; $\mathrm{CAD}=$ coronary arterial disease;

$\mathrm{CABG}=$ coronary artery bypass graft; $\mathrm{COPD}=$ chronic obstructive pulmonary disease;

$E S R D=$ end stage renal disease. 
The measurements were taken at three different locations in the ATA (zone OA, OB and $\mathrm{OC})$. We recorded the mean area change $\left(\mathrm{mm}^{2}\right)$, perimeter change $(\mathrm{mm})$ and maximum diameter change $(\mathrm{mm})$ and comparing these measurements during the cardiac cycle. At zone OA (0.78 vs. 0.89 vs. 1.41; p<0.001), zone 0B (0.72 vs. 0.68 vs. $0.81 ; p<0.001)$ and at zone $0 \mathrm{C}(0.76$ vs. 0.73 vs. 0.73; $<<0.001)$, see table 3 .

The mean change in area (in percentage) has a narrow range in the three groups (i.e. Zone $\mathrm{OA}=2.6 \%$, Zone $\mathrm{OB}=2.1 \%$, Zone $\mathrm{OC}=2.4 \%$ ), the mean perimeter change (Zone $\mathrm{OA}=3.1 \%$, Zone $\mathrm{OB}=2.1 \%$, Zone $\mathrm{OC}=2.4 \%)$, and the mean diameter change has the widest range (Zone $O A=4.7 \%$, Zone $O B=2.3$, Zone $O C=2.3 \%)$. As the area change has the most narrow range, it is likely the best measurement for TEVAR planning. The largest diameter change is in zone OA with $4.7 \%$ and even in zone $\mathrm{OB}$ it can be up to $17.8 \%$, see table 3 .

Table 3. Changes in mean aortic area, aortic perimeter and maximum diameter in the ascending aorta (ZO) at three different locations per cardiac cycle.

\begin{tabular}{llll}
\hline & Zone OA & Zone OB & Zone OC \\
\hline Area change & & & \\
Mean (\%) & & & \\
Min & $2.6 \%$ & $2.1 \%$ & $2.4 \%$ \\
Max & $0.00 \%$ & $0.00 \%$ & $0.00 \%$ \\
SD & $12.5 \%$ & $12.7 \%$ & $10.1 \%$ \\
Mean (mm) & 3.006 & 2.474 & 2.107 \\
Min & & & \\
Max & 0.78 & 0.72 & 0.76 \\
SD & 0.00 & 0.00 & 0.00 \\
\hline Perimeter change & 4.30 & 4.70 & 3.40 \\
& 0.930 & 0.844 & 0.672 \\
Mean (\%) & $3.1 \%$ & $2.1 \%$ & $2.4 \%$ \\
Min & & & \\
Max & $0.00 \%$ & $0.00 \%$ & $0.00 \%$ \\
SD & $13.7 \%$ & $15.2 \%$ & $10.8 \%$ \\
Mean (mm) & 3.663 & 2.828 & 2.294 \\
Min & & & \\
Max & 0.89 & 0.68 & 0.73 \\
SD & 0.00 & 0.00 & 0.00 \\
\hline$-\ldots$ & 3.90 & 5.00 & 3.30 \\
\hline & 1.068 & 0.927 & 0.700 \\
\hline
\end{tabular}


Table 3. Continued

\begin{tabular}{llll}
\hline & Zone OA & Zone OB & Zone OC \\
\hline Maximum diameter change & & & \\
Mean (\%) & & & \\
Min & $4.7 \%$ & $2.3 \%$ & $2.3 \%$ \\
Max & $0.00 \%$ & $0.00 \%$ & $0.00 \%$ \\
SD & $15.4 \%$ & $17.8 \%$ & $9.4 \%$ \\
& 3.677 & 2.849 & 2.337 \\
Mean (mm) & & & \\
Min & 1.41 & 0.81 & 0.73 \\
Max & 0.00 & 0.00 & 0.00 \\
SD & 4.10 & 5.90 & 3.10 \\
& 1.135 & 0.985 & 0.745 \\
\hline p-value & $<0.001$ & $<0.001$ & $<0.001$ \\
\hline
\end{tabular}

Intra- and inter-rater reliability was evaluated using the ICC. Intra-observer analysis showed good correlation for aortic diameter (ICC 0.99; mean difference $-0.001 \pm 0.52 \mathrm{~mm}$ ). Inter-observer analysis also showed good correlation for aortic diameter (ICC 0.97; mean difference $0.14 \pm 1.08 \mathrm{~mm}$ )(figure 3).
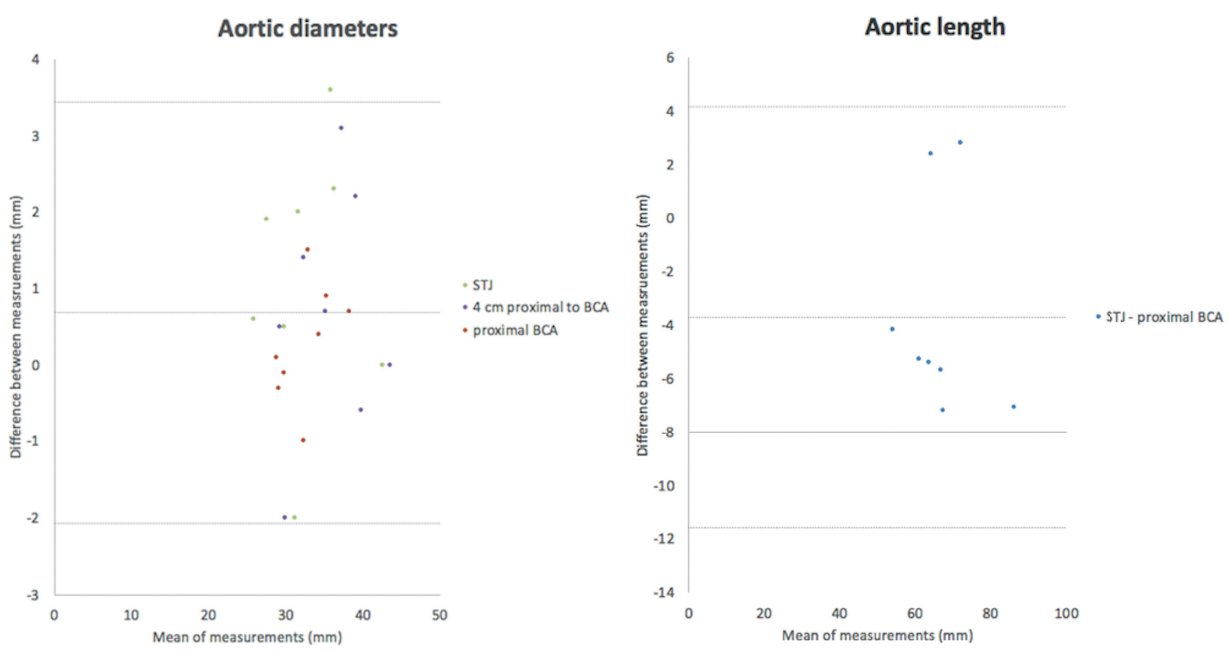

Figure 3. Bland Altman plots showing inter-observer variability for aortic diameter (left) and aortic length measurements (right).

\section{Discussion}

The aim of this study was to assess if other measurements in the ATA are more precise when planning for Zone 0 TEVAR. The ATA moves within the thoracic cavity, but is restricted by its attachments and side branches so it is not able to 
move freely. When the aorta moves in different directions, its natural round shape can take on a variety of different configurations, like an oval or in some cases a pear shape. In the ECG-gated CTA scans, motion is an integral part of the study and as such can delineate aortic movements with a higher degree of fidelity. Measuring only the diameter can result in inappropriate oversizing of the stent graft when planning for TEVAR. Oversizing of the stent graft is most effective in the range of $10-20 \%{ }^{5,6}$. Although, it is clear that in clinical practice stent graft implantation is often outside the instructions of use (IFU). It is our opinion and experience that due to the extreme motions in the ascending aorta, it is imperative to follow the IFU on how to measure inner or outer diameter?. In an article Tolenaar et al. showed that the difference in oversizing $(<10 \%, 10-20 \%$ or $>20 \%)$ did not result in a significant difference between stent graft related complications ${ }^{8}$.

Previous studies have investigated the effect of aortic pulsatility and movement of the $A T A^{9,10}$. Prehn et al. studied the effect of movement during the cardiac cycle ${ }^{9}$. Looking at the mean area and diameter change and the center of mass (COM) movement using dynamic ECG-gated CTA, they conclude that the dynamics of the aorta have a wide range and advise that future endograft designs should consider these movements to obtain durability, adequate sealing zones and clinical success ${ }^{9}$. However, they did not compare the variance in area versus diameter in Zone $0 \mathrm{~A}-\mathrm{C}$. The second study, by Rengier et al., tested the hypothesis that distension and displacement are substantial throughout the thoracic aorta ${ }^{10}$. Studying the COM and the diameter in ECG-gated CTA scans shows a mean aortic diameter change (in patients $>50$ years) of $5.4 \pm 2.0 \%$ and a COM displacement of $20.8 \pm 4.8 \%$ in the ATA. It should be noted that women have greater distension and displacement than men $(p<0.001)^{10}$. The difference of diameter change during the cardiac cycle gives an extra risk of incorrect oversizing. Yet another study analyzed the effect of respiratory movement on the aorta ${ }^{11}$ showing that the impact of respiratory movement was most pronounced in the ATA.

Dynamic imaging has become widely available and is more commonly used in pre-operative planning for TEVAR and seems to be most relevant in the ascending aorta. Muhs et al. studied the area and diameter change in the thoracic aorta, however, mainly in the aortic arch and descending aorta, with a diameter change at three centimeter distal to the left subclavian artery (LSA) of $17.8 \%{ }^{12}$. This results in an aortic mismatch when stent graft oversizing is closer 


\section{Chapter 7}

to $10 \%$. A study by Van Bogerijen et al. discussed the use of dynamic imaging and its advantages ${ }^{3}$. In conclusion they noted that dynamic imaging as a new imaging modality can help in pre-operative planning for more accurate stent graft selection and oversizing and post-operatively help in evaluating the endograft performance. Our results seem to corroborate these findings.

Even though, the study population consists of patients being evaluated for TAVR, the population is relatively similar. The mean age of 77 years of age is similar for a vascular patient and they tend to have the same comorbidities. The difference in mean change is largest in zone OA for the diameter (i.e. 4.7\%). Literature reports that closer to the aortic root the aorta has a wider range, which correlates with our results. The range of diameters is between $9.4-17.8 \%$, perimeter change $10.8-15.2 \%$ and in area $10.1-12.7 \%$. As previously mentioned, the amount of oversizing is between $10-20 \%$ and results in an aortic mismatch when using the diameter for endograft sizing ${ }^{6}$. Essentially, the same difference was found by Muhs et al. They reported the 17.8\% change in the descending thoracic aorta ${ }^{12}$. Based on our results the most precise measurement for correct endograft sizing seems to be the area. The range is not as wide compared to the diameter and perimeter measurements and the mean change in percentage is similar at all three locations (i.e. $2.1-2.6 \%$, see table 3 ).

This study has a few limitations. As mentioned before the study population consists of TAVR patients, however, they are similar to the TEVAR population regarding age and comorbidities. Nevertheless, the results might be different when there are vascular diseases, like aneurysmal or dissected aorta. Still, it gives a good insight and can be used for future comparison as a reference point. Secondly, a gross part of the measurements were done by a single physician, still the intra-observer variability analysis showed only a slight difference of under 1 $\mathrm{mm}$. The inter-observer variability analysis on the 10 patients in the pilot study showed similar results.

Nowadays, ECG-gated scanning is becoming more available and much more widely used for TEVAR planning. However, it is still unknown which phase is the most accurate and results in the lowest complication rate, as the dimensions differ between the systolic and diastolic phases ${ }^{13}$. A study by Csobay-Novák et al. mention that images at 30\% of the heart cycle have the largest diameter throughout the aorta ${ }^{14}$. 
The authors recommend studying the effect of these measurements in a prospective study. The differences in outcome using the diameter, the area or the perimeter for correct endograft sizing. Likewise, taking into account which phase of the ECG-gated CTA scan is most accurate for TEVAR planning, and yields the best clinical results.

In conclusion, this study shows that measuring the diameter may result in less accurate endograft sizing with a range rate of up to $17.8 \%$. Measuring the area or perimeter instead seems more precise when planning for TEVAR. However, these findings need to be further investigated in a prospective study to understand the clinical implications. 


\section{References}

1. Baikoussis NG, Antonopoulos CN, Papakonstantinou NA, Argiriou M, Geroulakos G. Endovascular stent grafting for ascending aorta diseases. J Vasc Surg. 2017 Nov;66(5):1587-601.

2. Zimpfer D, Schoder M, Gottardi R, Lammer J, Wolner E, Grimm M, et al. Treatment of Type V Endoleaks by Endovascular Redo Stent-Graft Placement. Ann Thorac Surg. 2007 Feb;83(2):6646.

3. van Bogerijen GHW, van Herwaarden JA, Conti M, Auricchio F, Rampoldi V, Trimarchi S, et al. Importance of dynamic aortic evaluation in planning TEVAR. Ann Cardiothorac Surg. 2014 May;3(3):300-6.

4. Roselli EE, Idrees JJ, Johnston DR, Eagleton MJ, Desai MY, Svensson LG. Zone zero thoracic endovascular aortic repair: A proposed modification to the classification of landing zones. J Thorac Cardiovasc Surg. 2018 Apr;155(4):1381-9.

5. Sincos IR, Aun R, da Silva ES, Belczak S, de Lourdes Higuchi M, Gornati VC, et al. Impact of Stent-Graft Oversizing on the Thoracic Aorta: Experimental Study in a Porcine Model. J Endovasc Ther. 2011 Aug;18(4):576-84.

6. van Prehn J, Schlösser FJ V, Muhs BE, Verhagen HJM, Moll FL, van Herwaarden JA. Oversizing of aortic stent grafts for abdominal aneurysm repair: a systematic review of the benefits and risks. Eur J Vasc Endovasc Surg. 2009 Jul;38(1):42-53.

7. lezzi R, Dattesi R, Pirro F, Nestola M, Santoro M, Snider F, et al. CT Angiography in Stent-Graft Sizing: Impact of Using Inner vs. Outer Wall Measurements of Aortic Neck Diameters. J Endovasc Ther. 2011 Jun;18(3):280-8.

8. Tolenaar JL, Jonker FHW, Moll FL, van Herwaarden J, Morasch MD, Makaroun MS, et al. Influence of Oversizing on Outcome in Thoracic Endovascular Aortic Repair. J Endovasc Ther. 2013;20(6):738-45

9. van Prehn J, Vincken KL, Muhs BE, Barwegen GKW, Bartels LW, Prokop M, et al. Toward endografting of the ascending aorta: insight into dynamics using dynamic cine-CTA. J Endovasc Ther. 2007 Aug 25;14(4):551-60.

10. Rengier F, Weber TF, Henninger V, Böckler D, Schumacher H, Kauczor H-U, et al. Heartbeatrelated distension and displacement of the thoracic aorta in healthy volunteers. Eur J Radiol. 2012 Jan;81(1):158-64.

11. Sailer AM, Wagemans BAJM, Das M, de Haan MW, Nelemans PJ, Wildberger JE, et al. Quantification of Respiratory Movement of the Aorta and Side Branches. J Endovasc Ther. 2015 Dec 17;22(6):905-11.

12. Muhs BE, Vincken KL, van Prehn J, Stone MKC, Bartels LW, Prokop M, et al. Dynamic CineCT Angiography for the Evaluation of the Thoracic Aorta; Insight in Dynamic Changes with Implications for Thoracic Endograft Treatment. Eur J Vasc Endovasc Surg. 2006 Nov;32(5):532-6.

13. Guo J, Jia X, Sai Z, Ge Y, Wang S, Guo W. Thoracic Aorta Dimension Changes During Systole and Diastole: Evaluation with ECG-Gated Computed Tomography. Ann Vasc Surg. 2016 Aug;35:16873.

14. Csobay-Novák C, Fontanini DM, Szilágyi BR, Szeberin Z, Szilveszter BA, Maurovich-Horvat P, et al. Thoracic aortic strain can affect endograft sizing in young patients. J Vasc Surg. 2015 Dec;62(6):1479-84. 
Pulsatile changes in ATA 



\section{Chapter 8}

\section{Arterial Strain and Distensibility in Type A Aortic Dissection Before and After Stent Graft Implantation}

Viony M. Belvroy ${ }^{1,2}$; Joost A. van Herwaarden²; Michael J. Reardon'; Su Min Chang'; Frans L. Moll2; Jean Bismuth ${ }^{1}$

Abstract accepted for presentation at SCVS (Society for Clinical Vascular Surgery) $48^{\text {th }}$ Symposium 2020, March 14-18 Huntington Beach, Ca, United States 


\section{Abstract}

Objective Although this has not yet been studied well, it is our estimation that after stent graft implantation the dynamics of the ascending aorta change. Understanding these changes is critical in appreciating the potential consequences of endovascular repair of type $A$ aortic dissections. The aim of this study is to delineate some of these dynamic adjustments.

Methods Eight electrocardiogram-gated cardiac computed tomography of five patients, who were admitted to our center for Type A Aortic Dissection, were reviewed retrospectively. Measurements of diameters and lengths of the ascending aorta were collected in five pre- and three post-operative scans. A semi-automatically outlined centerline was created in systolic and diastolic phases and the measurements were made in multi-planar views at three locations in the ascending aorta.

Results The mean age of the study population was $72 \pm 9$ years old. The proximal landing zone of the stent graft was distal to the sinotubular junction (STJ), while the distal landing zone was at the proximal margin of the brachiocephalic artery (BCA). The circumferential strain increases at the STJ from $5.46 \%$ preimplantation to $13.27 \%$ post-implantation, see also table 1 . In the mid ascending aorta a decrease is seen from $5.41 \%$ to $0.70 \%$. The arterial compliance showed a similar tendency, with an increase at the STJ $\left(1.70 \mathrm{~mm}^{3} / \mathrm{kPa}\right.$ to $5.53 \mathrm{~mm}^{3} / \mathrm{kPa}$ post-implantation) and a decrease mid ascending $\left(1.83 \mathrm{~mm}^{3} / \mathrm{kPa}\right.$ to $0.32 \mathrm{~mm}^{3}$ / $\mathrm{kPa}$ ). The aortic stiffness increases post-implantation mid ascending (3.92 to 5.79), however, decreases at the STJ (4.37 to 2.98).

Conclusion At locations where the stent graft is not implanted the strain increases and aortic stiffness decreases post-implantation. However, the aorta becomes stiffer with a stent graft in situ. This effect should be taken into account when treating ascending aortic diseases. Especially when treatment occurs close to the aortic valve as we estimate that it can have an effect on the cardiac function. In the era of ever increasing endovascular applications to the ascending aorta and arch, it is imperative that we appreciate the potential cardiac implications and realize that current devices are lacking compliance and are much stiffer than the native aorta. This paper provides a window into these changes.

Key words: ascending aorta, cardiac motion, thoracic endovascular aortic repair, TEVAR, 


\section{Introduction}

Conventional therapy for ascending aortic diseases is open surgery'. A previous study by Hagan et al. reported that $28 \%$ of patients are not suited for open repair ${ }^{2}$, however, currently this number has now decreased to $10-15 \%{ }^{3}$. Thoracic endovascular aortic repair (TEVAR) is a developing alternative treatment strategy for high risk patients, but is challenging, due to high curvature of the aortic arch, proximal fixation close to the aortic valve, risk of coronary injury and distal fixation might cover the innominate artery. Also, additional complications can occur; like perforation of the left ventricle, occlusion of the coronary arteries and injury or dissection of the aortic root ${ }^{4}$.

Throughout the cardiac cycle the dynamics and the shape of the aorta changes. New dynamic imaging, like electrocardiography-gated (ECG-gated) computed tomography (CT) and magnetic resonance imaging (MRI), is used to asses these changes and help planning endovascular repair in various aortic diseases ${ }^{5-9}$. Likewise, aortic compliance and stiffness change caused by natural aging and aortic pathologies ${ }^{10-12}$. Aortic stiffness is a risk factor for cardiovascular diseases and death ${ }^{12-14}$ and implanting a stent graft may have similar effects on the aorta. Stent grafts keep evolving, however, they still do not match the natural aortic wall. It is important to know, especially when performing endovascular repair in the ascending aorta, how these specific dynamics change. Dynamic changes have been studied in detail in different locations throughout the aorta in various aortic pathologies $9,15,16$.

This study assessed dynamic changes during the cardiac cycle in the ATA in patients with type $A$ aortic dissection (TAAD) with ECG-gated CTA scanning. The focus is to study the differences before and after stent graft implantation.

\section{Methods}

\section{Patient \& imaging data}

The local institutional review board of the Houston Methodist Hospital, approved of this retrospective study and waived the need for informed consent. Five patients were admitted to our hospital for evaluation and treatment of a Type A aortic dissection (AD) and underwent TEVAR. Patients were included when they seemed high risk or unfit for open repair. Five pre-operative electrocardiographic-gated 


\section{Chapter 8}

computed tomography angiography (ECG-gated CTA) scans and three postoperative scans were available for a retrospective review. Retrospective ECGGated CTA of the chest (plus abdomen) was obtained using a third generation Dual Source scanner (collimation 0.625 mm) (Somaton Force ${ }^{\circledR}$, Siemens AG, Forchheim, Germany). Automatic bolus-triggering was used, followed by iodinated contrast $\geq 4 \mathrm{ml} / \mathrm{s}$ via the antecubital vein, followed by saline push with same injection rate of $25-40 \mathrm{ml}$. The pre-operative scans starts superior to the brachiocephalic artery bifurcation into the right subclavian and right common carotid arteries and ends on distal DA. Images were reconstructed every $10 \%$ of the cardiac cycles starting from the beginning of the QRS-complex. The follow up scans were obtained using the same protocol, except it ends at the level of the superior mesenteric artery (SMA).

Scans were reviewed according to a predeveloped protocol. Measurements of minimum and maximum diameters and the total length of the ascending thoracic aorta (ATA) were collected at three locations throughout the ATA; Group OA: at the sinotubular junction (STJ); group OB: mid ascending; group OC: proximal BCA (figure 1).

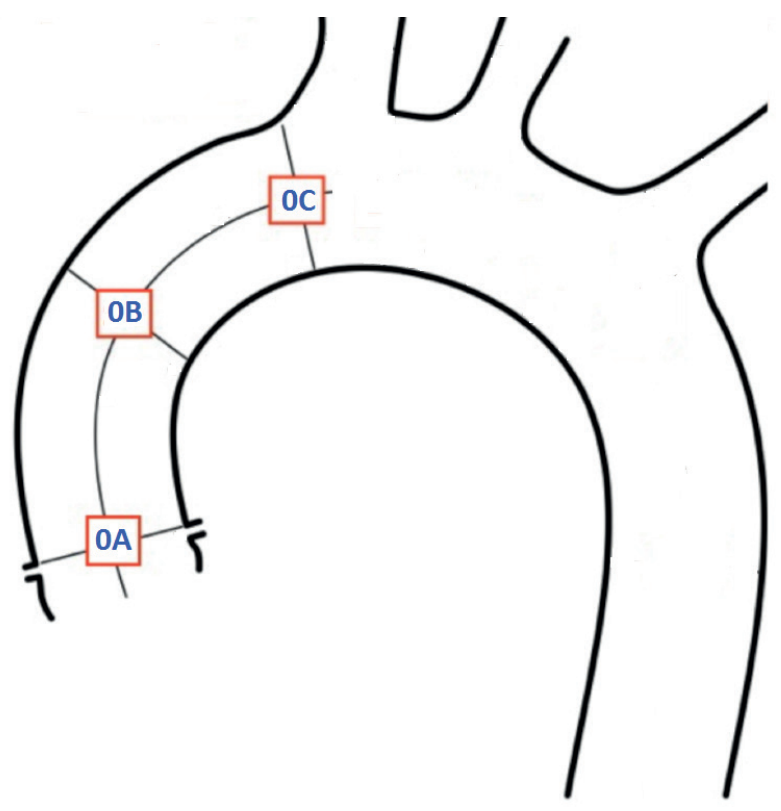

Figure 1. Locations of the measurements in the ascending aorta; Group OA: Sinotubular Junction (STJ), Group OB: Mid Ascending, Group OC: proximal brachiocephalic artery (BCA) 
Both systolic and diastolic phases were analyzed. The lowest and highest left ventricular volumes were measured to define these phases during the cardiac cycle. The 30-40\% and 70-80\% phases corresponded with the systolic and diastolic phases. The measurements were calculated using syngo.Via software (Siemens Healthcare GmbH, Germany), and performed in multi-planar views perpendicular to the semi-automatically created centerline (figure 2). The centerline was manually adjusted in case it was not accurate.

Exclusion criteria were non ECG-gated CTA scans, patients treated for aortic aneurysmal diseases and patients treated with open surgery for Type A AD.

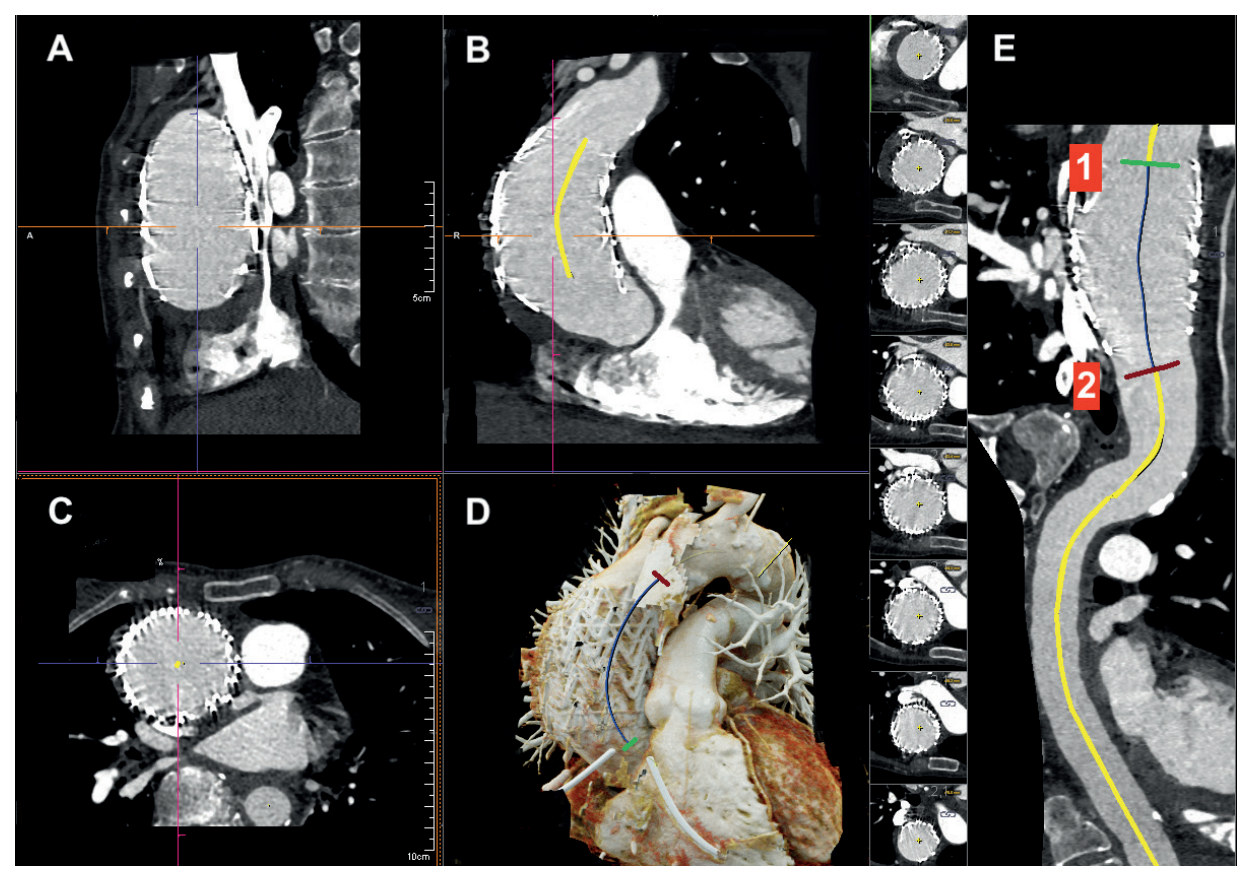

Figure 2. Multiplanar views of aortic measurements in sagittal view (A), frontal (B), axial (C), three-dimensional (D) and the centerline of the ascending aorta (E) with; 1) location of the sinotubular junction and 2) the proximal brachiocephalic artery.

\section{Aortic Pulsatile Distension measurements}

Different outcome measures were calculated regarding aortic pulsatile distension using the following equations ${ }^{17}$ : 


\section{Chapter 8}

1) Circumferential arterial strain $(\%)=($ Diameter Systolic [DS]- Diameter Diastolic[DD])/ Diameter Diastolic [DD] * 100

2) Longitudinal arterial strain $(\%)=$ (Aortic length in systole- Length in diastole)/ Length in diastole * 100

3) Arterial Compliance $(\mathrm{AC})(\mathrm{mm} 3 / \mathrm{kPa})=\omega^{*}\left(\mathrm{DS}^{2}-\mathrm{DD}^{2}\right) /(4$ *pulse pressure $[\mathrm{PP}])$

4) Arterial Distensibility (AD) $(\% / \mathrm{kPa})=100 *\left(\mathrm{DS}^{2}-\mathrm{DD}^{2}\right) /\left(\mathrm{PP}\right.$ * DD $\left.{ }^{2}\right)$

5) Stiffness Index (SI) (dimensionless)=In (Systolic blood pressure/ Diastolic blood pressure) / Arterial strain

6) Pressure-strain modulus $(\mathrm{Ep})(\mathrm{kPa})=\mathrm{PP} /$ Arterial strain

\section{Statistical analysis}

Normality was tested with the Shapiro Wilk test and comparison between the two groups was done with the independent sample T-test for normally distributed data or the Mann-Whitney $U$ test for non- normally distributed data. Intra-reliability was tested with a Bland Altman plot and the measurements were taken twice by one physician. The data was analyzed using SPSS Statistics 23 software (IBM Corp, Armonk, NY).

\section{Results}

The study population has a mean age of $72 \pm 9$ years and $60 \%$ were male. Other patient demographics are presented in table 1.

Table 1. Patients demographics

\begin{tabular}{lll}
\hline Patient characteristic & Median (QR) & Percentage (\%) \\
\hline Height (inch) & $69.5(59-71)$ & \\
Weight (Ib.) & $172(98-235)$ & \\
Gender - Male & 60 \\
Smoking & 60 \\
Chronic Kidney Disease & 20 \\
Diabetes Mellitus & 0 \\
Hypertension & 80 \\
Coronary Artery Disease & 40 \\
Coronary Artery Bypass Graft & 40 \\
Arterial fibrillation & 40 \\
Cerebrovascular Accident & 20 \\
Peripheral Arterial Disease & 20 \\
Hyperlipidemia & 60 \\
\hline
\end{tabular}


Important to notice is the location of the implanted stent graft. The proximal landing zone of the stent graft was distal to the sinotubular junction (STJ), while the distal landing zone was at the proximal margin of the brachiocephalic artery (BCA)(figure 2). The overall tendency shows an increase in circumferential strain, arterial compliance and distensibility and pressure strain-modulus at the STJ; strain (5.46\% pre-implantation to $13.27 \%$ post-implantation), compliance (1.70 $\mathrm{mm}^{3} / \mathrm{kPa}$ to $\left.5.53 \mathrm{~mm}^{3} / \mathrm{kPa}\right)$, distensibility $(0.17 \% / \mathrm{kPa}$ to $0.45 \% / \mathrm{kPa})$ and pressure strain-modulus (3.60 kPa to $8.54 \mathrm{kPa}$ ). However, mid ascending there is a decrease in strain (5.41\% to $0.70 \%)$, compliance $\left(1.83 \mathrm{~mm}^{3} / \mathrm{kPa}\right.$ to $0.32 \mathrm{~mm}^{3}$ / $\mathrm{kPa})$, distensibility $(0.18 \% / \mathrm{kPa}$ to $0.02 \% / \mathrm{kPa})$ and pressure strain-modulus (3.33 $\mathrm{kPa}$ to $0.45 \mathrm{kPa}$ )(table 2). The aortic stiffness index decreases at the STJ post-implantation (4.37 to 2.98) and increases mid ascending (3.92 to 5.79). The differences at the proximal BCA are not so notable with minor decrease in all the outcome measures, see table 2.

Table 2. Change in Aortic Dynamics at three locations in the Ascending Thoracic Aorta before and after stent graft implantation.

\begin{tabular}{|c|c|c|c|}
\hline & STJ* & Mid Ascending & Proximal BCA \\
\hline \multicolumn{4}{|l|}{ Circumferential Strain (\%) } \\
\hline Pre-implantation & $5.46(0.29-12.70)$ & $5.41(1.84-11.76)$ & $8.38(0.27-34.65)$ \\
\hline Post-implantation & $13.27(5.03-22.75)$ & $0.70(0.49-0.97)$ & $6.22(0.80-9.78)$ \\
\hline \multicolumn{4}{|l|}{ Longitudinal Strain (\%) } \\
\hline Pre-implantation & $13.59(7.50-22.91)$ & & \\
\hline Post-implantation & $10.36(4.36-15.02)$ & & \\
\hline \multicolumn{4}{|l|}{$\begin{array}{l}\text { Arterial Compliance }\left(\mathrm{mm}^{3} /\right. \\
\mathrm{kPa})\end{array}$} \\
\hline - $\quad$ Pre-implantation & $1.70(0.09-3.19)$ & $1.83(0.81-3.16)$ & $2.20(0.10-8.88)$ \\
\hline Post-implantation & $5.53(1.78-11.89)$ & $0.32(0.20-0.45)$ & $2.03(0.30-3.54)$ \\
\hline \multicolumn{4}{|l|}{ Arterial Distensibility (\%/kPa) } \\
\hline Pre-implantation & $0.17(0.01-0.41)$ & $0.18(0.05-0.43)$ & $0.29(0.01-1.23)$ \\
\hline Post-implantation & $0.45(0.14-0.77)$ & $0.02(0.01-0.03)$ & $0.19(0.03-0.28)$ \\
\hline \multicolumn{4}{|l|}{ Stiffness Index } \\
\hline Pre-implantation & $4.37(2.80-6.66)$ & $3.92(2.93-4.79)$ & $4.56(1.79-6.75)$ \\
\hline Post-implantation & $2.98(2.21-3.78)$ & $5.79(5.46-6.06)$ & $4.00(3.11-5.65)$ \\
\hline \multicolumn{4}{|l|}{ Pressure Strain-Modulus (kPa) } \\
\hline Pre-implantation & $3.60(0.17-8.38)$ & $3.33(1.32-6.82)$ & $5.56(0.16-22.87)$ \\
\hline Post-implantation & $8.54(3.62-15.01)$ & $0.45(0.32-0.56)$ & $4.28(0.47-7.04)$ \\
\hline
\end{tabular}

Data presented as Mean (range).

* STJ = sinotubular junction

** BCA = brachiocephalic artery 


\section{Chapter 8}

The intra-reliability was tested by the Bland Altman plot, see figure 3.
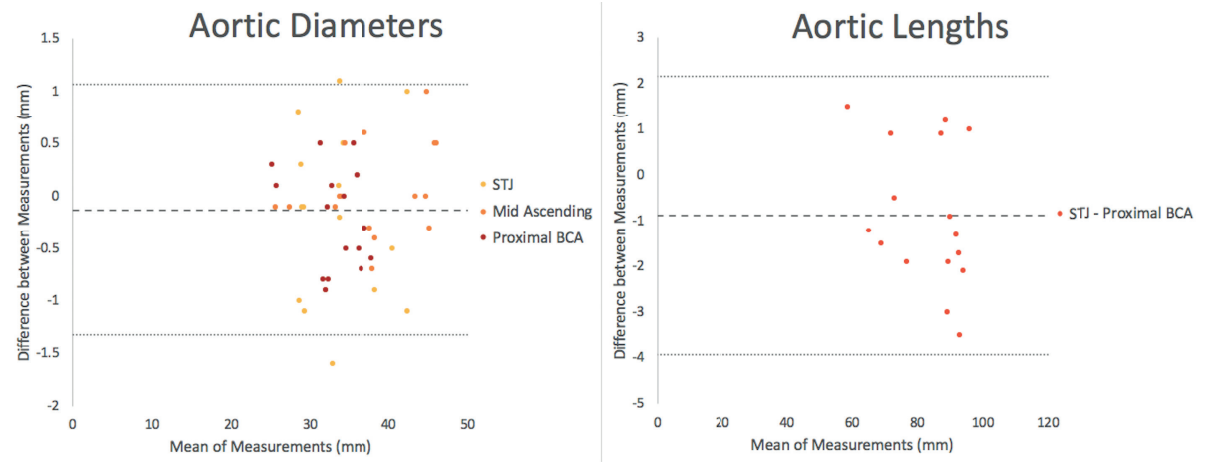

Figure 3. Bland Altman plots showing Intra-observer variability for aortic diameter (left) and aortic length measurements (right).

\section{Discussion}

Aortic pulsatile distension is an important factor in understanding aortic pathology. It has been studied thoroughly in the abdominal aorta and descending thoracic aorta $5,15,18$, showing differences in radial and longitudinal changes in the cardiac cycle. Previous studies say that pulsatile distension during the cardiac cycle is related to stent graft migration ${ }^{19}$. It has been proven that the ATA has the biggest range in aortic motion ${ }^{20}$, and maybe we can even assume that the incidence of stent graft migration may be higher in the ATA. As treatment in the ascending aorta is becoming more widely available with endovascular repair it is of value to learn more about the effect of stent graft implantation in zone 0 . The aim of this study was to assess the aortic pulsatile distension in patients treated for type A AD before and after stent graft implantation.

With relevant change in diameter and area during the cardiac cycle it has become more important to study aortic motion ${ }^{16,21}$. Using dynamic imaging to study aortic pathology reduces motion artifacts especially in the aortic root, ascending aorta and proximal $\operatorname{arch}^{22}$. Dynamic imaging is a relatively new imaging modality that can help in the pre-operative planning for optimal stent graft sizing and post-operatively in evaluating endograft performance ${ }^{23}$.

It still remains difficult to detect actual causes for aortic changes. However, the effect of these changes is extremely important in cardiovascular diseases. Arterial stiffness is crucial for related systolic and pulse pressure increase, a major predicter of stroke and myocardial infarction, and it has been associated with 
heart failure ${ }^{24-26}$. Still, the cause remains uncertain. Some studies show that it can be age-related and because of hypertension ${ }^{10,27,28}$. There is a mismatch between native aorta and stent graft regarding aortic stiffness. Even though, nowadays aortic stent grafts have a high conformability to the native aorta, the aorta evolves to be much stiffer after implantation. De Beaufort et al. created a porcine model to study aortic stiffness. After stent graft deployment the aortic stiffness increased ${ }^{29}$. A study by Nauta et al. found an increase in circumferential strain and longitudinal strain proximal from where the stent graft is implanted ${ }^{30}$, which can be an explanation for complications like retrograde dissection, aneurysmal formation and rupture. The effect of stent graft material on pulse wave velocity (PWV), which is a feasible marker for aortic stiffness, show an increase in PWV after stent graft implantation compared to the native aorta ${ }^{31}$.

As there is a mismatch between native aorta and stent graft, a previous study shows the increase in aortic stiffness after implantation ${ }^{29}$. Our results demonstrate the same. Where the stent graft was implanted (mid ascending), there was an increase in aortic stiffness of $48 \%$, a decrease in circumferential strain of $87 \%$ and a decrease of longitudinal strain of $24 \%$ (table 2). It can be assumed that aortic stiffness would increase after stent graft implantation, however, an increase of almost 50\% needs closer attention. To decrease the difference in mismatch, more conformable devices may be needed. Similar material to the native aorta should be used to have analogous aortic pulsatile distension. In our study the stent graft was implanted distal to the STJ. At this location, the strain and aortic compliance increased with $143 \%$ and $225 \%$ after implantation and the stiffness decreased with $32 \%$ (table 2). Similar findings were reported by Nauta et al. ${ }^{30}$ Endovascular aortic repair in the ATA has a proximal landing zone close to the aortic valve. The dynamic change after stent graft implantation can have a great effect on the valve. The authors suggest this should be studied more extensively for better understanding and to prevent short- and long-term cardiac complications.

This study has several limitations. Primarily the population size is relatively small. No firm conclusion can be drawn from this study. The measurements were performed by a single physician, however, the intra-observer analysis showed minor changes. Nowadays, ECG-gated scanning is becoming more available and much more widely used for TEVAR planning. However, it is still unknown which part of the cardiac phase is the most accurate and would result in the most appropriate endovascular management, as the dimensions differ between 


\section{Chapter 8}

the systolic and diastolic phases ${ }^{7}$. A study by Csobay-Novák et al. indicates that images at 30\% of the heart cycle have the largest diameter throughout the aorta ${ }^{32}$.

This article is, to our knowledge, the first comparing the effect of stent graft implantation in the ascending thoracic aorta in type A aortic dissection. The authors recommend studying the effect of aortic pulsatile distension on the aortic valve in the ATA and study more extensively the mismatch of native aorta and stent graft to create devices more similar to the native aorta.

In conclusion, the aorta becomes stiffer after stent graft implantation. Proximal to the stent graft the strain increases and aortic stiffness decreases. This might have an effect on the aortic valve and left ventricle which should be studied more extensively. Current devices potentially lack adequate compliance, nonetheless this article gives an insight into the differences between native aorta and stent grafts. We hope to give some pause into the excitement surrounding these life-saving, innovative therapies and reflect on its potential implications. 


\section{References}

1. Baikoussis NG, Antonopoulos CN, Papakonstantinou NA, et al. Endovascular stent grafting for ascending aorta diseases. J Vasc Surg. 2017;66(5):1587-1601. doi:10.1016/j.jvs.2017.07.064

2. Hagan PG, Nienaber CA, Isselbacher EM, et al. The International Registry of Acute Aortic Dissection (IRAD): new insights into an old disease. JAMA. 2000;283(7):897-903. doi:10.1001/ jama.283.7.897

3. Plichta RP, Hughes GC. Thoracic endovascular aortic repair for the ascending aorta: experience and pitfalls. J Vis Surg. 2018;4:92-92. doi:10.21037/jovs.2018.03.01

4. Khoynezhad A, Donayre CE, Walot I, et al. Feasibility of endovascular repair of ascending aortic pathologies as part of an FDA-approved physician-sponsored investigational device exemption. J Vasc Surg. 2016;63(6):1483-1495. doi:10.1016/j.jvs.2015.12.029

5. van Prehn J, Vincken KL, Sprinkhuizen SM, et al. Aortic pulsatile distention in young healthy volunteers is asymmetric: analysis with ECG-gated MRI. Eur J Vasc Endovasc Surg. 2009;37(2):168-174. doi:10.1016/j.ejvs.2008.11.007

6. van Prehn J, Bartels LW, Mestres G, et al. Dynamic aortic changes in patients with thoracic aortic aneurysms evaluated with electrocardiography-triggered computed tomographic angiography before and after thoracic endovascular aneurysm repair: preliminary results. Ann Vasc Surg. 2009;23(3):291-297. doi:10.1016/j.avsg.2008.08.007

7. Guo J, Jia X, Sai Z, et al. Thoracic Aorta Dimension Changes During Systole and Diastole: Evaluation with ECG-Gated Computed Tomography. Ann Vasc Surg. 2016;35:168-173. doi:10.1016/j.avsg.2016.01.050

8. de Heer LM, Budde RPJ, Mali WPTM, et al. Aortic root dimension changes during systole and diastole: evaluation with ECG-gated multidetector row computed tomography. Int J CardiovasC Imaging. 2011;27(8):1195-1204. doi:10.1007/s10554-011-9838-x

9. Muhs BE, Vincken KL, van Prehn J, et al. Dynamic Cine-CT Angiography for the Evaluation of the Thoracic Aorta; Insight in Dynamic Changes with Implications for Thoracic Endograft Treatment. Eur J Vasc Endovasc Surg. 2006;32(5):532-536. doi:10.1016/j.ejvs.2006.05.009

10. Redheuil A, Yu W-C, Wu CO, et al. Reduced ascending aortic strain and distensibility: earliest manifestations of vascular aging in humans. Hypertens (Dallas, Tex 1979). 2010;55(2):319-326. doi:10.1161/HYPERTENSIONAHA.109.141275

11. Bell V, Mitchell WA, Sigurðsson S, et al. Longitudinal and Circumferential Strain of the Proximal Aorta. J Am Heart Assoc. 2014;3(6):e001536. doi:10.1161/JAHA.114.001536

12. Cavalcante JL, Lima JAC, Redheuil A, et al. Aortic stiffness: current understanding and future directions. J Am Coll Cardiol. 2011;57(14):1511-1522. doi:10.1016/j.jacc.2010.12.017

13. Redheuil A, Wu CO, Kachenoura N, et al. Proximal aortic distensibility is an independent predictor of all-cause mortality and incident CV events: the MESA study. J Am Coll Cardiol. 2014;64(24):2619-2629. doi:10.1016/j.jacc.2014.09.060

14. Vlachopoulos C, Aznaouridis K, Stefanadis C. Prediction of Cardiovascular Events and AllCause Mortality With Arterial Stiffness. J Am Coll Cardiol. 2010;55(13):1318-1327. doi:10.1016/j. jacc.2009.10.061

15. de Beaufort HWL, Nauta FJH, Conti M, et al. Extensibility and Distensibility of the Thoracic Aorta in Patients with Aneurysm. Eur J Vasc Endovasc Surg. 2017;53(2):199-205. doi:10.1016/j. ejvs.2016.11.018

16. van Herwaarden JA, Bartels LW, Muhs BE, et al. Dynamic magnetic resonance angiography of the aneurysm neck: Conformational changes during the cardiac cycle with possible consequences for endograft sizing and future design. J Vasc Surg. 2006;44(1):22-28. doi:10.1016/j.jvs.2006.03.028

17. Nichols WW, O'Rourke MF, Vlachopoulos C. McDonald's Blood Flow in Arteries: Theoretical, Experimental and Clinical Principles. 6th Editio. CRC Press; 2013.

18. Zandvoort HJA, Moll FL, Domanian A, et al. Preoperative Infra- and Suprarenal Aortic Pulsatile Distension is Comparable between Relatively Young and Older Patients with an Abdominal Aortic Aneurysm. Ann Vasc Surg. 2014;28(4):845-849. doi:10.1016/j.avsg.2013.07.021 


\section{Chapter 8}

19. van Keulen JW, Moll FL, Barwegen GK, et al. Pulsatile distension of the proximal aneurysm neck is larger in patients with stent graft migration. Eur J Vasc Endovasc Surg. 2010;40(3):326-331. doi:10.1016/j.ejvs.2010.05.009

20. van Prehn J, Vincken KL, Muhs BE, et al. Toward endografting of the ascending aorta: insight into dynamics using dynamic cine-CTA. J Endovasc Ther. 2007;14(4):551-560. doi:10.1177/152660280701400418

21. van Keulen JW, van Prehn J, Prokop M, et al. Dynamics of the aorta before and after endovascular aneurysm repair: a systematic review. Eur J Vasc Endovasc Surg. 2009;38(5):586-596. doi:10.1016/j.ejvs.2009.06.018

22. Bhave NM, Nienaber CA, Clough RE, et al. Multimodality Imaging of Thoracic Aortic Diseases in Adults. JACC Cardiovasc Imaging. 2018;11(6):902-919. doi:10.1016/j.jcmg.2018.03.009

23. van Bogerijen GHW, van Herwaarden JA, Conti M, et al. Importance of dynamic aortic evaluation in planning TEVAR. Ann Cardiothorac Surg. 2014;3(3):300-306. doi:10.3978/j.issn.2225319X.2014.04.05

24. Mattace-Raso FUS, van der Cammen TJM, Hofman A, et al. Arterial Stiffness and Risk of Coronary Heart Disease and Stroke. Circulation. 2006;113(5):657-663. doi:10.1161/ CIRCULATIONAHA.105.555235

25. Giannattasio C, Achilli F, Failla M, et al. Radial, carotid and aortic distensibility in congestive heart failure: effects of high-dose angiotensin-converting enzyme inhibitor or low-dose association with angiotensin type 1 receptor blockade. J Am Coll Cardiol. 2002;39(8):1275-1282. doi:10.1016/ s0735-1097(02)01755-2

26. Boutouyrie P, Tropeano Al, Asmar R, et al. Aortic Stiffness Is an Independent Predictor of Primary Coronary Events in Hypertensive Patients. Hypertension. 2002;39(1):10-15. doi:10.1161/ hy0102.099031

27. Milan A, Tosello F, Naso D, et al. Ascending aortic dilatation, arterial stiffness and cardiac organ damage in essential hypertension. J Hypertens. 2013;31(1):1. doi:10.1097/HJH.0b013e32835aa588

28. Redheuil A, Yu W-C, Mousseaux E, et al. Age-Related Changes in Aortic Arch Geometry Relationship With Proximal Aortic Function and Left Ventricular Mass and Remodeling. JAC. 2011;58:1262-1270. doi:10.1016/j.jacc.2011.06.012

29. de Beaufort HWL, Conti M, Kamman A V., et al. Stent-Graft Deployment Increases Aortic Stiffness in an Ex Vivo Porcine Model. Ann Vasc Surg. 2017;43:302-308. doi:10.1016/j.avsg.2017.04.024

30. Nauta FJH, van Bogerijen GHW, Trentin C, et al. Impact of Thoracic Endovascular Aortic Repair on Pulsatile Circumferential and Longitudinal Strain in Patients With Aneurysm. J Endovasc Ther. 2017;24(2):281-289. doi:10.1177/1526602816687086

31. Kadoglou NPE, Moulakakis KG, Papadakis I, et al. Differential Effects of Stent-Graft Fabrics on Arterial Stiffness in Patients Undergoing Endovascular Aneurysm Repair. J Endovasc Ther. 2014;21(6):850-858. doi:10.1583/14-4772MR.1

32. Csobay-Novák C, Fontanini DM, Szilágyi BR, et al. Thoracic aortic strain can affect endograft sizing in young patients. J Vasc Surg. 2015;62(6):1479-1484. doi:10.1016/j.jvs.2015.06.225 
Dynamics after SG implantation 

Education in endovascular repair 



\section{Chapter 9}

\section{Metrics Reliably Differentiate Competency: Fundamentals of Endovascular and Vascular Surgery (FEVS)}

Viony M. Belvroy ${ }^{1,2}$; Barathwaj Murali3; Malachi G. Sheahan4; Marcia K. O'Malley $^{3}$; Jean Bismuth ${ }^{1}$

Abstract accepted for presentation at SCVS (Society for Clinical Vascular Surgery) $48^{\text {th }}$ Symposium 2020, March 14-18 Huntington Beach, $\mathrm{Ca}$, United States

Manuscript awarded with the SCVS Peter B Samuels Award 2020

1 Houston Methodist DeBakey Heart \& Vascular Center, Houston, Texas, United States

2 Department of Vascular Surgery, University Medical Center Utrecht, Utrecht, Netherlands

3 Department of Mechanical Engineering, Mechatronics and Haptic Interfaces Laboratory, Rice University, Houston, Texas, United States

4 Department of Vascular Surgery, Louisiana State University School of Medicine, New Orleans, Louisiana, United States 


\section{Chapter 9}

\section{Abstract}

Objective The Fundamentals of Endovascular \& Vascular Surgery (FEVS) is a curriculum that includes an endovascular model for skills testing, which aims to differentiate between competent and non-competent performers. The aim of our study is to further validate the model and test its reliability in assessing the performance of endovascular trainees in an uncontrolled setting.

Methods The model was tested exclusively in a virtual-reality environment. Fifty-two subjects were divided into three groups based on their endovascular experience: novice (<50 endovascular cases), intermediate (50 - 500 endovascular cases) and expert (>500 endovascular cases). Performance was evaluated in four tasks, measuring the tool tip position and velocity on the virtual model. Average tool tip velocity and movement smoothness in the velocity frequency domain are validated parameters defining proficiency of movement. The data were filtered and interpolated to calculate the metrics. Trials containing critical tool manipulation errors were excluded.

Results In total 52 tasks completed by novices, 25 completed by intermediates, and 38 completed by experts were analyzed to determine performance. The difference in performance between the novice and expert groups was statistically significant for guidewire smoothness; $P<0.001$. The expert group had a statistically significantly higher average guidewire velocity compared to the novice group $(p<0.001)$.

Conclusion The FEVS model continues to differentiate novices from experts based on their handling of guidewire and catheter tools, measured as smoothness and velocity. This model offers a useful instrument to test competency in endovascular surgeons. 


\section{Introduction}

In 2010, Bismuth et al. wrote a report about the need for uniformity of technical skills in graduating vascular surgery residents'. Throughout a residency program, trainees gain skills; however, these skills are never objectively evaluated in vascular surgery residents.

As a prerequisite for certification, it is required by the American Board of Surgery that graduating residents pass the Fundamentals of Laparoscopic Surgery (FLS) exam². Research with FLS demonstrates that with only moderate practice, significant improvement can be achieved ${ }^{3}$. Likewise, Fundamentals in Endoscopic Surgery (FES) has been developed to test endoscopic surgery skills ${ }^{4}$.

To objectify the needs for a vascular surgery educational program, Panetta et al. wrote guidelines for the curriculum in emerging technologies ${ }^{5}$. These elements are all essential for vascular education and will evolve concurrently with emerging technologies going forward.

Other programs for vascular surgery, like OSATS ${ }^{6}$ (Objective Structured Assessment of Technical Skill) and ICEPS (Imperial College Evaluation of Procedure Specific Skill), are already used in Europe. They have a high interobserver reliability and the ability to discriminate between level of training?

In this study, we validate the endovascular model that was first introduced by Duran et al. in $2015^{8}$. Our aim is test the reliability of the model in assessing the performance of endovascular trainees.

\section{Methods}

Methods used for this study are based on the previously published article by Duran et $\mathrm{al}^{8}$. The model was developed by members of the Association of Program Directors in Vascular Surgery (APDVS). They created a list of skills necessary for endovascular trainees to perform basic endovascular tasks. The model was tested in a virtual-reality environment, and the eight different tasks are laid out in Table 1. 


\section{Chapter 9}

Table 1. The eight fundamental tasks for endovascular trainees, created by the Fundamentals of Vascular Surgery Task Force of the Association of Program Directors in Vascular Surgery (APDVS)

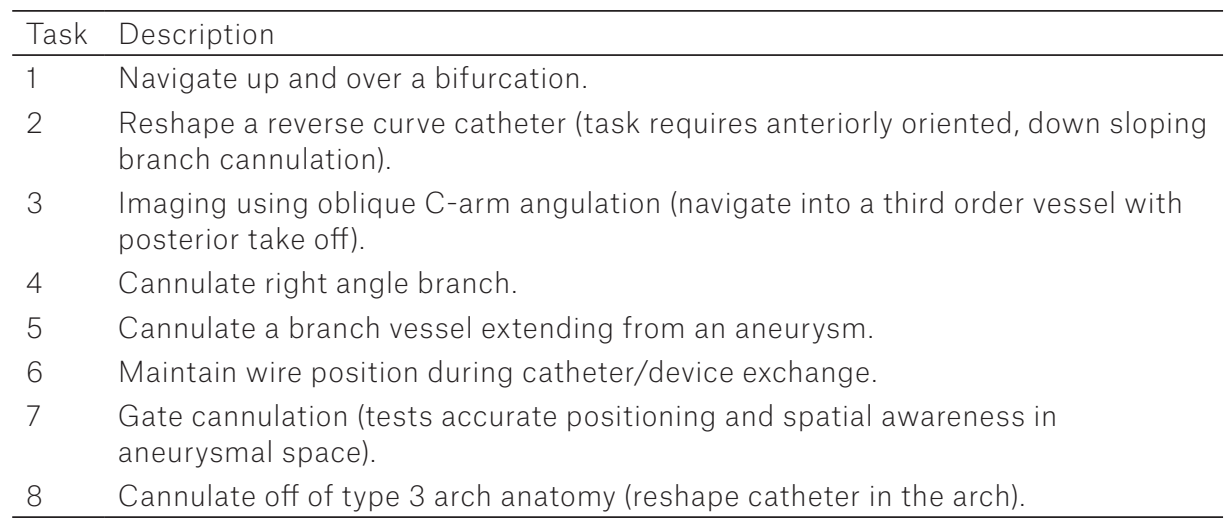

\section{Study subjects}

Fifty-two subjects participated in this study (40 male, 12 female). Based on their endovascular experience, the participants were divided into three groups: novices (<50 endovascular cases), intermediates (50 - 500 endovascular cases) and experts (>500 endovascular cases). The participants were a combination of medical students, residents, fellows, and attendants with zero to extensive experience in the vascular surgery field (30 novices, 11 intermediates and 11 experts). The novice group consisted of 18 students, seven starting residents, four starting fellows and one industry professional. The intermediate group consisted of five residents, three fellows and three attendings and the experts had three finishing residents, seven attending faculty and one physician assistant with experience in endovascular surgery (see table 2). The study subjects consented to participate in this study according to the Rice University Institutional Review Board.

Table 2. Number of tasks performed by subject of each experience level.

\begin{tabular}{ccccc}
\hline & $\begin{array}{c}\text { Novice } \\
(\mathrm{N}=30)\end{array}$ & $\begin{array}{c}\text { Intermediate } \\
(\mathrm{N}=11)\end{array}$ & $\begin{array}{c}\text { Experts } \\
(\mathrm{N}=11)\end{array}$ & Total \\
\hline Task 1 & 29 & 9 & 10 & 48 \\
Task 3 & 14 & 5 & 11 & 30 \\
Task 5 & 5 & 7 & 10 & 22 \\
Task 7 & 4 & 4 & 7 & 15 \\
Total & 52 & 25 & 38 & 115 \\
\hline
\end{tabular}




\section{Virtual-reality model}

The study was performed with a virtual reality model (Figure 1). Four of the eight tasks were used in this study (Table 1), which tested a variety of endovascular skills. The tasks included for validation are navigating up and over the bifurcation, imaging using oblique $\mathrm{C}$-arm angulation to navigate into a third order vessel with posterior take off, cannulate a branch vessel extending from an aneurysm and gate cannulation which test accurate positioning and spatial awareness in an aneurysmal space. In each task, a preselected guidewire, catheter and sheath were used to navigate through the virtual-reality model. The task was successfully completed if the guidewire, catheter and/or sheath were advanced up to a preidentified success point in the virtual model and if the completion time was less than 5 minutes.

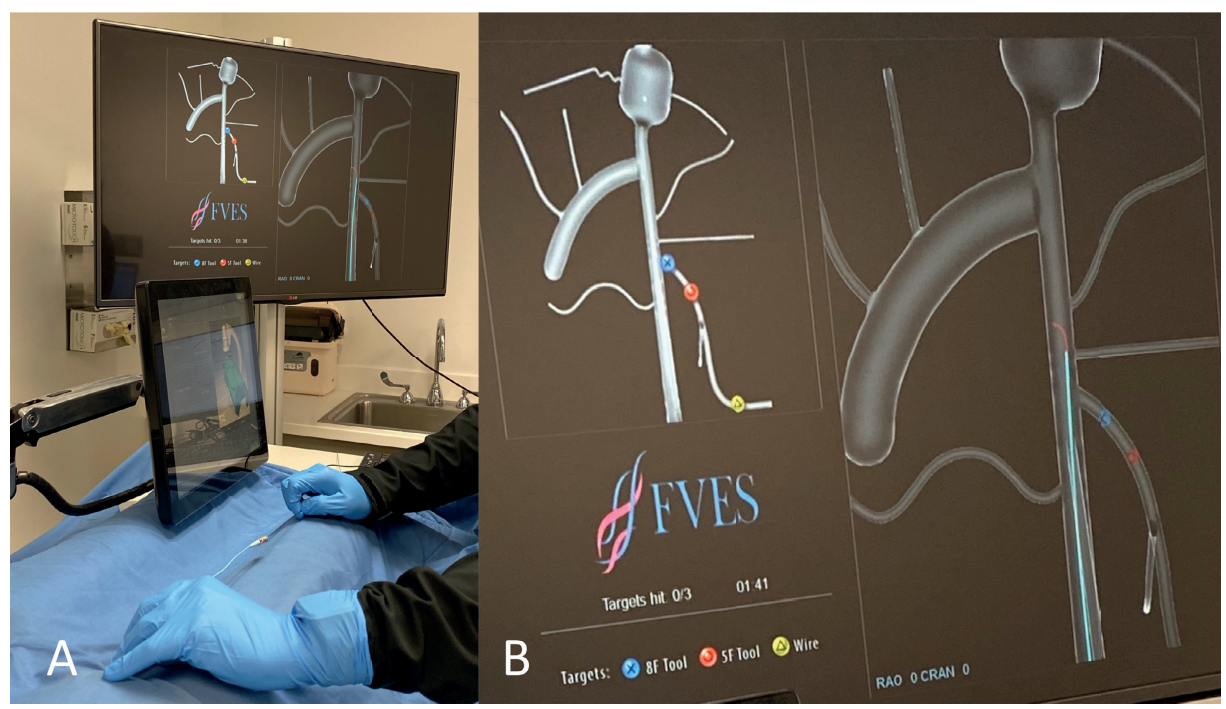

Figure 1. Overview (A) of an endovascular trainee working with the ANGIO Mentor Ultimate Stimulator (3D Systems, Littleton, CO) completing different tasks (B) by inserting the tools to the correct end point; guidewire (yellow), catheter (red) and sheath (blue).

\section{Motion analysis}

Two similar systems were used to collect data for the motion analysis. The ANGIO Mentor Flex Endovascular Simulator (3D Systems, Littleton, CO) and the ANGIO Mentor Ultimate Simulator (3D Systems, Littleton, CO). Optical sensors on the 


\section{Chapter 9}

simulator recorded the translation and rotation of practice guidewires, catheters, and sheaths inserted into the device, while preloaded module containing a virtualized training model used by the FEVS platform in simulated physical tool tip motions ${ }^{8}$. The module streamed $X, Y$, and $Z$ position data of each tool tip over a TCP network connection at varying sampling rates between $15-60 \mathrm{~Hz}$. The module also provided a means to calculate velocity by streaming the differences between adjacent position values throughout each task. Two different motion metrics were computed from the tool tip velocity data to analyze the quality of movement. Spectral arc length (SAL), which is a frequency-domain measure of movement smoothness and is proven to be significantly correlated to experience level for endovascular procedures performed on manual, simulator, and robotic platforms ${ }^{9}$. The average tool tip velocity was calculated for each tool by using their tangential velocity profile. Applying these principles to guidewire and catheter tip motion analysis objectively characterized the quality of motion and correlated it with performance ${ }^{10}$.

\section{Performance assessment}

Performance was evaluated in four tasks, measuring the tool tip position and velocity on the virtual model. Average tool tip velocity and movement smoothness evaluated in the frequency domain are validated parameters defining proficiency of movement 9,11 . Movement smoothness is measured as Spectral Arc Length $(S A L)$. Another measure of performance is idle time. This is defined as the total time that the surgical tools are stationary, which correlates to experience level ${ }^{12}$. The final metric to assess performance is the path length, which measured the length of the tool tip motion within the virtual model ${ }^{13}$. The data were filtered and interpolated to calculate the metrics. Trials containing critical tool manipulation errors were discarded.

\section{Data analysis}

The data were analyzed using MATLAB ${ }^{\circ}$ and Statistics Toolbox Release 2012b (The MathWorks Inc., Nathick, MA). Normality was tested using Q-Q plots and the homogeneity of variance was satisfied by O'Brien's test. Comparison between groups was tested using the one-way independent measures ANOVA. Tukey HSD was performed to test metrics that produced significant ANOVA results. When a subject completed more than one task, the data was averaged and compared between groups. Motion data from tasks containing critical failures were excluded 
and outlier removal was not performed. Correlations were tested using a linear regression model.

\section{Results}

A total number of fifty-two study subjects participated in this study and were divided into three groups based on their experience: 30 novices, 11 intermediates and 11 experts. The number of tasks completed per group were; 52 by novices, 25 by intermediates, and 38 by experts. Their performance was analyzed and a significant difference was found for SAL in guidewire $(p<0.001)$, average velocity $(p<0.001)$ and idle time $(p<0.001)$ (table 3)(figure 2). Post-hoc tests showed a statistically significant difference between novices and experts and intermediates and experts, however, not between novices and intermediates. No statistically significant differences were found for the tool catheter in smoothness and average velocity or for guidewire in path length across groups.

Table 3. Results of performance metrics; SAL, average velocity, idle time and path length. Calculated with one-way ANOVA and effect size (Cohen's f).

\begin{tabular}{ccc}
\hline Metric & Outcome & Effect Size (Cohen's f) \\
\hline SAL & $F(2,42)=9.38 ; p<0.001$ & 0.67 \\
Average Velocity & $F(2,42)=10.66 ; p<0.001$ & 0.71 \\
Idle Time & $F(2,42)=8.18 ; p<0.001$ & 0.62 \\
Path Length & $F(2,42)=2.67 ; p=0.200$ & 0.28 \\
\hline
\end{tabular}

A linear regression model was built and showed a positive correlation between $S A L$ and average velocity of the guidewire $(r(42)=0.72 ; p<0.001)$. Likewise, there was a positive correlation between SAL and Idle Time $(r(42)=0.70 ; p<0.001)$; however, there was no correlation between SAL and Path Length. 

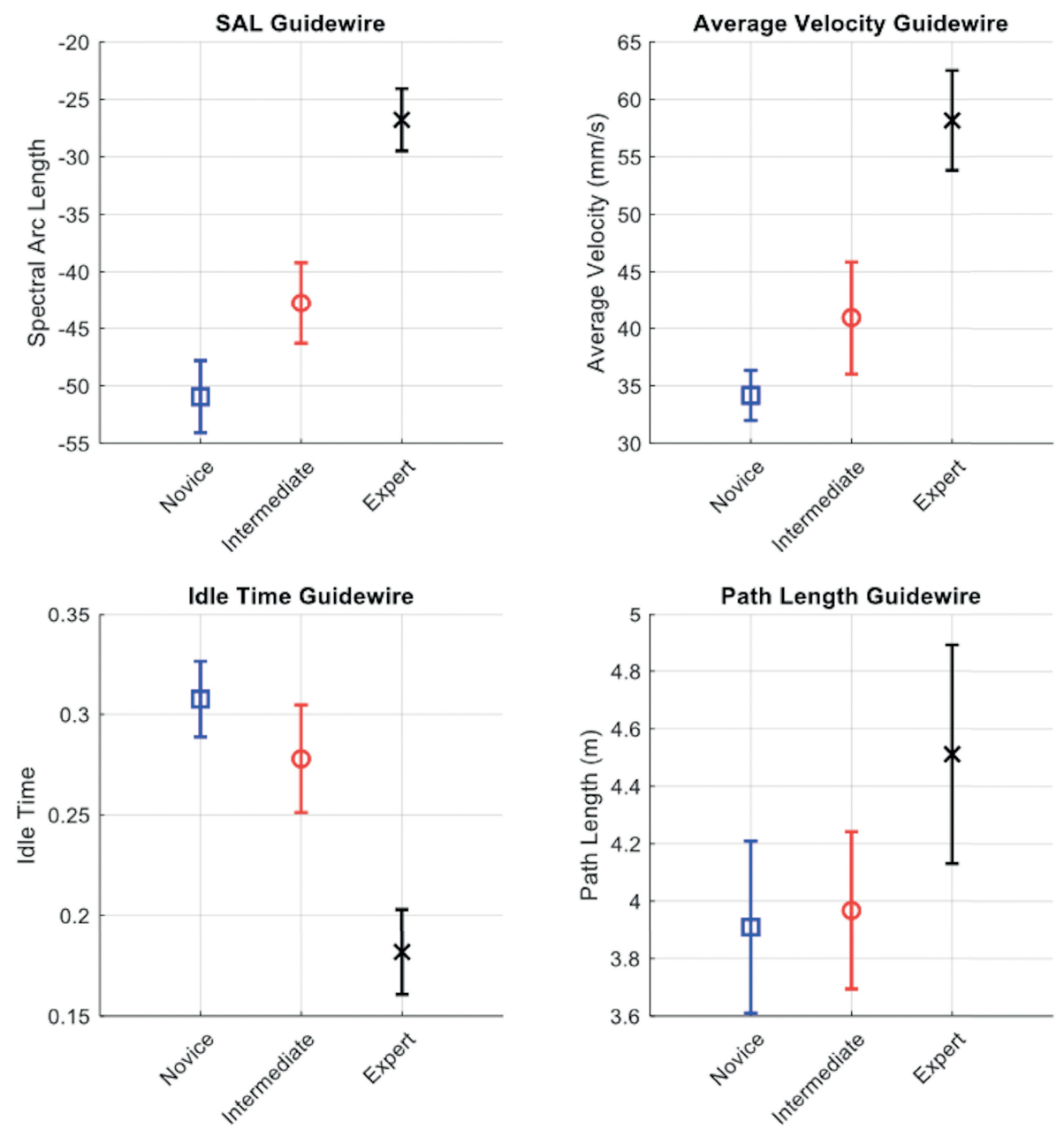

Figure 2. Plots showing the mean and standard error of the outcome measures for the guidewire in spectral arc length $(S A L)$, average velocity $(\mathrm{mm} / \mathrm{s})$, idle time and path length (m) for each experience level.

\section{Discussion}

The aim of this study was to provide further validation of the Fundamentals of Endovascular and Vascular Surgery (FEVS) in a virtual-reality model, which was first published by Duran et al. in 2015. The prior validation of the model had been performed in a controlled environment in an experimental lab. The goal of the current work was to broaden the evaluation of the model in a setting that more closely mirrored the real world non-experimental space. Even under these conditions, the model continues to differentiate novices from experts based on 
their experience and handling of the guidewire and catheter tools, measured as smoothness and average velocity. This further supports the notion that the model offers a useful instrument to test competency in endovascular surgeons.

In the previously published study by Duran et al., performance was tested between competent and non-competent ${ }^{8}$. In this study, the subjects were divided into three groups; novices, intermediates and experts, based on their experience and case load. There was a statistically significant difference between novices vs. experts and intermediates vs. experts. However, no difference was found between novices and intermediates. This shows that the important differentiation might be between the competent (expert) and the non-competent (novices and intermediates).

The main limitation of this work is that not all modules in the FEVS were tested in every participant and so a complete assessment of performance is not possible. We cannot verify that each module effectively reflects competency. Nevertheless, we can assert that modules evaluated in our initial studies remain valid in this analysis. Furthermore, although tool tip motion is able to differentiate competent from incompetent, it is unclear whether all metrics are valid or appropriately weighted for task validation. Ideally, a psychometric analysis has the potential to assess this latent question, because although motion capture does provide an objective evaluation it lacks the critical appraisal of the value of a specific metric ${ }^{14}$. In order to continue the validation process, the goal is to not only recruit more subjects, but to refine our metrics by assessing the correlation between the tool tip movements and performance.

The modules within the FEVS reflect a range of skills and difficulty. The importance of evaluating each individual module is therefore critical to understanding that the differentiation between competent and non-competent remains consistent throughout. As we continue to gauge the consistency of this model the number of participants evaluated will help define whether we are indeed testing "endovascular aptitude."

In summary, we are confident that the Fundamentals of Endovascular Surgery model is capable of differentiating competent from non-competent endovascular operators. Further studies and continued data collection and analysis will broaden our understanding of each module's task. We will continue to report on this research as it evolves since we remain certain that the need to have 
Chapter 9

an objective skills assessment tool is an imperative component of determining a trainee's level of competence. 


\section{References}

1. Bismuth J, Donovan MA, O'Malley MK, et al. Incorporating simulation in vascular surgery education. J Vasc Surg. 2010;52(4):1072-1080. doi:10.1016/j.jvs.2010.05.093

2. Fried GM. FLS assessment of competency using simulated laparoscopic tasks. J Gastrointest Surg. 2008;12(2):210-212. doi:10.1007/s11605-007-0355-0

3. Hafford ML, Van Sickle KR, Willis RE, et al. Ensuring competency: Are fundamentals of laparoscopic surgery training and certification necessary for practicing surgeons and operating room personnel? Surg Endosc. 2013;27(1):118-126. doi:10.1007/s00464-012-2437-7

4. Vassiliou MC, Dunkin BJ, Fried GM, et al. Fundamentals of endoscopic surgery: creation and validation of the hands-on test. Surg Endosc. 2014;28(3):704-711. doi:10.1007/s00464-013-3298-4

5. Panetta T, Matsumoto T, White R. Clinical curriculum and educational objectives for vascular surgery: endovascular therapy in the management of peripheral vascular disease: emerging technologies. 2010; (Available at http://www.vascularweb.org/APDVS/Documents/clinical_ curriculum_051010.pdf.).

6. Martin JA, Regehr G, Reznick R, et al. Objective structured assessment of technical skill (OSATS) for surgical residents. Br J Surg. 1997;84(2):273-278.

7. Pandey V, Wolfe JHN, Moorthy K, Munz Y, Jackson MJ, Darzi AW. Technical skills continue to improve beyond surgical training. J Vasc Surg. 2006;43(3):539-545. doi:10.1016/j.jvs.2005.09.047

8. Duran C, Estrada S, O'Malley M, et al. The model for Fundamentals of Endovascular Surgery (FEVS) successfully defines the competent endovascular surgeon. J Vasc Surg. 2015;62(6):16601666.e3. doi:10.1016/j.jvs.2015.09.026

9. Estrada S, Duran C, Schulz D, Bismuth J, Byrne MD, O'Malley MK. Smoothness of surgical tool tip motion correlates to skill in endovascular tasks. IEEE Trans Human-Machine Syst. 2016;46(5):647659. doi:10.1109/THMS.2016.2545247

10. Duran C, Estrada S, O'Malley M, Lumsden AB, Bismuth J. Kinematics effectively delineate accomplished users of endovascular robotics with a physical training model. J Vasc Surg. 2015;61(2):535-541. doi:10.1016/j.jvs.2014.10.104

11. O'Malley MK, Byrne MD, Estrada S, Duran C, Schulz D, Bismuth J. Expert Surgeons Can Smoothly Control Robotic Tools With a Discrete Control Interface. IEEE Trans Human-Machine Syst. 2019;49(4):388-394. doi:10.1109/THMS.2019.2919744

12. D'Angelo A-LD, Rutherford DN, Ray RD, et al. Idle time: an underdeveloped performance metric for assessing surgical skill. Am J Surg. 2015;209(4):645-651. doi:10.1016/j.amjsurg.2014.12.013

13. Aggarwal R, Grantcharov TP, Eriksen JR, et al. An Evidence-Based Virtual Reality Training Program for Novice Laparoscopic Surgeons. Ann Surg. 2006;244(2):310-314. doi:10.1097/01. sla.0000218094.92650.44

14. Lineberry M, Matthew Ritter E. Psychometric properties of the Fundamentals of Endoscopic Surgery (FES) skills examination. Surg Endosc. 2017;31(12):5219-5227. doi:10.1007/s00464-0175590-1 



\section{Chapter 10}

\section{Endo therapy for thoracic aortic dissection and IMH}

Viony M. Belvroy'; Ponraj Chinnadurai'; Jean Bismuth ${ }^{1}$ 


\begin{abstract}
Endovascular therapy is becoming the standard of care for treating aortic diseases. The continuously evolving technology helps improve new-generation stent grafts and the imaging modalities, so that it is possible to obtain durable results and decrease the amount of complications. The imaging modalities of CT angiography (CTA), transesophageal echocardiography (TEE), and in some cases, MR angiography (MRA), are used preoperatively to give an overview of the anatomy, including the aortic side branches, the landing zone, the angle of the take-off branch vessels, and the entry and re-entry tears. Intraoperatively, fluoroscopy and intravascular ultrasound (IVUS) are widely used. This chapter outlines the steps of endovascular therapy for aortic dissection and intramural hematoma.
\end{abstract}

Keywords: dissection, intramural hematoma, endo therapy, TEVAR, aortic disease 


\section{Introduction}

Thoracic aortic dissection can be classified as an acute or chronic disease based on the duration of symptoms at the time of presentation. Identifying a dissection within < 15 days of symptom initiation is considered the acute phase, between 15 - 92 days it is called the subacute phase and after 93 days it is considered chronic ${ }^{1}$. This classification is based on the morbidity and mortality rates that occurs in the different phases of onset. The classifications used are the anatomical classification according to the Stanford or DeBakey systems². The Stanford classification describes a dissection involving the ascending aorta as a Type A aortic dissection, while if the entry tear occurs distal to the left subclavian artery (LSA) it is considered a type B aortic dissection. The DeBakey classification uses the site of entry tear location, where type 1 originates in the ascending aorta and propagates to at least the aortic arch, type 2 originates and is confined in the ascending aorta, and type 3 originating distal to the LSA. A Type A dissection occurs twice as frequently as a Type B dissection. If Type $B$ dissections are uncomplicated, medical management is mainly focused on pain relief, maintaining a low blood pressure and control of heart rate ${ }^{3}$. Surgical treatment is generally reserved for complicated dissections. Although, surgical management can be handled with both open surgery or endovascular repair, it is clear that endovascular management is favored due to improved outcomes ${ }^{4}$. In this chapter we focus only on the endovascular treatment of aortic dissection.

An aortic Intramural Hematoma (IMH) is a hemorrhage within the media layer of the aortic wall without an intimal lesion ${ }^{5}$, but can be a precursor for aortic dissection. Data suggests that between 8 - 16 percent will develop into a dissection ${ }^{6}$. The classification of an IMH is the same as in aortic dissection. Type A IMH when occurring in the ascending aorta and type B when occurring in the descending aorta. Type B IMH occurs more often than type A. Medical therapy plays an important role in type $\mathrm{B} I \mathrm{MH}$ and is the mainstay of therapy. The mortality is lower with medical therapy, less cardiac complications and they less often develop into a type $B A D^{7,8}$. The 5-year survival rate is around $85 \%{ }^{9}$. In type $A I M H$ the medical treatment is more controversial. Of the patients who were treated medically $27 \%$ - 96\% had severe aortic events requiring aortic replacement during follow-up ${ }^{7}$. Others report that one-third of the medically treated patients develop into an $A D$, rupture and/or eventually need surgery $8,10,11$. If surgery is eventually 
necessary, patients with type $\mathrm{A} I \mathrm{MH}$ receive open surgical repair and patients with type B IMH can undergo thoracic endovascular aortic repair (TEVAR) ${ }^{12}$. Literature suggests medical treatment for uncomplicated type $\mathrm{B} I \mathrm{MH}$ with a 3-year aortic event-related mortality of 5.4\% oppose to open surgery (23.2\%) and endovascular therapy $(7.1 \%)^{13}$. Patients treated for IMH have a higher risk of developing retrograde aortic dissection (RAD) after TEVAR ${ }^{14}$, which should be taken into account when planning for endovascular therapy.

\section{Imaging pre- and post-operative}

Multiple imaging modalities can be used to diagnose an aortic dissection. The most commonly used is Computed Tomography Angiography (CTA), Transesophageal echocardiography (TEE) and in some cases Magnetic Resonance Angiography (MRA). In the acute setting time is of essence. When the patient is hemodynamically stable, the most commonly used imaging modality remains CTA (63\%), TEE (32\%) or MRA (4\%) ${ }^{15}$. In the hemodynamically unstable patient, availability and local expertise determine the appropriateness of the type of modality, in most cases this is CTA $^{16}$.

Imaging of IMH is the corner stone for diagnosis. This is mainly done with CTA, which has a negative predictive value of $100 \%{ }^{17}$. The typical finding on CTA is a crescent shape area of uniform hyper attenuation with associated aortic wall thickening, see figure 1. MRA is used less commonly because of slower scan times. However, MRA has the ability to differentiate between acute and chronic hematomas. On T2-weighted images (blood appears white), acute IMHs ( $<7$ days old) are hyperintense (bright white), and chronic IMHs (>7 days) are less intense, see Fig 13.1. A recent study by Schwein et al. suggests MR imaging criteria to confirm IMH oppose to $A D^{18}$. This pilot study confirms not only the pathology of the disease, but also lesion volume decrease during follow-up, which should make this a more commonly used imaging modality. 


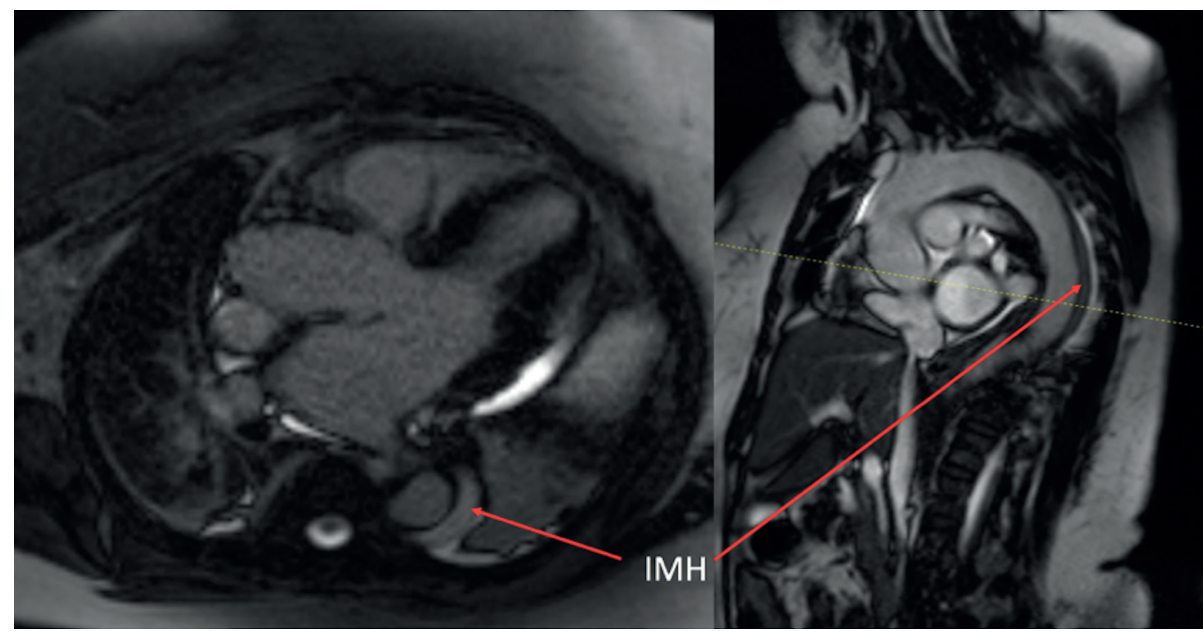

Figure 1. Axial and Sagittal MR image of 58-yo female patient showing chronic type B Intramural Hematoma

\section{Imaging intra-operative}

Primarily two imaging modalities are widely used in TEVAR, Fluoroscopy and IVUS (Intravascular Ultrasound). Fluoroscopy is used to assess the anatomy, placement and deployment of a stent graft. It is mainly used for the arteriography of the aorta and great vessels. Nowadays, it is not uncommon to further use a combination of the pre-operative CTA-imaging (3D) and fusion with fluoroscopy (2D or 3D). By fusing the images, the surgeon benefits from a continuous visualization of the intraoperative landmarks for improved endograft navigation and placement ${ }^{19}$.

IVUS provides real-time data during interventions and is mainly used for accurate graft sizing during the placement of endovascular stent grafts and some say is preferred over CTA ${ }^{20,21}$. It can provide imaging information that can reduce the contrast load in patients with renal dysfunction ${ }^{22}$. In aortic dissection we believe it is essential to use IVUS to help define the entry and re-entry sites during treatment ${ }^{23}$.

Unlike Type B dissections, the difficulty in a veritable IMH is that there is no intimal disruption. Therefore, it is unclear what the extent of endograft coverage of the descending aorta needs to be.

Another imaging modality for intra-operative usage is transesophageal echocardiography (TEE). This is mainly used to reduce the contrast load and radiation exposure. When using contrast TEE (cTEE) this imaging modality can give additional benefits, like in the preoperative characterization phase of aortic 


\section{Chapter 10}

pathology (identifying the number of entry-tears), or intraprocedural or postprocedural phase (slow and/or remaining flow, persistent leaks or retrograde dissection) $)^{24,25}$.

\section{Pre-operative planning}

As mentioned earlier, two main imaging modalities are used for the planning of TEVAR. MR and CT are widely used to give a clear overview of the aortic side branches (i.e. supra aortic trunks, celiac trunk), the landing zone, the angle of the take-off branch vessels and the entry- and re-entry tears, see Figures $2 \& 3$. It is important to observe whether the flow goes retrograde or antegrade into the false lumen.

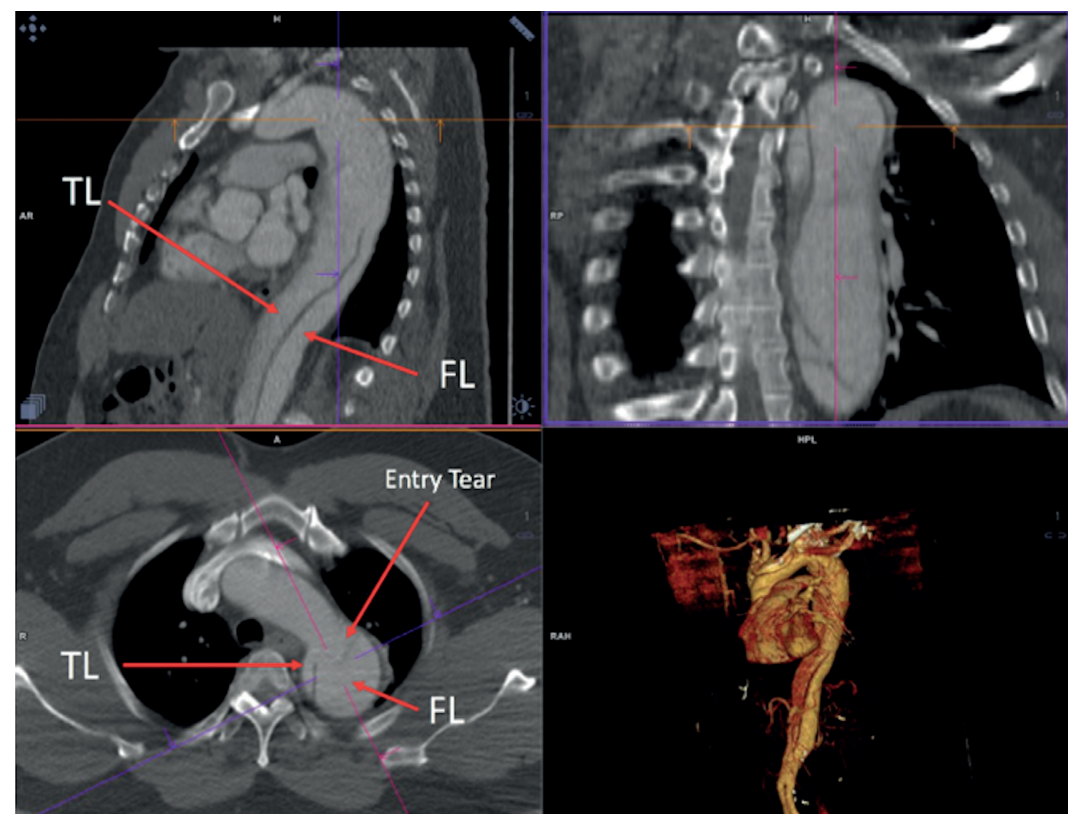

Figure 2. Multiplanar reconstructions of CTA scan of 49-yo male presented with Type B Aortic Dissection demonstrating the true (TL) and false lumen ( $F L)$ 


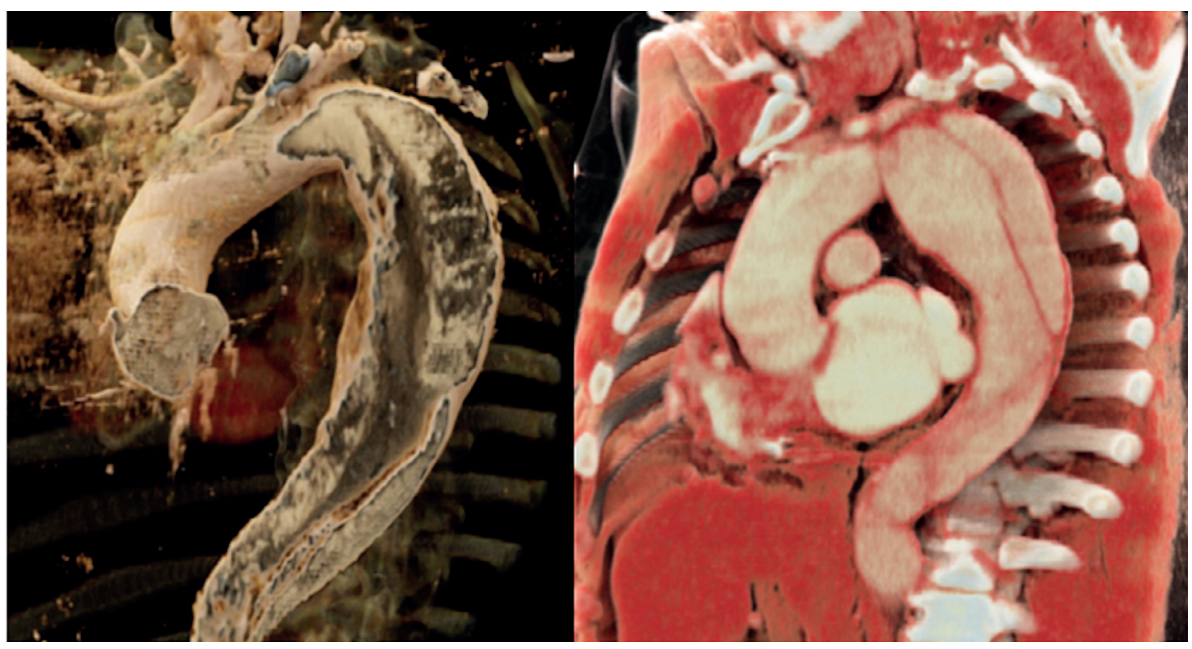

Figure 3. Illustration of advanced cinematic rendering of CT images showing type B Aortic Dissection

When planning for a type $\mathrm{A}$ aortic dissection/IMH, it is critical to pay attention to the innominate artery, and in case of a type B aortic dissection/IMH the left subclavian artery (LSA). It is necessary to avoid covering these arteries with the TEVAR, and critical to understand risks associated if they are covered. If there is a high risk of complications other surgical options can be considered such as debranching or some form of investigational device, which allows for preservation of the supra-aortic branches.

To get a continuous visualization of the critical landmarks during surgery fusion imaging is used. The use of this imaging ensures a reduction in contrast media, radiation exposure and procedure time 26,27 . Fusion imaging uses the preoperative cross-sectional images (CTA and MRA scan) and marks the critical landmarks.

In a 3D-3D registration the non-contrast-enhanced cone beam CT ( $\mathrm{nCBCT}$ ) is combined with the preoperative CTA to create a $3 D$ model. It is based on normalized mutual information and aligns bony structures and vessel calcifications and vessels ${ }^{28}$. It is clear that the more points of co-registration, the more likely that there is a reliable fusion.

A 2D-3D registration overlays the preoperative CTA scan over two projections of a 2D fluoroscopic images (anterior-posterior and lateral). Both 2D-3D and 3D-3D are good choices for co-registration during TEVAR ${ }^{19}$, see Figures $4 \& 5$. 

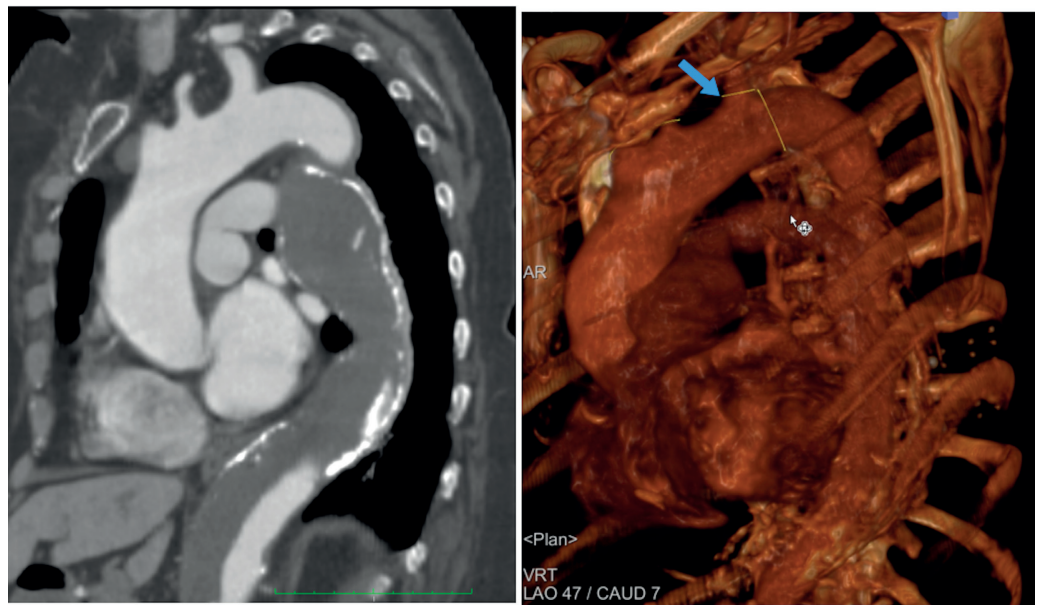

Figure 4. Sagittal (A) and volume rendered (B) CTA images demonstrating 3D planning for TEVAR procedure.

Origins of left Carotid and left subclavian arteries including the aortic landing zone for TEVAR were electronic marked in the planning CTA images (blue arrow)

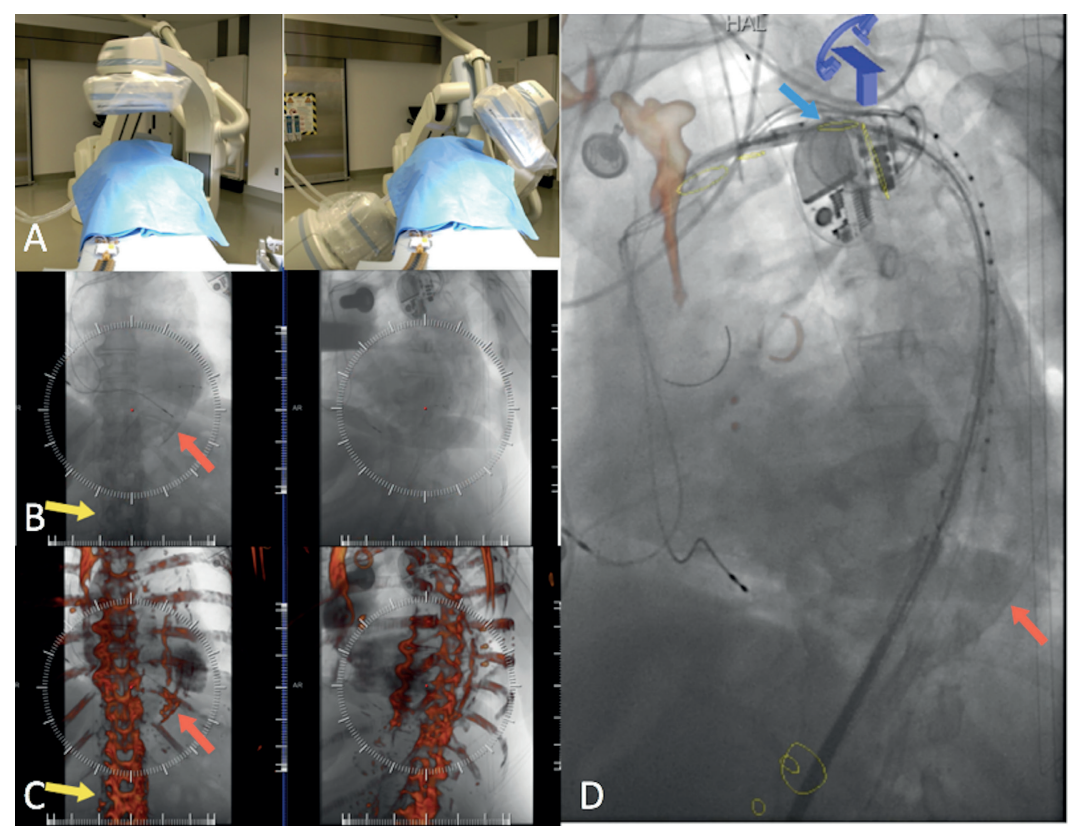

Figure 5. Illustration of 2D3D image fusion workflow for CTA-fluoroscopy image fusion A, B - Two fluoroscopic images were acquired at Antero-Posterior (AP) and Left-AnteriorOblique (LAO 45) views using a robotic C-arm angiography system

C - 3D CT images overlaid on 2D fluoroscopic images demonstrating 2D3D fusion using spine (yellow arrow) and aortic wall calcifications (red arrow) as landmarks

D - Overlay of vessel landmarks (yellow circles) from CTA on 2D fluoroscopy during stent graft deployment, at the planned landing zone (blue arrow) 
Intravascular ultrasound (IVUS) is a critical part of a TEVAR in the setting of aortic dissection. The distal portion consist of a cylindrical ultrasound transducer and is highly accurate in measuring the luminal diameter or at identifying the position of branch vessels, inspect vessel wall morphology, evaluate the presence of plaques or thrombi, and select appropriate landing zones for endografts ${ }^{29}$.

\section{Equipment for endovascular thoracic aortic repair}

As an interventionalist it is important to have expertise with the various tools that are commonly used in endovascular practice. TEVARs are no different in this respect. This not only includes the devices, but also the occlusion balloons, sheaths, guidewires and catheters.

The tools required for a TEVAR in the context of an aortic dissection or IMH is similarly not very different from a standard TEVAR, although there are some important nuances.

Sheaths are widely used to gain safe access to the vascular system when performing an endovascular procedure. In TEVAR the devices are generally larger, and this becomes even more of an issue for newer advanced devices with sidebranches or other variations. The benefit of sheaths is that they minimize localized access vessel trauma by the guidewire or catheter when repeatedly entering vesse ${ }^{30}$, but more importantly provide a safe port of access for tool delivery. Sheaths are made out of Teflon (tetrafluoroethylene), which is an inflexible material that comes with a low friction coefficient and is very torquable (turning the ex vivo portion results in rotation of the vivo portion). Torquability, can though vary by sheath and particularly by its apposition to the vessel wall. Therefore, if a sheath fits in a vessel with great difficulty due to size or occlusive disease, torqueing the sheath is unadvisable as the user may incur a vessel injury. Sheaths are sized by their inner diameter, so this should be taken into account when estimating the largest size-device, which can be inserted through them ${ }^{29}$. To determine maximum sheath size tolerated by a vessel, one would need to multiply the vessel actual inner diameter by a factor of 3 . Additionally, it is important to assess vessel occlusive disease to further evaluate risk of rupture.

Guidewires help the surgeon navigate through the vascular system without damaging the vessel. The stiff inner wire is tapered and doesn't extend to the end of the guidewire, so that the tip is more flexible and atraumatic to the vessel walls. There are different types of wire tip configurations; like J-curved, angled, 
straight or form into shape preferable by the surgeon, which is called the 'floppy' tip. Of equal importance is the core of the wire, which is generally either nitinol or stainless steel. A safe standard J-tip or Starter wire (Bentson) is generally used for initial access, although many use a soft glidewire. These are generally used to gain access to the ascending aorta in a TEVAR case. These wires are subsequently most commonly exchanged to stainless steel stiff wires over a support catheter of choice. The wires usually all have a form of antifriction coating and some even an antithrombogenic coating. For access to a specific vessel or catheterization the standard length of the guidewire is between 145 and $180 \mathrm{~cm}$. When the guidewire is needed to exchange catheters and devices during an endovascular procedure the length is usually between $260-300 \mathrm{~cm}^{29}$, which is always the case in TEVAR. As a rule of thumb in order to appropriately gauge the length of wire needed you simply double the shaft length of your catheter or device and that is the minimum wire length needed (ex. A device with shaft length of $120 \mathrm{~cm}$ needs at a minimum a $240 \mathrm{~cm}$ wire) .

This section is not intended to be an exhaustive discussion of all catheters, so will only be discussed for the purpose of performing a TEVAR. Catheters serve essentially three primary purposes; 1) an infusion flush catheter, 2) support catheter and 3) directional (selective) catheter. They are, essential to performing the intervention safely. A variety of materials are used to make catheters, ie polyurethane, polyethylene, nylon and Teflon, each with different characteristics. The flexibility/ability to track the guidewire to the intended position, the coefficient of friction and the capacity for torqueing help to choose for the correct cathteter ${ }^{29}$.

There are multiple devices, which can be used in the treatment of aortic diseases. There are instructions for use (IFU) for each of these, and we recommend referring to those for particular device. As there are different devices approved in each country, for the purposes of this chapter we will simply refer to the device in a general sense and not a vendor specific tool. Selection of device is most commonly based on availability and physician preference.

\section{Step by step Thoracic Endovascular Aortic Repair}

\section{Femoral Artery Access}

The first step is access to the vascular system. This can be done either through a percutaneous access or an open exposure of the access vessel. Mostly this 
is surgeon preference, unless a conduit is needed. Anecdotally, we prefer an open femoral exposure in cases of aortic dissection as it is our experience that, on occasion even the femoral artery can sometimes be a fragile vessel and so we favor a direct arterial repair rather than a percutaneous one. In the case of an aortic dissection, it is crucial to identify the extent of the dissection into the iliac or femoral vessels before accessing the femoral artery. Accessing the false lumen could have undesirable implications for the procedure. When puncturing the femoral artery it is critical to use ultrasound as guidance, particularly if the femoral artery is dissected. Depending on the device and procedure there may be a bilateral or unilateral groin access. We prefer to use a micro puncture set when accessing the vessels.

\section{Insertion of 0.035 Guidewire, Sheath and Support Catheter}

When the access is created a guidewire is inserted, followed by a $9 \mathrm{Fr}$ sheath. The $9 F r$ sheath is essential in order to be able to perform IVUS. With the appropriate support catheter the guidewire is advanced to the aortic valve. Commonly used guidewires for this purpose are the Bentson wire $260 \mathrm{~cm}$ (Cook Medical) or a hydrophyllic $260 \mathrm{~cm}$.

\section{Exchange to stiff wire}

To get the eventual device in the correct position a stiff guidewire is used. A catheter is therefore initially placed over the floppy guidewire, the floppy guidewire removed and exchanged for a stiff guidewire. We prefer a Lunderquist $300 \mathrm{~cm}$ (Cook Medical) stiff wire, but a number of other wires with adequate support can also be used.

\section{IVUS}

After placing the stiff wire in position an IVUS catheter is used to confirm that the wire is in the true lumen throughout the aorta. It is important to understand that the true lumen is generally the smaller of the two lumens and appears as a half-moon in most instances. Another reason to check is for side branches and entry and re-entry tears. See Figure 6. 


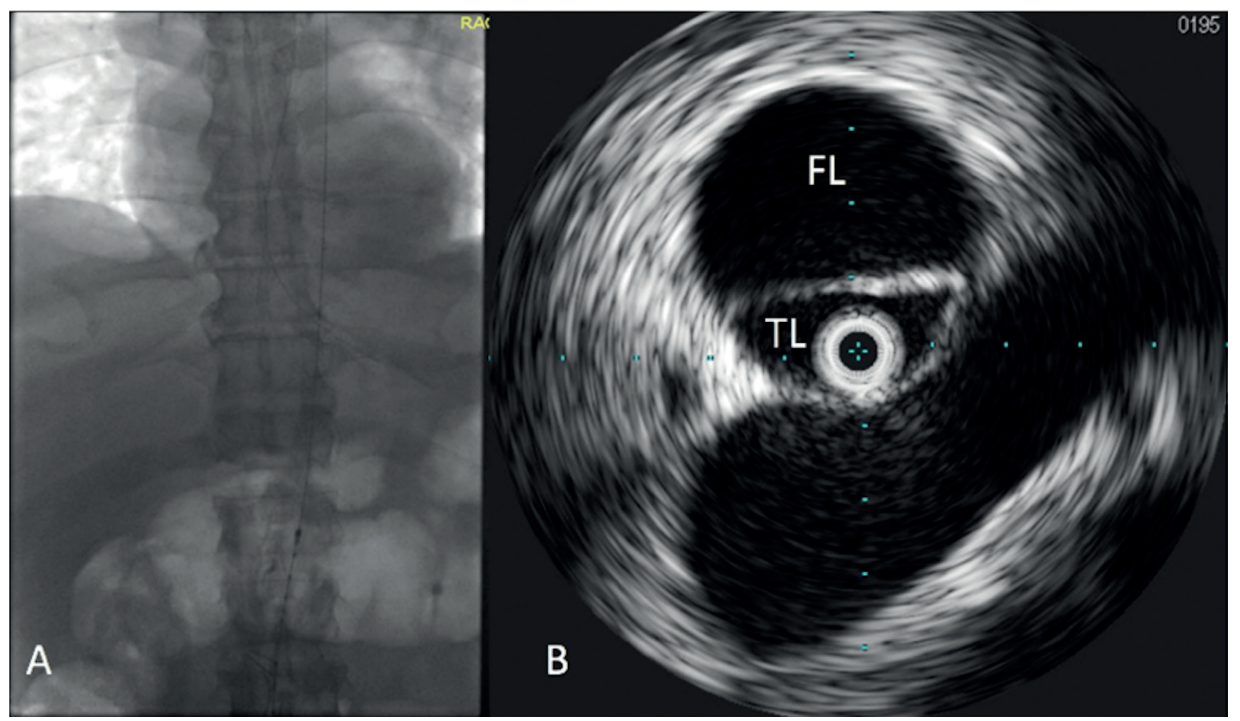

Figure 6. Intravascular Ultrasound (IVUS) of patient with type B Aortic Dissection A; IVUS catheter pull-back was performed under fluoroscopy.

B; Illustrative IVUS image demonstrating visualization of TL \& FL

\section{Place device into position}

When IVUS has confirmed the position of the wire in the true lumen, the device is advanced into position over the stiff guidewire.

\section{Aortogram}

The aortogram confirms your device position and is the last step prior to deployment. For a Type B dissection it is important that the aortogram include the arch as that will not only allow you to see the branch vessels, but it will also you to see your baseline aortic appearance so that you can assure that there is no retrograde dissection on your completion films. The aortogram is generally either done by getting a second wire through your existing sheath and bringing a pigtail into position or via a second femoral puncture on the contralateral side. During an arch aortogram it is imperative that you do this in a Left Anterior Oblique (LAO) projection 40-60 degrees. The actual angle can be estimated from the preoperative computed tomography angiogram. 


\section{Deploy stent graft}

When everything is in the correct position the stent graft will be deployed. Depending on the stent graft it might be possible to adjust the device a little more before full deployment.

\section{Aortogram to confirm}

After full deployment of the stent graft an angiogram is performed to confirm the position of the stent graft and check whether there is flow in the branch vessels and whether there is any evidence of retrograde aortic dissection, see Figure 7. If there is any doubt about a retrograde arch dissection a Transesophageal Echocardiogram (TEE) is a useful imaging modality, as is your IVUS.

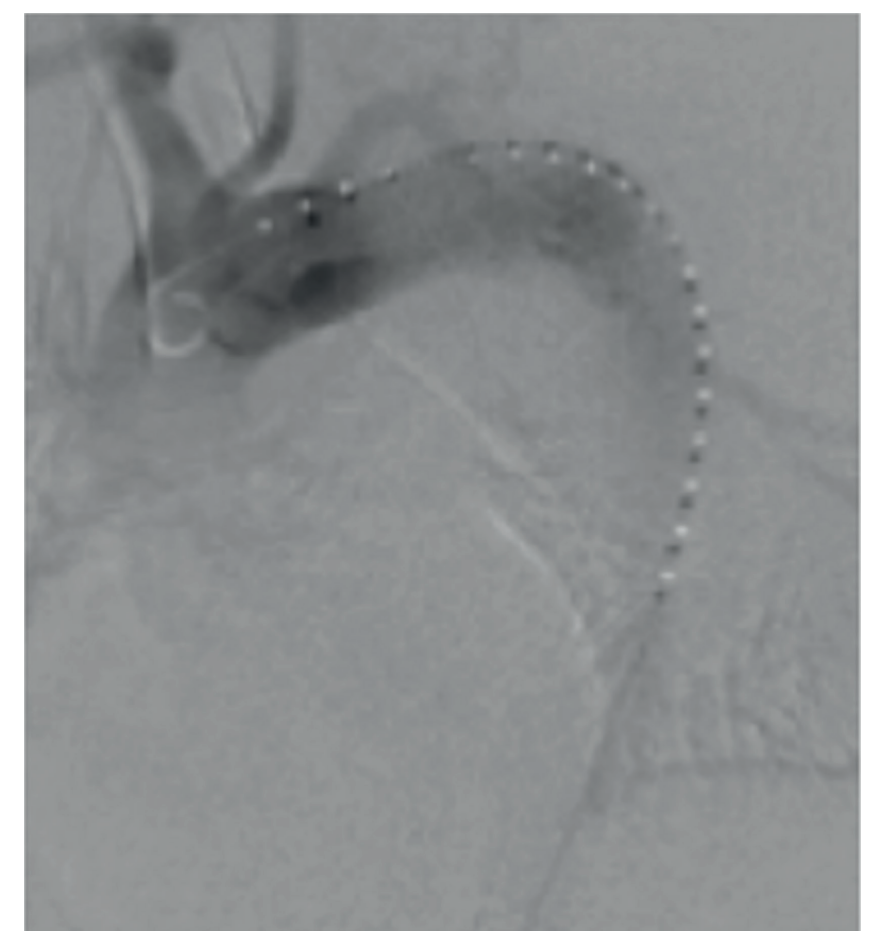

Figure 7. Aortagram post-stent graft implantation with no signs of endoleaks, retrograde dissection and with flow in the branch vessels. 


\section{Extended TEVAR}

When the disease involves the ascending aorta or/and the aortic arch there are different treatment options. Generally, open surgery is the standard for type A dissections and can consist of hemiarch repair or a total arch repair ${ }^{31,32}$.

Debranching the supra-aortic trunks affords options for extending endovascular options. There are three types of aortic debranching. The most commonly used are type I and type II. In a type I aortic debranching the supraaortic trunks are inserted in the ascending aorta to obtain a ZO landing zone for TEVAR. Type II aortic debranching consists of reconstruction of the ascending aorta to create a proximal ZO landing zone ${ }^{33}$.

A total arch repair is done when the disease extends mainly in the aortic arch. This often happens in combination with a frozen elephant trunk. The proximal portion is non-stented and consists of a dacron sleeve for a conventional surgical approach. The distal part consists of a stent graft ${ }^{34,35}$. A stent graft currently used for the frozen elephant trunk technique is the E-vita Open Plus Graft by JOTEC (Hechingen, Germany).

Totally endovascular solutions are currently being used as seen in anecdotal reports as well as purpose built devices, which are in trials. The overall techniques are essentially no different from that for type B dissection TEVAR, the precautions are just different based on landmarks such as the coronary arteries and Innominate artery. Additionally, it is important to have experience in crossing the aortic valve with a guidewire, understand rapid ventricular pacing and have TEE surveillance during the procedure. For the purposes of this chapter and due to the investigational status of this procedure in the ascending aorta and arch, we will not go into any further details. 


\section{PEARLS of TEVAR for Aortic Dissection}

- $\quad$ Three phases of onset; acute (<15 days), subacute (15 - 92 days), chronic (> 92 days)

- Medical management for uncomplicated type B aortic dissection and focus on pain relief, with blood pressure and heart rate reduction and close followup.

- Endovascular repair favorable over open surgery

- Imaging is critical. Pre-operative most common used in aortic dissection is CTA, to give a clear overview of the aortic side branches, landing zones, angles and entry- and re-entry tears. Intra-operative fluoroscopy and IVUS is essential to yield consistent and optimal results.

- $\quad$ Steps of TEVAR; 1) femoral artery access, 2) insertion of 0.035 guidewire, sheath and support catheter, 3) exchange to stiff wire, 4) IVUS, 5) place device in position, 6) aortogram, 7) deploy stent graft, 8) aortogram to confirm 


\section{References}

1. VIRTUE Registry Investigators. Mid-term Outcomes and Aortic Remodelling After Thoracic Endovascular Repair for Acute, Subacute, and Chronic Aortic Dissection: The VIRTUE Registry. Eur J Vasc Endovasc Surg. 2014;48(4):363-371. doi:10.1016/j.ejvs.2014.05.007

2. Nienaber CA, Eagle KA. Aortic dissection: new frontiers in diagnosis and management: Part I: from etiology to diagnostic strategies. Circulation. 2003;108(5):628-635. doi:10.1161/01. CIR.0000087009.16755.E4

3. Suzuki T, Eagle KA, Bossone E, et al. Medical management in type B aortic dissection. Ann Cardiothorac Surg. 2014;3(4):413-417. doi:10.3978/j.issn.2225-319X.2014.07.01

4. Li F-R, Wu X, Yuan J, et al. Comparison of thoracic endovascular aortic repair, open surgery and best medical treatment for type B aortic dissection: A meta-analysis. Int J Cardiol. 2018;250:240246. doi:10.1016/j.ijcard.2017.10.050

5. Goldberg JB, Kim JB, Sundt TM. Current understandings and approach to the management of aortic intramural hematomas. Semin Thorac Cardiovasc Surg. 2014;26(2):123-131. doi:10.1053/j. semtcrs.2014.07.003

6. Song J-K, Yim JH, Ahn J-M, et al. Outcomes of Patients With Acute Type A Aortic Intramural Hematoma. Circulation. 2009;120(21):2046-2052. doi:10.1161/CIRCULATIONAHA.109.879783

7. Tittle SL, Lynch RJ, Cole PE, et al. Midterm follow-up of penetrating ulcer and intramural hematoma of the aorta. J Thorac Cardiovasc Surg. 2002;123(6):1051-1059.

8. Song J-K, Kim H-S, Song J-M, et al. Outcomes of medically treated patients with aortic intramural hematoma. Am J Med. 2002;113(3):181-187.

9. Sueyoshi E, Sakamoto I, Fukuda M, et al. Long-term outcome of type B aortic intramural hematoma: comparison with classic aortic dissection treated by the same therapeutic strategy. Ann Thorac Surg. 2004;78(6):2112-2117. doi:10.1016/j.athoracsur.2004.05.048

10. Pelzel JM, Braverman AC, Hirsch AT, et al. International heterogeneity in diagnostic frequency and clinical outcomes of ascending aortic intramural hematoma. J Am Soc Echocardiogr. 2007;20(11):1260-1268. doi:10.1016/j.echo.2007.03.018

11. Estrera A, Miller C, Lee T-Y, et al. Acute Type A Intramural Hematoma: Analysis of Current Management Strategy. Circulation. 2009;120(11_suppl_1):S287-S291. doi:10.1161/ CIRCULATIONAHA.108.844282

12. Ferrera C, Vilacosta I, Gómez-Polo JC, et al. Evolution and prognosis of intramural aortic hematoma. Insights from a midterm cohort study. Int J Cardiol. 2017;249:410-413. doi:10.1016/j. ijcard.2017.09.170

13. Evangelista A, Czerny M, Nienaber C, et al. Interdisciplinary expert consensus on management of type B intramural haematoma and penetrating aortic ulcer. Eur J Cardio-Thoracic Surg. 2015;47(2):209-217. doi:10.1093/ejcts/ezu386

14. Idrees J, Arafat A, Johnston DR, et al. Repair of retrograde ascending dissection after descending stent grafting. J Thorac Cardiovasc Surg. 2014;147(1):151-154. doi:10.1016/j.jtcvs.2013.08.075

15. Moore AG, Eagle KA, Bruckman D, et al. Choice of computed tomography, transesophageal echocardiography, magnetic resonance imaging, and aortography in acute aortic dissection: International Registry of Acute Aortic Dissection (IRAD). Am J Cardiol. 2002;89(10):1235-1238.

16. Baliga RR, Nienaber CA, Bossone E, et al. The Role of Imaging in Aortic Dissection and Related Syndromes. JACC Cardiovasc Imaging. 2014;7(4):406-424. doi:10.1016/j.jcmg.2013.10.015

17. Hayter RG, Rhea JT, Small A, et al. Suspected aortic dissection and other aortic disorders: multi-detector row CT in 373 cases in the emergency setting. Radiology. 2006;238(3):841-852. doi:10.1148/radiol.2383041528

18. Schwein A, Khan M, Bennett M, et al. Proposed Magnetic Resonance Imaging Criteria to Diagnose Intramural Haematoma and to Predict Aortic Healing after Acute Type B Aortic Syndrome. Eur J Vasc Endovasc Surg. October 2018. doi:10.1016/j.ejvs.2018.09.017

19. Schulz CJ, Schmitt M, Böckler D, et al. Feasibility and accuracy of fusion imaging during thoracic endovascular aortic repair. J Vasc Surg. 2016;63(2):314-322. doi:10.1016/j.jvs.2015.08.089 
20. Lortz J, Tsagakis K, Rammos C, et al. Intravascular ultrasound assisted sizing in thoracic endovascular aortic repair improves aortic remodeling in Type B aortic dissection. Yu J, ed. PLoS One. 2018;13(4):e0196180. doi:10.1371/journal.pone.0196180

21. Wallace GA, Starnes BW, Hatsukami TS, et al. Intravascular ultrasound is a critical tool for accurate endograft sizing in the management of blunt thoracic aortic injury. J Vasc Surg. 2015;61(3):630635. doi:10.1016/j.jvs.2014.10.014

22. Marty B, Tozzi P, Ruchat P, et al. Systematic and exclusive use of intravascular ultrasound for endovascular aneurysm repair - the Lausanne experience. Interact Cardiovasc Thorac Surg. 2005;4(3):275-279. doi:10.1510/icvts.2004.094193

23. Pearce BJ, Jordan WD. Using IVUS during EVAR and TEVAR: Improving Patient Outcomes. Semin Vasc Surg. 2009;22(3):172-180. doi:10.1053/j.semvascsurg.2009.07.009

24. Agricola E, Slavich M, Rinaldi E, et al. Usefulness of contrast-enhanced transoesophageal echocardiography to guide thoracic endovascular aortic repair procedure. Eur Hear J - Cardiovasc Imaging. June 2015:jev118. doi:10.1093/ehjci/jev118

25. Agricola E, Slavich M, Bertoglio L, et al. Contrast-Enhanced TEE During Thoracic Endovascular Aortic Repair Procedure. JACC Cardiovasc Imaging. 2015;8(8):980-982. doi:10.1016/j. jcmg.2014.07.029

26. McNally MM, Scali ST, Feezor RJ, et al. Three-dimensional fusion computed tomography decreases radiation exposure, procedure time, and contrast use during fenestrated endovascular aortic repair. J Vasc Surg. 2015;61(2):309-316. doi:10.1016/j.jvs.2014.07.097

27. Hertault A, Maurel B, Sobocinski J, et al. Impact of hybrid rooms with image fusion on radiation exposure during endovascular aortic repair. Eur J Vasc Endovasc Surg. 2014;48(4):382-390. doi:10.1016/j.ejvs.2014.05.026

28. Miao S, Liao R, Pfister M, et al. System and method for 3-D/3-D registration between noncontrast-enhanced CBCT and contrast-enhanced CT for abdominal aortic aneurysm stenting. Med Image Comput Comput Assist Interv. 2013;16(Pt 1):380-387.

29. Khoynezhad A, Kruse MJ. Guidewires, Catheters, and Sheaths Used for Thoracic Endografting Procedures. J Card Surg. 2009;24(2):113-119. doi:10.1111/j.1540-8191.2008.00628.x

30. Kinney E V, Fogarty TJ, Newman CE. Catheter skills. Peripher Endovasc Interv 2nd ed SpringerVerlag, New York, NY. 1999:247-258.

31. Poon SS, Theologou T, Harrington D, et al. Hemiarch versus total aortic arch replacement in acute type A dissection: a systematic review and meta-analysis. Ann Cardiothorac Surg. 2016;5(3):156173. doi:10.3978/10465

32. Macgillivray TE. HOW I TEACH IT How I Teach Hemi-Arch Replacement. 2016. doi:10.1016/j. athoracsur.2016.02.047

33. Vallabhajosyula P, Szeto WY, Desai N, et al. Type II arch hybrid debranching procedure. Ann Cardiothorac Surg. 2013;2(3):378-386. doi:10.3978/2014

34. Di Bartolomeo R, Murana G, Marco L Di, et al. Frozen versus conventional elephant trunk technique: application in clinical practice. Eur J Cardio-thoracic Surg. 2017. doi:10.1093/ejcts/ ezw335

35. LeMaire SA, Weldon SA, Coselli JS. Total aortic arch replacement: current approach using the trifurcated graft technique. Ann Cardiothorac Surg. 2013;2(3):347-352. doi:10.3978/2007 



\section{Chapter 11}

Endovascular creation of acute in-vivo swine model and multi-modality imaging for understanding the pathophysiology of Type B Aortic Dissection

Viony M. Belvroy ${ }^{1,2}$, Ponraj Chinnadurai ${ }^{1}{ }^{3}$, Adeline Schwein ${ }^{1}$, Leslie Jenkins ${ }^{4}$, Maan Malahfji', Jean Bismuth ${ }^{1}$

1 Houston Methodist DeBakey Heart \& Vascular Center, Houston, Texas, United States

2 Department of Vascular Surgery, University Medical Center Utrecht, Utrecht, Netherlands

3 Advanced Therapies, Siemens Medical Solutions USA Inc., Malvern, Pennsylvania, United States

4 Department of Comparative Medicine, Houston Methodist Research Institute, Houston, Texas, United States 


\section{Abstract}

Introduction Type B aortic dissection is an aortic wall pathology with high morbidity-mortality rates that remains poorly understood, especially in terms of parameters that accurately predict vessel wall instability and aortic remodeling. The aim of this study was to create an in-vivo swine model of type B aortic dissection, and to understand its pathophysiology using multi-modality imaging techniques.

Methods Baseline imaging using CMR, arteriogram and cone-Beam CT were performed on a domestic swine. Under trans-esophageal echocardiography (TEE), fluoroscopy and cone-beam CT image guidance, the intima of the descending thoracic aorta was punctured. Heparinized saline was mixed with iodinated contrast and injected to create a hydro-dissection within the aortic media. After balloon dilation, phenylephrine bolus and infusion was started to induce hypertension to facilitate distal propagation of aortic dissection. Upon confirmation by TEE and intravascular ultrasound, a series of imaging studies were performed to image the aortic dissection including cone-beam CT, 4D-TEE and MR imaging. Upon completion, the animal was euthanized and the aorta harvested for histopathological examination.

Results Twelve animals, mean weight of $80.3 \mathrm{~kg}$, were included in this study and ten were female. There were no difficulties with vascular access. In three cases (25\%) aortic dissection distal to the subclavian artery was created successfully; 6,8 and $8 \mathrm{~cm}$ long. This was confirmed with multi-modality imaging and histopathological examination. In 5 (41.7\%) cases the animal died due to puncturing through the aortic wall. In four cases (33.3\%) a hematoma was created within the aortic wall without aortic dissection.

Conclusion Endovascular creation of Type B aortic dissection in a swine model consistently and with reproducibility was very challenging. Various lessons have been learned and will be implemented in the next phase of this experiment. Ability to access the aortic wall with precise depth and stability seems to be a critical factor in determining the success of creation of aortic dissection.

Key words: in-vivo model, type b aortic dissection, thoracic aorta, endovascular repair 


\section{Introduction}

Type B aortic dissection is a pathology with high morbidity-mortality rates and requires life-long surveillance. Chronic false lumen dilatation and aortic rupture both need close follow-up.

Treatment of type B aortic dissection can include either best medical management or combined with surgical intervention, either endovascular or open. Various trials have shown the benefits of endovascular repair over open surgical treatment ${ }^{1-3}$. However, the understanding of treating aortic dissection is still poor, especially regarding long-term remodeling. There have been computational models created to understand the pathophysiology. They facilitate the understanding of the flow dynamics and show that drag forces on the stent graft are high with the risk of stent graft migration ${ }^{4-6}$. Silicon in-vitro models have been developed that mimic a Type B aortic dissection and can be used in future models to study the physiology and flow dynamics 7,8 . Furthermore, a variety of ex vivo models were generated to study the morphology and flow parameters. The elements studied in detail were the size of the entry tear and the impact of false lumen pressure ${ }^{9}$, how different sides of the entry tear further propagate ${ }^{10}$, the depth of the entry tear ${ }^{11}$ and the development of the dissection further distal and Faure et al. created the first human ex vivo model to study the effect of endovascular treatment ${ }^{12}$. Likewise, there have been studies in canine models to create a model to test treatment options ${ }^{13-15}$. However, all these model were created via thoracotomy. To our knowledge, in only one study was the model created with endovascular access ${ }^{16}$. They used a retrograde approach to create the dissection in the thoracoabdominal aorta.

The objective of this study was to create an in-vivo porcine model of type $B$ aortic dissection in order to study the short- and long-term evolution of the pathology. The aims are to better understand the pathophysiology using multimodality imaging techniques and to create a chronic surviving animal. The uniqueness of this technique is an antegrade approach to keep the dissection as physiologic as possible. 


\section{Methods}

\section{Animal preparation}

This study was approved by the local Institutional Animal Care and Use Committee (IACUC). A total number of 12 domestic swine were used in this study as nonsurviving animals. The model was created to prove reliability and reproducibility. At the end of each experiment the animal was euthanized and the aorta harvested for histopathological examination.

\section{Multi-modality imaging}

Different imaging modalities were used peri-operatively. For baseline scanning 4D magnetic resonance imaging (MRI) was used, followed by cone-beam computed tomography (CBCT) with contrast for planning the surgical techniques. Intraoperatively fluoroscopy, trans-esophageal echocardiography (TEE), intravascular ultrasound (IVUS) and angiography have been used as guidance while creating the dissection. When the dissection was successfully created this was visualized with CBCT and 4D MRI.

For MRI imaging magnevist contrast was administered $(20 \mathrm{ml}$ per imaging round) and omnipaque contrast was given during the CBCT (12 cc/s) and the aortagram $(20 \mathrm{cc} / \mathrm{s})$.

\section{Surgical method}

The animal preparation was monitored by the comparative medicine program (CMP) team. The animals were on a standard diet and anesthesia was registered via a standardized protocol; drugs used are (varied per case) isoflurin, hydromorphone $(0.1-0.2 \mathrm{mg} / \mathrm{kg})$, ketamine $(11-33 \mathrm{mg} / \mathrm{kg})$, midazolam $(0.1-0.5$ $\mathrm{mg} / \mathrm{kg}$ ), buprenorphine (0.01 - $0.05 \mathrm{mg} / \mathrm{kg} \mathrm{IM})$ and/or cyclobenzaprine. Heparin was given to all animals (1000 UI per $10 \mathrm{~kg}+1000 \mathrm{UI}$ every hour).

Vascular access was created through the carotids (primarily the right carotid), femoral arteries and the left subclavian artery (LSA). Then, the aortic wall was punctured $2 \mathrm{~cm}$ distal to the LSA using the trans septal needle. While puncturing the aortic wall, a mix of fluids $(5 \mathrm{ml}$ of heparin/contrast/saline $(20 \%$ heparin and $80 \%$ contrast/saline) were injected to create a hydro-dissection within the aortic media. Balloon dilatation was used to enlarge the entry tear. In case of a successful dissection, drug induced hypertension was used to propagate 
the dissection more distally. For the drug induced hypertension phenylephrine was administered ( $1 \mathrm{mg} / \mathrm{ml}$ IV) until the systolic blood pressure was up to 200 $\mathrm{mmHg}$. In some cases norepinephrine $(20 \mathrm{mcg} / \mathrm{min}$ IV) was given and to prevent arrhythmia amiodarone was used. After the final round of imaging the animal was euthanized injecting buthanasia solution $(390 \mathrm{mg} / 4.5 \mathrm{~kg}$ IV) and the aorta harvested for histopathological examination.

\section{Results}

Twelve animals were included in the acute phase of the study, ten were female. Baseline scanning was successful in all animals and there were no difficulties with access creation. The pacing catheter was placed in the left common femoral vein in order to be able to control heart rate as necessary. When the TEE was in the correct position the trans septal needle was introduced to puncture the aortic wall. In 11 cases (91.7\%) the aortic wall was punctured $2 \mathrm{~cm}$ distal to the LSA, in one case it was $8 \mathrm{~cm}$ distally. The trans-septal needle was used in 7 cases (58.3\%), in 5 cases the off-road device was used (41.7\%). In most cases ( $N=10$ $(83.3 \%))$ the needle was inserted from a proximal position to puncture the aortic wall antegrade. This way, the dissection will be more physiological.

In 5 cases $(41.7 \%)$ the animal died on the table due to aortic rupture as the aortic wall was punctured. In those cases no post-operative MRI or CBCT was performed. The animal was euthanized directly and the aorta harvested for histopathological examination. In three cases (25\%), a successful dissection was created. Figure 1 shows the multi-modality imaging techniques used during the experiment. First the aortagram shows the false lumen distal to the LSA, which is confirmed by the CBCT. The 2D TEE imaging shows the intimal flap and the entry tear. The 4D TEE visualizes flow from the true lumen to the false lumen. The time-resolved MRA sequence shows contrast flow into the false lumen. In the sagittal view the cine MRI 2D shows the entry tear with flow into the false lumen and the axial view shows the exit tear with flow returning to the true lumen. In the 4D flow MRI the flow is reconstructed. 
Figure $2 \& 3$ shows the histopathology from the dissection.

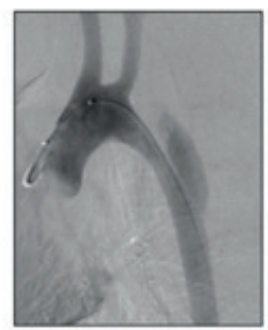

Aortogram

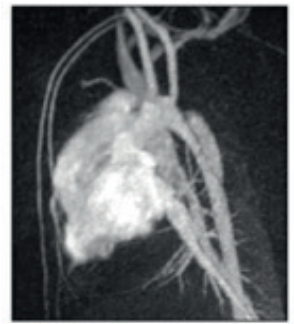

Time-resolved MRA

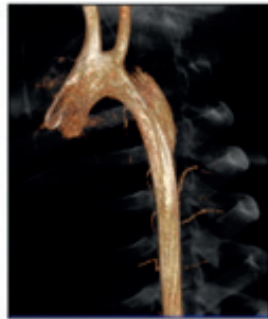

Cone-beam CT

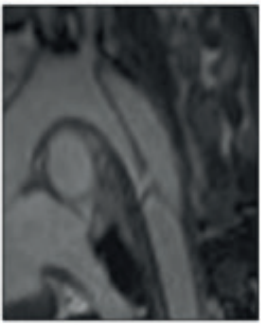

Cine MRI

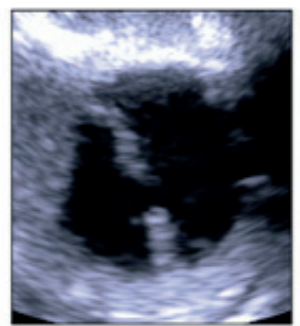

2D TEE

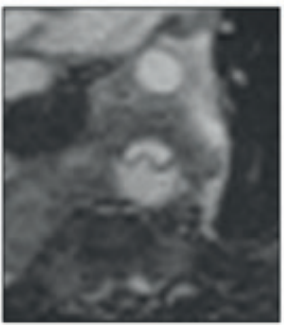

Cine MRI

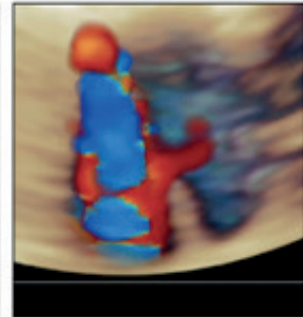

4D TEE

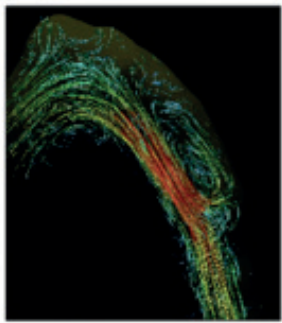

4D Flow MRI

Figure 1. Multi-modality imaging of the type $B$ aortic dissection created in the descending thoracic aorta. A female domestic pig, $70 \mathrm{~kg}$ with a $6 \mathrm{~cm}$ long dissection with entry and re-entry tears. (Videos of the multimodality imaging techniques are available upon request).
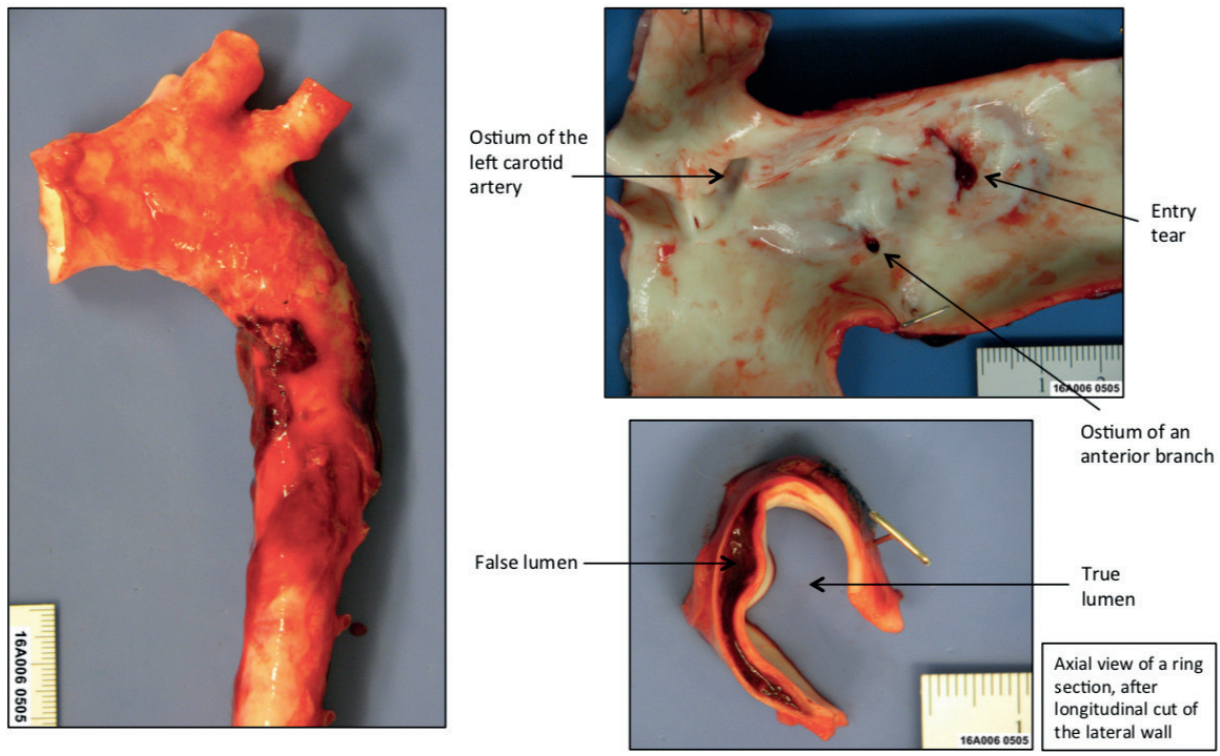

Figure 2. Pathology image of the type B dissection showing the entry tear, the true lumen and the false lumen. 


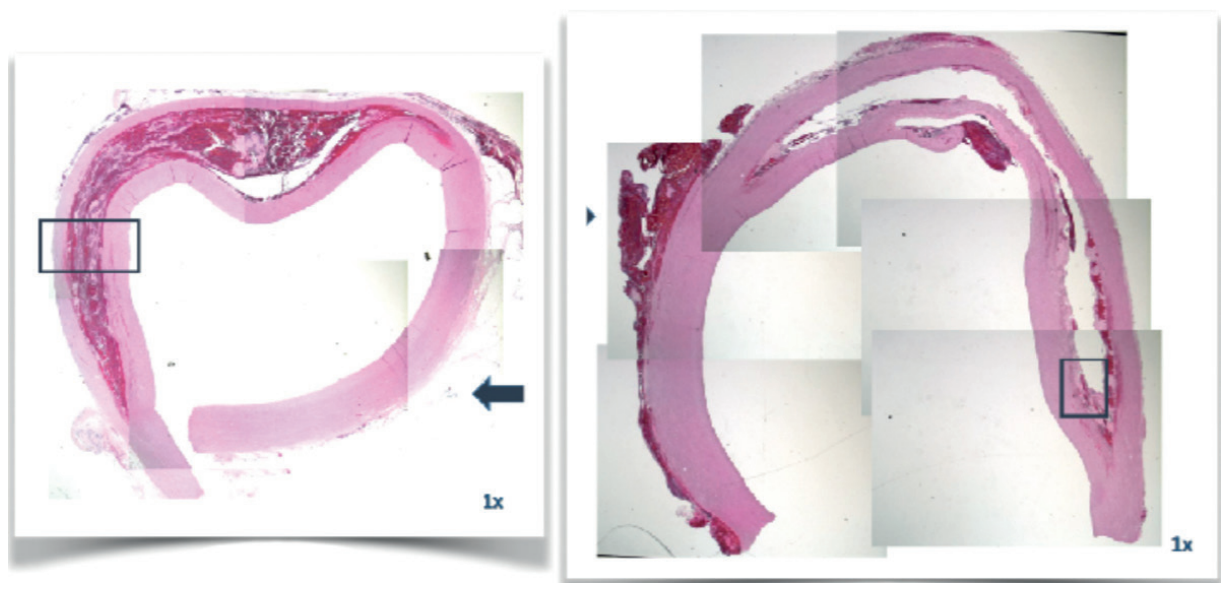

Figure 3. Histopathology images showing the dissection with intimal flap.

\section{Discussion}

This study gives an insight on how to create an in-vivo porcine model of Type B aortic dissection and how multi-modality imaging can be useful to study the pathophysiology. The techniques used showed predicaments on how to create the dissection from an antegrade approach with the right angle.

To our knowledge this was the first study that used an endovascular antegrade approach in creating an aortic dissection. Previous studies used thoracotomy access to create the dissection and they used canine models ${ }^{13-15}$. One showed a surgical approach of creating a two-end intimal flap by opening half of the circumferential aorta, leaving only the intima intact ${ }^{13}$. Another inserted a normal saline solution into the aortic wall, however, accessing through thoracotomy ${ }^{14}$. Only the study by Okuno et al. created the dissection through an endovascular approach in a swine model, however, accessing the aorta with a retrograde approach ${ }^{16}$. They had a success factor of $78.6 \%$, which was higher than our success rate (25\%). It seemed that creating retrograde access has more stability, as there is no angle of the aortic arch to overcome while puncturing the aortic wall. However, we think that using an antegrade approach has its advantages, as this is the physiological etiology of an aortic dissection.

After creating the dissection the goal was to let the dissection propagate further distally, which was obtained by inducing hypertension using drugs. Mainly, we used phenylephrine, a vasoconstrictor stimulating the alpha 1 receptors on blood vessels. Aiming for a systolic blood pressure of around $200 \mathrm{mmHg}$, seemed 


\section{Chapter 11}

difficult to obtain, as some animals reached high pressure with minimal doses and others required a higher dose. Switching to norepinephrine came with the same difficulties, where in some cases amiodarone was given to prevent arrhythmia. This taught us to be careful with dosing while inducing the hypertension.

The surgical technique had some predicaments regarding puncturing the aortic wall. By creating proximal access and puncture the aortic wall distal to the LSA, meant entering via the carotids or the LSA and overcome the angulation of the aortic arch. CBCT was used to measure the angles and bent the needle according to the anatomy. However, due to aortic wall motion throughout the cardiac cycle finding stability was a challenge. Furthermore, the aortic wall was extremely thin in the descending thoracic aorta (DTA). The depth of the puncture should not exceed 1-2 mm, which was again difficult due to aortic motion.

This study only consisted of acute animals, meaning they were euthanized after the experiment. Essentially this is considered to be the first part of our experiment; creating an animal model to study the pathophysiology, however, the second stage would be to develop a model to study the long-term evolution of the dissection. Assessment using multi-modality imaging techniques during follow-up and ultimately harvesting the aorta on the last day of the follow-up period, serve as the primary components of model estimation.

The endovascular creation of a type $B$ aortic dissection in a swine model was challenging. To consistently create the dissection was difficult due to the aortic wall motion and wall thickness. The depth of puncture and stability were key factors for the successful creation of a dissection.

Aortic dissection is a dynamic disease, which requires multi-modality imaging to understand the pathophysiology of this disease. Various lessons have been learned and will be implemented in the next phase of this experiment. 


\section{References}

1. Nienaber CA, Rousseau H, Eggebrecht H, et al. Randomized comparison of strategies for type B aortic dissection: the INvestigation of STEnt Grafts in Aortic Dissection (INSTEAD) trial. Circulation. 2009;120(25):2519-2528. doi:10.1161/CIRCULATIONAHA.109.886408

2. Cooper M, Hicks C, Ratchford E V, Salameh MJ, Malas M. Diagnosis and treatment of uncomplicated type B aortic dissection. Vasc Med. 2016;21(6):547-552. doi:10.1177/1358863X16643601

3. Brunkwall J, Lammer J, Verhoeven E, Taylor P. ADSORB: A Study on the Efficacy of Endovascular Grafting in Uncomplicated Acute Dissection of the Descending Aorta. Eur J Vasc Endovasc Surg. 2012;44(1):31-36. doi:10.1016/j.ejvs.2012.03.023

4. Cheng SWK, Lam ESK, Fung GSK, Ho P, Ting ACW, Chow KW. A computational fluid dynamic study of stent graft remodeling after endovascular repair of thoracic aortic dissections. J Vasc Surg. 2008;48(2):303-310. doi:10.1016/j.jvs.2008.03.050

5. Cheng Z, Tan FPP, Riga C V, et al. Analysis of flow patterns in a patient-specific aortic dissection model. J Biomech Eng. 2010;132(5):051007. doi:10.1115/1.4000964

6. Ben Ahmed S, Dillon-Murphy D, Figueroa CA. Computational Study of Anatomical Risk Factors in Idealized Models of Type B Aortic Dissection. Eur J Vasc Endovasc Surg. 2016;52(6):736-745. doi:10.1016/j.ejvs.2016.07.025

7. Birjiniuk J, Veeraswamy RK, Oshinski JN, Ku DN. Intermediate fenestrations reduce flow reversal in a silicone model of Stanford Type B aortic dissection. J Biomech. 2019;93:101-110. doi:10.1016/j. jbiomech.2019.06.019

8. Birjiniuk J, Ruddy JM, Iffrig E, et al. Development and testing of a silicone in vitro model of descending aortic dissection. J Surg Res. 2015;198(2):502-507. doi:10.1016/j.jss.2015.03.024

9. Tsai TT, Schlicht MS, Khanafer K, et al. Tear size and location impacts false lumen pressure in an ex vivo model of chronic type B aortic dissection. J Vasc Surg. 2008;47(4):844-851. doi:10.1016/j. jvs.2007.11.059

10. Dziodzio T, Juraszek A, Reineke D, et al. Experimental acute type B aortic dissection: different sites of primary entry tears cause different ways of propagation. Ann Thorac Surg. 2011;91(3):724-727. doi:10.1016/j.athoracsur.2010.11.056

11. Guo B, Dong Z, Pirola S, et al. Dissection Level Within Aortic Wall Layers is Associated with Propagation of Type B Aortic Dissection: A Swine Model Study. Eur J Vasc Endovasc Surg. 2019;58(3):415-425. doi:10.1016/j.ejvs.2019.02.026

12. Faure EM, Canaud L, Cathala P, Serres I, Marty-Ané C, Alric P. Human ex-vivo model of Stanford type B aortic dissection. J Vasc Surg. 2014;60(3):767-775. doi:10.1016/j.jvs.2013.06.083

13. Cui JS, Zhuang SJ, Zhang J, Mei ZJ, Jing ZP, Liao MF. Two-end intimal flap suturing method for establishing Stanford B type aortic dissection in a canine model. Eur J Vasc Endovasc Surg. 2009;38(5):603-607. doi:10.1016/j.ejvs.2009.07.005

14. Terai H, Tamura N, Yuasa S, Nakamura T, Shimizu Y, Komeda M. An experimental model of Stanford type B aortic dissection. J Vasc Interv Radiol. 2005;16(4):515-519. doi:10.1097/01. RVI.0000151142.80319.85

15. Tang J, Wang Y, Hang W, Fu W, Jing Z. Controllable and Uncontrollable Stanford Type B Aortic Dissection in Canine Models. Eur Surg Res. 2010;44(3-4):179-184. doi:10.1159/000283218

16. Okuno T, Yamaguchi M, Okada T, et al. Endovascular creation of aortic dissection in a swine model with technical considerations. J Vasc Surg. 2012;55(5):1410-1418. doi:10.1016/j.jvs.2011.10.088 



\section{Part 5:}

Summary, discussion 



\section{Chapter 12}

Summary, discussion \& future perspectives 


\section{Summary}

In this dissertation the focus lays on two main aortic pathologies, aneurysmal and dissection diseases, which can both be treated with thoracic aortic endovascular repair (TEVAR). TEVAR has recently become the treatment of choice, due to a fast recovery period after surgery and its suitability for the high risk patient who are unfit for open surgery ${ }^{1,2}$. However, the human anatomy is not always suitable for endovascular repair and as timing is of essence, an off-the-shelf stent graft is not always available.

In this dissertation you can find an overview of the limitations of devices that are used in endovascular repair. A summary is given on large trials investigating the difference in open surgery and endovascular aortic repair (EVAR), as well as considerations for the imaging modalities used preoperatively, perioperatively and postoperatively, and finally complications and the evolution of devices. Focusing on the descending thoracic aorta (DTA) and its complications a systematic review is performed on type $1 \mathrm{~b}$ endoleaks and its risk factors. This is followed by three studies on aortic tortuosity in the DTA. The first describes tortuosity in a healthy patient population between young $(<65)$ and older (> 65) patients, where older patients have a higher tortuosity index. Then, comparing a healthy population to patients with aneurysmal diseases and dissections. Patients with aneurysmal diseases have the highest amount of tortuosity. The final paper on aortic tortuosity describes the displacement forces throughout the DTA, divided in four equal zones, in three groups with a different amount of tortuosity (low $=<30^{\circ}$; moderate $=30^{\circ}-60^{\circ}$; high $=>60^{\circ}$ ). The high tortuosity group has the strongest displacement force.

The following section is on aortic dynamics in the ascending thoracic aorta (ATA). The first chapter is on the possibility of needing additional measurements for optimal endograft sizing in the ascending aorta, also called ZO. Normally, based on the diameter the right endograft size is calculated and used for TEVAR. However, in ZO the aortic dynamics are more extreme going from a circle shape to an oval in one cardiac cycle. Measurements were taken from electrocardiography (ECG)-gated computed tomography (CT) scans. The area has a smaller delta in the cardiac cycle than the diameter. The next chapter describes the aortic dynamics after stent graft deployment in the ascending aorta. The aorta becomes 
much stiffer at the location where the stent graft is deployed, however, proximal to the stent graft the aorta is more compliant.

The final section consists of studies related to education in vascular surgery. The first chapter validates a model, which has been developed to test performance in endovascular trainees. The model consistently differentiates novices from experts based on their smoothness and velocity in handling the guidewire and catheter. The second chapter describes Endotherapy in IMH and dissections. An overview is given on the imaging modalities that are used for treatment and the tools necessary for endovascular repair. The final chapter is on the endovascular creation of a swine model for type B aortic dissection. The aim is to study the pathophysiology using multi-modality imaging and to create a surviving model to test future treatment options. Due to aortic wall motion and wall thickness it was challenging to create this model consistently and with reproducibility. However, multi-modality imaging was very useful as aortic dissection is a dynamic disease.

\section{Discussion}

\section{Introduction to endovascular repair}

Large randomized trials were executed to compare open surgery with endovascular repair. The EVAR-1, Dream, ACE and the OVER trial ${ }^{3-6}$. A study by Powell et al., summarizes the outcomes of the large trials and gives a pooled analysis. The overall mortality is lower in the EVAR group 0 - 6 months postoperative, however, after 6 month follow-up the mortality is lower in the surgical group. The aneurysm-related mortality is lower in the EVAR group in the first 30 days. From 31 days - 3 years the aneurysm-related mortality is relatively equal in both groups. However, after three years the aneurysm-related mortality is almost five times higher in the EVAR group ${ }^{7}$. This was mainly due to secondary rupture and/or reinterventions. These studies are outdated and the devices have evolved. Still, the question remains if additional developmental changes are needed to obtain durable results and keep the complication rate at a minimum. Complications can occur after endovascular treatment even when the Instructions For Use (IFU) are fully respected. Endoleaks are the most common, but also surgery related, systemic and ischemic complications occur ${ }^{8-14}$. Imaging plays a key role in objectifying these complications and the SVS (Society of Vascular Surgery) practice guidelines recommend computed tomography angiography 
(CTA) and color duplex ultrasound (US) in the first month after EVAR, followed by annual follow up in case of no complications ${ }^{15}$. The European Society of Vascular Surgery (ESVS) guidelines recommend a similar follow-up with a CTA scan in the first month and in case of no complications, annual follow-up with CTA or US ${ }^{16}$. The first abdominal stent graft introduction is described in 1986 by Volodos et al. ${ }^{17}$ and later a trial was set up for a new type of stent graft in 1992 called the Endovascular Grafting System. This device came with several failures, such as frame fractures, type $1 b$ endoleaks and migration ${ }^{18}$. With the development of the unibody bifurcated stent graft, less complications occurred and the AncureTM (Guidant, EndoVascular Technologies Inc., USA) was FDA approved ${ }^{18}$. Modular stent grafts were developed with different fabrics and designs, however, other issues like flexibility and the delivery systems were still two impediments to these designs. An aortic stent graft must be able to endure radial and axial forces of pulsatile flow, but also conformable without migration. The durability of stent grafts has always been an important factor in young patients. However, also in our aging population devices need to last longer, so no reinterventions are necessary at an older age. Durability of the stent graft devices is an important factor now that our population is aging. Despite all engineering developments and interventional experience of physicians, still many studies are lacking long-term follow up (> 10 years) and there are no randomized trials comparing two different types of endografts $3,4,6,19$.

A large proportion of this dissertation is about treatment in the descending thoracic aorta (DTA). In our previous studies we observed a type $1 \mathrm{~b}$ endoleak ${ }^{20}$ and we became more interested in this phenomenon as the distal landing zone after TEVAR usually lays in the DTA. A systematic review was performed to learn more about this complication and its etiology. Sixteen articles were included in this review ${ }^{21-36}$. A mean incidence was found of 4.3\% [range: $1.0-15.0 \%$ ] and the mean follow up was between 12 - 72 months. One article describes tortuosity as an anatomical risk factor for the occurrence of a type $1 \mathrm{~b}$ endoleak, however, no other anatomical factors or clinical factors have been described. Treatment is necessary in most cases, however, nothing is reported on the prognosis with or without treatment. This systematic review shows the lack of evidence on type $1 \mathrm{~b}$ endoleak. No long-term follow up is reported on this complication and neither has the difference been made between older and newer generation stent grafts. A variety of clinical characteristics, like distal sealing zone, the amount 
of oversizing and different brands of stent grafts need to be addressed as well. More has been reported on the proximal type 1 endoleak, even though, they have a similar incidence and reintervention rate. Aortic tortuosity may be a risk factor for the development of type $1 \mathrm{~b}$ endoleaks, however, this needs to be studied more in detail. There is a serious need for better registration and publication of possible complications after TEVAR. With a close long-term follow-up and a more thorough understanding of the impact of more conformable devices on this complication and how it might be prevented in the future.

\section{Tortuosity in the descending thoracic aorta}

To understand the phenomenon of tortuosity in the aorta and define acceptable landing zones in the DTA this study observed 200 non-vascular patients. The patients were divided in two groups; young $(<65)$ and old (> 65). With 3Mensio Vascular software (3Mensio Medical Imaging B.V. Bilthoven, The Netherlands) CT scans were analyzed. Different outcome measurements were collected; tortuosity index, curvature ratio, maximum tortuosity angle and the level of occurrence (by vertebrae). The DTA was divided into four equal zones (4A - 4D) and the amount of tortuosity was divided into; low tortuosity $<30^{\circ}$, moderate tortuosity $30^{\circ}-60^{\circ}$ and high tortuosity $>60^{\circ}$. Results showed that with aging the aorta becomes more tortuous and there is no difference between males and females. These results show that aging plays an important role in aortic changes. Previous studies report on an increase in diameter, volume and length ${ }^{37,38}$. This study adds tortuosity as a changing factor in aging. As the aorta is more tortuous and longer future generations of stent grafts should almost be as conformable as the native aorta. The elder patient population benefits from endovascular repair, however, the anatomy might be less suitable for this kind of treatment ${ }^{39,40}$.

Tortuosity has an impact on the sealing zone and increases the occurrence of endoleaks, malpositioning and deployment failure ${ }^{41-43}$. Studying tortuosity in the diseased aorta may help future TEVAR planning to decrease tortuosityrelated complications. A similar method was used (described above) on analyzing tortuosity in the diseased DTA. Three groups were compared; a control group with non-vascular diseases ( $N=69)$, an aneurysmal group $(N=69)$ and a dissection group ( $N=69$ ). Tortuosity is more pronounced in the diseased aorta, with the aneurysmal group having the highest amount of tortuosity, which occurs more distal in the DTA. The Instructions For Use (IFU) of most current stent grafts 
report that a landing zone needs to be $<60^{\circ}$ angulation, this study reports that $10 \%$ of the dissection group and $14 \%$ of the aneurysm group have $>60^{\circ}$ angulation. Outcomes related to tortuosity should be studied in detail to understand the clinical implications of tortuosity and future generations of stent grafts should be more flexible to overcome tortuosity.

The final chapter dedicated to aortic tortuosity in the DTA is about the change in forces due to aortic tortuosity. In the abdominal aorta and iliac arteries it has been proven that tortuosity influences the magnitude and direction of displacement forces (DF) $36,44-46$. Thirty patients were divided into three groups with a different amount of tortuosity; low $=\left\langle 30^{\circ}\right.$, moderate $=30^{\circ}-60^{\circ}$, high $=>$ $60^{\circ}$. Computational Fluid Dynamics (CFD) were used to calculate these DF. This study shows that DF were significantly higher in the high tortuosity group. As seen in this study, the aorta was most tortuous in zone $4 \mathrm{C}$ and the DFs were highest in this zone, in a lateral direction. When the landing zone is in a tortuous part of the aorta stent graft related complications can occur ${ }^{47}$. Longer sealing zones, stronger stent grafts or active fixation are necessary to handle these DF 48 and obtain durable results knowing that lateral movement can cause stent-graft instability ${ }^{49}$.

\section{Dynamics in the ascending thoracic aorta}

Endovascular aortic repair is evolving, which makes treatment in the ATA more available with a minimal invasive option ${ }^{50}$. Treatment in zone 0 , which is close to the aortic root, has worse outcomes ${ }^{51}$. This is probably due to the different longitudinal and circumferential movements throughout the cardiac cycle. As the diameter differs in systole and diastole, additional, more precise measurements should be used when planning for TEVAR. The advantage of CT scans over cardiac magnetic resonance imaging (CMRI) is the improved temporal resolution, although the distinct advantage of CMRI is its ability to also evaluate the aortic valve. The aortic valve is a critical component of a thorough understanding of ATA motion. This study analyses ECG-gated CT scans to calculate the different measurements throughout the cardiac cycle. Scans were analyzed and data on the diameter, area and perimeter were collected at three different locations in the ATA. The mean difference of systole and diastole was calculated and shows that measuring the area or perimeter is more precise and accurate than the diameter with a delta of up to $17.8 \%$. Several studies show the variability in dynamics of 
the ATA and mention that future endograft designs should be aware of these differences ${ }^{52-54}$. Dynamic CTAs momentarily capture the repetitive twist of the aorta during the cardiac cycle, however, this has not been taken into account as a risk factor for TEVAR planning. Still, dynamic imaging has many advantages as it observes various phases throughout the cardiac cycle. This helps with more accurate stent graft sizing and evaluating device performances post-operatively ${ }^{55}$. Studying the effect of these different measurements in a prospective study, will give better insight in the clinical implications and most likely will result in better clinical outcomes.

Ten to fifteen percent of patients who need treatment in the ATA are not suitable for open repair ${ }^{56}$. Endovascular repair being minimally invasive will potentially be a better alternative treatment strategy. However, due to treatment close to the aortic valve and high curvature it remains challenging ${ }^{57}$. The aortic compliance and stiffness will change due to natural aging and/or pathologies ${ }^{58-60}$, which are current risk factors for cardiovascular disease and death60-62. The effect of implanting a stent graft may be similar and should be studied in more detail. Five pre-operative ECG-gated CTA scans and three post-operative scans were retrospectively reviewed. Data was collected on the circumferential and longitudinal strain, arterial compliance and distensibility and stiffness index. Where the stent graft was implanted a decrease was seen in strain, compliance and distensibility. The stiffness index increased with 48\%. Proximal to the stent graft the opposite was seen; increase in strain, compliance and distensibility and a decrease in the stiffness index. With pulsatile distension being related to stent graft migration and the biggest range of aortic motion in the ATA ${ }^{52,63}$, incidence of complications may be higher in the ATA. This is even more impactful since the margin of error during implantation is very small. The mismatch between native aorta and stent graft compliance needs to improve in order to keep a low complication rate. Devices need to be developed with more similar material to the native aorta, especially when treatment is close to the aortic valve.

\section{Education in endovascular aortic repair}

Training vascular surgery residents is highly subjective and the need for uniformity recommended ${ }^{64}$. A previous study reports on a model that test performance in endovascular trainees ${ }^{65}$. The aim of this study was to further validate the model by dividing the subjects into three groups; novices, intermediates and experts based 
on their experience in endovascular surgery. Tasks were executed in a virtual model and performance was tested by measuring smoothness (in spectral arc length; $S A L)$, average velocity, idle time and path length. A significant difference was found for guidewire motion in SAL $(p<0.001)$, average velocity $(p<0.001)$ and idle time $(p<0.001)$ between groups. Post-hoc tests showed only a significant difference between novices vs. experts and intermediates vs. experts. This model remains a validate tool to assess performance in endovascular trainees. Using this tool to assess competency vs. non-competency seems more reliable than comparing three groups with different experience levels. Even though, tool tip motion is able to differentiate competent from incompetent, it is unclear whether all metrics are valid or appropriately weighted for task validation. A psychometric analysis has the potential to assess this latent question, because although motion capture does provide an objective evaluation it lacks the critical appraisal of the value of a specific metric ${ }^{66}$.

Endovascular therapy for treatment of type B aortic dissection is commonly used. Intramural Hematoma (IMH) should be treated medically when uncomplicated as the aortic-event-related mortality is lower (5.4\%) opposed to $7.1 \%$ with endovascular therapy ${ }^{67}$. The ESC (European Society of Cardiology) and ESVS guidelines define IMH slightly different ${ }^{68}$, and distinguishing between $\mathrm{IMH}$ and dissection may not always be possible in clinical practice. With new more sophisticated imaging techniques it might be more likely to see IMH as a precursor to dissection ${ }^{68}$. Medical treatment is possible in uncomplicated $I M H$, however, in case of aortic dilatation (> $50 \mathrm{~mm}$ ) or IMH thickness (> $11 \mathrm{~mm}$ ) the risk of complications is larger and surgical treatment is recommended ${ }^{69}$. When considering the timing of Type $B$ aortic dissections, there are three phases of onset; the acute phase (<15 days), the subacute phase (15 - 92) and the chronic phase (> 92 days). Medical management for uncomplicated type B dissection focusses on pain relief, lowering blood pressure and heart rate and needs a close follow up. In case medical management is not enough, patients are commonly treated with endovascular repair in favor to open surgery in the acute or subacute phase $^{70}$. Imaging is important in the pre-, peri- and post-operative stages. CTA is most commonly used pre- and post-operatively. The steps of TEVAR: 1. Accessing the femoral artery; 2 . Insertion of 0.035 guidewire, sheath and support catheter; 3. Exchange to stiff wire; 4. Placement of the device into position; 5. Aortagram; 6. Deployment of the stent graft; 7 . Aortagram to confirm. 
Type B aortic dissection is a pathology with high morbidity and mortality which requires life-long surveillance and a close follow-up. Even though, endovascular repair shows benefits over open surgical treatment, a significant part of the pathophysiology remains unknown ${ }^{71-73}$. The aim of this study was to create a model to study the pathophysiology of aortic dissection by using multi-modality imaging techniques. Only one study created a swine model with an endovascular approach, however, they used the retrograde approach while puncturing the aorta from distal. Multi-modality imaging was used during creation of this model. For baseline scanning and post-dissection 4D magnetic resonance imaging (MRI) and cone-beam computed tomography (CBCT) was used. Intra-operative fluoroscopy, trans-esophageal echocardiography (TEE), intravascular ultrasound (IVUS) and angiography were used as guidance during the procedure. The aortic wall was punctured $2 \mathrm{~cm}$ distal to the LSA using a trans septal needle. Twelve animals were included and a successful dissection being created in $25 \%$. The depth of puncture and needle stability were key factors for a successful creation of the dissection. Multi-modality imaging helped understand the pathophysiology as aortic dissection is a dynamic disease.

\section{Future perspectives}

The main focus of this dissertation is on the anatomical and morphological features of the thoracic aorta. It points out what the effect can be of anatomical variations on the flow dynamics of the aorta. It also shows the effect of stent graft deployment and how the aorta evolves as a consequence. To study the impact of these features, long-term follow-up is necessary to observe complications closely together with their effect. Following and studying patterns can give new and better insights to develop future endografts and create new treatment strategies. Observational studies are more favorable than randomized controlled trials in this case. The systematic review in this dissertation shows the lack of evidence on type $1 \mathrm{~b}$ endoleak. Reasons for this shortage of information on this important complication is most likely the lack of long-term follow-up. Better registration and observations are needed to obtain durable results. A theory of ours, which is mentioned in the systematic review, is that the high shear stress creates a burst of energy at the end of the stent graft. This can result in aneurysmal expansion of the native aorta, with the result of a type $1 \mathrm{~b}$ endoleak or due to the high displacement forces the stent graft may migrate upwards. 
In this dissertation measurements were obtained on various aortic features, like the dynamics and tortuosity. For measuring these dynamics, the equations used were taken from a book, which was used in other papers as well ${ }^{74}$. However, literature reports a variety of measurement methods on obtaining the tortuosity. When using different methods it is not possible to compare the outcomes with each other. The need for a uniform method is crucial for future studies, so their results can be compared with each other and help with planning for endovascular repair.

This dissertation shows that there is a great mismatch between stent graft material and the native aorta. Devices are not compliant enough and will make the aorta much stiffer after implantation. More conformable devices are needed to make the mismatch between stent graft and aorta smaller. For example, devices can be made in the future from a different material that is more compliant and can handle tortuosity as well. With dynamic imaging the aortic movement throughout the cardiac cycle captures the repetitive twist of the aorta. However, the circumference of the aorta can change from a circle shape to an oval. Stent grafts should be developed to mimic the native aorta and its habits throughout the cardiac cycle. Collaborating closely with engineers is key factor for a successful development of devices. Successful collaborations are seen in the more productive research \& development (R\&D) groups. However, a study by Yoda shows that this type of collaboration still has some barriers ${ }^{75}$. Barriers can be related to understanding each other's technical terms, communication, scientific standards of evidence or the five forms of proximity (geographical, cognitive, organizational, social and institutional). Learning and understanding each other's differences can contribute to a successful collaboration. Treatment in the ascending aorta is high risk surgery for a number of reasons, including aortic angulation and motion, the aortic valve and coronary arteries. The effect of ascending aortic surgery on the aortic valve has not been studied well, nor has the influence of the aortic valve on the implanted device. Future studies on this subject are necessary as there have been cases where cardiac function has decreased after ascending aortic repair. A better collaboration between cardiologist, cardiac surgeons and vascular surgeons may help overcome this complication after treatment. 


\section{References}

1. Abraha I, Romagnoli C, Montedori A, Cirocchi R. Thoracic stent graft versus surgery for thoracic aneurysm. In: Abraha I, ed. Cochrane Database of Systematic Reviews. Chichester, UK: John Wiley \& Sons, Ltd; 2013:CD006796. doi:10.1002/14651858.CD006796.pub3

2. Li F-R, Wu XX, Yuan J, Wang J, Mao C, Wu XX. Comparison of thoracic endovascular aortic repair, open surgery and best medical treatment for type B aortic dissection: A meta-analysis. Int J Cardiol. 2018;250:240-246. doi:10.1016/j.ijcard.2017.10.050

3. De Bruin JL, Baas AF, Buth J, et al. Long-Term Outcome of Open or Endovascular Repair of Abdominal Aortic Aneurysm. N Engl J Med. 2010;362(20):1881-1889. doi:10.1056/ NEJMoa0909499

4. Lederle FA, Freischlag JA, Kyriakides TC, et al. Long-Term Comparison of Endovascular and Open Repair of Abdominal Aortic Aneurysm. N Engl J Med. 2012;367(21):1988-1997. doi:10.1056/ NEJMoa1207481

5. Becquemin J-P, Pillet J-C, Lescalie F, et al. A randomized controlled trial of endovascular aneurysm repair versus open surgery for abdominal aortic aneurysms in low- to moderate-risk patients. J Vasc Surg. 2011;53(5):1167-1173.e1. doi:10.1016/j.jvs.2010.10.124

6. Patel R, Sweeting MJ, Powell JT, Greenhalgh RM. Endovascular versus open repair of abdominal aortic aneurysm in 15-years' follow-up of the UK endovascular aneurysm repair trial 1 (EVAR trial 1): a randomised controlled trial. Artic 2366 www.thelancet.com. 2016;388. doi:10.1016/S01406736(16)31135-7

7. Powell JT, Sweeting MJ, Ulug P, et al. Meta-analysis of individual-patient data from EVAR-1, DREAM, OVER and ACE trials comparing outcomes of endovascular or open repair for abdominal aortic aneurysm over 5 years. Br J Surg. 2017;104(3):166-178. doi:10.1002/bjs.10430

8. Liaw JVP, Clark M, Gibbs R, Jenkins M, Cheshire N, Hamady M. Update: Complications and management of infrarenal EVAR. Eur J Radiol. 2009;71(3):541-551. doi:10.1016/j.ejrad.2008.05.015

9. Zarins CK, Bloch DA, Crabtree T, Matsumoto AH, White RA, Fogarty TJ. Stent graft migration after endovascular aneurysm repair: importance of proximal fixation. J Vasc Surg. 2003;38(6):12641272; discussion 1272. doi:10.1016/s0741-5214(03)00946-7

10. Golzarian J, Struyven J. Imaging of complications after endoluminal treatment of abdominal aortic aneurysms. Eur Radiol. 2001;11(11):2244-2251. doi:10.1007/s003300100912

11. Maleux G, Koolen M, Heye S. Complications after Endovascular Aneurysm Repair. Semin Intervent Radiol. 2009;26(01):003-009. doi:10.1055/s-0029-1208377

12. Wald R, Waikar SS, Liangos O, Pereira BJG, Chertow GM, Jaber BL. Acute renal failure after endovascular vs open repair of abdominal aortic aneurysm. J Vasc Surg. 2006;43(3):460-466. e2. doi:10.1016/j.jvs.2005.11.053

13. Arnaoutoglou E, Kouvelos G, Papa N, et al. Prospective evaluation of post-implantation inflammatory response after EVAR for AAA: influence on patients' 30 day outcome. Eur J Vasc Endovasc Surg. 2015;49(2):175-183. doi:10.1016/j.ejvs.2014.12.006

14. Sharif MA, Lee $B, L a u L L$, et al. Prosthetic stent graft infection after endovascular abdominal aortic aneurysm repair. J Vasc Surg. 2007;46(3):442-448. doi:10.1016/j.jvs.2007.05.027

15. Chaikof EL, Dalman RL, Eskandari MK, et al. The Society for Vascular Surgery practice guidelines on the care of patients with an abdominal aortic aneurysm. J Vasc Surg. 2018;67(1):2-77.e2. doi:10.1016/j.jvs.2017.10.044

16. Moll FL, Powell JT, Fraedrich G, et al. Management of Abdominal Aortic Aneurysms Clinical Practice Guidelines of the European Society for Vascular Surgery. Eur J Vasc Endovasc Surg. 2011;41:S1-S58. doi:10.1016/j.ejvs.2010.09.011

17. Volodos' NL, Shekhanin VE, Karpovich IP, Troian VI, Gur'ev IA. [A self-fixing synthetic blood vessel endoprosthesis]. Vestn Khir Im / / Grek. 1986;137(11):123-125.

18. Moore WS, Rutherford RB. Transfemoral endovascular repair of abdominal aortic aneurysm: results of the North American EVT phase 1 trial. EVT Investigators. J Vasc Surg. 1996;23(4):543553. doi:10.1016/s0741-5214(96)80032-2 


\section{Chapter 12}

19. United Kingdom EVAR Trial Investigators, Greenhalgh RM, Brown LC, et al. Endovascular versus Open Repair of Abdominal Aortic Aneurysm. N Engl J Med. 2010;362(20):1863-1871. doi:10.1056/ NEJMoa0909305

20. van Bakel T, Romarowski R, Morganti S, et al. Blood Flow after Endovascular Repair in the Aortic Arch: A Computational Analysis. AORTA. 2018;06(03):081-087. doi:10.1055/s-0039-1683771

21. Ammar CP, Larion S, Ahanchi SS, Lavingia KS, Dexter DJ, Panneton JM. Anatomic severity grading score for primary descending thoracic aneurysms predicts procedural difficulty and aortic-related reinterventions after thoracic endovascular aortic repair. J Vasc Surg. 2016;64(4):912-920.e1. doi:10.1016/j.jvs.2016.03.451

22. Czerny $M$, Cejna $M$, Hutschala $D$, et al. Stent-graft placement in atherosclerotic descending thoracic aortic aneurysms: midterm results. J Endovasc Ther. 2004;11(1):26-32. doi:10.1177/152660280401100103

23. Parmer SS, Carpenter JP, Stavropoulos SW, et al. Endoleaks after endovascular repair of thoracic aortic aneurysms. J Vasc Surg. 2006;44(3):447-452. doi:10.1016/j.jvs.2006.05.041

24. Piffaretti G, Mariscalco G, Lomazzi C, et al. Predictive factors for endoleaks after thoracic aortic aneurysm endograft repair. J Thorac Cardiovasc Surg. 2009;138(4):880-885. doi:10.1016/j. jtcvs.2009.02.024

25. Riambau V, Giudice R, Trabattoni P, et al. Prospective multicenter study of the low-profile Relay stent-graft in patients with thoracic aortic disease: the RE-GENERATION study. Ann Vasc Surg. January 2019. doi:10.1016/j.avsg.2018.10.017

26. Rylski B, Blanke P, Siepe M, et al. Results of high-risk endovascular procedures in patients with non-dissected thoracic aortic pathology: intermediate outcomes. Eur J Cardiothorac Surg. 2013;44(1):156-162. doi:10.1093/ejcts/ezs694

27. Yunoki J, Kuratani T, Shirakawa Y, et al. Mid-term results of endovascular treatment with the Gore TAG device for degenerative descending thoracic aortic aneurysms. Gen Thorac Cardiovasc Surg. 2015;63(1):38-42. doi:10.1007/s11748-014-0436-4

28. Melissano G, Kahlberg A, Bertoglio L, Chiesa R. Endovascular exclusion of thoracic aortic aneurysms with the 1- and 2-component Zenith TX2 TAA endovascular grafts: analysis of 2-year data from the TX2 pivotal trial. J Endovasc Ther. 2011;18(3):338-349. doi:10.1583/10-3340.1

29. Farber MA, Lee WA, Szeto WY, Panneton JM, Kwolek CJ. Initial and midterm results of the Bolton Relay Thoracic Aortic Endovascular Pivotal Trial. 2017;65(6):1556-1566.e1. doi:10.1016/j. jvs.2016.11.061

30. Geisbüsch P, Skrypnik D, Ante M, et al. Endograft migration after thoracic endovascular aortic repair. J Vasc Surg. December 2018. doi:10.1016/j.jvs.2018.07.073

31. Hughes GC, Lee SM, Daneshmand MA, et al. Endovascular repair of descending thoracic aneurysms: results with \&quot;on-label\&quot; application in the post Food and Drug Administration approval era. Ann Thorac Surg. 2010;90(1):83-89. doi:10.1016/j.athoracsur.2010.03.052

32. Kratimenos T, Antonopoulos CN, Tomais D, et al. Repair of descending thoracic aortic aneurysms with Ankura Thoracic Stent Graft. J Vasc Surg. October 2018. doi:10.1016/j.jvs.2018.07.065

33. Makaroun MS, Dillavou ED, Wheatley GH, Cambria RP, Gore TAG Investigators. Five-year results of endovascular treatment with the Gore TAG device compared with open repair of thoracic aortic aneurysms. J Vasc Surg. 2008;47(5):912-918. doi:10.1016/j.jvs.2007.12.006

34. Matsumura JS, Melissano G, Cambria RP, et al. Five-year results of thoracic endovascular aortic repair with the Zenith TX2. J Vasc Surg. 2014;60:1-10. doi:10.1016/j.jvs.2014.01.043

35. Morales JP, Greenberg RK, Lu Q, et al. Endoleaks Following Endovascular Repair of Thoracic Aortic Aneurysm: Etiology and Outcomes. J Endovasc Ther. 2008;15:631-638.

36. Nakatamari H, Ueda T, Ishioka F, et al. Discriminant analysis of native thoracic aortic curvature: Risk prediction for endoleak formation after thoracic endovascular aortic repair. J Vasc Interv Radiol. 2011;22(7):974-979. doi:10.1016/j.jvir.2011.02.031

37. Craiem D, Casciaro ME, Graf S, Chironi G, Simon A, Armentano RL. Effects of aging on thoracic aorta size and shape: A non-contrast CT study. In: 2012 Annual International Conference of the IEEE Engineering in Medicine and Biology Society. Vol 2012. IEEE; 2012:4986-4989. doi:10.1109/ EMBC.2012.6347112 
38. Craiem D, Chironi G, Redheuil A, et al. Aging impact on thoracic aorta 3D morphometry in intermediate-risk subjects: looking beyond coronary arteries with non-contrast cardiac CT. Ann Biomed Eng. 2012;40(5):1028-1038. doi:10.1007/s10439-011-0487-y

39. Czerny M, Funovics M, Ehrlich M, et al. Risk Factors of Mortality in Different Age Groups After Thoracic Endovascular Aortic Repair. Ann Thorac Surg. 2010;90(2):534-538. doi:10.1016/j. athoracsur.2010.03.096

40. De Rango P, Isernia $G$, Simonte $G$, et al. Impact of age and urgency on survival after thoracic endovascular aortic repair. J Vasc Surg. 2016;64(1):25-32. doi:10.1016/j.jvs.2015.11.054

41. Chen CK, Liang IP, Chang HT, et al. Impact on outcomes by measuring tortuosity with reporting standards for thoracic endovascular aortic repair. J Vasc Surg. 2014;60(4):937-944. doi:10.1016/j. jvs.2014.04.008

42. Bowman JN, Silverberg D, Ellozy S, et al. The Role of Anatomic Factors in Predicting Success of Endovascular Repair of Thoracic Aortic Aneurysms. Vasc Endovascular Surg. 2010;44(2):101-104. doi:10.1177/1538574409347392

43. Boufi M, Guivier-Curien C, Dona B, et al. Risk Factor Analysis for the Mal-Positioning of Thoracic Aortic Stent Grafts. Eur J Vasc Endovasc Surg. 2016;52(1):56-63. doi:10.1016/j.ejvs.2016.03.025

44. Figueroa CA, Taylor CA, Chiou AJ, Yeh V, Zarins CK. Magnitude and Direction of Pulsatile Displacement Forces Acting on Thoracic Aortic Endografts. J Endovasc Ther. 2009;16(3):350358. doi:10.1583/09-2738.1

45. Chen J, Gutmark E, Mylavarapu G, Backeljauw PF, Gutmark-Little I. Numerical investigation of mass transport through patient-specific deformed aortae. J Biomech. 2014;47(2):544-552. doi:10.1016/j.jbiomech.2013.10.031

46. van Keulen JW, Moll FL, Tolenaar JL, Verhagen HJM, van Herwaarden JA. Validation of a new standardized method to measure proximal aneurysm neck angulation. J Vasc Surg. 2010;51(4):821828. doi:10.1016/j.jvs.2009.10.114

47. Rahmani S, Grewal IS, Nabovati A, Doyle MG, Roche-Nagle G, Tse LW. Increasing angulation decreases measured aortic stent graft pullout forces. J Vasc Surg. 2016;63(2):493-499.

48. Ongstad SB, Miller DF, Panneton JM. The use of EndoAnchors to rescue complicated TEVAR procedures. J Cardiovasc Surg (Torino). 2016;57(5):716-729.

49. Rafii BY, Abilez OJ, Benharash P, Zarins CK. Lateral movement of endografts within the aneurysm sac is an indicator of stent-graft instability. J Endovasc Ther. 2008;15(3):335-343. doi:10.1583/082422.1

50. Baikoussis NG, Antonopoulos CN, Papakonstantinou NA, Argiriou M, Geroulakos G. Endovascular stent grafting for ascending aorta diseases. J Vasc Surg. 2017;66(5):1587-1601. doi:10.1016/j. jvs.2017.07.064

51. Roselli EE, Idrees JJ, Johnston DR, Eagleton MJ, Desai MY, Svensson LG. Zone zero thoracic endovascular aortic repair: A proposed modification to the classification of landing zones. $J$ Thorac Cardiovasc Surg. 2018;155(4):1381-1389. doi:10.1016/j.jtcvs.2017.11.054

52. van Prehn J, Vincken KL, Muhs BE, et al. Toward endografting of the ascending aorta: insight into dynamics using dynamic cine-CTA. J Endovasc Ther. 2007;14(4):551-560. doi:10.1177/152660280701400418

53. Rengier F, Weber TF, Henninger $V$, et al. Heartbeat-related distension and displacement of the thoracic aorta in healthy volunteers. Eur J Radiol. 2012;81(1):158-164. doi:10.1016/j. ejrad.2010.08.023

54. Sailer AM, Wagemans BAJM, Das M, et al. Quantification of Respiratory Movement of the Aorta and Side Branches. J Endovasc Ther. 2015;22(6):905-911. doi:10.1177/1526602815605325

55. van Bogerijen GHW, van Herwaarden JA, Conti M, et al. Importance of dynamic aortic evaluation in planning TEVAR. Ann Cardiothorac Surg. 2014;3(3):300-306. doi:10.3978/j.issn.2225319X.2014.04.05

56. Plichta RP, Hughes GC. Thoracic endovascular aortic repair for the ascending aorta: experience and pitfalls. J Vis Surg. 2018;4:92-92. doi:10.21037/jovs.2018.03.01

57. Khoynezhad A, Donayre CE, Walot I, Koopmann MC, Kopchok GE, White RA. Feasibility of endovascular repair of ascending aortic pathologies as part of an FDA-approved physiciansponsored investigational device exemption. J Vasc Surg. 2016;63(6):1483-1495. doi:10.1016/j. jvs.2015.12.029 


\section{Chapter 12}

58. Redheuil A, Yu W-C, Wu CO, et al. Reduced ascending aortic strain and distensibility: earliest manifestations of vascular aging in humans. Hypertens (Dallas, Tex 1979). 2010;55(2):319-326. doi:10.1161/HYPERTENSIONAHA.109.141275

59. Bell V, Mitchell WA, Sigurðsson S, et al. Longitudinal and Circumferential Strain of the Proximal Aorta. J Am Heart Assoc. 2014;3(6):e001536. doi:10.1161/JAHA.114.001536

60. Cavalcante JL, Lima JAC, Redheuil A, Al-Mallah MH. Aortic stiffness: current understanding and future directions. J Am Coll Cardiol. 2011;57(14):1511-1522. doi:10.1016/j.jacc.2010.12.017

61. Redheuil A, Wu CO, Kachenoura N, et al. Proximal aortic distensibility is an independent predictor of all-cause mortality and incident CV events: the MESA study. J Am Coll Cardiol. 2014;64(24):2619-2629. doi:10.1016/j.jacc.2014.09.060

62. Vlachopoulos C, Aznaouridis K, Stefanadis C. Prediction of Cardiovascular Events and AllCause Mortality With Arterial Stiffness. J Am Coll Cardiol. 2010;55(13):1318-1327. doi:10.1016/j. jacc.2009.10.061

63. van Keulen JW, Moll FL, Barwegen GK, Vonken EPA, van Herwaarden JA. Pulsatile distension of the proximal aneurysm neck is larger in patients with stent graft migration. Eur J Vasc Endovasc Surg. 2010;40(3):326-331. doi:10.1016/j.ejvs.2010.05.009

64. Bismuth J, Donovan MA, O'Malley MK, et al. Incorporating simulation in vascular surgery education. J Vasc Surg. 2010;52(4):1072-1080. doi:10.1016/j.jvs.2010.05.093

65. Duran C, Estrada S, O'Malley M, et al. The model for Fundamentals of Endovascular Surgery (FEVS) successfully defines the competent endovascular surgeon. J Vasc Surg. 2015;62(6):16601666.e3. doi:10.1016/j.jvs.2015.09.026

66. Lineberry M, Matthew Ritter E. Psychometric properties of the Fundamentals of Endoscopic Surgery (FES) skills examination. Surg Endosc. 2017;31(12):5219-5227. doi:10.1007/s00464-0175590-1

67. Evangelista A, Czerny M, Nienaber C, et al. Interdisciplinary expert consensus on management of type B intramural haematoma and penetrating aortic ulcer. Eur J Cardio-Thoracic Surg. 2015;47(2):209-217. doi:10.1093/ejcts/ezu386

68. Czerny M, Chairperson E, Schmidli J, et al. Current options and recommendations for the treatment of thoracic aortic pathologies involving the aortic arch: an expert consensus document of the European Association for Cardio-Thoracic surgery (EACTS) and the European Society for Vascular Surgery (ESVS). doi:10.1093/ejcts/ezy313

69. Erbel R, Aboyans V, Boileau C, et al. 2014 ESC Guidelines on the diagnosis and treatment of aortic diseases: Document covering acute and chronic aortic diseases of the thoracic and abdominal aorta of the adult. The Task Force for the Diagnosis and Treatment of Aortic Diseases of the European . Eur Heart J. 2014;35(41):2873-2926. doi:10.1093/eurheartj/ehu281

70. Riambau V, Böckler D, Brunkwall J, et al. Editor's Choice - Management of Descending Thoracic Aorta Diseases: Clinical Practice Guidelines of the European Society for Vascular Surgery (ESVS). Eur J Vasc Endovasc Surg. 2017;53(1):4-52. doi:10.1016/j.ejvs.2016.06.005

71. Nienaber CA, Rousseau H, Eggebrecht $H$, et al. Randomized comparison of strategies for type $B$ aortic dissection: the INvestigation of STEnt Grafts in Aortic Dissection (INSTEAD) trial. Circulation. 2009;120(25):2519-2528. doi:10.1161/CIRCULATIONAHA.109.886408

72. Cooper M, Hicks C, Ratchford E V, Salameh MJ, Malas M. Diagnosis and treatment of uncomplicated type B aortic dissection. Vasc Med. 2016;21(6):547-552. doi:10.1177/1358863X16643601

73. Brunkwall J, Lammer J, Verhoeven E, Taylor P. ADSORB: A Study on the Efficacy of Endovascular Grafting in Uncomplicated Acute Dissection of the Descending Aorta. Eur J Vasc Endovasc Surg. 2012;44(1):31-36. doi:10.1016/j.ejvs.2012.03.023

74. Nichols WW, O'Rourke MF, Vlachopoulos C. McDonald's Blood Flow in Arteries: Theoretical, Experimental and Clinical Principles. 6th Editio. CRC Press; 2013.

75. Yoda T. The effect of collaborative relationship between medical doctors and engineers on the productivity of developing medical devices. R\&D Manag. 2016;46(S1):193-206. doi:10.1111/ radm.12131 
Summary | Discussion 



\section{Chapter 13}

Samenvatting en discussie in het Nederlands 


\section{Samenvatting}

In dit proefschrift ligt de focus op de twee voornaamste aorta pathologieën, namelijk aneurysma en dissectie van de aorta, welke beide behandeld kunnen worden met thoracaal endovasculair herstel (TEVAR). TEVAR is tegenwoordig de eerste keus behandeling, vanwege een snel postoperatief herstel en het is daarnaast geschikt voor de hoog-risico patiënt, die niet in aanmerking komt voor open chirurgie ${ }^{1,2}$. Door variatie in anatomie van de patiënt is endovasculair herstel niet altijd een optie en omdat timing van essentieel belang is, is een over-thecounter stent graft niet altijd geschikt voor de patiënt.

In dit proefschrift vindt u een overzicht van de beperkingen van stent grafts welke worden gebruikt bij endovasculair herstel. Er wordt een samenvatting gegeven van de belangrijke onderzoeken naar het verschil tussen open chirurgie en endovasculaire aorta herstel (EVAR). Daarnaast beschrijven we de beeldvormende modaliteiten die pre-, peri- en postoperatief werden gebruikt, complicaties van de behandeling en tevens de evolutie van stent grafts. In een systematische review beschrijven we type 1b-endoleaks, inclusief risicofactoren en complicaties, waarbij we ons gericht hebben op het dalende gedeelte van de thoracale aorta (DTA). Dit wordt gevolgd door drie studies naar kronkeligheid (tortuositeit) van de DTA. De eerste studie beschrijft het verschil in tortuositeit in een gezonde patiëntenpopulatie tussen jonge $(<65)$ en oude (>65) patiënten, waarbij onze belangrijkste bevinding is dat oudere patiënten een hogere tortuositeitsindex hebben. Vervolgens wordt een gezonde populatie vergeleken met patiënten met aneurysmata en dissecties. Patiënten met aneurysmata hebben een hogere hebben de grootste hoeveelheid tortuositeit. Het derde artikel beschrijft in drie groepen met een verschillende hoeveelheid tortuositeit (laag $=<30^{\circ}$; matig $=30^{\circ}$ - 60\%; hoog $=>60^{\circ}$ ) de verplaatsingskrachten door de DTA, waarbij de DTA is verdeeld in vier gelijke zones. Uit dit onderzoek blijkt dat in de groep met hoge tortuositeit de verplaatsingskracht het grootst is.

Het volgende gedeelte van dit proefschrift beschrijft de aortadynamiek in het opstijgende gedeelte van thoracale aorta (ATA). Het eerste hoofdstuk onderzoekt de waarde van aanvullende metingen in het bepalen van de endograft-maat in de oplopende aorta. Dit gedeelte van de ATA wordt ook wel zone 0 (ZO) genoemd. In de huidige praktijk wordt op basis van de diameter de juiste endograft-maat berekend. . In ZO is de aortadynamiek echter extremer; de aorta-omtrek varieert 
hier in één hartcyclus tussen een cirkelvorm en een ovale vorm. In dit onderzoek werden aanvullende metingen verricht met behulp van elektrocardiografie (ECG)gated computed tomography (CT) scans. Uit deze metingen blijkt dat er gedurende één hartcyclus een kleinere variatie is in het 'oppervlak' in vergelijking met de diameter. Het volgende hoofdstuk beschrijft de aortadynamiek na de plaatsing van een stent graft in het opstijgende gedeelte van de aorta. De stijfheid van de aorta neemt toe op de locatie waar de stent graft wordt geplaatst. Proximaal van de stent graft blijkt er een toename zijn van elasticiteit (compliance) van de aorta.

Het laatste deel van dit proefschrift bestaat uit studies met betrekking op onderwijs in de vaatchirurgie. Het eerste hoofdstuk valideert een model, dat is ontwikkeld om de prestaties van arts assistenten in de endovasculaire chirurgie te toetsen. Het model toetst het niveau van bekwaamheid door middel van het hanteren van het gereedschap welke gebruikt worden bij endovasculaire ingrepen. Het tweede hoofdstuk beschrijft Endotherapie bij Intramuraal Hematoma (IMH) en dissecties. Er wordt een overzicht gegeven van de beeldvormingsmodaliteiten die worden gebruikt voor de behandeling. Daarnaast beschrijven we de hulpmiddelen die gebruikt worden bij endovasculair herstel. Het laatste hoofdstuk beschrijft de ontwikkeling van een varkensmodel voor aortadissectie type B. Met behulp van dit model is het mogelijk om de pathofysiologie te bestuderen door middel van multimodality imaging. Daarnaast kan met behulp van dit toekomstige behandelopties worden getest. Vanwege de aortadynamiek en de wanddikte was het een uitdaging om dit model consistent en reproduceerbaar te maken. Het gebruik van multi-modality imaging was echter zeer nuttig omdat de aortadissectie een dynamische ziekte is.

\section{Discussie}

\section{Introductie van endovasculair herstel}

Er zijn gerandomiseerde onderzoeken (EVAR-1, Dream, ACE en de OVER-trial ${ }^{3-6}$ ) uitgevoerd met als doel om open chirurgie te vergelijken met endovasculair herstel bij patiënten met abdominale aneurysmata. In een systematische review door Powell et al., worden de bovengenoemde onderzoeksresultaten samengevat. De totale mortaliteit binnen 6 maanden is lager in de EVAR-groep, maar in de periode daarna is de mortaliteit lager in de open chirurgie groep. De aneurysma- 
gerelateerde mortaliteit is lager in de EVAR-groep in de eerste 30 dagen. In de periode van 31 dagen tot 3 jaar is de aneurysma-gerelateerde mortaliteit relatief gelijk in beide groepen. Na drie jaar is de aneurysma-gerelateerde mortaliteit bijna vijf keer hoger in de EVAR-groep?. Dit was voornamelijk te wijten aan het scheuren van de aneurysmazak en / of de noodzaak tot een nieuwe operatie. De bovengenoemde onderzoeken zijn echter gedateerd en de stent grafts zijn tegenwoordig aanzienlijk verbeterd. Toch blijft de vraag of verdere verbeteringen nodig zijn om optimale resultaten te verkrijgen en de complicaties tot een minimum te beperken. Complicaties kunnen optreden na endovasculaire behandeling, zelfs wanneer de gebruiksaanwijzing van de stent grafts (Instructions for Use $=$ IFU) volledig wordt gerespecteerd. Endoleaks zijn de meest voorkomende complicaties, maar ook chirurgische, systemische en ischemische complicaties kunnen optreden ${ }^{8-14}$. Beeldvorming speelt een belangrijke rol bij het objectiveren van deze complicaties en de richtlijnen van de SVS (Society of Vascular Surgery) bevelen computed tomografie-angiografie (CTA) en colour duplex echografie aan in de eerste maand na EVAR, gevolgd door jaarlijkse follow-up in geval van geen complicaties $^{15}$. De richtlijnen van de European Society of Vascular Surgery (ESVS) bevelen een soortgelijke follow-up aan, met een CTA-scan in de eerste maand en in geval van geen complicaties, jaarlijkse follow-up met CTA of echo duplex ${ }^{16}$. De eerste introductie van een abdominale stent graft is beschreven in 1986 door Volodos et al. ${ }^{17}$ en later werd een studie opgezet voor een nieuw type stent graft in 1992 genaamd het Endovascular Grafting System. Deze stent graft kwam met verschillende gebreken, zoals type $1 b$ endoleaks en migratie ${ }^{18}$. Met de ontwikkeling van de unibody (de zijtakken (branches) zitten al aan de stent graft) stent graft traden minder complicaties op en werd de AncureTM (Guidant, EndoVascular Technologies Inc., VS) genoemd en werd goedgekeurd door de FDA[18]. Modulaire stent implantaten (verschillende componenten worden aan elkaar verbonden) werden ontwikkeld met verschillende stoffen en ontwerpen, maar flexibiliteit en de afleversystemen waren nog steeds twee belemmeringen voor deze ontwerpen. Een aortastent moet in staat zijn de radiale en axiale krachten van pulserende flow te verdragen, maar ook vergelijkbaar blijven zonder te migreren. De houdbaarheid van stent grafts is altijd een belangrijke factor geweest bij jonge patiënten. Echter, ook in onze ouder wordende populatie is deze houdbaarheid van stent grafts belangrijk. Stent grafts moeten langer meegaan, zodat een nieuwe operatie op oudere leeftijd vermeden kan worden Ondanks alle technische ontwikkelingen 
en ervaring van artsen, ontbreekt het nog steeds aan data met lange termijn uitkomsten (> 10 jaar) en er zijn geen gerandomiseerde onderzoeken waarin twee verschillende soorten endografts worden vergeleken 3,4,6,19.

In dit proefschrift ligt de focus voor een groot deel op de behandeling van aneurysmata in het dalende deel van de thoracale aorta (DTA). Uit een voorgaand onderzoek door van Bakel et al. werd een type 1b endoleak waargenomen ${ }^{20}$, doordat de stent graft naar boven was verplaatst door verschillende krachten. In een systematische review wordt uitgezocht wat de verschillende risicofactoren zijn van het ontstaan van een type $1 \mathrm{~b}$ endoleak. Zestien artikelen werden opgenomen in deze review ${ }^{21-36}$. Een gemiddelde incidentie werd gevonden van 4,3\% [bereik: 1,0 - 15,0\%] en de gemiddelde follow-up was tussen $12-72$ maanden. Eén artikel beschrijft tortuositeit als een anatomische risicofactor voor het optreden van een type $1 \mathrm{~b}$ endoleak, maar er zijn geen andere anatomische of klinische factoren beschreven. Behandeling is in de meeste gevallen noodzakelijk, maar er wordt niets gerapporteerd over de prognose, met of zonder behandeling. Deze systematische review toont het gebrek aan bewijs voor type $1 \mathrm{~b}$ endoleaks. Er wordt namelijk niet gerapporteerd over de lange termijn follow-up van deze complicatie en er is ook geen verschil gemaakt tussen de oudere en nieuwere stent graft generaties. De impact van verschillende klinische kenmerken, zoals distale sealingszone, de hoeveelheid oversizing en verschillende merken stent grafts moeten ook worden onderzocht. Er is meer informatie beschikbaar over de proximale type 1 endoleak, hoewel ze een vergelijkbare incidentie en reinterventierato hebben. Tortuositeit van de aorta kan een risicofactor zijn voor de ontwikkeling van type $1 \mathrm{~b}$ endoleaks, dit moet echter beter worden bestudeerd. Het is van groot belang dat er adequate registratie is van de complicaties die optreden na TEVAR. Daarnaast is lange termijn follow-up noodzakelijk om een beter inzicht in de impact van deze complicatie te krijgen en hoe dit in de toekomst kan worden voorkomen.

\section{Tortuositeit in de dalende thoracale aorta}

Om het fenomeen van tortuositeit in de aorta te analyseren en om acceptabele landingszones in de DTA te definiëren, werd de volgende studie opgezet. In dit onderzoek zijn van 200 niet-vasculaire patiënten de CT-scans geanalyseerd met 3Mensio Vascular-software (3Mensio Medical Imaging B.V. Bilthoven, Nederland). De patiënten werden verdeeld in twee groepen o.b.v. leeftijd $(<65$ jaar en $>65$ 
jaar). Het doel van het onderzoek was om te kijken naar tortuositeitsindex, de curvatuur rato van de aorta, de maximale tortuositeits angulatie en de locatie waar de maximale tortuositeit voorkomt (m.b.v. de ruggenwervels). De DTA werd verdeeld in vier gelijke zones (4A - 4D) en de hoeveelheid tortuositeit werd verdeeld in; lage tortuositeit $<30^{\circ}$, matige tortuositeit $30^{\circ}-60^{\circ}$ en hoge tortuositeit $>60^{\circ}$. De resultaten toonden aan dat in de leeftijdscategorie $>65$ jaar oud de aorta kronkeliger wordt en er geen verschil is tussen mannen en vrouwen. Deze resultaten tonen aan dat veroudering een belangrijke rol speelt bij aorta-veranderingen. Voorgaande onderzoeken beschreven een toename in diameter, volume en lengte ${ }^{37,38}$. Onze studie voegt tortuositeit toe als een belangrijke veranderende factor bij veroudering. Aangezien de tortuositeit toeneemt naarmate de patiënt ouder wordt, is het van belang dat toekomstige stent graft generaties een ongeveer gelijke compliantie hebben als de aorta. De oudere patiëntenpopulatie profiteert van endovasculair herstel aangezien de herstel periode korter is en de operatie minder invasief. Echter is het mogelijk dat de anatomie minder geschikt is voor deze behandeling 39,40 .

De tortuositeit heeft een impact op de sealing-zone van de stent graft met de aorta en verhoogt het optreden van endoleaks, mispositionering en het falen van endograft deployment ${ }^{41-43}$. Het bestuderen van de tortuositeit in de zieke aorta kan toekomstige TEVAR-plannen helpen om tortuositeits gerelateerde complicaties te verminderen. Een vergelijkbare methode werd gebruikt (hierboven beschreven) voor het analyseren van tortuositeit in de zieke DTA. Drie groepen werden vergeleken; een controlegroep zonder vaatziekten ( $N=69)$, een aneurysma-groep $(N=69)$ en een dissectie-groep $(N=69)$. De tortuositeit is meer uitgesproken in de zieke aorta, waarbij de groep met aneurysmata de grootste hoeveelheid tortuositeit heeft en meer distaal voorkomt in de DTA. De gebruiksaanwijzing (IFU) van de meeste huidige stent grafts rapporteren dat een landingszone een hoek van $<60^{\circ}$ moet hebben. In deze studie heeft $10 \%$ van de dissectie-groep en $14 \%$ van de aneurysma-groep een hoek van $>60^{\circ}$. De effecten van de tortuositeit moeten in detail worden bestudeerd om de klinische relevantie van tortuositeit te begrijpen en toekomstige stent graft generaties moeten flexibeler zijn om toch met deze tortuositeit minder complicaties te hebben.

Het laatste hoofdstuk is gewijd aan de tortuositeit in de DTA en de verandering in krachten als gevolg van tortuositeit. In de abdominale aorta en iliacale arteriën is bewezen dat de tortuositeit, de grootte en richting van 
verplaatsingskrachten (DF) beïnvloeden ${ }^{28,44-46}$. In deze studie werden dertig patiënten verdeeld in drie groepen met een verschillende mate van tortuositeit; laag $=<30^{\circ}$, matig $=30^{\circ}-60^{\circ}$ en hoog $=>60^{\circ}$. Computational Fluid Dynamics (CFD) werd gebruikt om de DF te berekenen. Deze studie toont aan dat DF significant hoger waren in de groep met grootste tortuositeit. De aorta was het meest kronkelig in zone 4C en de DF's waren het hoogst in deze zone en de grootste krachten gingen in zijwaartse richting. Wanneer de landingszone zich in een bochtig deel van de stent bevindt, kunnen stent graft gerelateerde complicaties optreden ${ }^{47}$. Wetende dat deze zijwaartse krachten instabiliteit van de stent graft kunnen veroorzaken moeten er maatregelen genomen worden ${ }^{48}$. Langere sealings-zones, sterkere stent grafts of actieve fixatie zijn nodig om deze DF aan te kunnen ${ }^{49}$ en resultaten te verkrijgen met zo min mogelijk complicaties.

\section{De dynamica in de oplopende thoracale aorta}

Het endovasculaire aorta herstel blijft zich ontwikkelen, waardoor behandeling in het opstijgende gedeelte van de thoracale aorta (ATA) nu meer beschikbaar is met de minimaal invasieve operatie techniek ${ }^{50}$. De behandeling in zone 0 , dicht bij de aortaklep, heeft slechtere resultaten ${ }^{51}$. De oorzaak hiervan kan komen door verschillende longitudinale en circumferentie bewegingen gedurende de hartcyclus. Aangezien de diameter verschilt in de systole en de diastole, moeten aanvullende, nauwkeurigere metingen worden gebruikt bij de planning voor TEVAR. Het voordeel van CT-scans ten opzichte van cardiac magnetic resonance imaging (CMRI) is de verbeterde temporele resolutie en CMRI evalueert ook de aortaklep. De aortaklep is een belangrijke factor om de ATA-bewegingen te begrijpen. Deze studie analyseert de bewegingen van de aorta op ECG-gated CT-scans gedurende de hartcyclus. Data van de diameter, het gebied (area) en de omtrek werden verzameld op drie verschillende locaties in de ATA. De delta tussen de systole en de diastole werd berekend en deze laat zien dat het meten van het gebied en de omtrek nauwkeuriger is dan het meten van de diameter. De diameter had zelfs een maximale delta van 17,8\%. Verschillende studies tonen de variabiliteit in dynamiek van de ATA en vermelden dat toekomstige endograftontwerpen zich bewust moeten zijn van deze verschillen ${ }^{52-54}$. De dynamische CTA scans vangen de repetitieve draaiing van de aorta tijdens de hartcyclus op, maar momenteel wordt hiermee geen rekening mee gehouden bij TEVARplanning. Toch heeft de dynamische beeldvorming veel voordelen omdat het de 
verschillende fasen van de hartcyclus observeert. Op deze manier kan de maat van de stent graft nauwkeuriger worden vastgesteld en ook het effect postoperatief beter worden geëvalueerd ${ }^{55}$. Een prospectieve studie zal een beter inzicht geven in de klinische relevantie van het effect van deze verschillende metingen en zal hoogstwaarschijnlijk resulteren in betere klinische resultaten.

Tien tot vijftien procent van de patiënten die in de ATA moeten worden behandeld, zijn niet geschikt voor open chirurgie ${ }^{56}$. Endovasculair herstel, wat minimaal invasief is, is een mogelijk betere alternatieve behandelingsstrategie. Vanwege de behandeling dicht bij de aortaklep en de hoge kromming van de aortaboog blijft het echter uitdagend ${ }^{57}$. De compliantie en de stijfheid van de aorta zullen veranderen als gevolg van natuurlijke veroudering en / of pathologieën ${ }^{58-60}$, wat momenteel belangrijke risicofactoren zijn voor hart- en vaatziekten en overlijden ${ }^{60-62}$. Het effect van een stent graft implantatie kan vergelijkbaar zijn en moet daarom beter bestudeerd worden. Vijf preoperatieve ECG-gated CTA-scans en drie postoperatieve scans werden retrospectief beoordeeld. Gegevens werden verzameld over de circumferentie- en longitudinale rek, arteriële compliantie en uitrekbaarheid en stijfheidsindex. Waar de stent graft werd geïmplanteerd, werd een afname waargenomen in rek, compliantie en uitrekbaarheid. De stijfheidsindex steeg met 48\%. Proximaal van de stent graft werd het tegenovergestelde gezien; toename van rek, compliantie en uitrekbaarheid en een afname van de stijfheidsindex. Aangezien pulserende distensie gerelateerd is aan stent graft migratie en de aortabewegingen in de ATA nog dynamischer zijn ${ }^{52,63}$, kan de incidentie van complicaties hoger zijn in de ATA. Dit is zelfs nog effectiever omdat de foutenmarge tijdens de implantatie erg klein is. De mismatch tussen de aorta en de stent graft moet worden verbeterd om zo min mogelijk complicaties te krijgen. Stent grafts moeten worden ontwikkeld met meer vergelijkbaar materiaal als de oorspronkelijke aorta, vooral wanneer de behandeling dicht bij de aortaklep is.

\section{Onderwijs in endovasculaire aortareparatie}

Het beoordelen van arts-assistenten in de vaatchirurgie is zeer subjectief en er is behoefte aan meer uniformiteit en objectiviteit ${ }^{64}$. Er is een wetenschappelijk model beschikbaar dat de prestaties test bij endovasculaire arts-assistenten, tussen competent en niet-competent ${ }^{65}$. Het doel van deze studie was om dit model verder te valideren. De studie deelnemers werden in drie groepen verdeeld; 
beginners, intermediairs en experts op basis van hun ervaring in de endovasculaire chirurgie. Verschillende taken werden uitgevoerd in een virtueel model en de prestaties werden getest door het meten van de gladheid (in spectrale booglengte; $S A L$ ), de gemiddelde snelheid, de inactieve tijd (idle time) en de afstand wat ze aflegden (path length). Er werd een significant verschil gevonden voor de guidewire in SAL ( $p<0,001)$, gemiddelde snelheid $(p<0,001)$ en inactieve tijd ( $p$ $<0,001)$ tussen groepen. Post-hoc analyse toonde alleen een significant verschil tussen de beginners versus de experts en de intermediairs versus de experts. Dit model blijft een objectief model om de prestaties bij endovasculaire artsassistenten te beoordelen. Hoewel de beweging van de tooltip in staat is om competent van incompetent te onderscheiden, is het onduidelijk of alle metrics geldig of correct gewogen zijn voor validatie. Een psychometrische analyse heeft de potentie om deze latente vraag te beoordelen, want hoewel het vaststellen van motion wel een objectieve evaluatie biedt, mist het de kritische beoordeling van de waarde van een specifieke metrics ${ }^{66}$.

De behandeling voor een type B aorta dissectie wordt veelal endovasculair behandeld. Een intramuraal hematoom (IMH) wordt vaak medicamenteus behandeld, indien ongecompliceerd, aangezien de aorta-gerelateerde mortaliteit lager (5.4\%) is dan bij endovasculaire behandeling $(7.1 \%)^{67}$. De ESC (European Society of Cardiology) en ESVS-richtlijnen definiëren IMH enigszins anders ${ }^{68}$ en een onderscheid maken tussen IMH en dissectie is in de klinische praktijk niet altijd mogelijk. Met de komst van nieuwe, meer geavanceerde beeldvormingstechnieken is het waarschijnlijker dat IMH wordt gezien als een voorloper van dissectie ${ }^{68}$. Medicamenteuze behandeling is mogelijk bij ongecompliceerde $\mathrm{IMH}$, maar in geval van aortadilatatie (> $50 \mathrm{~mm}$ ) of $\mathrm{IMH}$-dikte $(>11 \mathrm{~mm})$ is het risico op complicaties groter en wordt chirurgische behandeling aanbevolen ${ }^{69}$. Er zijn drie fasen van type $B$ aortadissecties; de acute fase ( $<15$ dagen), de subacute fase (15 - 92) en de chronische fase (> 92 dagen). Medicamenteuze behandeling voor het ongecompliceerde type B-dissectie richt zich op pijnverlichting, verlaging van de bloeddruk en de hartslag frequentie en vergt een nauwe follow-up. Als medicamenteuze behandeling niet voldoende is, worden patiënten vaak behandeld met endovasculair herstel in de acute of subacute fase ${ }^{70}$. Beeldvorming is belangrijk in de pre-, peri- en postoperatieve stadia. CTA wordt meestal pre- en postoperatief gebruikt. De stappen van TEVAR: 1. Toegang tot de a. femoralis; 2. Het inbrengen van 0.035 guidewire, sheath en ondersteunende katheter; 3 . 
Wissel naar stijve guidewire; 4. De stent graft in positie brengen; 5. Aortagram; 6. Plaatsing van de stent graft; 7. Aortagram om de positie te bevestigen.

Type B aortadissecties hebben een hoge morbiditeit en mortaliteit wat levenslange surveillance vereist. Hoewel endovasculair herstel voordelen biedt ten opzichte van open chirurgie, blijft een aanzienlijk deel van de pathofysiologie onbekend ${ }^{71-73}$. Het doel van deze studie was het creëren van een model om de pathofysiologie van dissecties te bestuderen. Dit met behulp van multimodality beeldvormingstechnieken. Slechts één studie creëerde een zelfde soort varkensmodel met een endovasculaire benadering, echter, gebruikten ze een retrograde benadering, wat niet pathofysiologisch is. Voor baseline scanning en postoperatief werd 4D magnetic resonance imaging (MRI) en cone-beam computed tomography (CBCT) gebruikt. Intra-operatief werden fluoroscopie, trans-oesofageale echocardiografie (TEE), intravasculaire echografie (IVUS) en angiografie gebruikt als leidraad tijdens de procedure. De aortawand werd $2 \mathrm{~cm}$ distaal van de LSA aangeprikt met behulp van de trans-septale naald. Twaalf dieren werden gebruikt in deze study en een succesvolle dissectie werd gecreëerd in $25 \%$. De belangrijkste redenen voor een succesvolle creatie van de dissectie waren de diepte van de naaldpunctie en stabiliteit van de naald. Het gebruik van de multi-modality beeldvorming heeft geholpen om de pathofysiologie te begrijpen, aangezien dissecties een dynamische ziekte zijn.

\section{Toekomstperspectieven}

De belangrijkste focus van dit proefschrift ligt op de anatomische en morfologische kenmerken van de thoracale aorta. Onze resultaten tonen aan wat het effect is van anatomische variaties op de stroomdynamiek van de aorta. Daarnaast toont het ook de impact van de plaatsing van een stent graft in de aorta heeft een effect op de dynamica. Toekomstige onderzoeken zijn noodzakelijk om de complicaties op lange termijn te evalueren. Hierdoor kunnen behandelstrategieën worden aangepast en toekomstige endografts worden verbeterd. Observationele studies zijn in dit geval gunstiger dan gerandomiseerde gecontroleerde studies. De systematische review in dit proefschrift toont het gebrek aan bewijs voor type $1 \mathrm{~b}$ endoleak. Redenen voor dit tekort aan informatie over deze belangrijke complicatie zijn waarschijnlijk ook het gebrek aan een lange follow-up duur. Betere registratie en observaties zijn nodig om de resultaten te verbeteren. Onze theorie, welke ook wordt genoemd in de systematische review, is dat de hoge mate van 
shear stress (een kracht die mogelijk deformatie van de aorta kan veroorzaken) een uitbarsting van energie veroorzaakt aan het einde van het stent graft. Dit kan resulteren in aneurysmale verwijding van de aorta, met als resultaat een type $1 \mathrm{~b}$ endoleak of door de hoge DF kan de stent graft naar boven migreren.

In dit proefschrift zijn verschillende metingen gedaan om kenmerken van de aorta te objectiveren, zoals de dynamiek en de tortuositeit. Voor het meten van de dynamica zijn de vergelijkingen overgenomen uit een literair boek, wat ook in andere artikelen werd gebruikt ${ }^{74}$. Echter, in de literatuur is er geen unanimiteit om de tortuositeit te verkrijgen. Er worden verschillende methoden gebruikt en daarom is het niet mogelijk om deze uitkomsten met elkaar te vergelijken. De behoefte aan een uniforme methode is cruciaal voor toekomstige studies, zodat de resultaten met elkaar kunnen worden vergeleken.

Dit proefschrift laat zien dat er een grote mismatch is tussen stent graft materiaal en de aorta. Endografts zorgen ervoor dat de aorta na implantatie veel stijver wordt. Meer conforme stent grafts zijn nodig om de mismatch tussen stent grafts en de aorta kleiner te maken. De endografts kunnen bijvoorbeeld in de toekomst worden gemaakt van ander materiaal met een soortgelijke compliantie en welke ook tegen tortuositeit kan. Met behulp van dynamische beeldvorming kan gedurende de hartcyclus de repetitieve draaiing van de aorta worden vastgesteld. Evenals, dat de omtrek van de aorta kan veranderen van een cirkelvorm naar een ovaal. Stent grafts moeten worden ontwikkelt om de aorta en zijn habitus gedurende de hartcyclus na te kunnen bootsen. Nauwe samenwerking met ingenieurs is belangrijk voor een succesvolle ontwikkeling van stent grafts. Succesvolle samenwerkingen worden gezien in de meer productieve onderzoeks- en ontwikkelingsgroepen (R\&D). Uit een studie van Yoda blijkt echter dat dit soort samenwerking nog steeds een aantal barrières kent ${ }^{75}$. Barrières kunnen verband houden met het begrijpen van elkaars technische termen, communicatie, wetenschappelijke bewijsstandaarden of de vijf vormen van nabijheid (geografische, cognitieve, organisatorische, sociale en institutionele). Het leren en begrijpen van elkaars verschillen kan bijdragen aan een succesvolle samenwerking. Behandeling in de stijgende aorta is een operatie met een hoog risico vanwege een aantal redenen, waaronder aorta-angulatie en beweging, de aortaklep en de kransslagaders. Het effect van behandeling in ZO op de aortaklep is tot op heden niet goed onderzocht, noch de invloed van de aortaklep op de geïmplanteerde stent graft. Toekomstige studies over dit onderwerp zijn 
Chapter 14

noodzakelijk, aangezien er gevallen zijn geweest waarin de hartfunctie significant is afgenomen na endovasculair herstel van de aorta. Een betere samenwerking tussen cardioloog, hartchirurgen en vaatchirurgen kan deze complicatie na de behandeling helpen overwinnen. 


\section{Referenties}

1. Abraha I, Romagnoli C, Montedori A, Cirocchi R. Thoracic stent graft versus surgery for thoracic aneurysm. In: Abraha I, ed. Cochrane Database of Systematic Reviews. Chichester, UK: John Wiley \& Sons, Ltd; 2013:CD006796. doi:10.1002/14651858.CD006796.pub3

2. Li F-R, Wu XX, Yuan J, Wang J, Mao C, Wu XX. Comparison of thoracic endovascular aortic repair, open surgery and best medical treatment for type B aortic dissection: A meta-analysis. Int $J$ Cardiol. 2018;250:240-246. doi:10.1016/j.ijcard.2017.10.050

3. De Bruin JL, Baas AF, Buth J, et al. Long-Term Outcome of Open or Endovascular Repair of Abdominal Aortic Aneurysm. N Engl J Med. 2010;362(20):1881-1889. doi:10.1056/ NEJMoa0909499

4. Lederle FA, Freischlag JA, Kyriakides TC, et al. Long-Term Comparison of Endovascular and Open Repair of Abdominal Aortic Aneurysm. N Engl J Med. 2012;367(21):1988-1997. doi:10.1056/ NEJMoa1207481

5. Becquemin J-P, Pillet J-C, Lescalie F, et al. A randomized controlled trial of endovascular aneurysm repair versus open surgery for abdominal aortic aneurysms in low- to moderate-risk patients. $J$ Vasc Surg. 2011;53(5):1167-1173.e1. doi:10.1016/j.jvs.2010.10.124

6. Patel R, Sweeting MJ, Powell JT, Greenhalgh RM. Endovascular versus open repair of abdominal aortic aneurysm in 15-years' follow-up of the UK endovascular aneurysm repair trial 1 (EVAR trial 1): a randomised controlled trial. Artic 2366 www.thelancet.com. 2016;388. doi:10.1016/S01406736(16)31135-7

7. Powell JT, Sweeting MJ, Ulug P, et al. Meta-analysis of individual-patient data from EVAR-1, DREAM, OVER and ACE trials comparing outcomes of endovascular or open repair for abdominal aortic aneurysm over 5 years. Br J Surg. 2017;104(3):166-178. doi:10.1002/bjs.10430

8. Liaw JVP, Clark M, Gibbs R, Jenkins M, Cheshire N, Hamady M. Update: Complications and management of infrarenal EVAR. Eur J Radiol. 2009;71(3):541-551. doi:10.1016/j.ejrad.2008.05.015

9. Zarins CK, Bloch DA, Crabtree T, Matsumoto AH, White RA, Fogarty TJ. Stent graft migration after endovascular aneurysm repair: importance of proximal fixation. J Vasc Surg. 2003;38(6):12641272; discussion 1272. doi:10.1016/s0741-5214(03)00946-7

10. Golzarian J, Struyven J. Imaging of complications after endoluminal treatment of abdominal aortic aneurysms. Eur Radiol. 2001;11(11):2244-2251. doi:10.1007/s003300100912

11. Maleux G, Koolen M, Heye S. Complications after Endovascular Aneurysm Repair. Semin Intervent Radiol. 2009;26(01):003-009. doi:10.1055/s-0029-1208377

12. Wald R, Waikar SS, Liangos O, Pereira BJG, Chertow GM, Jaber BL. Acute renal failure after endovascular vs open repair of abdominal aortic aneurysm. J Vasc Surg. 2006;43(3):460-466. e2. doi:10.1016/j.jvs.2005.11.053

13. Arnaoutoglou E, Kouvelos G, Papa N, et al. Prospective evaluation of post-implantation inflammatory response after EVAR for AAA: influence on patients' 30 day outcome. Eur J Vasc Endovasc Surg. 2015;49(2):175-183. doi:10.1016/j.ejvs.2014.12.006

14. Sharif MA, Lee B, Lau LL, et al. Prosthetic stent graft infection after endovascular abdominal aortic aneurysm repair. J Vasc Surg. 2007;46(3):442-448. doi:10.1016/j.jvs.2007.05.027

15. Chaikof EL, Dalman RL, Eskandari MK, et al. The Society for Vascular Surgery practice guidelines on the care of patients with an abdominal aortic aneurysm. J Vasc Surg. 2018;67(1):2-77.e2. doi:10.1016/j.jvs.2017.10.044

16. Moll FL, Powell JT, Fraedrich G, et al. Management of Abdominal Aortic Aneurysms Clinical Practice Guidelines of the European Society for Vascular Surgery. Eur J Vasc Endovasc Surg. 2011:41:S1-S58. doi:10.1016/j.ejvs.2010.09.011

17. Volodos' NL, Shekhanin VE, Karpovich IP, Troian VI, Gur'ev IA. [A self-fixing synthetic blood vessel endoprosthesis]. Vestn Khir Im / / Grek. 1986;137(11):123-125.

18. Moore WS, Rutherford RB. Transfemoral endovascular repair of abdominal aortic aneurysm: results of the North American EVT phase 1 trial. EVT Investigators. J Vasc Surg. 1996;23(4):543553. doi:10.1016/s0741-5214(96)80032-2 


\section{Chapter 14}

19. United Kingdom EVAR Trial Investigators, Greenhalgh RM, Brown LC, et al. Endovascular versus Open Repair of Abdominal Aortic Aneurysm. N Engl J Med. 2010;362(20):1863-1871. doi:10.1056/ NEJMoa0909305

20. van Bakel T, Romarowski R, Morganti S, et al. Blood Flow after Endovascular Repair in the Aortic Arch: A Computational Analysis. AORTA. 2018;06(03):081-087. doi:10.1055/s-0039-1683771

21. Ammar CP, Larion S, Ahanchi SS, Lavingia KS, Dexter DJ, Panneton JM. Anatomic severity grading score for primary descending thoracic aneurysms predicts procedural difficulty and aortic-related reinterventions after thoracic endovascular aortic repair. J Vasc Surg. 2016;64(4):912-920.e1. doi:10.1016/j.jvs.2016.03.451

22. Czerny $M$, Cejna $M$, Hutschala $D$, et al. Stent-graft placement in atherosclerotic descending thoracic aortic aneurysms: midterm results. J Endovasc Ther. 2004;11(1):26-32. doi:10.1177/152660280401100103

23. Hughes GC, Lee SM, Daneshmand MA, et al. Endovascular repair of descending thoracic aneurysms: results with \&quot;on-label\&quot; application in the post Food and Drug Administration approval era. Ann Thorac Surg. 2010;90(1):83-89. doi:10.1016/j.athoracsur.2010.03.052

24. Kratimenos T, Antonopoulos CN, Tomais D, et al. Repair of descending thoracic aortic aneurysms with Ankura Thoracic Stent Graft. J Vasc Surg. October 2018. doi:10.1016/j.jvs.2018.07.065

25. Makaroun MS, Dillavou ED, Wheatley GH, Cambria RP, Gore TAG Investigators. Five-year results of endovascular treatment with the Gore TAG device compared with open repair of thoracic aortic aneurysms. J Vasc Surg. 2008;47(5):912-918. doi:10.1016/j.jvs.2007.12.006

26. Matsumura JS, Melissano G, Cambria RP, et al. Five-year results of thoracic endovascular aortic repair with the Zenith TX2. J Vasc Surg. 2014;60:1-10. doi:10.1016/j.jvs.2014.01.043

27. Morales JP, Greenberg RK, Lu Q, et al. Endoleaks Following Endovascular Repair of Thoracic Aortic Aneurysm: Etiology and Outcomes. J Endovasc Ther. 2008;15:631-638.

28. Nakatamari H, Ueda T, Ishioka F, et al. Discriminant analysis of native thoracic aortic curvature: Risk prediction for endoleak formation after thoracic endovascular aortic repair. J Vasc Interv Radiol. 2011;22(7):974-979. doi:10.1016/j.jvir.2011.02.031

29. Parmer SS, Carpenter JP, Stavropoulos SW, et al. Endoleaks after endovascular repair of thoracic aortic aneurysms. J Vasc Surg. 2006;44(3):447-452. doi:10.1016/j.jvs.2006.05.041

30. Piffaretti G, Mariscalco G, Lomazzi C, et al. Predictive factors for endoleaks after thoracic aortic aneurysm endograft repair. J Thorac Cardiovasc Surg. 2009;138(4):880-885. doi:10.1016/j. jtcvs.2009.02.024

31. Riambau V, Giudice R, Trabattoni P, et al. Prospective multicenter study of the low-profile Relay stent-graft in patients with thoracic aortic disease: the RE-GENERATION study. Ann Vasc Surg. January 2019. doi:10.1016/j.avsg.2018.10.017

32. Rylski B, Blanke P, Siepe M, et al. Results of high-risk endovascular procedures in patients with non-dissected thoracic aortic pathology: intermediate outcomes. Eur J Cardiothorac Surg. 2013;44(1):156-162. doi:10.1093/ejcts/ezs694

33. Yunoki J, Kuratani T, Shirakawa Y, et al. Mid-term results of endovascular treatment with the Gore TAG device for degenerative descending thoracic aortic aneurysms. Gen Thorac Cardiovasc Surg. 2015;63(1):38-42. doi:10.1007/s11748-014-0436-4

34. Melissano G, Kahlberg A, Bertoglio L, Chiesa R. Endovascular exclusion of thoracic aortic aneurysms with the 1- and 2-component Zenith TX2 TAA endovascular grafts: analysis of 2-year data from the TX2 pivotal trial. J Endovasc Ther. 2011;18(3):338-349. doi:10.1583/10-3340.1

35. Farber MA, Lee WA, Szeto WY, Panneton JM, Kwolek CJ. Initial and midterm results of the Bolton Relay Thoracic Aortic Endovascular Pivotal Trial. 2017;65(6):1556-1566.e1. doi:10.1016/j. jvs.2016.11.061

36. Geisbüsch P, Skrypnik D, Ante M, et al. Endograft migration after thoracic endovascular aortic repair. J Vasc Surg. December 2018. doi:10.1016/j.jvs.2018.07.073

37. Craiem D, Casciaro ME, Graf S, Chironi G, Simon A, Armentano RL. Effects of aging on thoracic aorta size and shape: A non-contrast CT study. In: 2012 Annual International Conference of the IEEE Engineering in Medicine and Biology Society. Vol 2012. IEEE; 2012:4986-4989. doi:10.1109/ EMBC.2012.6347112 
38. Craiem D, Chironi G, Redheuil A, et al. Aging impact on thoracic aorta 3D morphometry in intermediate-risk subjects: looking beyond coronary arteries with non-contrast cardiac CT. Ann Biomed Eng. 2012;40(5):1028-1038. doi:10.1007/s10439-011-0487-y

39. Czerny M, Funovics M, Ehrlich M, et al. Risk Factors of Mortality in Different Age Groups After Thoracic Endovascular Aortic Repair. Ann Thorac Surg. 2010;90(2):534-538. doi:10.1016/j. athoracsur.2010.03.096

40. De Rango P, Isernia $G$, Simonte $G$, et al. Impact of age and urgency on survival after thoracic endovascular aortic repair. J Vasc Surg. 2016;64(1):25-32. doi:10.1016/j.jvs.2015.11.054

41. Chen CK, Liang IP, Chang HT, et al. Impact on outcomes by measuring tortuosity with reporting standards for thoracic endovascular aortic repair. J Vasc Surg. 2014;60(4):937-944. doi:10.1016/j. jvs.2014.04.008

42. Bowman JN, Silverberg D, Ellozy S, et al. The Role of Anatomic Factors in Predicting Success of Endovascular Repair of Thoracic Aortic Aneurysms. Vasc Endovascular Surg. 2010;44(2):101-104. doi:10.1177/1538574409347392

43. Boufi M, Guivier-Curien C, Dona B, et al. Risk Factor Analysis for the Mal-Positioning of Thoracic Aortic Stent Grafts. Eur J Vasc Endovasc Surg. 2016;52(1):56-63. doi:10.1016/j.ejvs.2016.03.025

44. Figueroa CA, Taylor CA, Chiou AJ, Yeh V, Zarins CK. Magnitude and Direction of Pulsatile Displacement Forces Acting on Thoracic Aortic Endografts. J Endovasc Ther. 2009;16(3):350358. doi:10.1583/09-2738.1

45. Chen J, Gutmark E, Mylavarapu G, Backeljauw PF, Gutmark-Little I. Numerical investigation of mass transport through patient-specific deformed aortae. J Biomech. 2014;47(2):544-552. doi:10.1016/j.jbiomech.2013.10.031

46. van Keulen JW, Moll FL, Tolenaar JL, Verhagen HJM, van Herwaarden JA. Validation of a new standardized method to measure proximal aneurysm neck angulation. J Vasc Surg. 2010;51(4):821828. doi:10.1016/j.jvs.2009.10.114

47. Rahmani S, Grewal IS, Nabovati A, Doyle MG, Roche-Nagle G, Tse LW. Increasing angulation decreases measured aortic stent graft pullout forces. J Vasc Surg. 2016;63(2):493-499.

48. Rafii BY, Abilez OJ, Benharash P, Zarins CK. Lateral movement of endografts within the aneurysm sac is an indicator of stent-graft instability. J Endovasc Ther. 2008;15(3):335-343. doi:10.1583/082422.1

49. Ongstad SB, Miller DF, Panneton JM. The use of EndoAnchors to rescue complicated TEVAR procedures. J Cardiovasc Surg (Torino). 2016;57(5):716-729.

50. Baikoussis NG, Antonopoulos CN, Papakonstantinou NA, Argiriou M, Geroulakos G. Endovascular stent grafting for ascending aorta diseases. J Vasc Surg. 2017;66(5):1587-1601. doi:10.1016/j. jvs.2017.07.064

51. Roselli EE, Idrees JJ, Johnston DR, Eagleton MJ, Desai MY, Svensson LG. Zone zero thoracic endovascular aortic repair: A proposed modification to the classification of landing zones. $J$ Thorac Cardiovasc Surg. 2018;155(4):1381-1389. doi:10.1016/j.jtcvs.2017.11.054

52. van Prehn J, Vincken KL, Muhs BE, et al. Toward endografting of the ascending aorta: insight into dynamics using dynamic cine-CTA. J Endovasc Ther. 2007;14(4):551-560. doi:10.1177/152660280701400418

53. Rengier F, Weber TF, Henninger $V$, et al. Heartbeat-related distension and displacement of the thoracic aorta in healthy volunteers. Eur J Radiol. 2012;81(1):158-164. doi:10.1016/j. ejrad.2010.08.023

54. Sailer AM, Wagemans BAJM, Das M, et al. Quantification of Respiratory Movement of the Aorta and Side Branches. J Endovasc Ther. 2015;22(6):905-911. doi:10.1177/1526602815605325

55. van Bogerijen GHW, van Herwaarden JA, Conti M, et al. Importance of dynamic aortic evaluation in planning TEVAR. Ann Cardiothorac Surg. 2014;3(3):300-306. doi:10.3978/j.issn.2225319X.2014.04.05

56. Plichta RP, Hughes GC. Thoracic endovascular aortic repair for the ascending aorta: experience and pitfalls. J Vis Surg. 2018;4:92-92. doi:10.21037/jovs.2018.03.01

57. Khoynezhad A, Donayre CE, Walot I, Koopmann MC, Kopchok GE, White RA. Feasibility of endovascular repair of ascending aortic pathologies as part of an FDA-approved physiciansponsored investigational device exemption. J Vasc Surg. 2016;63(6):1483-1495. doi:10.1016/j. jvs.2015.12.029 


\section{Chapter 14}

58. Redheuil A, Yu W-C, Wu CO, et al. Reduced ascending aortic strain and distensibility: earliest manifestations of vascular aging in humans. Hypertens (Dallas, Tex 1979). 2010;55(2):319-326. doi:10.1161/HYPERTENSIONAHA.109.141275

59. Bell V, Mitchell WA, Sigurðsson S, et al. Longitudinal and Circumferential Strain of the Proximal Aorta. J Am Heart Assoc. 2014;3(6):e001536. doi:10.1161/JAHA.114.001536

60. Cavalcante JL, Lima JAC, Redheuil A, Al-Mallah MH. Aortic stiffness: current understanding and future directions. J Am Coll Cardiol. 2011;57(14):1511-1522. doi:10.1016/j.jacc.2010.12.017

61. Redheuil A, Wu CO, Kachenoura N, et al. Proximal aortic distensibility is an independent predictor of all-cause mortality and incident CV events: the MESA study. J Am Coll Cardiol. 2014;64(24):2619-2629. doi:10.1016/j.jacc.2014.09.060

62. Vlachopoulos C, Aznaouridis K, Stefanadis C. Prediction of Cardiovascular Events and AllCause Mortality With Arterial Stiffness. J Am Coll Cardiol. 2010;55(13):1318-1327. doi:10.1016/j. jacc.2009.10.061

63. van Keulen JW, Moll FL, Barwegen GK, Vonken EPA, van Herwaarden JA. Pulsatile distension of the proximal aneurysm neck is larger in patients with stent graft migration. Eur J Vasc Endovasc Surg. 2010;40(3):326-331. doi:10.1016/j.ejvs.2010.05.009

64. Bismuth J, Donovan MA, O'Malley MK, et al. Incorporating simulation in vascular surgery education. J Vasc Surg. 2010;52(4):1072-1080. doi:10.1016/j.jvs.2010.05.093

65. Duran C, Estrada S, O'Malley M, et al. The model for Fundamentals of Endovascular Surgery (FEVS) successfully defines the competent endovascular surgeon. J Vasc Surg. 2015;62(6):16601666.e3. doi:10.1016/j.jvs.2015.09.026

66. Lineberry M, Matthew Ritter E. Psychometric properties of the Fundamentals of Endoscopic Surgery (FES) skills examination. Surg Endosc. 2017;31(12):5219-5227. doi:10.1007/s00464-0175590-1

67. Evangelista A, Czerny M, Nienaber C, et al. Interdisciplinary expert consensus on management of type B intramural haematoma and penetrating aortic ulcer. Eur J Cardio-Thoracic Surg. 2015;47(2):209-217. doi:10.1093/ejcts/ezu386

68. Czerny M, Chairperson E, Schmidli J, et al. Current options and recommendations for the treatment of thoracic aortic pathologies involving the aortic arch: an expert consensus document of the European Association for Cardio-Thoracic surgery (EACTS) and the European Society for Vascular Surgery (ESVS). doi:10.1093/ejcts/ezy313

69. Erbel R, Aboyans V, Boileau C, et al. 2014 ESC Guidelines on the diagnosis and treatment of aortic diseases: Document covering acute and chronic aortic diseases of the thoracic and abdominal aorta of the adult. The Task Force for the Diagnosis and Treatment of Aortic Diseases of the European . Eur Heart J. 2014;35(41):2873-2926. doi:10.1093/eurheartj/ehu281

70. Riambau V, Böckler D, Brunkwall J, et al. Editor's Choice - Management of Descending Thoracic Aorta Diseases: Clinical Practice Guidelines of the European Society for Vascular Surgery (ESVS). Eur J Vasc Endovasc Surg. 2017;53(1):4-52. doi:10.1016/j.ejvs.2016.06.005

71. Nienaber CA, Rousseau H, Eggebrecht $H$, et al. Randomized comparison of strategies for type $B$ aortic dissection: the INvestigation of STEnt Grafts in Aortic Dissection (INSTEAD) trial. Circulation. 2009;120(25):2519-2528. doi:10.1161/CIRCULATIONAHA.109.886408

72. Cooper M, Hicks C, Ratchford E V, Salameh MJ, Malas M. Diagnosis and treatment of uncomplicated type B aortic dissection. Vasc Med. 2016;21(6):547-552. doi:10.1177/1358863X16643601

73. Brunkwall J, Lammer J, Verhoeven E, Taylor P. ADSORB: A Study on the Efficacy of Endovascular Grafting in Uncomplicated Acute Dissection of the Descending Aorta. Eur J Vasc Endovasc Surg. 2012;44(1):31-36. doi:10.1016/j.ejvs.2012.03.023

74. Nichols WW, O'Rourke MF, Vlachopoulos C. McDonald's Blood Flow in Arteries: Theoretical, Experimental and Clinical Principles. 6th Editio. CRC Press; 2013.

75. Yoda T. The effect of collaborative relationship between medical doctors and engineers on the productivity of developing medical devices. R\&D Manag. 2016;46(S1):193-206. doi:10.1111/ radm.12131 
Samenvatting | Discussie 



\section{Chapter 14}

Review Committee

Acknowledgments (dankwoord)

List of publications

About the author 
Chapter 14

\section{Review Committee}

Prof. dr. R.L.A.W. Bleys

Department of Anatomy

University Medical Center Utrecht

Prof. dr. G.J. de Borst

Department of Vascular Surgery

University Medical Center Utrecht

Prof. dr. M.H. Emmelot-Vonk

Department of Clinical Geriatrics

University Medical Center Utrecht

Prof. dr. T. Leiner

Department of Radiology

University Medical Center Utrecht

Prof. dr. J.P.P.M. de Vries

Department of Surgery

University Medical Center Groningen 


\section{Acknowledgments (dankwoord)}

Beste prof. Moll, bedankt voor alle wijze woorden gedurende dit promotie traject. $\mathrm{Na}$ onze gezellige WhatsApp belletjes raakte ik vaak nog meer gemotiveerd en stond ik opnieuw versteld van de vele kennis die u mij kon vertellen over de vaatchirurgie, maar ook over Indonesië. Samen worden we 101 dit jaar, wat een leeftijd! Nogmaals, hartelijk dank voor alles en ik vind het een eer om onder u te mogen promoveren!

Dear Jean, thank you so much for the inspiration, the many comments on my English, the support, and the American life lessons. In times of stress and difficulties you were able to put things back into perspective. Other times, you would sent me movie quotes about the Dutch or 'being afraid of some Guatemaleness'! I promise I will never tell you beforehand whether I'm traveling alone or not.. Thanks again for the many opportunities you gave me!

Dear Santi, life is good, and Italian life even better! Thank you for sharing your passion for Italy and vascular surgery with me. Besides delicious rooftop BBQs, amazing dinners at Lago di Como, and much more, you taught me that building relationships and enjoying life at its fullest is just as important as working hard!

Beste Joost, ik wil je ontzettend bedanken voor de kritische blik op mijn artikelen, $i k$ heb daar veel van geleerd. Af en toe dacht ik te Amerikaans en jij zorgde ervoor dat de Nederlandse (Europese) visie weer naar boven kwam.

Geachte leden van de beoordelingscommissie: prof. dr. Bleys, prof. dr. G.J. de Borst, prof. dr. Emmelot-Vonk, prof. dr. Leiner en prof. dr. de Vries, ik wil jullie hartelijk bedanken voor het beoordelen van mijn proefschrift.

Collega's uit het UMC: prof. de Borst, Stijn Hazenberg en de promovendi van de vaatchirurgie met in het bijzonder Marjolijn, Marloes en Nathalie. Hartelijk dank voor de samenwerking en gezellige tijden!

To my Italian colleagues: prof. Auricchio, Michele Conti, Rodrigo Romarowski, Gabriele Piffaretti, Massimiliano Marrocco Trischitta, Domenico Spinelli, 


\section{Chapter 14}

Alessandro Caldarola. Thank you for the collaborations and teaching me about Italian culture!

Houston Methodist Hospital: attendings \& residents: Alan Lumsden, Michael Reardon, Su Min Chang, Dipan Shah, Stephan Little, Charu Bavare, Moritz Wyler von Ballmoos, Thomas McGillivray, Eric Peden, Zsolt Garami, Ponraj Chinnadurai, Susmitha Gadde, Ray Prakash, Mohammad Ghosn, Mujeeb Zubair, Eric Yang, Stephen Igo, Michael Patterson and Yvette Whittier. Thank you all for the good times and collaborations.

Dear MITIE team: Kyle Autry, Jeremy Hinojosa, Becca Swan, Louis Magnus and Stefano Filippo. Thank you for the fun times during the experiments, for getting up early, your patience throughout the day and also the happy hours. It has been a blast working with you!

To my colleagues from Rice University: dr. O'Malley and Barath Murali. Thank you for the collaboration and all the best to you Barath on your PhD! Hartelijk dank mannen voor het opzetten van dit mooie promotie traject! Frederik, Jip, Guide, Foeke en in het bijzonder Arnoud, jij introduceerde mij bij deze groep. Het was de start van een geweldig avontuur!

Lieve Hec, ik wil je bedanken voor alle mooie tijden die we samen hebben meegemaakt. Het beantwoorden van mijn vele vragen over de promotie, de geweldige tripjes op de scooter (toeren door de wijngaarden van Pavia herinner ik me als de dag van gister), de uitjes naar het strand met heerlijke focaccia, het wegwijs maken in Houston en nog veel meer. Het wordt tijd om de lijst nog langer te maken!

Lieve Ignas (Iggy), ondanks dat we nooit in dezelfde stad hebben gewoond, een maatje ben je geworden. Met mooie avonturen in Valencia, Houston, New York en met kers op de taart; $4^{\text {th }}$ of July in Ann Arbor!

Diederik, bedankt voor de geweldige tijden in Valencia \& Houston en de vele wijze woorden over natuurlijk.. CFD! 
Yunus, super bedankt voor het co-hosten van mijn tripje naar Ann Arbor. Vond het erg gezellig om je beter te leren kennen en ik wens je alle succes de komende tijd met je PhD!

Beste Susan \& Cobie, hartelijk dank voor jullie hulp en het regelen van zaken binnen het UMC tijdens mijn promotie. Jullie weten de weg in het UMC als geen ander en dat heeft mij ontzettend geholpen de afgelopen 3 jaar. Bedankt!

Lieve meiden van Equinox, met in het bijzonder Els, Nien, Sas, Len, Nico, Marit, Bien, Loes, Laura, Suus, Char en Jamie. Ik wil jullie ontzettend bedanken voor de mooie tijden in Maastricht en voor de geweldige vriendschappen. Na drie jaar weg te zijn geweest, is er weinig veranderd en kom ik nog steeds altijd thuis in een warm bad! Heel mooi om te zien hoe het Maastrichtse doorleeft. Kan niet wachten tot de volgende borrels en avonturen!

Lieve dames van DJC Fedeltà, wat een geweldige tijden hebben we gehad tijdens onze studententijd. Ik vind het prachtig om te zien hoe iedereen zijn eigen plekje heeft gevonden en dat zelfs ons lustrum nog wordt gevierd! Na drie jaar kom ik gelukkig op tijd terug voor alle komende bruiloften, ik heb er zin in om dit met jullie te vieren! Lieve Hilde \& Laura, wat een heerlijke trip was het in Milaan, het betekent veel voor me dat jullie me zijn komen opzoeken!

Jarno, jij hebt ook bijgedragen aan het tot stand komen van dit proefschrift. Je support om aan dit avontuur te beginnen en hoe je altijd in me geloofde ben ik je heel dankbaar voor.

Bella Lianne, een mix van English and Nederlands spreken we altijd en af en toe wat Italiano tussendoor. Although, dat begrijp ik toch echt maar half. Vond het echt heel gezellig toen je naar London kwam en bedankt voor alle leuke tijden met Internations. De onderonsjes als Dutchies-zijnde is toch ook gewoon heerlijk!

Dear Linda, my Asian Latina! Your kind, loving words and sparkling personality is amazing. You see the good in people! I will always hear your voice commenting on my squatting skills. Thank you! 


\section{Chapter 14}

Dear Dany, you are such an amazing person and I'm so happy that I have met you. Laughing at me for my grammar mistakes or skyping during Aerosmith, I miss those days. I wish you all the best with your residency and Axelrad, Jinya and Coltivare haven't been the same without you!

Lieve Chris, van heerlijke zeilweekendjes naar eindeloze gesprekken tijdens het koken, ik vind het heel bijzonder hoe snel je een van mijn betere maatjes bent geworden in Houston! Ik wil je bedanken voor je steun en support waar mijn gedachten dan ook heen gingen en je bezorgdheid toen ik tijdelijk geen wifi had. Succes nog in Houston en ik zie je snel weer in NL!

Lieve Shai, zusje! Ik leerde je kennen aan het begin van je studententijd en sindsdien is er weinig veranderd aan onze vriendschap. Ik vind het heel speciaal om te zien hoe jij je hebt ontwikkeld en ben trots op hoever je bent gekomen!

Dear Andras family, Jim, Elisa, James and Mike, thank you for being my family away from home. First at Thanksgiving and later also for Christmas. You were so welcoming and it made the holidays less lonely!

Francie, amore! Thank you for always laughing at me when I try to speak Italian, for teaching me about disagio's and making me feel at home in Milano. You were there for my birthday last year in London and this year you're coming to Amsterdam. That's amazing and I can't thank you enough for your always sweet words and enthusiasm!

Dear Sam, Valentine's Day got a whole different meaning after meeting you. Can't believe we've been through so much already and can't thank you enough for being such an awesome friend! The stunning hikes in Italy, running down the hill after drinking too much grappa, and singing hip-hop is one of my favorite memories! It's time to make some new ones!

Dear Skye, even though we did not complete the half marathon, I'm still proud of us! Thank you for being such an awesome person and all the fun nights and sweet words! 
Lieve Marit, van klasgenootjes naar huisgenootjes en ondertussen kennen we elkaar al meer dan 10 jaar en is de vriendschap altijd hetzelfde gebleven, ondanks dat ik vertrokken was uit Amsterdam. Bedankt dat ik altijd een slaapplekje had waar dan ook, voor de gezellige huisfeestjes en de heerlijke borrelavonden met rode wijn \& Daan (al ging jij sporten en bleven wij 3 uur lang kletsen zonder te bewegen, sporten komt later hè Daan)! Dit jaar wordt ook een bijzonder jaar voor jullie en ik ben heel blij dat ik dit geluk met jullie mag delen!

Paloma, wifey! I'm so happy that I have met you and I can't thank Hector enough for that! Taco Tuesday's will never be the same without you! Thank you for letting me stay in your amazing casa for my final weeks. No matter how hard you work, you also enjoy life to the fullest! Luckily you're a traveler, so I will see you soon in Europe or wherever on this earth, maybe even at Java! Guess now you have to go visit, right Rodri?!

Dear Audrey \& Justine, thank you for making me feel at home in Houston. Lovely dinners, riding bulls at the rodeo, and awesome road trips, y'all are amazing! Building a bonfire shouldn't be that difficult with an engineer, an architect, and a doctor, right?! Audrey, it means so much that you're coming to the Netherlands and I can't wait for another trip!

Lieve Myrt \& Non, van Maastrichtse avonturen, naar huisgenootjes in Amsterdam, naar tripjes over de gehele wereld (Costa Rica, Milano, Jordanië, Texas en binnenkort Myanmar)!! Ik kan me gelukkig prijzen met zulke vriendinnen en jullie zijn een grote steun geweest gedurende deze drie jaar, maar natuurlijk al veel langer! Ik kan niet wachten tot de volgende avonturen, ik heb jullie gemist!

Lieve Dees, wat een heerlijke tijden hebben we gehad in Houston. Om jou te zien groeien in je moeder-rol, was heel bijzonder! Ik wil jou en Alex bedanken dat ik altijd de deur bij jullie kon platlopen, de gezellige avonden bij Miller's en de bezorgdheid toen ik in Guatemala zat. Gelukkig hoef ik Charlie maar twee maanden te missen!

Lieve Soof (aka Thelma), te bedenken dat onze vriendschap is gegroeid door alle trips die we hebben gemaakt vind ik heel speciaal. De vele bel-uren compenseren 


\section{Chapter 14}

wel voor een heleboel (mega handig die mute-functie)! Gent, Milaan, Jordanië, Texas en natuurlijk de vele nachtjes dat ik bij jou heb mogen slapen in onze Thelma \& Louise outfit (I love it)! Door jou liep ik niet voor gek in Texas (ranch, cleansing, purchase). Ontzettend bedankt voor alles lieve paranimf en kan niet wachten om samen met jou weer in hetzelfde land te wonen!

Lieve Huub, jouw positiviteit en inspirerende woorden raakten me al in het begin van mijn studententijd en wat heb ik veel van je geleerd! PhDs komen met ups and downs, het acen van een sollicitatie begint met een goede outfit (eigenlijk belangrijker) en hoelahoepen is beter met zijn tweeën (erg belangrijk als paranimf). Altijd heb ik bij je mogen slapen in Roffa en stiekem voel ik me kind aan huis bij jullie. De roadtrip door Texas was geweldig en kan niet wachten tot Myanmar!

Lieve papa \& mama, ik kan jullie niet genoeg bedanken voor alles wat jullie voor mij hebben gedaan! Door jullie ben ik gegroeid als persoon en heb ik onwijs veel mogelijkheden gekregen in het leven. Mede door jullie oneindige support ben ik gekomen tot waar ik nu ben en daar ben ik jullie ontzettend dankbaar voor! Waar ik ook op de wereld zat, jullie kwamen mij altijd opzoeken. Lieve ouders, ik hou van jullie! 


\section{List of Publications}

In peer-reviewed journals

V.M. Belvroy, B. Murali, M.G. Sheahan, M.K. O'Malley, J. Bismuth; Motion metrics reliably differentiate competency: Fundamentals of endovascular and vascular surgery (FEVS); Submitted

V.M. Belvroy, P. Chinnadurai, A. Schwein, M. Malahfji, L. Jenkins, J. Bismuth; Endovascular creation of acute in-vivo swine model and multi-modality imaging for understanding pathophysiology of type B aortic dissection; Submitted

V.M. Belvroy, J.A. van Herwaarden, M.J. Reardon, S.M. Chang, F.L. Moll, J. Bismuth; Arterial strain and distensibility in type A aortic dissection before and after stent graft implantation; Submitted

V.M. Belvroy, M.M. Zubair, J.A. van Herwaarden, S. Trimarchi, F.L. Moll, J. Bismuth; Important variances of longitudinal and circumferential movements in ZO of the aorta during the cardiac cycle; Submitted

M. Domanin, V.M. Belvroy, M. Conti, F. Auricchio, M. Ferraresi, V. Marangon, S. Trimarchi; Report on migration / drag forces after TEVAR in the proximal and distal thoracic aorta; Submitted

V.M. Belvroy, R.M. Romarowski, T.M.J. van Bakel, J.A. van Herwaarden, J. Bismuth, F. Auricchio, F.L. Moll, S. Trimarchi: Impact of aortic tortuosity on displacement forces in descending thoracic aortic aneurysm; European Journal of Vascular and Endovascular Surgery (2020)

V.M. Belvroy, H.W.L. de Beaufort, J.A. van Herwaarden, J. Bismuth, G. Piffaretti, F.L. Moll, S. Trimarchi; Tortuosity of the descending thoracic aorta in patients with aneurysm and type B aortic dissection; World Journal of Surgery (2019) 
M.M. Zubair, H.W.L. de Beaufort, V.M. Belvroy, A. Schwein, A. Irshad, L.F. Gomez, P. Chinnadurai, F. Nabi, E.Y. Yang, S. Trimarchi, M.J. Reardon, J. Bismuth; Impact of cardiac cycle on thoracic aortic geometry - morphometric analysis of ECG-gated computed tomography; Annals of Vascular Surgery (2019)

V.M. Belvroy, H.W.L. de Beaufort, J.A. van Herwaarden, S. Trimarchi, F.L. Moll, J. Bismuth: Type 16 endoleaks after thoracic endovascular aortic repair are inadequately reported: a systematic review; Annals of Vascular Surgery (2019)

V.M. Belvroy, H.W.L. de Beaufort, J.A. van Herwaarden, J. Bismuth, F.L. Moll, S. Trimarchi: Tortuosity of the descending thoracic aorta: normal values by age; PLOSONE (2019).

M.M. Marrocco-Trischitta, B. Rylski, F. Schofer, F. Secchi, G. Piffaretti, H.W.L. de Beaufort, V.M. Belvroy, J. Bismuth, M. Czerny, S. Trimarchi: Prevalence of type III arch configuration in patients with type B aortic dissection; European Journal of Cardiothoracic Sugery (2019).

V.M. Belvroy, I.B. Houben, S. Trimarchi, H.J. Patel, F.L. Moll, J.A. van Herwaarden: Identifying and addressing the limitations of EVAR technology; Expert Review of Medical Devices (2018).

Book chapter

V.M. Belvroy, P. Chinnaduraj, J. Bismuth (bookchapter): Endotherapy in IMH and dissetion; Springer (submitted). 


\section{About the author}

Viony Maria Belvroy was born on April 17, 1989, in Hengelo, The Netherlands. In the same town, she attended high school Twickel College (atheneum), from which she graduated in 2008. After graduation, she successfully completed the propaedeutic year of Physiotherapy at the Amsterdam University of Applied Sciences (HvA). In her younger years, she enthusiastically spent time at her mother's work in the hospital, which made her decide to pursue a career in medicine. She started medical school at the University of Maastricht in 2009. Amongst her extracurricular activities, Viony organized research projects for the IFMSA (International Federation of Medical Students Association), served as chairwoman of her sorority, and organized the introduction week for incoming students. To broaden her horizon as a medical student, she completed three internships abroad (Ophthalmology in Denmark, Community Medicine in Nepal, and Pediatrics in South Africa). After graduation, she became a surgical resident (ANIOS) at the Department of General Surgery at the Reinier de Graaf Groep in Delft. Her international curiosity was heightened after successfully completing her internships. This motivated her to start an international PhD program at the Department of Vascular Surgery at the University Medical Center Utrecht under the supervision of prof. dr. F.L. Moll in January 2017. Viony spent a year doing research with prof. dr. S. Trimarchi at the Thoracic Aortic Research Center of I.R.C.C.S. Policlinico San Donato in Italy and continued her PhD in February 2018 at the DeBakey Heart \& Vascular Center of the Houston Methodist Hospital in Houston, TX, United States. She attended and presented at several world-class medical conferences, from which she received 2 awards: $2^{\text {nd }}$ prize for Best Poster Presentation (European Society of Vascular Surgery 2018, Valencia, Spain) and an invitation to present at the Rising Stars \& Global Stars session (Charing Cross 2019, London, United Kingdom). After her dissertation defense, Viony will move back to The Netherlands to continue to pursue a career in general surgery. 



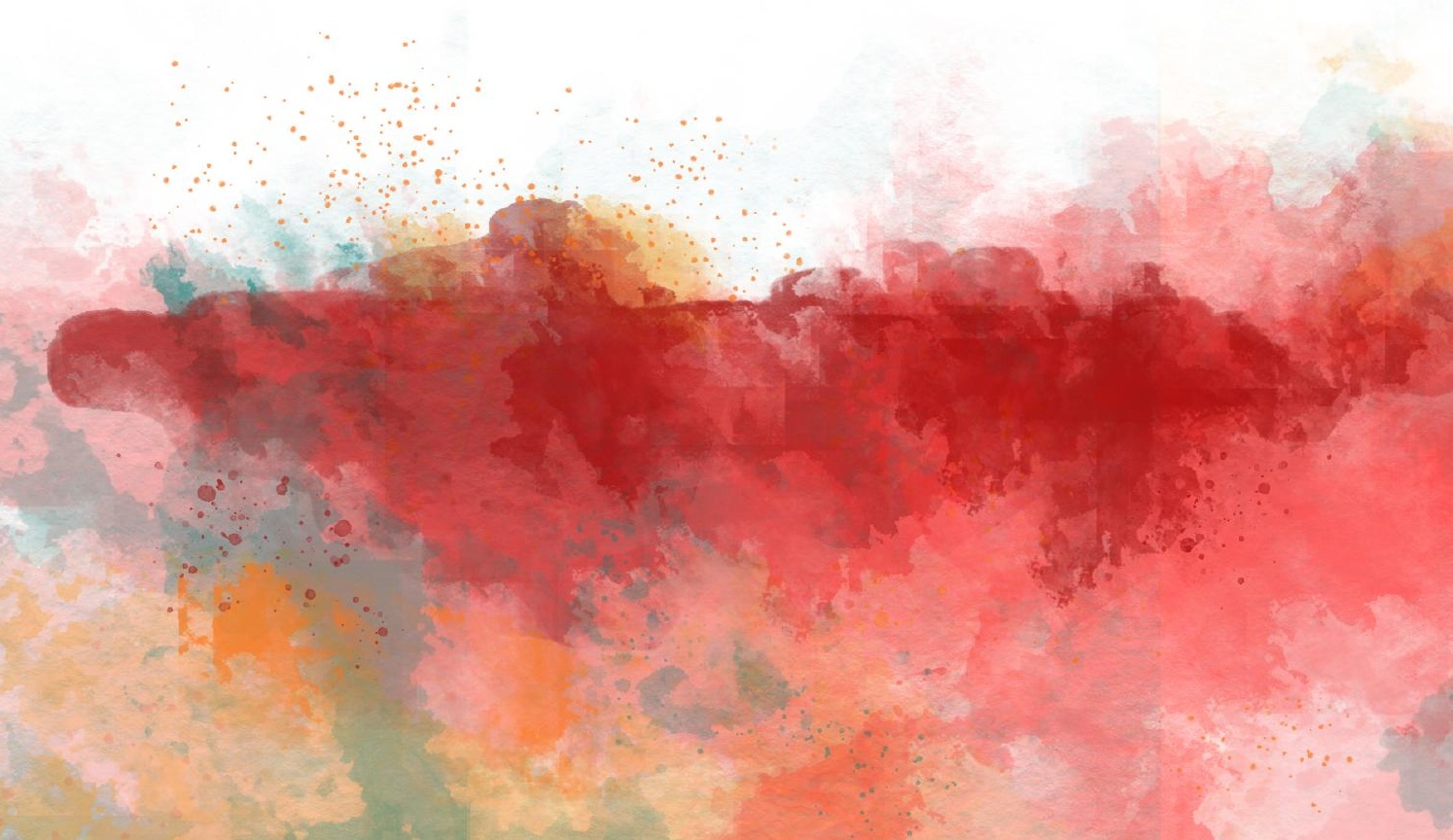